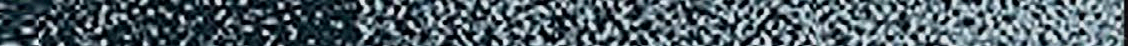

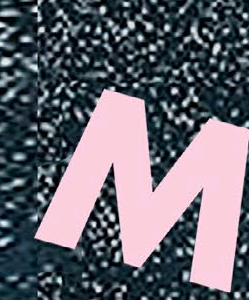

$$
\text { . }
$$

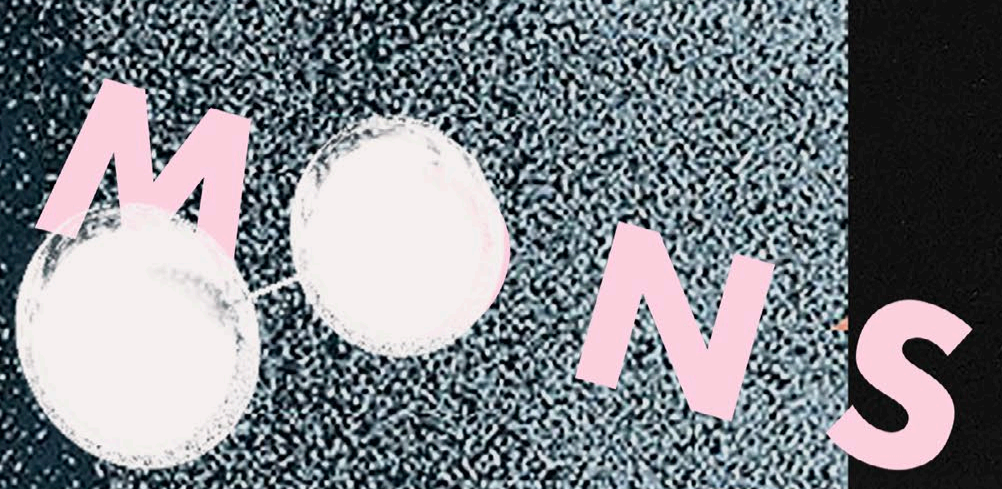

* 30 \%

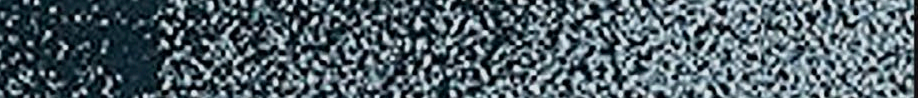

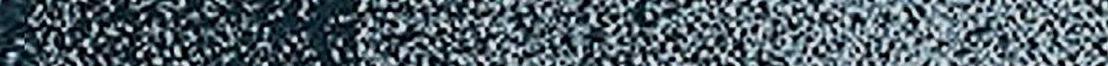

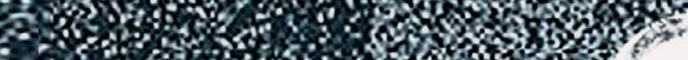

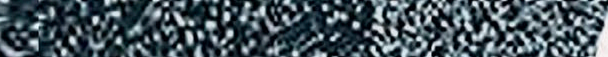

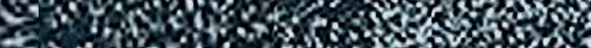

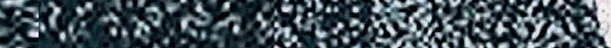

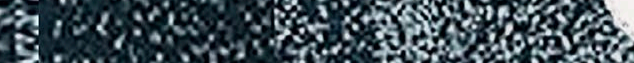

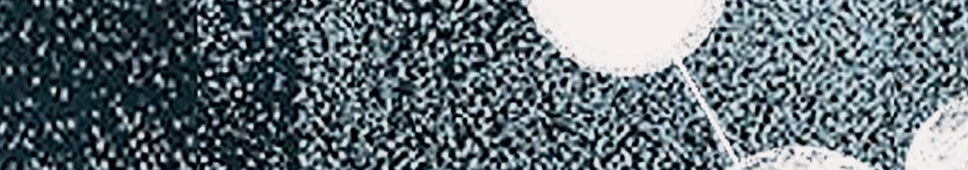

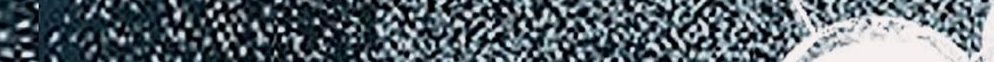

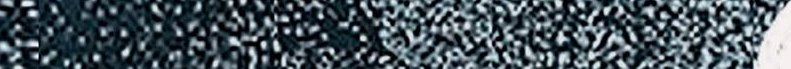

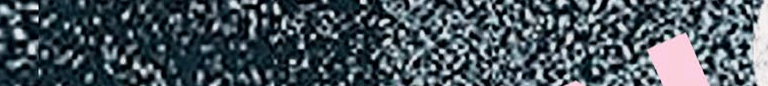

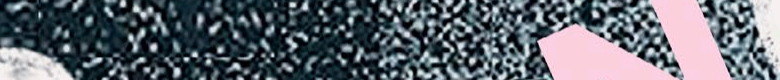

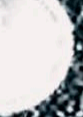
$4.5 \%$.

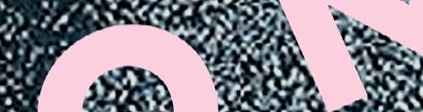
Yis. 等,
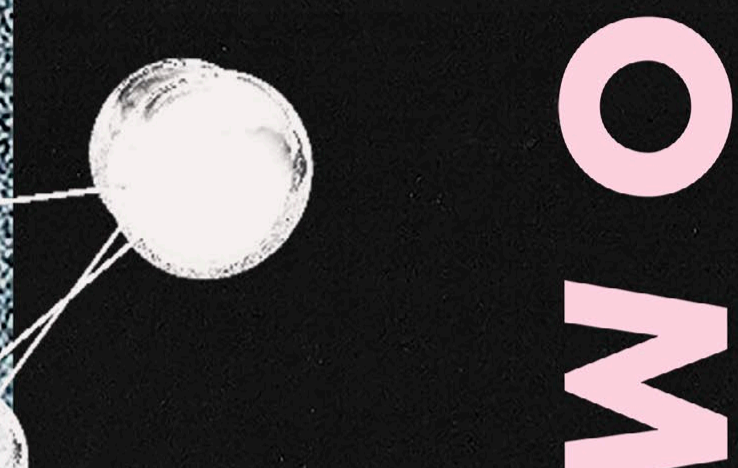
\%

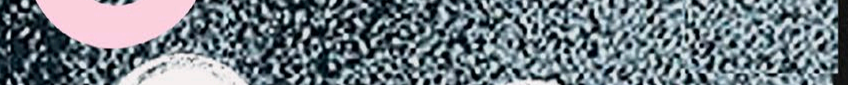

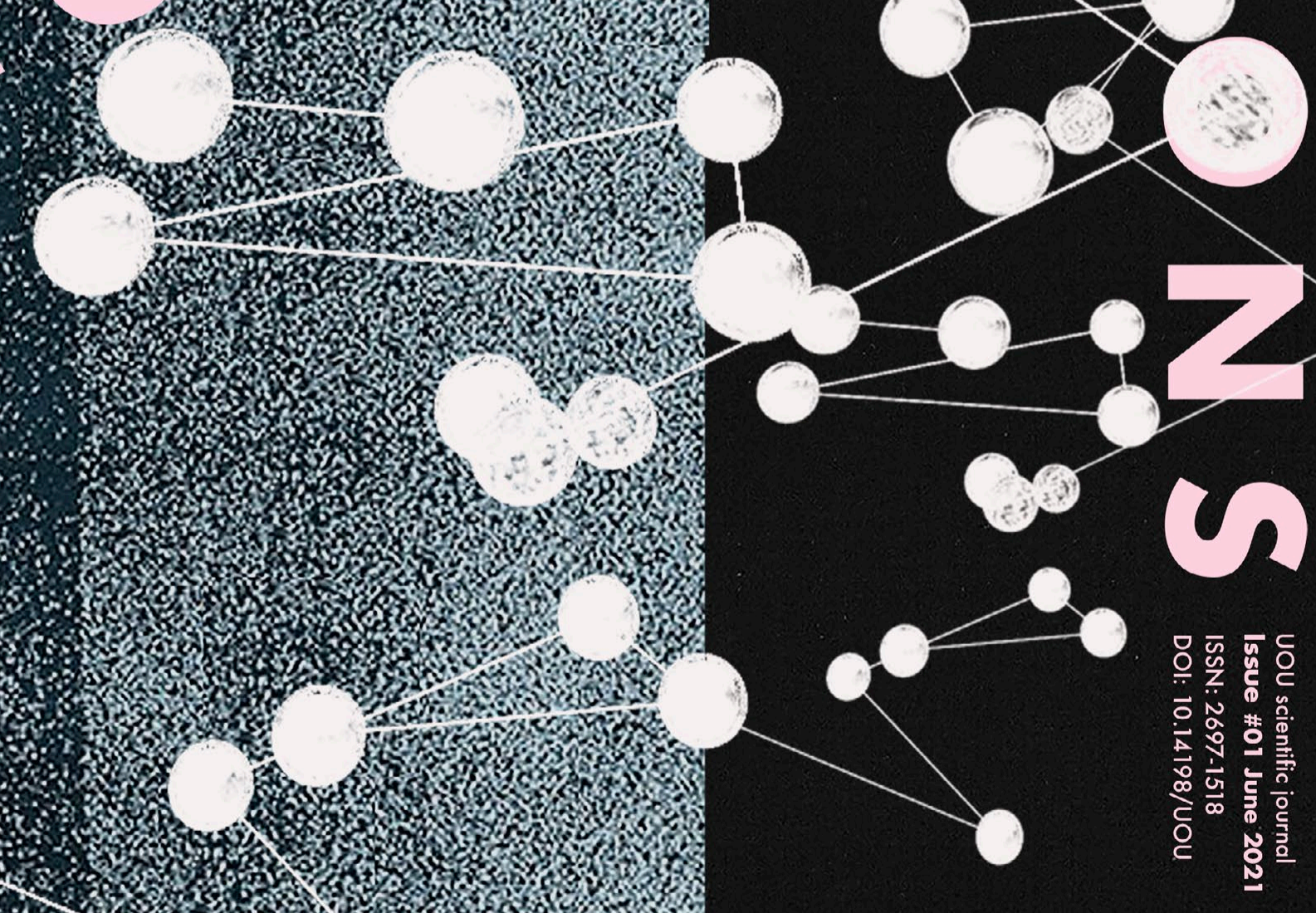

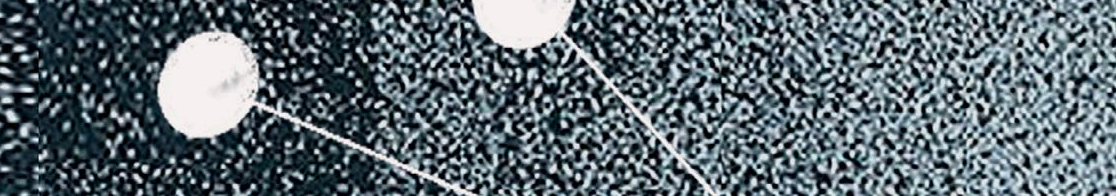

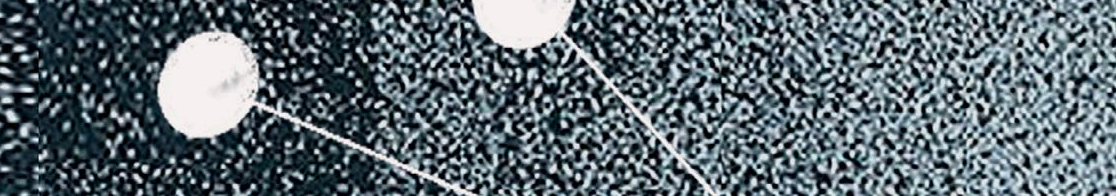

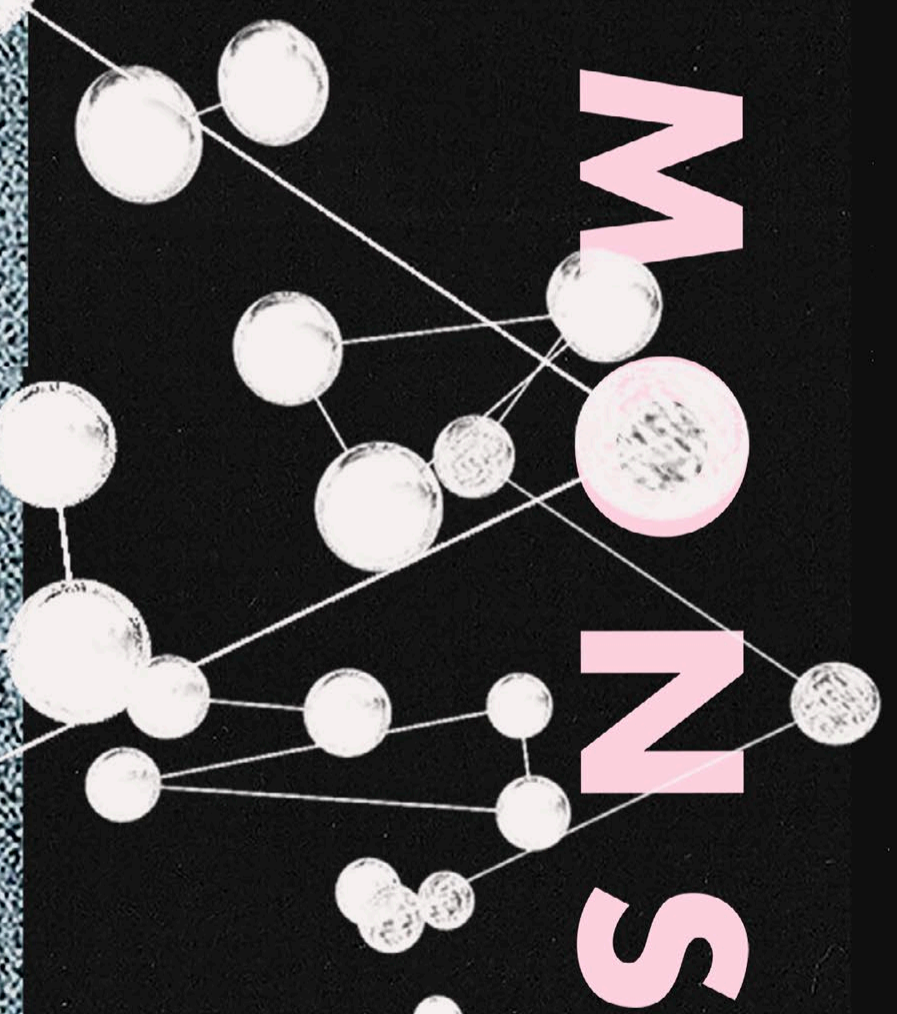

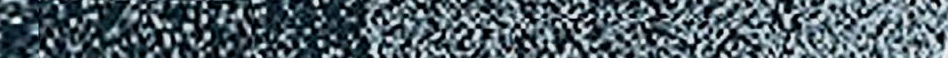

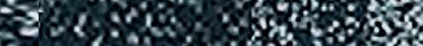

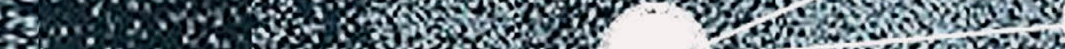
(1) n.

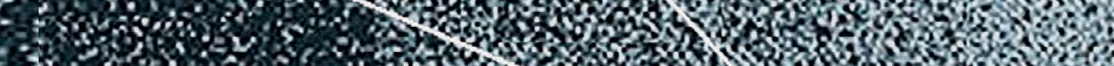

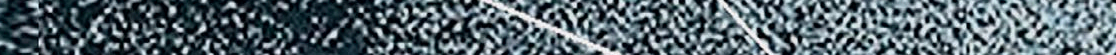

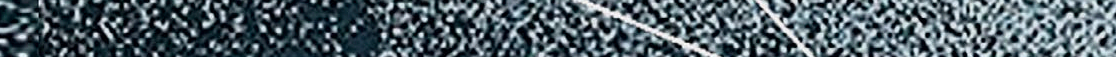
nal \#01 UOU Tientific journal \#01 UOU scientific journal \#01 UOU scie 


\section{UOU scientific journal Issue \#01/ COMMONS June 2021}

\section{Editor in chief}

Maria Luna Nobile / UMA Umeå University, Sweden

\section{Editorial board}

Joaquín Alvado Bañón / Alicante University, Spain Hocine Aliouane-Shaw / ENSAP Bordeaux, France Maria Hadjisoteriou / University of Nicosia, Cyprus Marie Kraft / Malmö University, Sweden

Mike Devereux / UWE Bristol, UK

\section{Graphic designers}

Raúl Díaz Valera, Maria Luna Nobile, Javier Sánchez Merina.

\section{Editor-proofreader}

Trevor Garnham / Honorary Fellow of Kingston University, UK

\section{Director}

Javier Sánchez Merina / Alicante University, Spain

Department of Graphic Expression, Design and Projects Escuela Politécnca Superior ALICANTE UNIVERSITY

Carretera San Vicente del Raspeig s/n 03690 San Vicente del Raspeig. Alicante (SPAIN)

ISSN: $2697-1518$

DOI: $10.14198 /$ UOU

https://revistes.ua.es/uou uou@ua.es 


\section{Scientific Board}

Sofia Aleixo / Universidade de Évora, Portugal Ozan Avci / MEF Üniversitesi, Turkey

Andreea Calma / Universitatea „Ion Mincu”, Romania

José Antonio Carrillo Andrada / American University in Dubai, UAE

Martina D'Alessandro / Università di Bologna, Italy

Antonio Esposito / Università di Bologna, Italy

Yiorgos Hadjichristou / University of Nicosia, Cyprus

Thomas Loeffler / University in Cairo, Egypt

Valerio Morabito / Studi Mediterranea di Reggio Calabria, Italy

Marcin Kolakowski / University of Lincoln, United Kingdom

Jerzy Łątka / Wrocław University of Science and Technology, Poland

Giorgio Liverani / Università di Bologna, Italy

Miguel Luengo Angulo / Universidad Europea, Spain

Markella Menikou / University of Nicosia, Cyprus

Mauricio Morales Beltrán / Yaşar Üniversitesi, Turkey

Yianna Moustaka / London South Bank University, United Kingdom

Luke Murray / London South Bank University, United Kingdom

Tomas Ooms / KULeuven Campus Sint-Lucas Brussel/Gent

Szabolcs Portschy / Budapest University of Technology, Hungary

Piotr Smiechowicz / London South Bank University, United Kingdom

Heiner Stengel / IUBH Internationale Hochschule, Germany

All manuscripts submitted to the UOU scientific journal have been reviewed by the Editorial Committee, which approved the academic quality, format and publication standards.

The scientific articles included in the Sections: Interpretations,

Prototypes, Experiments, Interferences, Overseas, have been double-blind peer-reviewed by external evaluators, chosen by the Editorial Board from among experts in the relevant fields of study.

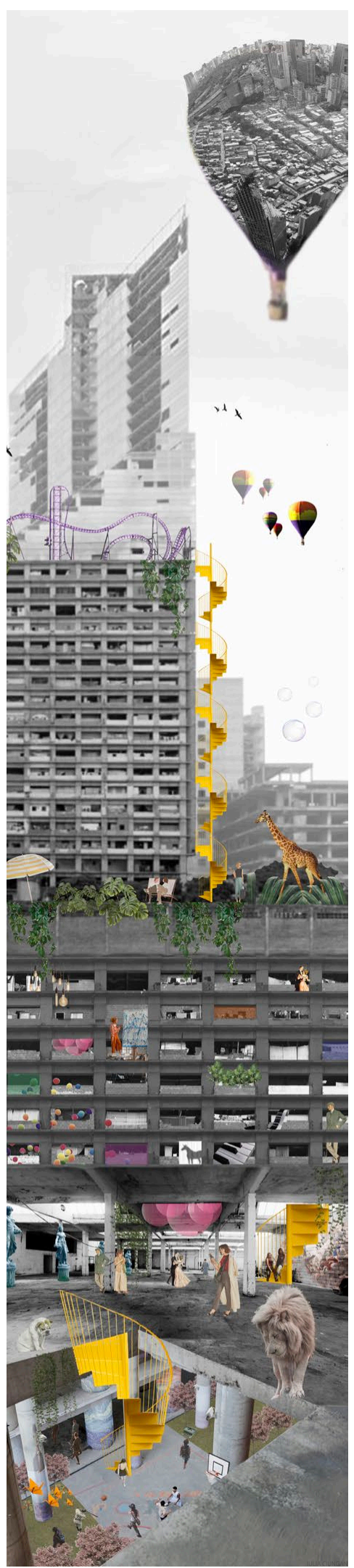




\section{table of contents}

UNIVERSITY of Universities [UOU]: Redefining the basis of International Teaching of Architecture

Javier Sánchez Merina

\section{Editorial}

An Introduction: the Need for a Space of Experimentation

Maria Luna Nobile

A Manifesto: Circus Island

Joaquín Alvado Bañón

Conversation on a Common Manifesto

Joaquín Alvado Bañón, Maria Hadjsoteriou, Mike

Devereux

\section{Interpretations}

From Commons to Urban Commons

Complexity and Contradiction in the Translation of a

Concept

Francesco Caneschi

Prototypes

Rhodo Workhome: Rethinking the post-pandemic Residence

A Symbiosis of Living and Creating Organic Materials Marie Roels

Portable Ecologies

Dialogue with the Architecture from the Anthropocene María José Marcos

Coccapani Planetary Garden

A transgenerational, common, possible learning space

Bruna Sigillo

Experiments

Conventional Complacency in British Housing-

Self-Build Absence in Comparison to the Netherlands

Emma Davies 


\section{Interferences}

\section{Low-Tech - Freedom, Creativity \& Love}

Translating Erich Fromm's Psychoanalysis into Analyses of Architecture

Marcin Mateusz Kołakowski

The virus is up and the system is down

A Peruvian case for cosmopolitics in urban studies

Bruno Enrico Chichizola

\section{Agencies}

H2OS, anti-desertification eco-village in Senegal

A research-based project

TAM Associati

\section{Atlas}

Commons. An ATLAS of possibilites

Maria Luna Nobile, Marie Kraft

\section{Students contributions}

Anastasia Milonas; Andreea Diana Roman, Anna Van Amersfoort; Ario Racho; Cecilia Elisabeth Eleanora Gustafsson; Enric Alonso, María Ponce; Larisa Daniela Gabor; Laura Adina Stupariu, Alina loana Constantin; Marta Selles; Raluca Ioana Negoescu, Iulia Ciungan;Thomas Bromley; Vendela Serrreli

The Celebration of Places and Instants of Moments

María Ponce

\section{Overseas}

Examining the Role of the Nature in New Commons

Two Experimental Architectural Design Studios

Nuray Özaslan, Fatma Kolsal, Sevgin Aysu Balkan 

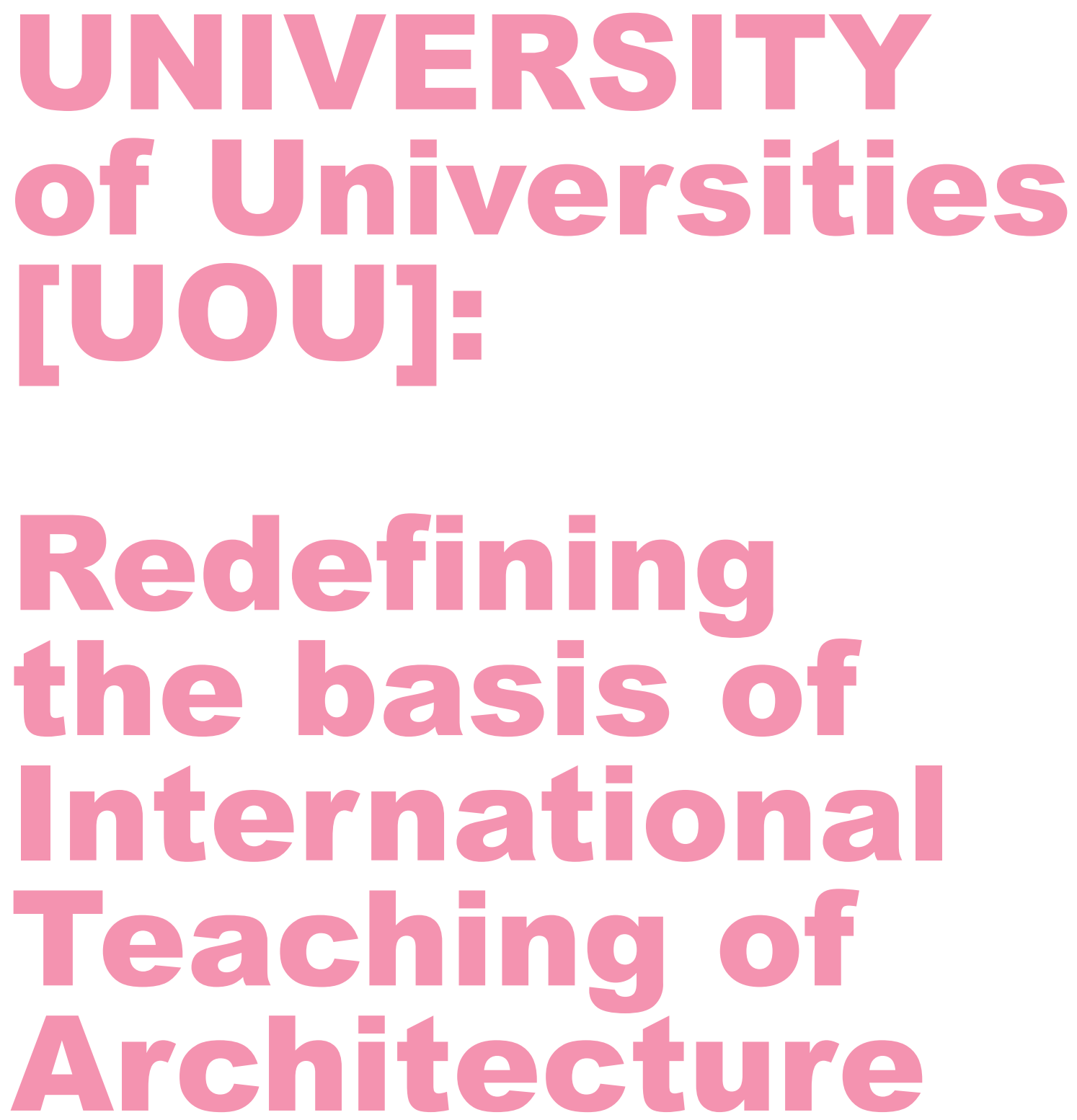

\section{Sánchez Merina, Javier ${ }^{1}$}

1Department of Graphic Expression, Design and Projects / Alicante University, Spain https://orcid.org/0000-0003-1973-690X

jsm@ua.es

Citation: Sanchez Merina J. (2021). "UOU Redefining the Basis of International Teaching in Architecture" UOU

scientific journal \#01, 6-11.

ISSN: 2697-1518. https://doi.org/10.14198/UOU.2021.1.01

This document is under a Creative Commons Attribution 4.0 International license (CC BY 4.0) 
When thinking about teaching and knowledge exchange, is it possible to enhance quality by using international online teaching? That is the aim of our pedagogic project born out of a lockdown affecting students and teachers of Architecture at home. From the combination of confinement and teaching, a brand-new initiative has been designed focusing on higher education: UNIVERSITY of Universities. It is an international project developed by teachers of international universities, starting the academic year 2020-2021.

\section{BACKGROUND}

March 2020 obliged us to stop and reflect on our daily routines. It was the beginning of a new way of thinking. If the pandemic provoked instant changes in our lives from its very beginning, with the passage of months it has become clear that many of these changes are not transient. They will remain with us as a "new normality".

This text is a reflection upon the opportunities for the International Teaching of Architecture that have emerged out of the lockdown brought about by the pandemic in Europe and beyond.

As academics running separate design studios, our objective established well before the pandemic, has always been an internationalisation of architectural education. The internationalisation we speak of goes well beyond simply teaching through the medium of English to students on Erasmus exchange experiencing a new local culture. What we mean by 'internationalization' is a release from local constraint for a moment to allow students to be exposed to experts from different paradigms of architectural education in different cultures. Each expert brings his or her specialist knowledge for all to share, regardless of the framework in which they normally teach. It is a celebration of the fact that architecture is a globally taught discipline and that it is good for us all to learn together. Therefore, it is important to state from the beginning, that the online teaching demanded by a lockdown of our traditional studios is just such a tool to reach that objective.

\section{INTERNATIONAL DESIGN STUDIO}

The last academic year 2019/20 finished with a debate between our colleagues, teachers of architectural design. Many of them missed the face-to-face teaching and saw online teaching that tried to mimic the studio as provoking a physical and intellectual distance with the students. In some cases that might have impacted negatively upon student attainment. But others saw some positive outcomes. Many of us, working in design studios with an already strong international emphasis, have seen not only highly valued results from our students, but also have also discovered, in a natural way, a new pedagogy that does not try to emulate face-to-face teaching.

The fact that an important part of our student cohort was drawn from students on the Erasmus exchange played somewhat in our favour. These students began returning to their countries for good as soon as news broke from their home country about a pending lockdown. This allowed us to foresee the need for three months' worth of online teaching before it was compulsory. Beyond the virtual lectures, crits and tutorials, the submissions for the end of the year also needed to be redefined. We drew at least two remarkable points from this experience that made our practice different from colleagues working with a larger proportion of home students:

\section{The importance of continuing the staff exchange between international universities, despite the} difficulties in travelling. Each student on exchange in (the now virtual) studio was asked to invite a significant professor from his or her home school of architecture to participate in the final crit. In every sense, it was a priceless experience to have in the same crit twenty 'favourite' teachers from all over the world.

\section{The importance of expanding the classroom;} during the lockdown students continued to work in groups in different scenarios. This time with a responsibility that produced a new type of emerging architect, as well as a different architecture from that produced by working faceto-face. Now, they are much more autonomous, with projects that materialise reflections over solutions, addressing and proposing new realities.

As we reached the end of a 
WORKSHOP \#1

ARCH: architecture \& food - an international buffet

AMERICAN UNIVERSITY IN DUBAI +

EUROPEAN UNIVERSITY IN MADRID

WORKSHOP \#2

$\mathrm{ARCH}$ : architecture as the art of building communities

UMEÅ UNIVERSITY + MALMÖ UNIVERSITY

WORKSHOP \#3

ARCH: cognitive mapping

UNIVERSITY OF NICOSIA

WORKSHOP \#4

$\mathrm{ARCH}$ : elements of architecture for the

confinement

ALICANTE UNIVERSITY

WORKSHOP \#5

ARCH: architecture through language

UWE BRISTOL

WORKSHOP \#6

$\mathrm{ARCH}$ : discover nature in our buildings

ION MINCU UAU BUCHAREST

Fig. 1 UOU Fisrt Semester 2020/21 
hectic academic year and the start of the next, 2020/21, we found that the pandemic did not go away. But for us, that new year started by building on our experience and with a will to expand the international, online lessons we had learnt. So, having detected the two very positive and unique points noted above, our proposal for that new academic semester consisted of organising a studio course built on a network of studio-based academics from different worldwide schools of architecture with a triple aim:

\section{To extend the reach of our universities by bringing} together a coordinated team of international teachers with their specific research interests and practice specialisms.

\section{To extend the notion of the classroom beyond its walls.}

By appreciating the 'space for learning' as being more than physical space but instead it being 'a landscape of life', we enrich the students' cultural and learning environment. Ironically, perhaps, we can internationalise more by staying at home. As noted at the top of this paper, for us, 'internationalisation' is not simply experiencing English language teaching in a new local culture.

\section{To extend the international student experience, till now mainly provided by}

Erasmus+, to a larger group of students than would otherwise normally have been the case. And subsequently be in a position to bring our new experience to bear on the Erasmus+ programme once the pandemic has subsided.
The 'team' of studio leaders involved numbers about thirtyfive at the time of writing but is ever growing. Each studio leader has the trust of the entire team and the freedom to propose and direct a two-week online workshop, based on his or her specialisation, for all the students of the different schools participating in the experience. The other academic staff become tutors in the workshop. After these two weeks, another studio leader takes over with a new workshop, while the former director becomes a tutor of his/her students and so on. That rotating leadership of the workshops maintains the important studio role of 'supervisor' supporting the 'student', but also provides close academic help for the director of each workshop.

For semester one 2020/21 the participating universities were:

Alicante University (Spain); American University Dubai (UAE) + European University Madrid (Spain); Ion Mincu University (Romania); Umeå University + Malmö University (Sweden); University of Nicosia (Cyprus); University of the West of England, Bristol (UK).

These multicultural workshops constituted an international exchange network of studio teachers interested in learning from each other. In this way, the staff participating have not only been suggested by the students, but also, they are teachers willing to accept this basic concern for the exchange of knowledge. And this is, in fact, one of the main values of this pedagogic project: to question the pyramidal system of education, where the students are at the base and the professor on the top. But not only at the top; at the same time often well isolated from other colleagues. Now, the educational model follows a horizontal relationship; everybody teaches, everybody learns.

At the end of the semester, there was a series of six International Workshops designed to work better online than face-to-face. And, just as with the Surrealists' exquisite corpse game, every workshop was an addition to the former one. The whole becomes greater than the sum of its parts, and that is reflected in the students' portfolios.

And, of course, keeping in mind the different academic calendars and engagements of the participants, each university participated in those desired workshops, without it being compulsory to follow all of them. The menu is, then, à la carte and can be fitted bespoke to any student working at the same academic level.

That first semester finished fulfilling all the challenges both for students and teachers:

\section{THE STUDENT EXPERIENCE}

Recognising the different nature of teaching in each university, and the fact that students are engaged in classes other than studio, these workshops are designed not to involve extra hours over and above normal studio time for the students. The studio leader works his/her studio around the 
WORKSHOP \#1

ARCH+ARTS: the space for learning as a landscape of life

ALICANTE UNIVERSITY

WORKSHOP \#2

ARTS: maps of memory

ACADEMY OF FINE ARTS MUNICH

WORKSHOP \#2a

$\mathrm{ARCH}$ : treatment

BOLOGNA UNIVERSITY

WORKSHOP \#2b

ARCH: permissive city

ENSAP BORDEAUX

WORKSHOP \#2C

ARCH: architectural narrative - event

LONDON SOUTH BANK UNIVERSITY

WORKSHOP \#3a

$A R C H$ : psychoanalysis of the design process

UNIVERSITY OF LINCOLN

WORKSHOP \#3b

ARCH: ephemeral architecture: urban follies

ÉVORA UNIVERSITY

WORKSHOP \#3c

ARCH: evolution of forgotten

UNIVERSITY OF NICOSIA

WORKSHOP \#4a

ARCH: homeland miniatures

MEF UNIVERSITY ISTANBUL

WORKSHOP \#4b

ARCH: pop up

WROCLAW UNIVERSITY + YASAR

UNIVERSITY IZMIR

WORKSHOP \#5

ARCH + ARTS: competition / research: marble

ALICANTE UNIVERSITY

WORKSHOP \#6

ARTS: small scale and isolated occurrences

FINE ARTS OF THE UNIVERSITY OF PORTO

WORKSHOP \#6a

ARCH: the 'review of reviews'

UWE BRISTOL

WORKSHOP \#6b

ARCH: sharing the voids

UMEA UNIVERSITY + MALMÖ UNIVERSITY

WORKSHOP \#6c

$\mathrm{ARCH}$ : rivers

BUDAPEST UNIVERSITY

WORKSHOP \#6d

$\mathrm{ARCH}$ : housing Europe

IUBH HAMBURG

WORKSHOP \#7

ARTS: moving bodies - on art and walking

ICELAND UNIVERSITY OF THE ARTS

WORKSHOP \#7a

$\mathrm{ARCH}$ : the existent and the non-existent

ION MINCU UAU BUCHAREST

WORKSHOP \#7b

ARCH: inside outside

UNIVERSITÀ DI REGGIO CALABRIA

WORKSHOP \#7c

ARCH: spatial agency: a detail

KULEUVEN BRUSSEL

WORKSHOP \#7d

ARCH: architectural cornerstones

GERMAN UNIVERSITY IN CAIRO
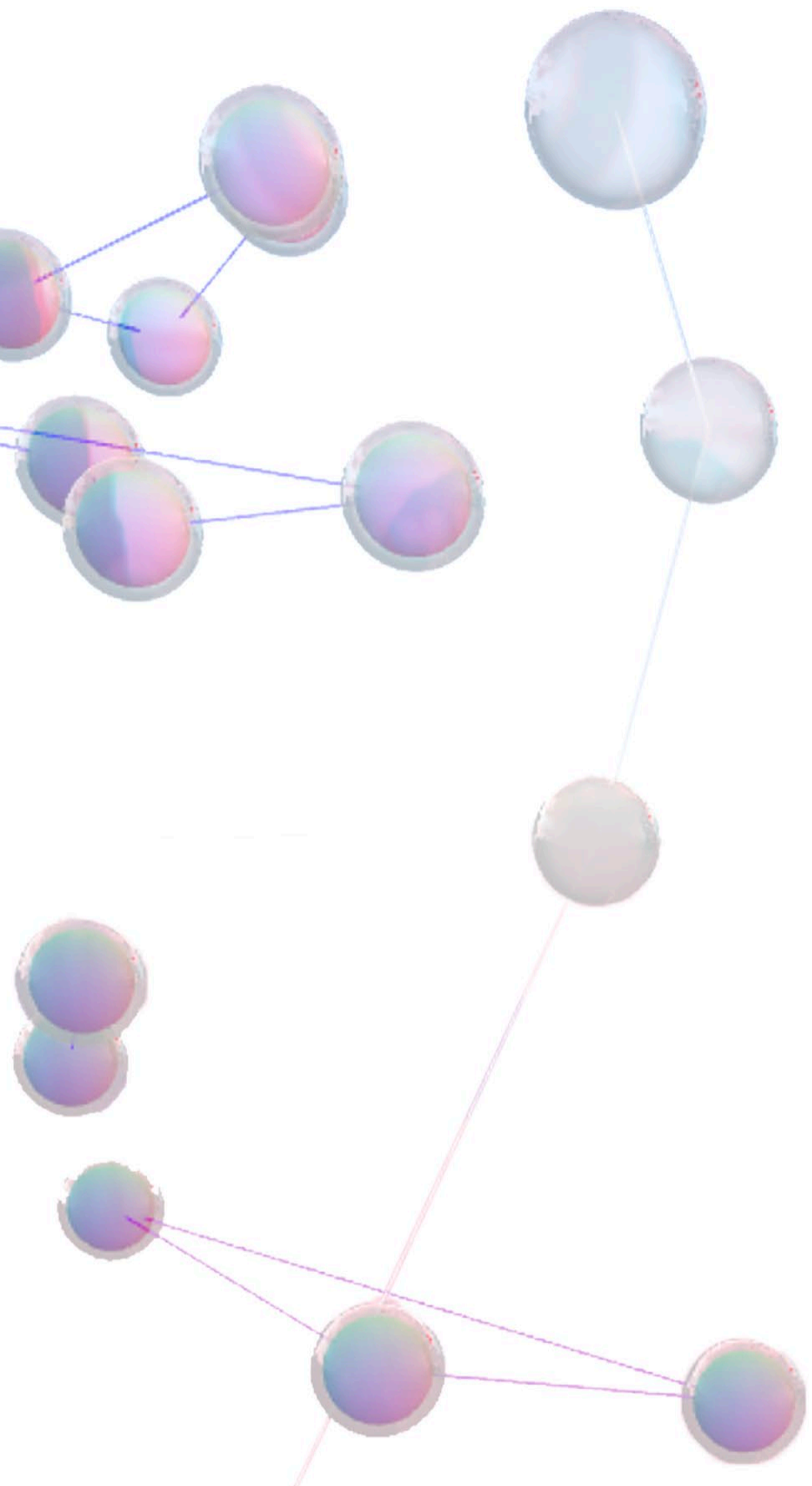
workshops. Whilst, because of staff availability, the normal weekly studio timetable might be adjusted, the cumulative hours of activity required of a student is not altered. The opportunity to work with academics from a wide range of universities, backgrounds and cultures greatly enhances the international feel of the degree programme. As the outputs and confidence grew this experience became more and more enriched.

\section{THE STAFF EXPERIENCE}

Staff exchange has always been an integral part of the Erasmus+ programme, but clearly is limited to those able to travel abroad in normal teaching times.

The development of digital architectural workshops opens up the possibility of teaching students in other institutions to many academics who have never had the chance to do so face to face. It also allows them to help colleagues deliver each workshop through their roles as tutors. The exchange of pedagogical ideas was a major outcome of that pilot year.

What started with 6 universities in the first semester, just a few months later multiplied by 4 the number of collaborators. We began the second semester 20/21 with 24 schools of architecture: Alicante University (SPAIN); American University Dubai (UAE); Bologna University (ITALY); Budapest University of Technology and Economics (HUNGARY); ENSAP Bordeaux (FRANCE); European University Madrid (SPAIN);
Evora University (PORTUGAL); German University in Cairo (EGYPT); Ion Mincu University (RUMANIA); IUBH Internationale Hochschule Hamburg (GERMANY); KU Leuven Brussels (BELGIUM); London South Bank University

(UK); Malmö University (SWEDEN); MEF University İstanbul (TURKEY); Reggio Calabria (ITALY); Umeå University (SWEDEN); University of Lincoln (UK); University of Nicosia (CYPRUS); Uwe Bristol (UK); Wroclaw University (POLAND; Yasar University Izmir (TURKEY)

This was a fast increase in quantity that also intensifies the quality of the project: firstly, due to the diversity of international universities, a range that goes from Sweden to Portugal, and from Turkey to Iceland. But also, since now there are more workshops than teaching weeks in the semester, the students can afford to choose between a range of offers. That means that they design their own education. According to personal interest, each of the students is able to select up to 10 workshops, just keeping in mind that they don't coincide in time.

This is a new role for the students, who is hence much more active in this educative system, where they define what kind of architects they want to be. In addition, the Schools of Architecture always have valued an intense collaboration with artists. Therefore, we included in this fresh vision to UOU an exchange of ARTS workshops, each of them directed by different teachers from International Schools of Arts: Academy of Art -Therapy - Munich (GERMANY); Porto University - Facultade de Belas Artes - (PORTUGAL); Reykjavik University of Arts (ICELAND)

This is what we call the UNIVERSITY of Universities and lays the foundations of a proposal for a EUROPEAN UNIVERSITY that completes the ERASMUS programme.

\section{https://uou.ua.es}

It is our intention that this pedagogic initiative will continue running over the next academic years, even once the pandemic has passed. But to maintain this experience in time, we do need to work up a research project capable of constantly feeding us.

This has been precisely the origin of UOU scientific journal. A biannual publication where every issue will underline a specific topic that has been addressed in the series of workshops developed every semester by the professors and students participating in UNIVERSITY of Universities.

UOU scientific journal will have a different Editor in Chief for each issue, the directors of the different UOU workshops, who will take the research of this journal as a precious opportunity to go beyond with our teaching. 


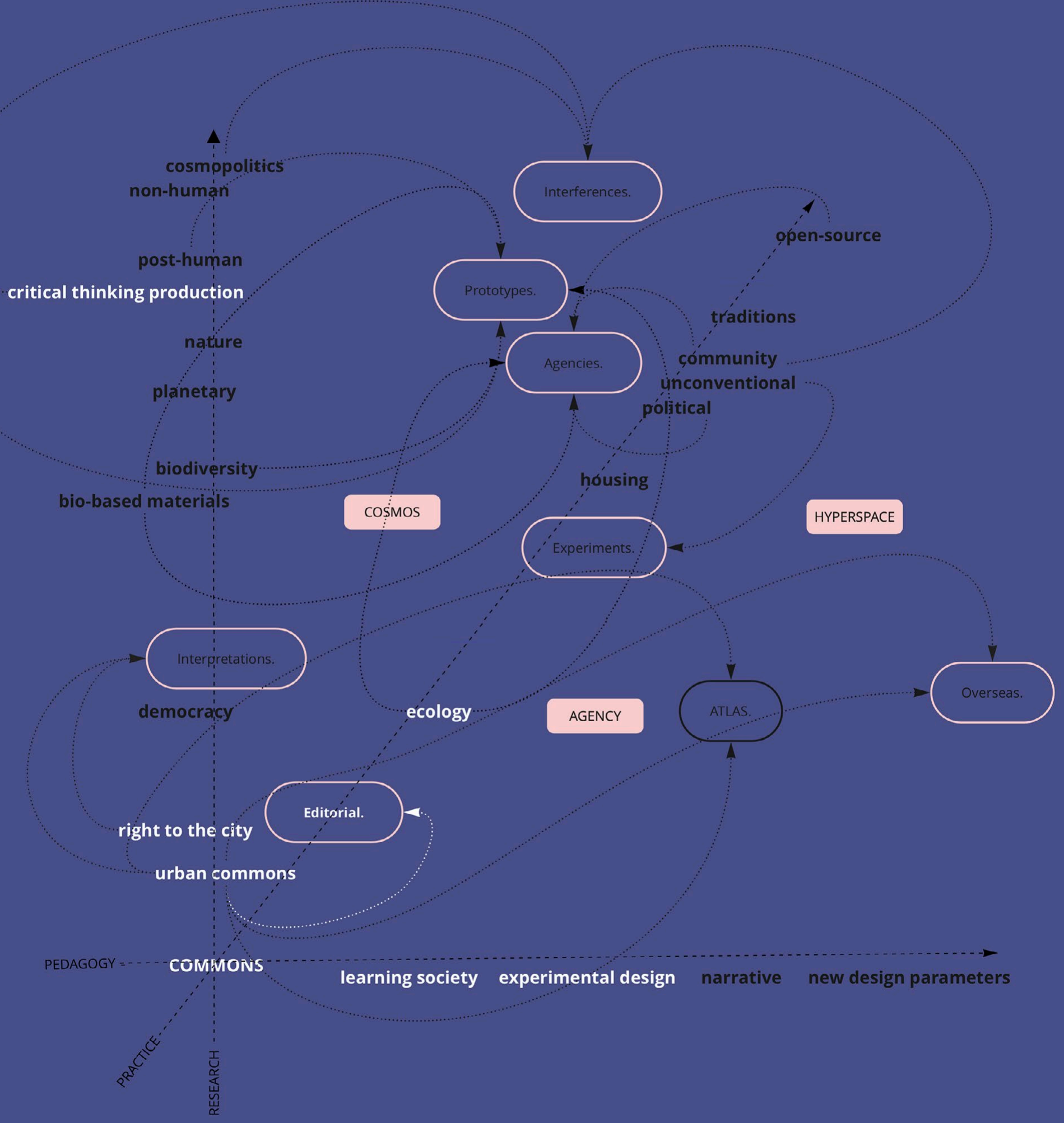



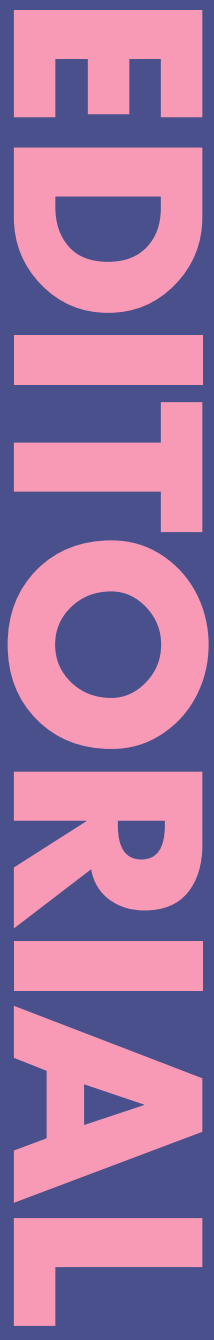


\section{An Introduction:}

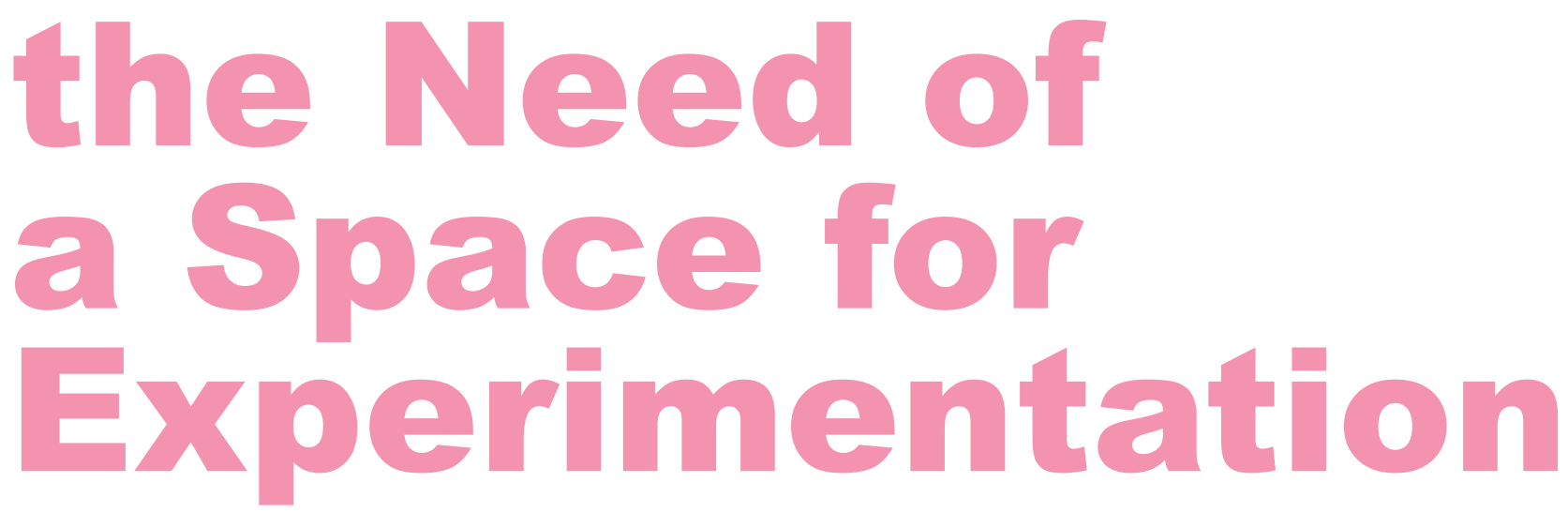

\section{Nobile, Maria Luna ${ }^{1}$}

${ }^{1}$ Umeå School of Architecture / Umeå University, Sweden https://orcid.org/0000-0001-8958-2999

maria.nobile@umu.se

Citation: Nobile, M.L. (2021). An Introduction: the Need of a Space for Experimentation. UOU scientific journal \#01, 14-21.

ISSN: 2697-1518. https://doi.org/10.14198/UOU.2021.1.02

This document is under a Creative Commons Attribution 4.0 International license (CC BY 4.0) 
We are living in times of urgency.

In the current year, we have been forced to translate and discover new values, both in Education and Research in Architecture. While we have had to rethink the space of the room and the boundaries of our individual space in between four walls, a floor and a ceiling, and the world outside, other typologies of spaces have been imagined and -all of a sudden- this hybrid space between the physical and the digital space became a reality. Therefore, in this context, the notion of Commons, in its wide acceptation, has been helping us to define a new typology of space, starting from the space of the classroom.

The notion of space has been changing immediately because of the pandemic, forcing us to consider the virtual dimension as a new possibility to interweave the private, public and common aspects of our lives and interconnect them in the definition of a Common Place. This immediately changed the notion of relationships, underlining the value of the notion of community and exchange, removing the existing boundaries and bringing us into the future.

In this Common Place,

\section{UNIVERSITY of Universities}

has been designed with the idea of sharing an international staff of academics with their own background knowledge and research with students coming from different countries, improving the internationalization, opening the borders, travelling without moving, testing and designing a curriculum towards another future for the academia and looking forward to a professional environment that will be slightly different from the one that we already know.

As stated in the concept of the project, UNIVERSITY of Universities (UOU) was founded in July 2020 as an experimental Architecture Programme in the Design Studio for the academic year $2020 / 21$ in the different schools of architecture involved. It is in the intention of moving beyond the virtual lectures, crits and tutorials, in search of new exercises that not only re-define the pedagogical approach to the discipline, but also gives us the opportunity of re-defining the basis of a new Programme in the Architectural Education. (UOU Project, 2020)

\section{UNIVERSITY of Universities is} an open and collective space, where the rules are defined by the community of students and teachers involved in it. It is an open and democratic network that occupies a space that has no boundaries and that does not belong to a specific country or city.

As the ILAUD ${ }^{1}$ Residential Course in Architecture and Urbanism - established by Giancarlo De Carlo in Urbino in September 1976 - was conceived as an itinerant and open alternative to the traditional education of the young architects, so UOU can be seen as a powerful machine to underline the potential of the "laboratory" as the space (material or immaterial) where this energy can be produced.
Indeed, looking at what is UOU, our mind goes immediately to the ILAUD founded by Giancarlo De Carlo in the 70's. The main intentions of ILAUD highlighted by Giancarlo De Carlo (ILAUD Yearbook 1977), have been to create an international network of students and professors among different Universities in Europe, to experiment with new methodologies and techniques for the architectural design, to provide the space for researchers and teachers in the academia to have the opportunity to compare their didactic approaches, and opening a channel for intercultural exchange between universities. At ILAUD, students were invited from different schools of Architecture in Europe $^{2}$, English was chosen as a common language of communication, and a yearbook has been the tool both to collect the reflections that occurred and as way of communicating outside what happened inside the classroom.

The different backgrounds of students, coming from a highly diverse range of geographic and cultural contexts, resulted in different approaches and methods, and the evidence of the importance of opening a debate on the new role of the architects at that time (ILAUD Yearbook 1977).

In order to achieve this aim, the school provided specific tools for developing a critical consciousness. Magazines, for instance, were considered by De Carlo a fundamental tool to appreciate different approaches to the architectural debate. What we have definitely learned 
from this experience, after more than 40 years, is the necessity of an intercultural way of learning and the endless possibilities that this way of thinking is opening for future architects. But what are the common values that can be enhanced and adapted to the needs of current society? How can we fix and transmit what we have learned and experienced during this academic year?

\section{The UOU scientific journal}

was born in Sweden in November 2020 in the framework of a research seminar on the topic of International Research hosted by the Umeå School of Architecture. This addressed the need for providing a place for all the research from the enormous production of reflections and experiments that were part of the UOU project during the autumn semester involving a team of academics from all over Europe. The Journal has been designed as a space to host reflection on topics linked to contemporary debates in Architecture that are at the center of the discourse on the education of future architects, made possible by the opportunities that have emerged from the experience of exchange between the European Universities on the question of the Internationalization of Teaching Architecture in a time of pandemic. In this sense, the research is a tool to reinforce the education, and the education acts as a testing tool and space for experimentation. This experiment gave us the possibility of enhancing the value of the international exchange between cultures and empowering education in architecture thanks to the opportunity of sharing the same common space over enormous distance and different time zones. The reflection on the notion of commons from now on will be enriched by the experience of pushing the limits of time and space and rethinking the notion of values in an innovative and unprejudiced way.

An ATLAS of possibilities, both here and now.

\section{The UOU scientific journal} includes researchers' and practitioners' contributions in the form of Articles, that are the core of this Journal, and a reflection on education including student's contributions in the form of Projects in the section ATLAS. The call for this first issue of the journal opened with a reflection on the work of two architects that have been an inspiration for this work, and their texts that are currently on my desk: Giancarlo De Carlo as the author of Architecture of Participation, and Ralph Erskine as the author of Democratic Architecture, with the intention of reflecting on the connections between their lives and researches and looking at the impact of their way of using practice as a tool for testing the theoretical approach to the discipline, as well as the idea of trusting in collaborations.

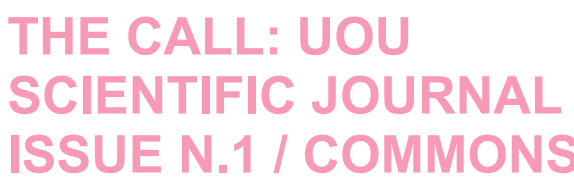

In 1982 the English-Swedish architect Ralph Erskine, opened a lecture by reflecting on the definition of "Architecture as the Art of Building Communities"3. His point of view, which led to a more radical way of considering the role of the architect in society, can be considered as the heritage from the main intention shared by Team 10 during the CIAM in 1959 in Otterlo with Aldo van Eyck, Giancarlo De Carlo, José Antonio Coderch - above the others - while introducing the notion of Democratic Architecture and Architecture of Participation.

With the escalation of the climate crisis at the present time, social inequities and political divergence, the general concern about access to natural and common resources, including space, all this is leading architects and planners to reconsider the notion of values in claiming their collective role towards the definition of a new right to the city ${ }^{4}$. The pandemic has opened a new scenario in which the notion of communing and sharing is assuming a new value and defining new spaces. How can architecture respond to social challenges and climate crisis? Where is the limit of architecture as a discipline in facing the human condition in relation to the scale of the impact on nature? What is the role of architects in response to social and spatial inequalities? What impact can the notion of Commons have on the transformation of cities? And what agency must designers have in contributing to such a transition in the current condition of Urgency? In this framework Commons, the first Issue of the UOU 


\section{The Call: \\ Commons*}

\section{*The use of the term}

Commons might be

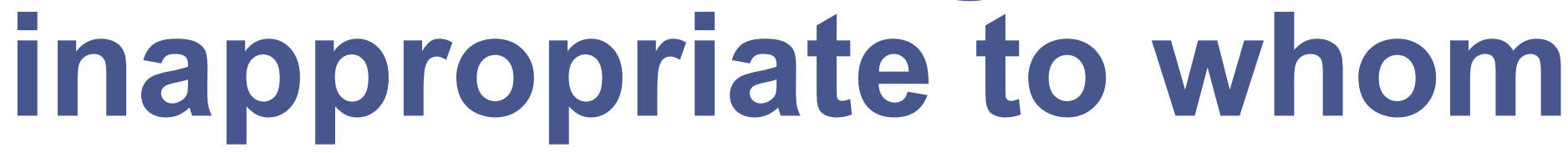

reading this journal

is not ready for

adventures.

scientific journal, aims to redefine the notion of values in relation to material and innovative practices from an unprejudiced aspect.

In England, the word "commons" is generally associated with the Enclosure Acts of the late 18th and early 19th centuries. Commons had existed in the countryside since time immemorial - open grassland, wide roadside verges and heathland on which small farmers and peasants had the right to graze their animals. Enclosure was associated with the rise of modern science in the Age of Enlightenment which impacted on farming by what became known as 'improvement'. Improvement was inextricably linked to capitalism, which was becoming entrenched and its grip extensive. Typically, the main landowners of a parish would pursue enclosure of common land through a particular Act of Parliament and, if passed, commissioners would be appointed to carry it out. Parliament was dominated by landowning aristocracy and the church, and commissioners were big landowners and farmers from outside the village who were engaged to turn the commons into fields, which were then acquired by large landowners. Access to commons, and woods was essential to the survival of the peasant and small farmer with 'rights of common' to graze their cows and sheep. Although this more scientific approach to farming might appear to be a logical extension of past changes, it was in reality a quasi-legalized land grab by landowning classes over the rights of the common people. ${ }^{5}$

For the reader of this Journal the notion of Commons translated in our urban (and digital) environments is to be conceived more as collective production of resources and spaces in general - material or immaterial - rather than with the resources themselves. 
This opens a reflection on the process of spatial organization in the relations between production, ownership and access to these resources, with an open eye on the effect of the Pandemic.

This call for articles aims at exploring the notion of Commons in the field of research in architecture and urbanism along three axes of investigation.

\section{AGENCY: PRACTICES AND GEOGRAPHIES OF COMMON PLACES}

\section{Practices}

One of the urgent questions in architecture is: are we building or making places? This call invites the authors to reflect on the possibilities for a place to become the scenario of new and inventive practices that generate architectural processes of value.

This means to consider the territory as a whole, highlighting initiatives both in the social and political realm that embody a certain spirit of experimentation and with the infinite possibilities related to the specificity of architecture itself: quality of spaces, relation to context, adaptability, flexibility, openness. An Atlas of pioneering places ${ }^{6}$ that explore and experiment through collective processes the notion of building communities in a specific context and place.

\section{Geographies}

The process of mapping extends and enriches our interaction with the specific conditions of a site and its atmosphere. Can the perception of the users allow us to understand and experience the unique characteristics of a specific place? The 'agency' of the map, is that which exploits the research to identify, decode and create the potential of possibilities for a specific place and to define the foundation for a future transformation ${ }^{7}$. If mapping is understood, not as a process of representing geographies or ideas, but as a tool for research and translating into action, how can we as architects effect the way these geographies and ideas are manipulated?

\section{HYPERSPACE: TECTONICS AND HYBRIDS OF COMMON ELEMENTS}

\section{Tectonics}

Cities are often judged by their relationships within society. Under these novel circumstances, what the experts are looking for is a necessary change in architecture more than to architects themselves. Without a doubt, it is time to question the single authorship of the future of Architecture: more than ever, as a discipline, it cannot continue being taught singularly, nor on a local level.

How can the Tectonic as a representation of authorship in architecture recapture its link to the social context and common values? How can the fundamental elements ${ }^{8}$ incorporate and translate the needs for a radical change in the definition of a new role for the architect in a future society?

\section{Hybrids}

Architecture, open and expansive in nature, has explored unlikely interactions and projected hybrids with unpredictable results. The notion of bigamy ${ }^{9}$ for example, is based on the evidence that multiple elements that apparently don't fit together can be merged together to create a new creation or genre. We have the possibility of building the world that we want to inhabit. This is a positioning that will allow us to experiment with new parameters in architecture, opening the path to new ideas that previously seemed impossible or unknown. In this sense, the notion of commons intersects with the definition of hybridity in the discovery of innovative and unprejudiced techniques and materials for defining new kinds of common material and immaterial spaces and explorations. What are the disciplines involved in this interaction? How can common data and digital commons drive the material explorations in architecture?

\section{COSMOS: MEANING AND VALUES OF COMMON ECOLOGIES}

\section{Meanings}

The architect is a storyteller. What would architecture be without a story? We suggest it would not be architecture. But to tell a story we need a language in which to communicate and we need to specify the actors and their movement in the space. What does it mean to imagine and, indeed, experience a space without seeing it? What is the 
common language that enables architecture to be perceived, in terms of knowledge and interaction, within the place itself? How can imaginaries ${ }^{10}$ be conceived and built by the living inhabitants through the definitions of common values overcoming the cultural identities and boundaries?

\section{Values}

The city and, at a micro scale, the building can be explored as a mosaic of spaces defined by the patterns of events which we experience in it ${ }^{11}$. The pandemic offered us a chance of enhancing new values, not only in terms of relationship between human beings, but enabling us to discover and redefine the notion of inception spaces, undetermined spaces, third places, and to determine the importance of nature in the design of our everyday life spaces. But not only this: for in a sense the traditional notion of common ecology disrupts the basic values of dwelling, a room, an apartment, a city. What is the role of the undetermined spaces in the city, both in terms of nature and dwellings? Can architecture be open to the unplanned, and highlight the value of the inhabitants' role in defining a flexible notion of dwelling?

\section{ECHOES: \\ ARCHITECTURE AND COMMONS, TOWARDS A NEW ROLE FOR THE ARCHITECTS OF THE FUTURE.}

The potential of an international call for articles lies mainly in its possibility of it being interpreted by many different voices and languages. As a result, the first call for articles of the UOU Scientific Journal has seen contributions from researchers and practitioners bringing their own original research and projects aiming to interpret the notion of Commons as a way of understanding the value of an architecture which is no longer hiding behind the definition of authorship that has distinguished the role of the architect for decades. The introduction by the coordinator of the UOU Project, Javier Sánchez Merina, is leading us to an unpredictable path, which from July 2020 has been a continuous process of discovery towards new possible explorations. The contribution shared from Joaquín Alvado started from a conversation within the members of the editorial board, and was enriched by the contribution of Mike Devereux and Maria Hadjisoteriou on the future of education and practice in architecture.

It is more and more evident that we are facing new possibilities in the of way of conceiving architecture, overcoming the boundaries of the disciplines and learning from the specificity of our cities and cultural values where the discipline of architecture needs to recapture its political role.

The section "Interpretations" bring us onto a journey that uses the existing literature on the topic of Urban Commons as a way to reflect upon new paths of research. In this, the author Francesco Caneschi introduces the notion of temporariness as a material for an architecture of becoming the scenery of multiple interactions between people and places, opening a reflection on possible kind of architectures, where typologies are replaced by "Prototypes" that experiment with new materials and actions. This is the case of Marie Roels' proposal for the Rhodo Workhome, an experimental project in collaboration with $\mathrm{KU}$ Louvain and the city of Ghent, offering new possible meanings and functions. This echoes the work of Maria José Marcos with her Portable Ecologies recently exhibited in the Spanish

Pavilion at the 17th Architecture Biennale of Venice, which works with traditional functions but innovative responses to the urgent need to adapt existing spaces to the current condition - rethinking the spaces for education - as in the project by Bruna Sigillo for the Coccapani Planetary Garden, winner of the competition Next Landmark 2020 launched by Iris Ceramiche and Floornature.

The contribution of

TAM Associati, with the experimental project $\mathrm{H} 2 \mathrm{OS}$ anti-desertification eco-village in Senegal, includes one of the reflections on the vision of architecture that the founders, Simone Sfriso, Raoul Pantaleo and Massimo Lepore have been testing through their extensive work. In this project, the architecture is conceived as a device that serves the community, with the proposition of Taking care of people and places, principles and resources, as expressed in an exemplary way in the Italian Pavilion in the 15th Architecture Biennale of Venice, curated by TAM Associati on the topic of 
Common good in Architecture.

While these contributions are re-defining the agency of architecture, the contribution included in the section "Experiments" by Emma Davies, compares the approach of two European countries to tradition and the value of Self Build construction as a possibility for an architecture of the future in specific contexts and in the framework of a specific field of research. And on the same path, the contribution by Marcin Kolakowski, based on his comprehensive experience in research and education of Low-Tech, opens the section related to "Interferences" with other disciplines, in this case where Psychoanalysis is used as a key to understand and translate architectural concepts dealing with the idea of values and meaning of common ecologies. The Peruvian case presented by Bruno Chichizola conducts us through a reflection upon the actual impact of the pandemic on the use of public/private spaces in the urban environment, using the ethnographic method as a way to understand and test the theoretical framework on cosmopolitism.

Reflection on the research into pedagogy in architecture is expressed through the contribution from other Schools of Architecture who have shared their pedagogical practices and experiences with us, through analyses of the notion of Commons in the contemporary city. In the case of a group including Orfina Fatigato, Viviana Saitto, Gennaro Finale, Vittoria di
Giulio and Mario Galterisi of the Department of Architecture of the University of Naples Federico II, this involved rethinking the neighborhood of Poplar in East London, specifically questioning the notion of authorship and values in the Robin Hood Gardens housing project. Similarly, the contribution from Eskişehir Technical University, by Nuran Özaslan, Fatma Kolsal and Sevgin Aysu Balkan, examines the role of Nature in the interpretation of the new commons through three experimental Design Studios.

A special place in our ATLAS is given to the contributions of a selection of works from the two week workshop held during the UOU Fall Semester 2020. These include a reflection on reactivation of abandoned places and focusing primarily on a new understanding of the role of architects in a future society, dealing more and more with participatory design tools and with the reuse of existing buildings and interpreting the notion of social and environmental sustainability. A window was opened towards the future where the imaginary landscapes developed by our students - and by the students who have answered the call - with unexpected results of reflections shared in this short Workshop lead by Marie Kraft and myself and accompanied by our UOU colleagues. In this section, the projects of the students are to be considered as a test bed for our work and reflections as researchers, practitioners and educators.

We are living in times of urgency. And it is with this urgency of generating new ideas we, as architects, are finding our places for new opportunities, claiming our place, acting in the common sphere and reinforcing the boundaries of our discipline, while dealing with the need of continuously connecting with other fields of research and studies.

\section{REFERENCES}

\section{ILAUD - De Carlo}

2. Escuela Técnica Superior de Arquitectura of Barcelona, the Katholieke Universiteit of Leuven, the Massachusetts Institute of Technology, the Oslo School of Architecture, The University of Urbino and the Eidgenossische Technische Hochescule of Zurich.

3. R.Erskine, Democratic

Architecture, the Univeral and Useful Art, in: RSA Journal, September 1982, London.

4. H.Lefebrve, Le Droit à la Ville, Points, Paris 1968.

5. A paragraph on the meaning of the concept "Commons" has been added to the Call for articles by Trevor Garnham, our Editor proof-reader that has been a valuable contributor to the work of this Journal.

6. Encore Hereux, Infinite Places (Lieux Infinis) - Constructing Buildings Or Places?, Publisher Editions B42, 2018.

7. J.Corner, The Agency of Mapping. Speculations, Critiques and Inventions, 2011.

8. R.Koolhaas, AMO, Harvard GSD, Elements of Architecture, Tashen, 2018.

9. Byarke Ingels Group, Yes is more. An Archicomic on Architectural Evolution, Tashen, 2018.

10. R.Barthes, Le Degré zéro de l'écriture suivi de Nouveaux essais critiques, Editions du Seuil, Paris 1977.

11. C.Alexander, The timeless way of building, New York, Oxford University Press, 1979 


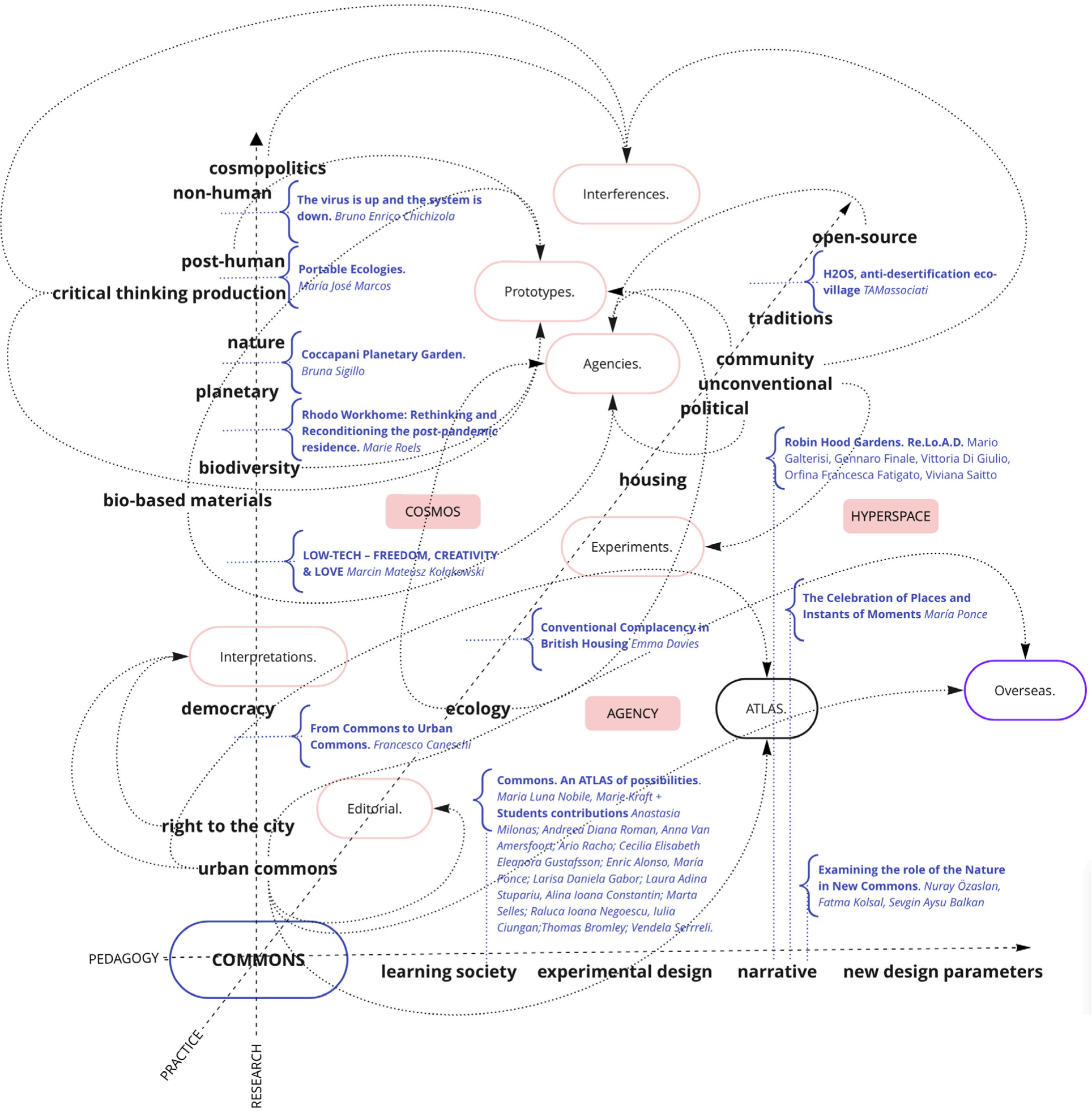




\section{A manifesto: circus Island}

\section{Alvado Bañón, Joaquín ${ }^{1}$}

${ }^{1}$ Department of Graphic Expression, Design and Projects / Alicante University, Spain joaquin.alvado4@gmail.com

Citation: Alvado Bañón, J. (2021). A Manifesto: Circus Island. UOU scientific journal \#01, 22-25.

ISSN: 2697-1518. https://doi.org/10.14198/UOU.2021.1.03

This document is under a Creative Commons Attribution 4.0 International license (CC BY 4.0)

First, we need an Architectonical space for learning. We name it. Circus Island.

Circus Island must be a constellation of public spheres as narratives of autonomous subjectivity. We will seek to enact a multidisciplinary direction through which architectonic practices and processes come most alive. We will constitute a map of contemporary knowledge circuits where art, theory, science, culture, ecology, and politics collide. Urban systems and metaterritory experience open to freedom openness and changes. No verb in this sentence.

UOU, our international studio, is an area of uncertainty and reflection. This space must be built to embrace everyone; students, teachers, institutions, guests and citizens, hundreds of voices within a discursive dynamic system.

UOU, the "Circus Island" is a democratic space for discussion.

The construction of this experimental space need:

1. Openness. To incorporate open formats and new work contexts, experimental practices and learning systems.

2. To incorporate student's upcoming and active vision. The student is part of our teaching. Our goal is autonomy based on their own maps of projective action.

3. To embrace diversity. Working on broad contexts. Students and teachers experience on their capabilities, knowledge and limits as an essential part for the teaching portfolio.

4 Proposals for the future. The space is for managing the future reality.

5. Uncertainty. Emotion to work on the unknown, to find the 
structure for the fiction. To accept complexity of knowledge in contemporary teaching.

6. Research as autonomy of thought. To be committed to scientific knowledge to expand research and knowledge.

7. Imagination. Imaginative space as a process of relationship.

8. To build an exhibition space, a document. UOU is a document, a portfolio in itself.

9. Discussion as a search for knowledge. To accept the multidisciplinary approach of a changing profession.

11. $\underline{\text { Risk. }}$. The UOU was born in an unreferenced context, on a bizarre online periphery.

12. Dynamicity. Travel for deferred knowledge.

The Circus Island; the space for UOU, is a collective, dynamic, experiential and future-looking process. It is for living and to live in. It is productive and exciting. It is an adventure, a risk.

Circus Island: A leisure space, a space for fun, to enjoy and to spend a good time, a space for happiness; a soft space, a space to love, to fraternize, to become close friends; a conflictive space, a space to argue, to discuss and to win.

\section{MASK}

"Architecture is a fuzzy amalgamation of ancient knowledge and contemporary practice, an awkward way to look at the world and an inadequate medium to operate on it... Architecture is too slow. Yet, the word "architecture" is still pronounced with certain reverence (outside of the profession). It embodies the lingering hope -or the vague memory of hope- that shape, form, coherence could be imposed on the violent surf of information that washes over us daily. Maybe, architecture doesn't have to be stupid after all. Liberated from the obligation to construct, it can become a way of thinking about anything -a discipline that represents relationships, proportions, connections, effects, and the diagram of everything."

Rem Koolhass. "Content"

Circus Island is a critical and experimental vision of contemporary urban society. We propose a Mask; an architecture about the making of architecture.

Masking ourselves as a process in which an individual changes or "masks" their natural personality. We will work to find our architectonic mask and build it. We will become architects.

As Hejduk in Victims; We will project our Island to portray an analogous city, an experimental version of the contemporary city.

Radicality, detour, digression as critical reflection.

Architectural typology, to mobilize a repertoire of building elements drawn into an exchange between theatrical and formal/expressive practices. 


\section{LANGUAGE}

Language systems reside in individual minds, they have a separate existence and thus remain detached from their users.

Rorty defines an "ironist as someone who fulfills three conditions.

(1) She has radical and continuing doubts about the final vocabulary she currently uses, because she has been impressed by other vocabularies, vocabularies taken as final by people or books she has encountered.

(2) She realizes that argument phrased in her present vocabulary can neither underwrite nor dissolve these doubts.

(3) Insofar as she philosophizes about her situation, she does not think that her vocabulary is closer to reality than others, that it is in touch with a power not herself.

Ironists describe themselves as subject to change, always aware of the contingency and fragility of their final vocabularies, and thus of themselves.

The opposite of irony is common sense. UOU needs a new vocabulary to establish the rules of our architecture. Let us find a foolish act or idea

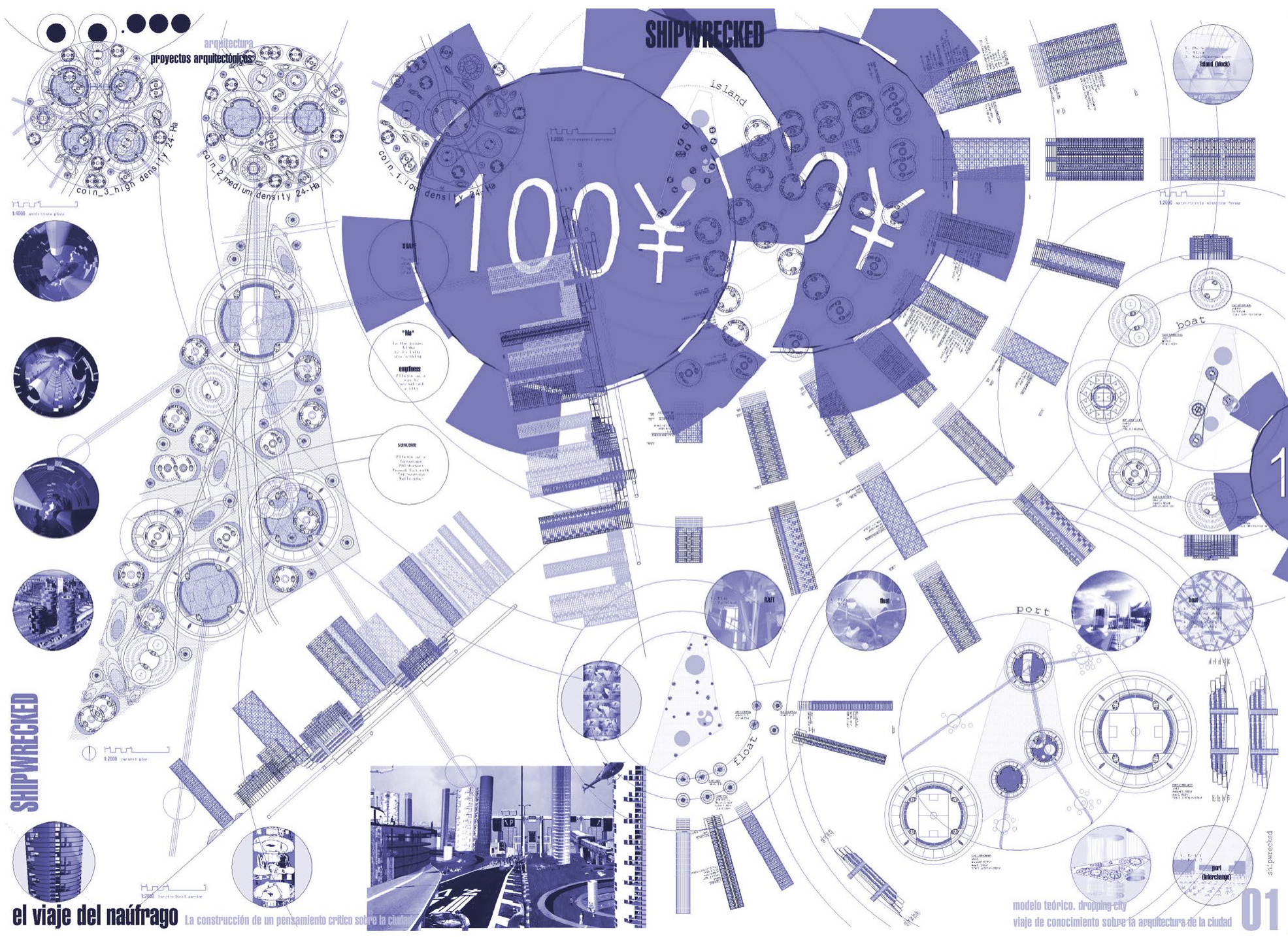




\section{DYNAMIC KNOWLEDGE}

In Circus Island we try to find the language throw the vocabulary. What do we refer to when we talk about Architecture?

This is the question for our architectural research at the UOU. We want to talk from scratch about innovation, social behaviour, nature, growth, time, change, sustainability, weather, citizenship, atmosphere, water, adaptability, welfare and environment. We use research as a technical tool to work on diversity, an open future, emotion, imagination and a complete portfolio to establish a dynamic process that will help us formulate concepts concerning architecture and life.

Dynamic knowledge is related to time, space and existence. The online procedures are real dynamic systems, chaotic descriptions. In dynamic systems, time and space are interdependent; there is no apparent center or order. In our research, we focus on dynamic grids of geometry, which create the shape of a structure, thus giving architectural design presence. As a Dynamic system, we work with iteration and sensitivity as initial conditions. It is under those parameters that a system process becomes a structure. Our approach is related to two main items: emptiness and dynamic systems. Emptiness is related to iteration and recursion, while dynamic systems are related to sensitivity to initial conditions.

Emptiness as a "democratic space" is projected as a conflict between virtual and real space. It gives architecture a kind of depth that is not exhausted on a spatial scale, but works jointly with virtual space to manifest its void as a possibility. It is a probability, and it is shown as a domain within the realm of possibility. It transcends architecture's perception as an "object" at the moment or stage that we become aware of its existence. Networks connecting spaces are instruments for understanding their structural functions. Diagrams and grid maps depend on the network shape and quality. In our research, networks are based on cultural background. New policies for sustainable cultural thought will become the answer to future design questions and new identity systems.

Our approach works with dynamic, online structures. Each unit becomes a tensional network of visual negotiations. Virtuality reinforces the effect of chaotic order in such a way that certain "informal" elements become structural supports for space. The visual complex of spatial interconnections is established through democratic architecture as an emptiness. The tensional organisation is based on grids, on creating three-dimensional connections in which order is magnified into a labyrinth of structures at a small-object scale.

Circus Island is a dynamic system. Dynamic systems' sensitivity to initial conditions means that a system's asymptotic behaviour can be altered by even the slightest of changes in the initial conditions: "the butterfly effect". As we well know, we need to educate the next generations to stay true to the initial conditions. 


\section{Conversation on a common manifesto}

\section{Alvado Bañón, Joaquín1; Hadjisoteriou, Maria; Devereux, Mike ${ }^{3}$}

${ }^{1}$ Alicante University, Spain joaquin.alvado4@gmail.com

${ }^{2}$ University of Nicosia, Cyprus hadjisoteriou.m@unic.ac.cy

${ }^{3}$ UWE Bristol, UK

mike.devereux@uwe.ac.uk

Citation: Alvado Bañón, J.; Hadjisoteriou, M.; Devereux, M. (2021). "Conversation on a Common Manifesto." UOU scientific journal \#01, 26-33.

ISSN: 2697-1518. https://doi.org/10.14198/UOU.2021.1.04

This document is under a Creative Commons Attribution 4.0 International license (CC BY 4.0)

JA First, we need an Architectonical space for learning. We name it. Circus Island. 
JA Circus Island must be a constellation of public spheres as narratives of autonomous subjectivity. We will seek to enact the multidisciplinary direction through which architectonical practices and processes come most alive. We will constitute a map of contemporary knowledge circuits where art, theory, science, culture, ecology, and politics collides. Urban systems and metaterritory experience open to freedom openness and changes.

MD I think you have the right tone of excitement, exploration and creativity alongside a feeling of this being something new, for new times. What I feel is important with a manifesto is that it sets a framework in which to understand our adventure, to encourage contributions to a journal (and to judge them) and that this matches the aspirations of UoU architectural teaching. Amongst the vast range of journals and teaching experiences

we need to be identifiably different and communicate that. I like the analogy with 'constellation' as we are scattered around Europe and beyond with the UoU project - and just like a star in a constellation we are (I hope) illuminating architectural thinking and research to the maximum extent we can.

But I am a bit unclear here on your reference to 'public' when referring to spheres. UoU means - university of universities. A university (in the UK at least) for example is (apparently) a publically accessible institution, but access is controlled by the state education system and its examinations. You need these to achieve entry. The university itself is autonomous of the state (the public) and acts like a private institution (it costs students a minimum of $£ 9,250$ per year for their tuition) so that means that it is not public in the sense that l'd like architectural education to be. Many potentially good architects are excluded - the system

is public only in a limited way. I wonder if it is worth expanding upon 'public' to explain it more widely. In the case of the journal

I think 'public' should be used to encourage anyone with a voice to articulate an argument / research - not necessarily just academic (in the way you have invite student contributions).

JA UOU, our international studio, is an area of uncertainty and reflection. This space must be built among everyone, students, teachers, institutions, guests and citizens, hundreds of voices within a discursive dynamic system.

UOU, the "Circus Island" is a democratic space for discussion. 
MD I am very supportive of the multi-disciplinarity that you espouse to. Perhaps an explicit mention of 'technology' (unless you see it as 'science') might be something helpful to the reader, and perhaps alongside thoughts of 'urban systems' and 'metaterritory' it is worth balancing that with 'detailed' and 'micro' in terms of scale of investigation and discovery.

JA The construction of this experimental space need:

1. Openness. To incorporate open formats and new work contexts. Experimental practices and learning systems.

2. To incorporate student's upcoming and active vision. The student is part of our teaching. Our goal the autonomy based on their own maps of projective action.

3. To embrace diversity. Working on broad contexts. Students and teachers experience on their capabilities, knowledge and limits as an essential part for the teaching portfolio.

4 Proposal for the future. The space is for managing the future reality.

MH What is this future reality?

If we begin from the notion, as Lefevre argues, that (social) space is a (social) product, a dialogue on the potential role of the future architect is crucial in pedagogy.

Opening up vital questions as

'is the production of space a collaborative process?' 'can we make the process of architecture a dialogue?'

'how do we involve local actors- as co-authors?'

Allows for new definitions of the role that an architect has to play, going away from the idea of an architect as a dictating designer, but rather discuss it as a facilitator, an agent.

[Lefebvre H. The production of space. Blackwell; 1991.]

JA 5. Uncertainty. Emotion to work on the unknown to find the structure for the fiction. To accept complexity of knowledge in contemporary teaching.

6. Research as autonomy of thought. It is committed to scientific knowledge to expand research and knowledge.

7. Imagination. Imaginative space as a process of relationship.

8. To build an exhibition space, a document. UOU is a document, a portfolio itself.

9. Discussion as a search for knowledge. To accept the multidisciplinary approach of a changing profession.

11. Risk. The UOU was born in an unreferenced context, on a bizarre online periphery.

12. - Dynamicity. Travel for deferred knowledge. 
MD In terms of \#04 'the future reality' I wonder if we can be 'real' about the future. We, as designers, are I hope able to influence the future but I enjoy the experimentation and creativity that we bring away from our position away from reality. We might inform reality perhaps, but without being playful I would argue that our 'reality' is stifled and loses its potential. In some ways \#05 embraces what I am trying to say. Another point that springs to mind in reading the principles, and

I do not wish be pedantic here. You use the word 'scientific' and indeed it is in the title of the journal, but I am sure that you do not propose by this to demote the humanities and arts as disciplines and methods for and of research, or indeed as

means of teaching. Perhaps that needs drawing out more.

You do of course start off with this as a statement at the top of the manifesto so I am sure it is in your mind as an intended direction.

JA The Circus Island, the space for UOU, is a collective, dynamic, experiential and future process. It is a living and to live in. It is productive and exciting. It is an adventure, a risk.

MD You capture the important aspects of UoU: imagination, discussion, democracy, diversity etc... I would be inclined to think that we might emphasise a spirit of community (a 'common'). By this I mean that staff and students are mutually supportive of each other. The whole (of $\mathrm{UoU}$ ) is bigger than the sum of its parts. We are creating a space in which architectural education and research is able to grow by the help each participant (experienced or not) brings to it.

\begin{abstract}
JA Circus Island: A leisure space, a space for fun, to enjoy and to spend a good time, a space for happiness; a soft space, a space to love, to fraternize, to become close friends; a conflictive space, a space to fight, to discuss and to win.
\end{abstract}

MD Whilst I agree with the mood of your manifesto, and the way in which you are structuring it there is one phrase on which

I would urge caution; that is, "a space to fight, to discuss and

to win." Personally, I do not have to win. I enjoy learning and discussing, but winning is not my goal- educating, learning and enjoyment are my goals. For me, in UoU there is no 'winning' or 'losing.' If you are a participant (within the full meaning of that word - not just an attendee) then you cannot lose. 


\begin{abstract}
JA 1. Mask
"Architecture is a fuzzy amalgamation of ancient knowledge and contemporary practice, an awkward way to look at the world and an inadequate medium to operate on it... Architecture is too slow. Yet, the word "architecture" is still pronounced with certain reverence (outside of the profession). It embodies the lingering hope -or the vague memory of hope- that shape, form, coherence could be imposed on the violent surf of information that washes over us daily. Maybe, architecture doesn't have to be stupid after all. Liberated from the obligation to construct, it can become a way of thinking about anything -a discipline that represents relationships, proportions, connections, effects, and the diagram of everything."

Rem Koolhass. "Content"

Circus Island is a critical and experimental vision of contemporary urban society. We propose a Mask, an architecture about the making of architecture.

Masking ourselves as a process in which an individual changes or "masks" their natural personality. We will work to find our architectonical mask and build it. We will become architects As Hejduk in Victims, We will project our Island to portray an analogous city an experimental version of the contemporary city. Radicality, detour, digression as a critical reflection.

Architectural typology, to mobilize a repertoire of building elements drawn into an exchange between theatrical and formal/expressive practices.
\end{abstract}

MD I find your quote from Koolhaas appropriate. For me, he has tried hard to redefine architectural thinking. Not so much always in a purely, rational philosophical way but certainly intelligently. As he puts it "I think one of the important evolutions is that we no longer feel compulsively the need to argue, or to justify things on a kind of rational level. We are much more willing to admit

that certain things are completely instinctive and others are really intellectual." For us, I would argue that there is a place for the instinctive (and obviously the intellectual) and the 'mask' helps this. It allows us to suggest, to proclaim, to assert ideas that we feel, without always the need to be able to instantly justify. Through discussion and experiment we can test the ideas, but we can come to the 'island' without having done the testing. The methods of testing are innumerable, and you draw our attention to some important ones: The mask allows us to test without fear of judgment. If I am correct, Hedjuk draws us to the idea of a 'masque' (Berlin Masque) and not a 'mask'. The former is a form of entertainment (cp masquerade), often allegorical; whilst the latter is simply a face covering 9as we have to wear in these pandemic days). Personally, I see UoU as a drama, a 


\section{JA 2. Language}

Language systems reside in individual minds, they have a separate existence and thus remain detached from their users. Rorty define an "ironist as someone who fulfills three conditions: (I) She has radical and continuing doubts about the final vocabulary she currently uses, because she has been impressed by other vocabularies, vocabularies taken as final by people or books she has encountered;

(2) she realizes that argument phrased in her present vocabulary can neither underwrite nor dissolve these doubts;

(3) Insofar as she philosophizes about her situation, she does not think that her vocabulary is closer to reality than others that it is in touch with a power not herself". Ironists describe themselves are subject to change, always aware of the contingency and fragility of their final vocabularies, and thus of their selves.

The opposite of irony is common sense.

UOU needs a new vocabulary to establish the rules of our architecture. Let us find a foolish act or idea.

MD I completely agree. We need a new language of architecture. It needs to embrace a way of thinking beyond the physical. In that it can share intellectual space with many other disciplines. It can be ironic (ie. Richard Rorty) and it can even be cynical if it helps make a point, but it should never be destructive, only constructive. Architectural language has all too often been aloof and corrosive. My workshop later this semester will focus on that. Perhaps here is a good moment to expand upon your sense of finding a 'foolish act or idea' so that the point

\section{JA 3. Dynamic Knowledge}

In Circus Island we try to find the language throw the vocabulary.

The question is:

What do we refer to when we talk about Architecture?

This is the question for our architectural research at the UOU. We want to talk from scratch about innovation, social behaviour, nature, growth, time, change, sustainability, weather, citizenship, atmosphere, water, adaptability, welfare and environment.

We use research as a technical tool to work on diversity, an open future, emotion, imagination and a complete portfolio to establish a dynamic process that will help us formulate concepts 
concerning architecture and life.

Dynamic knowledge is related to time, space and existence. The online procedures are real dynamic systems, chaotic descriptions. In dynamic systems, time and space are interdependent; there is no apparent center or order. In our research, we focus on dynamic grids of geometry, which create the shape of a structure, thus giving architectural design presence. As a Dynamic system, we work with Iteration and sensitivity as initial conditions. It is under those parameters that a system process becomes a structure. Our approach is related to two main items: emptiness and dynamic systems. Emptiness is related to iteration and recursion, while dynamic systems are related to sensitivity to initial conditions.

Emptiness as a "democratic space" is projected as a conflict between virtual and real space. It gives architecture a kind of depth that is not exhausted on a spatial scale, but works jointly with the virtual space to manifest its void as a possibility. It is a probability, and it is shown as a domain within the realm of possibility. It transcends architecture's perception as an "object" at the moment or stage that we become aware of its existence. Networks connecting spaces are instruments for understanding their structural functions. Diagrams and grid maps depend on the network' shape and quality. In our research, networks are based on cultural background. New policies for sustainable cultural thought will become the answer to future design questions and new identity systems.

MH Inclusive Architecture / Urban Commons Raising awareness for and claiming the right of the people to the city as another aspect of addressing the Urban Commons could introduce a new system / a new identity.

Addressing people's diverse needs; understanding of the user, not as a generic person but as a unique individual that has the right to co-inhabit, co-appropriate the city, could radically shift the direction and essence of architecture and the built environment.

Could we facilitate people to appropriate architecture? Allowing users to act as equal social actors, can influence the way spaces are shaped.

How can we think of the notion of Commons in architecture? How is it converted in a spatial quality?

If we consider space as a container where social realities unfold in as Stavrides argues, then an investigation on strategies of performative space systems can unfold opportunities for various inhabitation and appropriation scenarios thus enhancing opportunities of Common activities and appropriation taking place in the city.

[Stavrides S. Common spaces of urban emancipation. Manchester: Manchester University Press; 2019] 
MD Here, I think the key word that you hit upon is 'iteration.' If design, both in academic research and in practice, is anything it is iterative. A conversation with ourselves and between ourselves that plays out in time, and now plays in virtual space.

I am not entirely clear what you mean here by 'emptiness' as a condition of the approach. Are you thinking, we start with a blank

canvas, a tabula rasa and that the dynamic system forms from there - like (back to your metaphor of a constellation) a big bang

theory? And, as you suggest, such an emptiness is somehow democratic? Does it need rules (like the laws of physics) to keep

it under control or is the emptiness to be left to its own devises so we see where it leads us?

JA Our approach works with dynamic, online structures.

Each unit becomes a tensional network of visual negotiations.

Virtuality reinforces the effect of chaotic order in such a way that certain "informal" elements become structural supports for space. The visual complex of spatial interconnections is established through democratic architecture as an emptiness. The tensional organisation is based on grids, on creating threedimensional connections in which order is magnified into a labyrinth of structures at a small-object scale.

MD I think the 'dynamic online structures' is a helpful aidemémoire but the link between democratic and emptiness needs elaboration to be clearer to an audience not familiar with such terminology.

\begin{abstract}
JA Circus Island is a dynamic system. Dynamic systems' sensitivity to initial conditions means that a system's asymptotic behaviour can be altered by even the slightliest of changes in the initial conditions: "the butterfly effect". As we well know, we need to educate the next generations to stay true to the initial conditions.
\end{abstract}

MD What I understand by your 'dynamic system' is that it evolves but is always useful - it informs. You refer to this (as I read it) as creating 'new policies for sustainable cultural thought.' That is laudable.

Again, thanks very much for the thought provoking draft. It has certainly made me think and become even more enthusiastic (if it is possible to be even more enthusiastic!) about UoU. I would be very happy to discuss any of this further and look forward to 



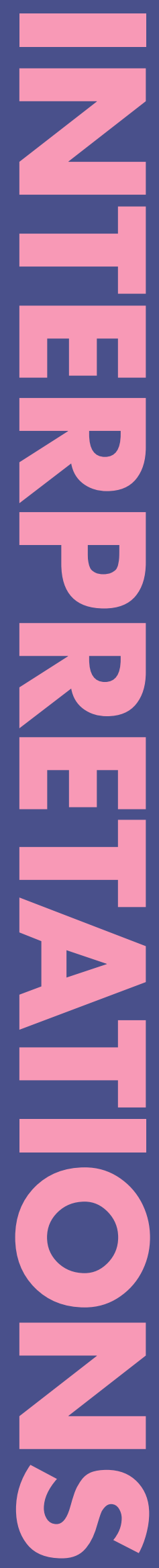




\section{From Commons to Urban Commons}

\section{Complexity and Contradiction in the Translation of a Concept}

commons

urban commons

diritto alla città

strumenti glocali democrazia sfuggente

commons urban commons right to the city glocal tools fugitive democracy

\section{Caneschi, Francesco ${ }^{1}$}

${ }^{1}$ FAUP - Faculdade de Arquitetura da Universidade do Porto, Portugal. DIDA - Department of Architecture of the University of Florence, Italy. https://orcid.org/0000-0002-9547-4967

francescocaneschi@gmail.com 


\section{Da Commons a}

\section{Urban Commons}

Complessità e contraddizioni nella

traduzione di un concetto

La nozione di commons è stata tradotta, nelle ultime due decadi, dal campo di studio delle risorse naturali alla dimensione urbana. Come per ogni traduzione si perde qualcosa e si trova qualcos'altro.

La teoria degli urban commons, ancora lontana dal presentarsi come completa o esaustiva, viene frequentemente accostata all'inflazionato slogan del dirittto alla città.

Questo articolo vuole illustrare come e perché i concetti di commons, diritto alla città e urban commons sono collegati fra loro. Questo studio permetterà di evidenziarne le differenze e dunque di percepirne le complessità e le contraddizioni. La teoria degli urban commons verrà inquadrata attarverso la cornice teorica del concetto di commons, studiato da Hardin e Ostrom, attraverso le nozioni di abitudine e performance articolate da Hardt e Negri e infine attraverso la metafora della soglia sviluppata da Stavrides.

Nelle conclusioni dell'articolo verra evidenziata la natura strettamente relazionale degli urban commons, e verranno proposte delle relazioni fra questa teoria $\mathrm{e}$ i concetti di processo, tempo e democrazia sfuggente.
The notion of commons has been translated, in the last two decades, from the field of natural resources to the urban dimension. As every translation goes, something is lost, and something can be found.

The theory of urban commons, far from being complete or exhaustive, has been also linked to the inflated slogan of the right to the city.

This article will try to illustrate how and why the concepts of commons, right to the city and urban commons are linked together. This insight will allow us to understand the differences between these concepts and, therefore, will point out any complexities and contradictions. Urban commons will be addressed through the theoretical frame of the concept of commons, studied by Hardin and Ostrom, through the notions of habit and performance as articulated by Hardt and Negri, and through the metaphor of the threshold developed by Stavrides.

The conclusion of the article will highlight the relational nature of the urban commons, and the findings will outline their relation with the concepts of process, time and fugitive democracy. 
The topic of Urban Commons is discussed more and more every day, both in academia and the mass media, especially associated with another definition: "The right to the city"', the title of the book by Lefebvre and which has become an international slogan.

\section{Urban Commons appears} today as a fundamental topic, above all because the majority of this planet inhabitants lives in urbanized areas. The definition urban commons presents two main differences compared with the slogan the right to the city. The first one is that the word city is an obsolete concept if used to describe today's urban environment, mainly because it's linked to the idea of the city-state. The word urban refers instead to a process that characterizes the geography of the world.

The second difference is between the meaning of the word right, that means «a moral or legal claim to have or get something or to behave in a particular way ${ }^{2}$, and the word common that means «the same in a lot of places or for a lot of people» ${ }^{3}$.The difference between right and common is emphasized by the connotation that the second term takes when it is declined in the plural commons: «people not of noble birth viewed as forming a political order» ${ }^{4}$. The word commons is connotated by a dimension of a shared political action about something that is collective. The word right suggests something that is taken for granted, a claim.

The translation of right to the city - that seems important since the debate is international

- in Italian as in French,

Portuguese and Spanish, is

similarly translated in "Diritto alla città". Actually, the original title of the book was "Le Droit à la ville".

Droit refers directly to the sphere of knowledge of the law: «Ensemble des règles qui régissent les rapports des membres d'une même société; légalité. Science qui a pour objet l'étude de ces règles. $\aleph^{5}$.

\section{Peter Marcuse, amongst} other authors, have stressed ${ }^{6}$ that right to the city could be updated with the definition of right to the urban life. The problem with this update is that the word right is still in it, meaning that the dimension of the claim, the taken for granted, resonates still. Even with this update, it could still be necessary to clarify, as Marcuse $^{7}$ suggests, what is this right and who are the ones entitled to this right. Common seems to adapt better to the following discourse because it suggests an opening of meanings and, as the definition of the Collins Dictionary ${ }^{8}$ implies a political dimension. Nevertheless, the definition urban commons presents some problems with the translation too. Specifically, because there is not a proper translation. The word commons is charged with its history in English culture and the language. In Italian for example, urban commons is translated in bene comune, that literally means "common good", where the second term stands for either a qualitative or quantitative evaluation. To properly grasp the translation of the concept of the commons into the definition urban commons, it is necessary to understand the origins of the first term.

"Historically in Europe, 'commons' were shared agricultural fields, grazing lands and forests that were, over a period of five hundred years, enclosed with communal rights being withdrawn by landowners and the state. The narrative of enclosure is one of privatization, the haves versus the have nots, the elite versus the masses ${ }^{9}{ }^{9}$ The commons were a resource opened to all social classes, whose ending coincided with the advance of the processes of Industrialization and subsequent urbanization". ${ }^{10}$

The main bibliographic reference related to this socio-spatial experience, extensively quoted in many publications, is the book "The Magna Carta Manifesto: Liberty and Commons for all" by Linebaugh. ${ }^{11}$ In the introduction to the book, the author states that the reason why he decided to write a book about the Magna Carta is that it is more important than ever that the question of the commons is brought up in the contemporary political agenda.

\section{Kratzwald summarizes} the historical nature of the commons, ending up by asking a fundamental question for the present time:

"The 'common land' was legally the property of the aristocratic landowner, however they were only permitted to restrict access to certain aspects (in particular the hunt, while other aspects were 
required to remain accessible to the farmers for precisely regulated use types. [...] The important realization here is: the right to the commons is something that the king must respect and not something that he can grant. It is not a favor; it is a right that is granted to every person at birth. Because nobility's ability to dispose over their land was restricted, the commons were always contested. It was therefore for good reason that the right to defend the commons was set out in the Magna Carta, namely in order to prevent their enclosure and appropriation by the nobility or the clergy. Once a year during a public festival, the common land was paced off and all fences and walls that had been erected in the past year were permitted to be torn down. What would this process mean in today's city?"12

The link between urban commons and right to the city seems to intensify by looking at it from an historical point of view, but the commons as natural resources and the urban commons are quite different, as this article will try to make clear. Kratzwald proceeded by quoting the phrase coined by Linebaugh "there is no commons without commoning", to make explicit that the common good, to exist, needs to be continuously recreated. 'Cities are in the midst of a rapid process of change, where the boundaries between private and public can shift daily"13. This consideration is even more pertinent if applied in a pandemic context as with the present Covid-19. This pandemic brought about an extreme reduction and enclosure of public space, both physically and conceptually.

The everyday physical detachment from the possibility to experience the public urban environment, denying both present and future. This, being the commons, is something that needs to be reproduced collectively through communal activity. In the time of a pandemic, such as Covid 19, the possibility of reproducing the commons looks like a problem without solution. This absence of a solution recalls the main topic of the article "the tragedy of the commons", written by Hardin in 1968: "The class of "No technical solution problems" has members. My thesis is that the "population problem," as conventionally conceived, is a member of this class. ${ }^{14}$

Hardin begins his article by quoting the conclusions of two experts on the nuclear arms race: as long as it is considered necessary to protect a country from nuclear war, is necessary to expand one's own nuclear armament, which at the same time induces others to the same. With the result that every step forward in a nuclear arms race is one step backward for the safety and well-being of the planet. This is a problem with no technical solution.

Hardin claims that the unlimited growth of the earth's population cannot cope with the resources of a limited planet. Two years before his article, the first image of the whole earth was published, and it was used for the cover of the "Whole Earth Catalog"15. This image of the earth as a single element projected in one single sphere was, for the editor of the catalog, the symbol of the necessity to consider our world and our species collectively.

With an eye on the glass half empty, Hardin takes the example of the "pasture open to all". Each herdsman in his own pasture knows the maximum number of animals that he can let graze without depleting the resource itself, without overgrazing. But in a pasture open to all, each herdsman will try to maximize his profit adding animals to the herd because the loss of the common pasture will not be a direct loss for him in an immediate future, while adding an animal will directly increase his revenues. Only a fraction of the loss will be his own problem:

"Therein is the tragedy. Each man is locked into a system that compels him to increase his herd without limit in a world that is limited. Ruin is the destination toward which all men rush, each pursuing his own best interest in a society that believes in the freedom of the commons." 16

The issues raised by Hardin have been studied and revisited by the Nobel Prize winner Elinor Ostrom ${ }^{17}$ by extending the research, looking for historical background and precedents. She and her colleagues studied in detail some real case studies, and developed a theory for the management of the commons, outlining eight design principles:

"1) clearly definite boundaries

2) congruence between appropriation and provision 
rules and local conditions 3 ) collective-choice arrangements 4) monitoring 5) graduated sanctions 6) conflict-resolution mechanism 7) minimal recognition of rights to organize 8) nested enterprises"18.

The research and its findings were developed over decades with a consistent base of case studies. The design principles are framed in the context of the Common Pool Resources (CPR): "The term "commonpool resource" refers to a natural or man-made resource system that is sufficiently large as to make it costly (but not impossible) to exclude potential beneficiaries from obtaining benefits from its use." ${ }^{19}$

The two inquiries about the commons both by Ostrom and Hardin are focused on the management of natural resources, but considerations surfaced in this field that are fundamental to problematize the urban commons. Another category is essential to understand the topic of the commons; the one of the freeriders, which means all the individuals that participate in the consumption of the benefits of a common without taking part in their reproduction and maintenance. Stavrides points out that the urban dimension, and the possibility of commoning in it, are tautologically different from the question of the commons as natural resources:

«If urban space is considered merely as a quantity, if urban space is reduced to a commodity to be distributed amongst people who inhabit it, than "urban commons" can be reduced to a set of goods or resources, more like water, air, electricity, land, etc. If, however, urban commons are the emergent results of multiple processes of urban commoning, then the urban space is revealed to have a crucially important role that differs from most of the good and services distributed within a city. ${ }^{20}$

Urban commons cannot be thought of as solely physical resources that are exploited in an urban environment. But then, how to define them?

The editors of "The Urban Commons: Moving Beyond State and Market" identify three main features that generally defines the commons: a common resource, the practice of commoning and a group that share those practices, the commoners. The main problems to be faced when talking about the urban commons are, in fact: what are the characteristics that defines an urban common, what are the problematics in their management, and how do they differ from the issues studied by Ostrom in the field of CPR.

It is probably useful to define what is meant by "urban" related to the commons.

"In the book Understanding Knowledge as a Commons (2007b), co-edited with Charlotte Hess, Ostrom thus distinguishes between subtractive and non-subtractive resources. In contrast to subtractive resources, nonsubtractive ones refer to resources where one person's use does not reduce other people's benefits. For example,
Hess and Ostrom suggest that knowledge is a nonsubtractive resource since its use does not affect the pool of knowledge negatively when people share it (Hess and Ostrom, 2007a: 5; see also Gudeman, 2001: 27). Now, what happens if we apply this distinction to the urban domain? Certainly, things start to look a bit messier than Ostrom's own examples suggest. On the one hand, parts of a city - such as roads and traffic systems more generally - might be conceived of as a subtractive resource. Since, for instance, the available space on roads is limited, adding more cars will affect the shared resource in a negative way. On the other hand, however, no city would be a city without the inhabitants actively using its streets. And indeed, both the commercial and subjective value of particular places (such as parks or shopping malls) may increase by being used and shared, meaning that - at least to some extent - they constitute non-subtractive resources.

Put differently: the act of consuming does not detract but rather increases value, a point strongly made in this volume's chapter by Zapata and Campos who demonstrate how waste, one residual of consumption, may constitute a commons for poor people. A related point is, as Bruun argues in her contribution to this volume, that markets and commons may not be as neatly separable as suggested in much Ostromian commons literature: it may indeed be possible to identify commons within market contexts." 21 
The first problem for an analogy between the principles pointed out by Ostrom and the urban commons consists in the impossibility of defining the borders, geographically and metaphorically, of the urban. By urban is meant a process $^{22}$ and not a defined physical space, as it was for the city enclosed by walls. This indeterminacy reflects many of the definitions of the commons, amongst which there is the one enunciated by Harvey:

"The common is not to be construed, therefore, as a particular kind of thing, asset or even social process, but as an unstable and malleable social relation between a particular self-defined social group and those aspects of its actually existing or yet-to-becreated social and/or physical environment deemed crucial to its life and livelihood. There is, in effect, a social practice of commoning." 23

Harvey claims that the urban commons are a process and not a defined object, as was the city. What is persistent in this definition, and in the previously quoted characterizations of the commons, is the necessary identification of the practice of commoning and of the commoners. But how can a group of commoners in an urban environment be identified? And even after the group of commoners is defined, how are the boundaries of an urban common defined? Do the bike lanes constitute an aspect of urban commons? Or do the bike lanes become an urban common when a group of individuals physically express their necessities about the improvements needed for a bike lane?

The question of the urban commons distances itself from the historically conceived commons because of the main feature of the city, or rather of the urban environment, that is to be an exchange and sharing space. Cities, as the urban commons, do not exist without citizen or commoners, but at the same time the groups of citizens and of commoners are not clearly defined. A city lives through all the actors that temporarily or sporadically pass through the city itself. Here the question should be raised of dwelling related to urban commons. Many of the movements relating to the slogan "right to the city" came because of increased tourism in city centers, that pushed out the inhabitants to accommodate more tourists with a higher purchasing power. This is an example of the capital appropriation and of the predominance of free riders, where the commoners that participated in the creation of an atmosphere of a city are excluded from the resource they helped to create.

The study of any single processual aspect of urbanity, although interconnected with other processes, needs to be analyzed by the following variables in order to be classified as an urban common:

The nature of this resource, the urban commons, can be "subtractive", "nonsubtractive" and "miscellaneous". This last category represents the resources that assume a value only when they are used, but at the same time, they can be saturated if overused. The streets of a city belong to this last category, language to the second, and a pasture to the first one.

The nature of the user of an urban common is linked to the nature of the common itself. Every urban common is used and reproduced by active actors (the commoners) and passive actors (free-riders). Every urban common has a specific relation with these two categories. There are urban commons that can be both used and produced by both categories and there are others that are reproduced only through commoners.

With regard to the nature of the practice of communing can range from the predominance of exchange value to the predominance of use value.

The production of specific goods that are distinctive of an urban area implies a sharing between the producers with a predominance of exchange value. A public football field, for example, where the set of rules for the use of the field are established through social interaction and does not imply an economic exchange, is such a predominance of use value. Even if the football field is financed by a public institution and therefore by taxpayers.

These three variables are not categories, but rather they represent the core problematics that appears in every discussion about urban commons.

Albeit at first the topic of urban commons suggests a focus on 


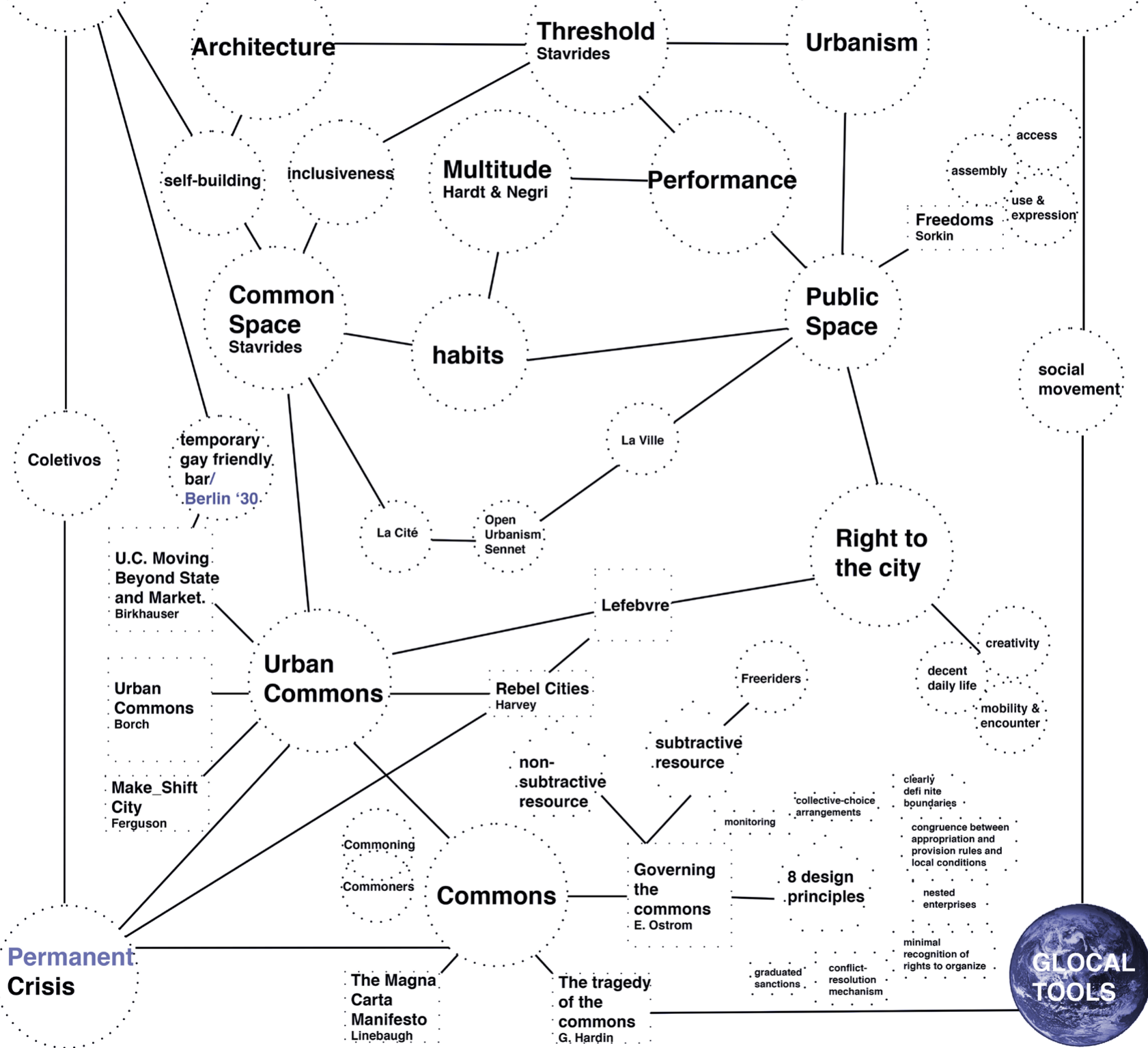

the practices of commoning linked to the predominance of use value, the urban dimension - the city itself - is born as the result of a surplus value. The urban environment is linked to the exchange value, to the market, since its inception.

\section{Urban common is a} conceptual tool, whose theoretical border appears vast. Nonetheless, to be useful, it needs to be used as a precision instrument. The three variables previously proposed need to be clear every time the subject of urban commons is broached. A precise approach and perimeter are necessary when the topic is housing, for example, (Han, Didi K. Imamasa, 2015 in Dellenbaugh 2015), while another is developed if the topic is the urban air quality (Orvar Löfgren (Borch, p. 68).

Susser and Tonnelat propose a subdivision of the urban commons into three broad categories, developing the subdivision of the "rights to the city" proposed by Lefebvre ${ }^{24}$, Purcell ${ }^{25}$ e Stanek ${ }^{26}$ : a right to everyday life, right to assembly, and the right to creative activity.

"The first urban commons revolves around issues of production, consumption, and use of public services and public goods reframed as a common means for a decent everyday life. The second urban commons comprises the public spaces of mobility and encounters collectively used and claimed by citizens, such as streets, subways, cafés, public gardens, and even the World Wide Web. Next, we contend that the city can also offer a third type of urban commons under the form of collective visions within which each individual may find a place. This is illustrated by the work of artists in mobilizing communities, and redefining the conditions of perception of their 
social and spatial environment.

This "redistribution of the sensible" (Rancière 2000) makes up the last ingredient of the right to the city, creativity." 27

This categorization appears to be over-reductive. It seems that the urban commons are something existing independently of the practice of commoning, as something taken for granted. The right to everyday life is not easily translatable in the field of urban commons. In the same article they state indeed that the first category and the second one are, in fact, "potential urban commons". The definition itself - "three urban commons" appears to be limited compared to the question of commoning, because very different tools are needed to analyze the topic of public services or questions about the production of goods.

Sloterdijk proposed a vision that is a better a representation of urban commons, compared to the categorization derived from the right to the city:

"He argues that a city constitutes a kind of condensed 'macro foam' of singular bubbles, i.e., basic forms of sociality (2004: 655). This image, not only entails that relationality and density are crucial features in Sloterdijk's notion of the city, but also suggests that, since each bubble may be seen as a commons; consequently the city is best conceived as a 'meta collector' of numerous differentiated commons that only share with one another their physical being-in-the-city, rather than a macro (or meso) commons (2004: 655)." 28
In this representation arises the possibility to conceptualize separately the urban commons from the physical space of the city, i.e., a difference between public space and common space.

The difference between a public resource managed by the public administration and an urban common consists of the different possibility of modifying the resource/common in question. It is possible to use a public good according to the rules established by the administration. But to alter these rules, I have to go through a series of representative filters (through the political figures that represent me within the state bodies). I alter and modify an urban common through my performance or habits. And, it is worth remembering, always through direct interaction.

The discrepancy between public good, market and commons forms the basis of Ostrom's text. A commoning practice can crystallize over time and become public management, which is an established trend: the state and the market continually extrapolate value from commoning practices.

The relationship between state, market and commoning is of fundamental importance in the field of urban commons. Sorkin proposed another tripartite categorization of the freedoms that are essential for a successful urban environment: freedom of assembly, freedom of access, and freedom of use and expression. ${ }^{29}$
Even without explicitly mentioning the question of urban commons, Sorkin's reflection allows us to understand the question from an intuitive point of view. Let's start by identifying the common ground of his reflection with the theory of urban commons. His text begins by quoting the work of Amartya Sen "Development as Freedom" 30 , in which the object of study is the potential of individuals to become active actors of change, rather than mere receivers of distributed goods. This is the first point in common between the question of freedoms raised by Sorkin and the urban commons, which underlines the fundamental difference between a public space and a common space. The first one is guaranteed by the state entity, and it can be used freely by the citizens, as kind of free riders, even if it is paid with taxes and therefore is actually paid by citizens. The alternative to being passive receivers consists in the ability to be active actors. A free rider becomes an active actor through the practice of sharing, or rather of building together a common practice.

\section{If the urban commons} are a conceptual tool for understanding the building of common practices, the freedoms that Sorkin and Sen have studied, are those freedoms that allow the proliferation of these practices. The urban could be represented by the IT metaphor of hardware and software: the freedoms offered by a city are the hardware ("potential urban commons") and the commoning practices are the software. It's 
important to understand that the freedoms offered by the city are not only concrete morphological elements but also a legal apparatus within which the public life develops.

"The first is freedom of assembly, the main expression of democracy in space, a concept enshrined in the constitution. By definition, physical assembly requires a space that is conducive to it, and the range of such sites streets, plazas, parks, cafés, meeting halls, ballrooms, front stoops - signal, in their variety and fit, how the public gather and mix."31

It's feasible to imagine the following sequence of events: some actors begin to exploit the freedoms available to them. When more individuals share the same freedom, whether it is meeting in the park on Saturday, or meeting on a bicycle on the way to work, the individual experience can become a collective event, a shared experience. The repetition of a shared experience becomes a habit. Hardt and Negri identify habits as the practice of sharing put into practice.

"One resource in modern philosophy for understanding the production and productivity of the common can be found in American pragmatism and the pragmatic notion of habit. Habit allows the pragmatists to displace the traditional philosophical conceptions of subjectivity as located either on the transcendental plane or in some deep inner self. They seek subjectivity rather in daily experience, practices, and conduct. Habit is the common in practice: the common that we continually produce and the common that serves as the basis for our actions. Habit is thus halfway between a fixed law of nature and the freedom of subjective action-or, better, it provides an alternative to that traditional philosophical binary. Habits create a nature that serves as the basis of life." 32

\section{Raising a challenge to} this definition, it is useful to remember that free riders are not always commoners, that is, those who participate in the reproduction of the commons. $A$ person who uses a community garden does not coincide with those who actively participate in its maintenance, for example. In this hypothesis, free riders could very well have the habit of going to the park, but going to the park does not necessarily coincide with the production of commons. The problematic nature of this abstraction arises in relation to the fact that the definition urban commons does not appear in the book Multitude ${ }^{33}$. The approach to the commons, intended for example as CPR, is different and must necessarily be different from the approach to the urban commons.

In the event of a crisis or opportunity, habits can lead to the creation of processes of shared actions, therefore to the practice of the commons, transforming a free-rider into a commoner.

\section{"[...] we can communicate only on the basis of} languages, symbols, ideas, and relationships we share in common, and in turn the results of our communication are new common languages, symbols, ideas, and relationships. Today this dual relationship between production and the commonthe common is produced and it is also productive - is key to understanding all social and economic activity." 34

In Stavrides' book "Common Space", the two words urban commons appear together only in the bibliography, and it presents the same level of abstraction presented in Multitude: "Commoning is not a process of production or appropriation of certain goods meant to be shared. Commoning is about complex and historically specific processes through which representations, practices and values intersect in circumscribing what is to be shared and how in a specific society" 35 .

\section{Whatever the abstraction} may be, it is adequate for the interpretation proposed in this article. A habit in itself is not enough to define a common good, even if the habit is exercised simultaneously by different actors at the same time.In order to speak of "commons" and "commoners" a sharing process is necessary over a period of time, as the words "process" and "historically" suggest. Furthermore, the intersection of "practices and values" suggests a conscious action.

The process of the practices of commoning is reflected not only in the collective nature of the practice and its rituality - its repetition over time - but also in the extent and composition 
of the group of active actors. Stavrides links the question of the reproduction of the commons to the necessity to expand the number of active actors. A commoning practice, to ensure its reproduction, must be an open system. Open to the involvement and integration of new actors in the practice of sharing.

According to Hardt and Negri, the process of integration of new active actors, such as the creation of new practices of commonality, can take place through the concepts of "habits" and "performance". Hardt and Negri propose an agenda for the productivity of the common good:

"The productivity of the common furthermore, must be able to determine not simply the reform of existing social bodies but their radical transformation in the productive flesh of the multitude.

There are indeed numerous theories that accomplish this transformation to the conditions of postmodernity, and we can summarize them well in the conceptual shift from habit to performance as the core notion of the production of the common." 36

Thy continue their exposition by referring to Judith Butler and Paolo Virno:

"Performance, like habit, involves neither a fixed immutable nature nor spontaneous individual freedom, residing instead between the two, a kind of acting in common based on collaboration and communication. Unlike the pragmatists' notion of habit, however, queer performativity is not limited to reproducing or reforming the modern social bodies. The political significance of the recognition that sex along with all other social bodies is produced and continuously reproduced through our everyday performances is that we can perform differently, subvert those social bodies, and invent new social forms. Queer politics is an excellent example of such performative collective project of rebellion and creation." ${ }^{37}$

Habits and Performance, however, do not take on two distinct connotations in the text by Hardt and Negri. They define the latter as an evolution of habits, and then indicating it as an alternative option: «Like the formation of habits, or performativity or development of languages, this production of the common is neither directed by some central point of command and intelligence nor is the result of a spontaneous harmony among individuals, but rather it emerges in the space between, in the social space of communication ${ }^{38}$.

The ambiguity and difficulty of circumscription of the urban commons can perhaps be clarified by Stavrides' metaphor of the thresholds. "Considering common spaces as threshold spaces opens the possibility of studying practices of spacecommoning that transcend enclosure and open towards new commoners. ${ }^{39}$

Common spaces, whose vitality is reproduced by its users, are therefore physical and mental places, which evolve over time. The threshold is a space of uncertainty, in which it is almost never certain who or what one meets. In addition to being an uncertain space, it is also indeterminate.

Indeterminate in the sense that it is not always possible to understand exactly when we are crossing a threshold and indeterminate because we do not always know how long it will take us to cross it. The threshold is a poetic metaphor, well described by R.S. Thomas:

[...]What

to do but, like Michelangelo's

Adam, put my hand

out into unknown space, hoping for the reciprocating touch? ${ }^{40}$

The metaphor of the threshold reflects the versatility of the question of urban commons, which, as Borch writes, are an exquisitely relational phenomenon and therefore uncertain. «The central observation we take from Howard's work is that, contra Ostrom, the notion of a commons as a self-evident and independent object makes little sense when applied to the urban. In the city, the commons is an inherently relational phenomenon. ${ }^{41}$

This dynamism and uncertainty can extend beyond a simplifying spatial circumscription or social grouping, they can also extend to the temporal dimension, a reflection that strengthens the closeness of the concept of urban commons to the concept of process.

A good example presented in Borch's book is that of the Berlin gay bars in the 1930s. Gay culture was a subculture 
that manifested itself secretly, as documented by the guides on the clubs of the city.

"[...] many 'gay spaces' were not 'gay' all the time - they were transitory and fleeting. Club nights would open and close, move venue, or may only take place once or twice, and might take place on different days of the week - the 'friendship balls' at Köhlers on Tiekstraße, for example, were only for 'like-minded men' on Thursdays, Saturdays and Sundays (Moreck, 1931: 139). There was a complex temporal map to overlay the physical one, without which the city would be, for gay men, unusable for the purposes which they intended. Unlike an institutional common, like a pasture, forest or common fishery, the urban common is not always there to be exploited. It must be constantly reproduced." 42

Temporariness must be considered a characteristic of the urban commons. Time must be contemplated and this perspective facilitates the understanding of the relationship between an urban common and the commoners who reproduce it: it is a temporary relationship that happens in the moment of sharing, as an exercise of habit or in the moment of change through performance. It is through our direct action that we can create and recreate the common goods. This perception of the urban commons recalls Wolin's definition of "fugitive democracy":

"Democracy in the late modern world cannot be a complete political system, and given the awesome potentialities of modern forms of power and what they exact of the social and natural world, it ought not to be hoped or striven for. Democracy needs to be reconceived as something other than a form of government: as a mode of being which is conditioned by bitter experience, doomed to succeed only temporarily, but is a recurrent possibility as long as the memory of the political survives. [...] Democracy is a political moment, perhaps the political moment, when the political is remembered and recreated. Democracy is a rebellious moment that may assume revolutionary, destructive proportions, or may not." 43

Therefore, the city, or rather the urban environment, being temporarily appropriated by communal practices, can truly be understood as a potential urban common. It is the space of our freedom that becomes our, and continues to be so, through the exercise of the freedom itself. Here it is interesting to understand how the public administration can decide whether or not to promote the proliferation of urban commons, adding or restricting the freedoms of individuals in an urban space. The city and the resources it has at its disposal are the infrastructure on which sharing practices can arise and grow. The definition of these freedoms can be experimented temporarily, from time to time, to understand if there is a margin of actors willing to appropriate them.
${ }^{1}$ Lefebvre, Henry. Writings on cities, translated and edited by Eleonore Kofman and Elizabeth Lebas.

Blackwell Publisher, Oxford, 1996

${ }^{2}$ https://www.

oxfordlearnersdictionaries.com/ definition/english/right_3 2021/03/29

${ }^{3}$ https://dictionary.cambridge.org/ dictionary/english/common 16/11/2020

${ }^{4}$ ibidem.

${ }^{5}$ https://www.larousse.fr/ dictionnaires/francais/droit/26842 $30 / 03 / 2021$

${ }^{6}$ Marcuse, Peter. From critical urban theory to the right to the city. City 13:2-3,185-197. Routledge, London and New York, 2009

7ibidem.

${ }^{8} \mathrm{https}: / / w w w . c o l l i n s d i c t i o n a r y$. com/dictionary/english/commons $16 / 11 / 2020$

${ }^{9}$ Borch , Christian; Kornberger, Martin (ed.). Urban Commons: Rethinking the City. Rouledge, London and New York, 2015. p. 55

${ }^{10}$ Dellenbaugh, Mary et al.(eds). Urban Commons: Moving Beyond State and Market. Birkhauser, Basel, 2015.

${ }^{11}$ Linebaugh, Peter. The Magna Carta Manifesto: Liberty and Commons for all. University of California Press, Berkley/Los Angeles/ London, 2008.

\footnotetext{
${ }^{12}$ Kratzwald, Brigitte. Urban Commons-Dissident practices in Emancipatory Spaces. In Dellenbaugh, Mary et al.(eds). Urban Commons: Moving Beyond State and Market. Birkhauser, Basel, 2015.

13ibidem.

${ }^{14}$ Hardin, Garrett. The Tragedy of the Commons. 1968. http://www. garretthardinsociety.org/articles_pdf/ tragedy_of_the_commons.pdf consultato il $16 / 11 / 2020$
}

${ }^{15}$ Brand, Stewart(ed.). Whole Earth Catalog. Princeton University Press, Princeton, 1968.

${ }^{16}$ Hardin, Garrett. The Tragedy of the Commons. 1968. http://www. garretthardinsociety.org/articles_pdf/ tragedy_of_the_commons.pdf 
consultato il $16 / 11 / 2020$

${ }^{17}$ Ostrom, Elinor. Governing the Commons The evolution of the institutions for collective actions. Cmbridge University Press, New York, 1990.

18ibidem.

19ibidem.

${ }^{20}$ Stavrides, Stavros. On urban commoning: the city shapes institutions of sharing. in Ferguson, Francesca 8ed.). Make_Shift City renegotiating the urban commons. Jovis Berlag GmbH, Basel, 2014.

${ }^{21}$ Borch, Christian; Kornberger, Martin (ed.). Urban Commons: Rethinking the City. Rouledge, London and New York, 2015.

${ }^{22}$ Brenner, Neil. Theses on Urbanization. Public Culture 25:1 DOI 10.1215/08992363- 1890477. Duke University Press, Durham, 2013.

${ }^{23}$ Harvey, David. Rebel Cities. Verso, London, 2012.

${ }^{24}$ Lefebvre, Henri. 1968. Le droit à la ville. Paris: Anthropos.

${ }^{25}$ Purcell, Mark. 2002. Excavating Lefebvre: The right to the city and its urban politics of the inhabitant. GeoJournal 58(2): 99-108.

${ }^{26}$ Stanek, Lukasz. 2011. Henri Lefebvre on space. Minneapolis: University of Minnesota Press.

${ }^{27}$ Susser, Ida. Tonnelat, Stéphane. Transformative cities: The three urban commons Focaal-Journal of Global and Historical Anthropology 66 (2013): 105-132 @ Stichting Focaal and Berghahn Books doi:10.3167/ fcl.2013.660110

${ }^{28}$ Borch , Christian; Kornberger, Martin (ed.). Urban Commons: Rethinking the City. Rouledge, London and New York, 2015.

${ }^{29}$ Sorkin, Micheal. All over the Map. Verso, London ad New York, 2011.

${ }^{30}$ Sen, Amartya. Development as freedom. Oxford University Press, Oxford \& New York, 1999.

${ }^{31}$ Sorkin, Micheal. All over the Map. Verso, London ad New York, 2011.

${ }^{32}$ Hardt, Michael. Negri, Antonio. Multitude. Penguin Book, London, 2005. 33ibidem.

${ }^{34}$ ibidem.

${ }^{35}$ Stavrides, Stavros. Common-

Space-The-City-as-Commons. Zed

Books, London, 2016.

${ }^{36} \mathrm{Hardt}$, Michael. Negri, Antonio. Multitude. Penguin Book, London, 2005.

${ }^{37}$ ibidem.

38ibidem.

${ }^{39}$ Stavrides,Stavros. CommonSpace-The-City-as-Commons. Zed Books, London, 2016.

${ }^{40}$ R. S. Thomas, "Threshold" from The Poems of R. S. Thomas. Copyright (C 2001 by Kunjana Jaikin. https://www. poetryfoundation. org/poems/52748/threshold56d231793e538 consultato il 2020$11-24$

${ }^{41}$ Borch, Christian; Kornberger, Martin (ed.). Urban Commons: Rethinking the City. Rouledge, London and New York, 2015.

\section{${ }^{42}$ ibidem London and New York,} 2015.

${ }^{43}$ Wolin, Sheldon S. Fugitive Democracy and Other Essays. Princeton University Press, Princeton and Oxford, 2016.

\section{BIBLIOGRAPHY}

Borch, Christian; Kornberger, Martin (ed.). Urban Commons: Rethinking the City. Rouledge, London and New York, 2015. Brand, Stewart(ed.). Whole Earth Catalog. Princeton University Press, Princeton, 1968.

Brenner, Neil. Theses on Urbanization. Public Culture 25:1 DOI 10.1215/08992363- 1890477. Duke University Press, Durham, 2013.

Dellenbaugh, Mary et al.(eds). Urban Commons: Moving Beyond State and Market. Birkhauser, Basel, 2015.

Hardin, Garrett. The Tragedy of the Commons. 1968. http://www. garretthardinsociety.org/articles_pdf/ tragedy_of_the_commons.pdf consultato il 16/11/2020

Hardt, Michael. Negri, Antonio. Multitude. Penguin Book, London, 2005. Harvey, David. Rebel Cities. Verso, London,2012.
Lefebvre, Henry. Writings on cities, translated and edited by Eleonore Kofman and Elizabeth Lebas. Blackwell Publisher, Oxford, 1996

Linebaugh, Peter. The MAgna Carta Manifesto: Liberty and Commons for all. University of California Press, Berkley/Los Angeles/London, 2008.

Marcuse, Peter. From critical urban theory to the right to the city. City 13:2-3,185-197. Routledge, London and New York, 2009.

Ostrom, Elinor. Governing the Commons The evolution of the institutions for collective actions. Cmbridge University Press, New York, 1990.

Purcell, Mark. 2002. Excavating Lefebvre: The right to the city and its urban politics of the inhabitant. GeoJournal 58(2): 99-108.

Sen, Amartya. Development as freedom. Oxford University Press, Oxford \& New York, 1999. Sorkin, Micheal. All over the Map. Verso, London ad New York, 2011.

Stavrides, Stavros. On urban commoning: the city shapes institutions of sharing. in Ferguson, Francesca 8ed.). Make_Shift City renegotiating the urban commons. Jovis Berlag GmbH, Basel, 2014.

Stavrides,Stavros. Common-SpaceThe-City-as-Commons. Zed Books, London, 2016. Stanek, Lukasz. 2011. Henri Lefebvre on space. Minneapolis: University of Minnesota Press.

Susser, Ida. Tonnelat, Stéphane. Transformative cities: The three urban commons Focaal-Journal of Global and Historical

Anthropology 66 (2013): 105-132 @ Stichting Focaal and Berghahn Books doi:10.3167/fcl.2013.660110

Thomas, R. S. . "Threshold" from The Poems of R. S. Thomas. Copyright (C) 2001 by Kunjana Jaikin. https://www. poetryfoundation. org/poems/52748/threshold56 d231793e538 consultato il 202011-24

Wolin, Sheldon S. Fugitive Democracy And Other Essays. Princeton University Press, Princeton And Oxford, 2016. 



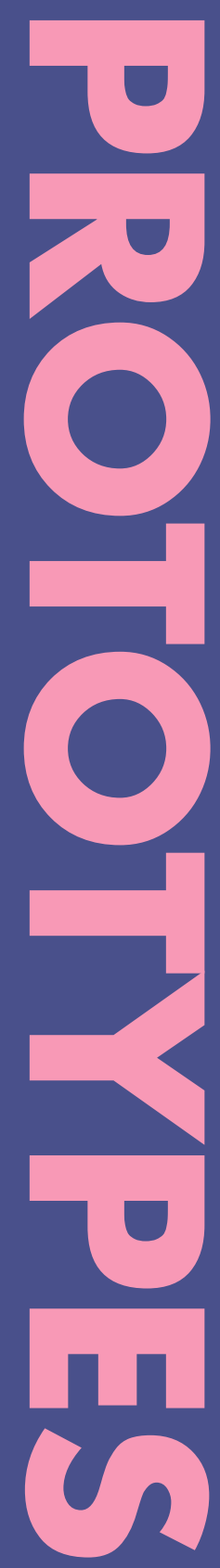




\section{Rhodo Workhome: Rethinking the post-pandemic residence}

\section{A symbiosis of living and creating organic materials}

gemeenschap bio-based producten architectuur milieubescherming

community bio-based materials residential architecture ecological recovery

\section{Roels, Marie ${ }^{1}$}

1'Department of Architecture / KU Leuven, Campus Sint-Lucas, Ghent, Belgium marie.roels97@gmail.com 


\section{Rhodo Werkhuis: Het heruitvinden van de post-pandemische residentie}

\author{
Samenwonen met het maken \\ van organische materialen
}

\footnotetext{
Tijdens de wereldwijde pandemie hebben we onze waarden heroverwogen. Door van thuis uit te leven, hebben we geleerd zowel de nabijheid van mensen als die van een natuurlijke omgeving te waarderen. Daarnaast hebben we gemerkt hoe benauwd een gezinswoning kan aanvoelen en hebben we ons gerealiseerd dat we architectuur nodig hebben die aanpasbaar is aan verschillende situaties om comfortabel samen te kunnen leven. Als reactie hierop bestudeert dit onderzoek een nieuwe manier van wonen, die een sterke gemeenschap, een pro-milieu houding en een innovatieve gediversifieerde manier van leven omarmt. Deze drie aspecten komen samen in het maken van biobased materialen 1 binnen een co-housing project: 'The Rhodo Workhome'. Deze materialen worden gemaakt van de Rhododendron ponticum, een exotische en invasieve soort die, als onderdeel van dit onderzoek, uit bossen in België wordt verwijderd en in dit huis wordt verwerkt tot mycelium, papier, bio plastiek en kleurstoffen. De productieprocessen en de daaruit voortvloeiende materialen hebben niet alleen een invloed op de dagelijkse gewoonten van de bewoners, maar ook op de materialiteit en het ontwerp van het huis.
}

During the global pandemic, we have reassessed our values. Through living from home, we have learned to appreciate both the proximity of people and a natural environment. In addition, we noticed how cramped a family home can feel and realised that we need architecture that is adaptable to varying situations to live comfortably together. In response, this research investigates a postpandemic way of living, one that brings together a strong community of people, a pro-environmental attitude and an innovative diversified way of living. These three aspects collide through the process of making bio-based materials ${ }^{1}$ inside a co-housing project: 'The Rhodo Workhome'. These materials are created from the Rhododendron ponticum, an exotic and invasive species that, as part of this research, is being removed from forests in Belgium and processed into mycelium, paper, bioplastic and natural dyes inside this home. The production processes and their resulting materials not only impact the habits of the residents, but also the materiality and design of the house. Firstly, the Rhododendron is integrated in the home through drying, storing and processing the plant material in preparation of the various products. Secondly, the community within the housing project comes together to process these materials. Finally, the bio-based materials themselves are used to reorganise the house from time to time. Because of their short lifespan and compostable properties, this can happen more frequently compared to traditional durable building materials. The architectural findings within this research expand from a new materiality in architecture to a post-pandemic way of living in symbiosis with growing and making bio-based materials. 


\section{INTRODUCTION}

This research started from two fundamental principles. On the one hand, rethinking the traditional house in response to how we experience the global pandemic from home. And on the other hand, from an environmentally conscious position: keeping in mind that the making of architecture should be accompanied by a contribution to the environment. These two aspects are brought together in 'The Rhodo Workhome', a cluster of traditional houses in the city centre of Ghent, which is renovated into a co-housing project.

\section{Rethinking the traditional house}

During this global pandemic we are obliged to stay inside. Activities which we often execute away from home, such as working and exercising, are brought inside the house. Because of this intensive use, several architectural and social loopholes in traditional housing are being uncovered. The consequences of the lockdown were studied on 1,006 Italians and showed that "the longer the isolation and the less adequate the physical space where people were isolated, the worse the mental health (e.g., depression)."2 Through experiencing this challenging way of living in lockdown, we learn to value specific architectural, social and environmental aspects of living. This research focusses on the following. Firstly, we think more about caring for the common wealth of nature. Secondly, while living- and working from home we feel how important it is to have a strong community of people, around us. Thirdly, we realised that a more intensive and varied use of indoor spaces demands a new type of architecture and lifestyle. This research will address these three specific aspects of the global pandemic and, as a reaction, aim to create a home that can adapt itself to these environmental, spatial and social conditions.

\section{Environmentally conscious position}

These three conditions collide through the process of making bio-based materials inside a co-housing project: 'The Rhodo Workhome'. The materials are created from the Rhododendron ponticum, an exotic invasive species that, as part of this research, is being removed from forests in Belgium.

The plants are collected at 'The Rhodo Workhome' and processed by the residents into different bio-based materials such as mycelium, paper, bioplastic and natural dyes. The residents live together with the grow- and make-processes of these materials. This symbiosis of living and making results in an environmentally conscious attitude, on the one hand, and a new type of organic materiality in residential architecture, on the other hand.

\section{Design methodology}

The design methodology of this home is carried out in such a way, that it implements the various processes of making from the start of the design exercise. As a result, a flexible architectural program is designed, which is based on, not only the needs of the residents and their community, but also the requirements of the Rhododendron-based products. In this way, the project is built up by incorporating both human- and nature-based design. As a consequence, this multi-disciplinary research focusses both on architectural design as well as nurturing a community and supporting biodiversity.

\section{RETHINKING THE TRADITIONAL HOUSE}

Reassessing our values during the gllobal pandemic

Architectural practice

is highly complex and an entanglement of many different processes and concerns, involving complex relationships between community, ecology and society. Residential architecture raises fundamental questions about living together. This research focusses on dimensions that are specifically uncovered by the global pandemic, which are the following: malfunctioning of spaces in traditional housing, social isolation of both individuals and people working from home and living in a densely built city without nature nearby.

Malfunctioning of spaces in traditional housing

During the global pandemic many households are being challenged by the limitations of their living spaces, which no longer function as they did before. From one day to the next, we are obliged to work, exercise, learn and relax from home. In her social anthropologic article, 
Constance Smith describes how "Experiences of lockdown are drastically altered by housing and space." ${ }^{3}$ One of the most substantial adaptations we had to make as a consequence of covid-19 is working from home. During the global pandemic it is happening to all of us. Working from home in a house that is not designed for this function can be challenging. Today, in a post-pandemic society where home-based work continues to grow, there is a demand in merging the two functions: working and living. On top of that, there is a rise in nontraditional households such as young workers living together, grandparents who stay with their children, couples who co-house in order to share the costs. These new living and working combinations require a new way of building and renovating our houses. 'The Rhodo Workhome' researches how to design spatial configurations according to this post-pandemic way of living.

Social isolation of both singles and people working from home

In its essence, 'The Rhodo Workhome' is about creating a community on different scales. First and foremost, 'The Rhodo Workhome' is designed in response to social isolation amongst home-based workers and loneliness amongst singles in lockdown. This social isolation which is occurring in lockdown, is argued in 'A Study on 1,006 Italians Under COVID19 Lockdown'4 and goes hand in hand with working from home. Frances Holliss, architect and Doctor of philosophy in the field of 'The architecture of home-based work', states in her doctoral research that there is a "blindness to homebased work and its social and spatial consequences ${ }^{5}$ ". In reaction, this project aims to create an open co-housing and co-working environment which includes a strong community, to fight social isolation. This community is called 'The Rhodo Community' and invites people outside of 'The Rhodo Workhome' to participate in the processes of making Rhododendron-based materials. Amongst other perks, 'The Rhodo Community' will be able to use the co-working spaces and join workshops organised by 'The Rhodo Workhome'. In return, an open-minded, responsible and trustworthy attitude is required from the people that are part of 'The Rhodo Community'. In addition, this co-housing project creates a platform of opportunities and collaborations with organisations, artists and universities. These will be discussed later in this article in the section: 'Social and environmental impact through collaborations'. 'The Rhodo Workhome' provides an open workspace in the city centre of Ghent and above all, represents a shared, transparent, fair and comfortable environment, through its co-housing structure and its participative processes.

\section{ENVIRONMENTALLY CONSCIOUS POSITION}

Living in a densely built city without nature nearby Constance Smith states that "While the rich can escape to second homes, cramped housing and lack of outdoor space make extended time at home much harder to endure." In response, 'The Rhodo Workhome' which includes five small traditional houses and is situated in the city centre of Ghent, aims to expose its residents to nature

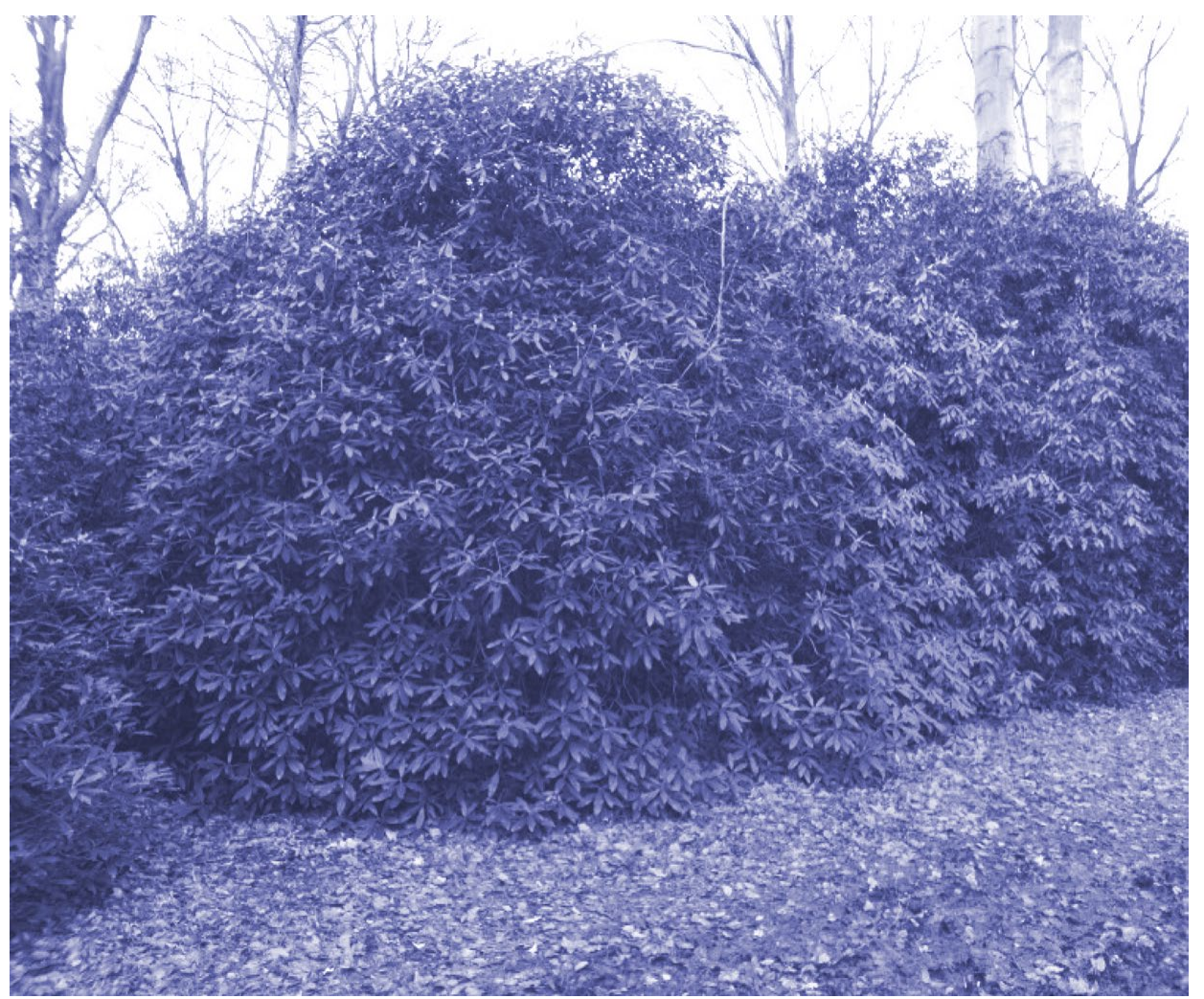

Fig. 1 - Rhododendron ponticum bushes in Wetteren - Den Blakken. 

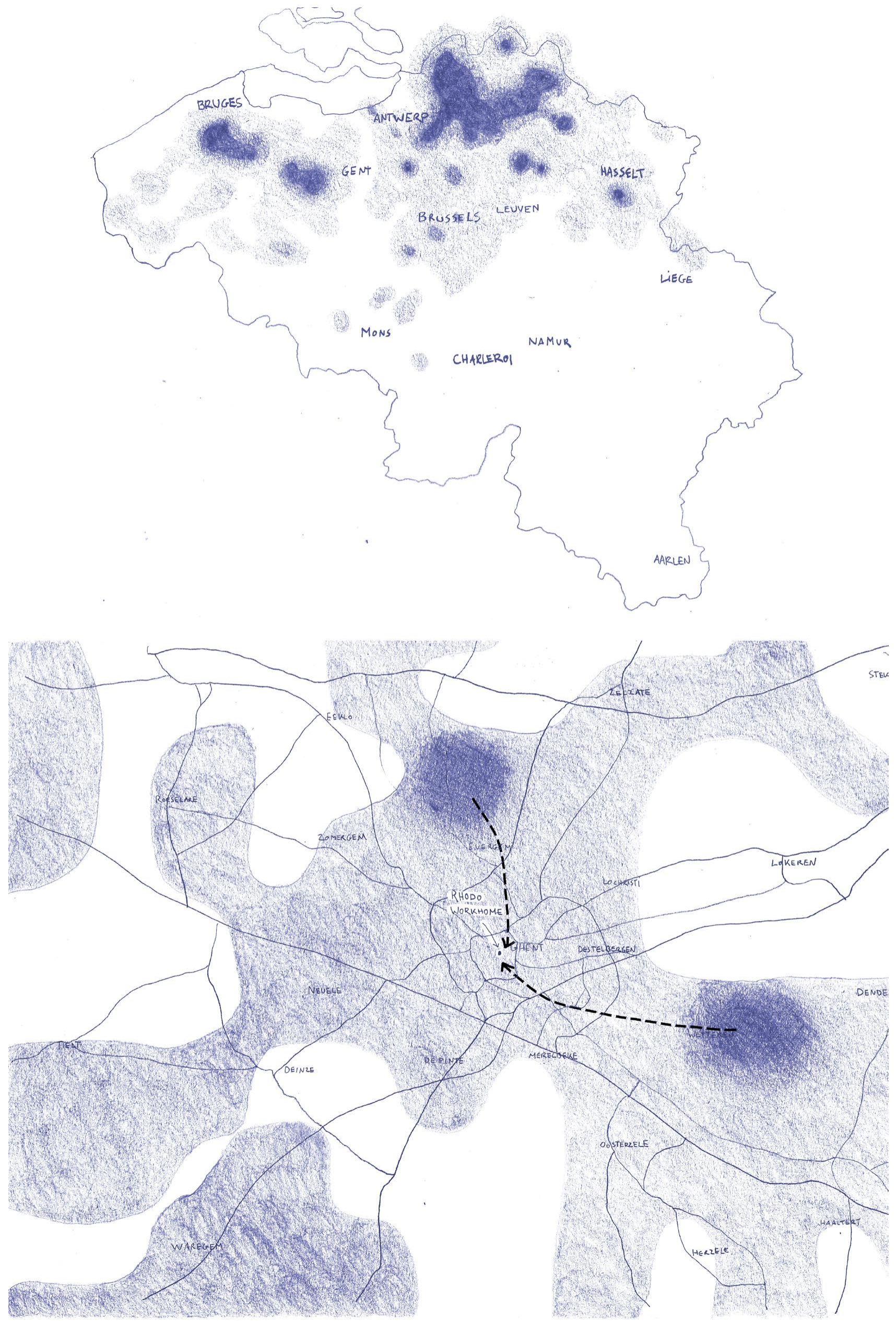
on three different levels. Firstly, by creating a cohousing project that includes a common garden. Secondly, by introducing the Rhododendronbased production processes inside the house. And thirdly, by representing a community that raises awareness on a scale that generates impact in restoring biodiversity. More specifically, 'The Rhodo Workhome' is a circular-minded project that partners up with 'Natuurpunt'. This is a Belgian organisation which, among other tasks, removes the Rhododendron ponticum from Flemish forests. ${ }^{6}$ This is an exotic invasive species in west Europe and is native in south Europe, mainly in Turkey. (fig.

1) The species thrive in our climate, growing and spreading very fast while preventing native species from growing. As a consequence, they are taking over the shrub layer in our forests which has resulted in a critical reduction of biodiversity in Belgium. In reaction to this increasing problem, Natuurpunt is removing Rhododendron ponticum plants to restore our ecosystems. Nevertheless, after the removal, the plant material is treated like waste and brought to container parks. This is where this research steps in to recover the wasted plant into bio-based materials. After the removal, the plant material is collected at 'The Rhodo Workhome' and recovered into Rhododendron-based materials. The Rhododendron plants that are being processed inside contribute to the ideology that lies at the heart of 'The Rhodo Workhome'. Namely, contributing to the recovery of biodiversity by processing a plant, that would otherwise be thrown away, and living inside a house which is enriched by these natural elements. The study by Rita Berto and Giuseppe Barbiero, on 'How the Psychological Benefits Associated with Exposure to Nature Can Affect Pro-Environmental Behavior' discusses how, "it is fundamental to foster a connection to Nature not only to enhance perceived restorativeness (a useful way to cope with daily hassles), but also to have people keener to behave pro-environmentally"7. In this way, by being in close connection to these natural material processes, 'The Rhodo Workhome' aims to increase the pro-environmental attitude of its residents.

\section{Rhododendron ponticum}

\section{Since there are several} exotic invasive species in Belgium, this section will clarify the reason of choosing the Rhododendron ponticum as the processed plant species. The first reason is its area of expansion. In Belgium, this species is invading mainly the northern part and more specifically the areas around Bruges, Ghent, Brussels, Hasselt and Antwerp. The dark zones on the map in indicate where high concentrations of Rhododendron shrubs are present. (fig. 2) In Ghent and its surrounding sub-urban areas specifically, more than 2000 plants have been observed, which is one-fifth of the total amount of 10000 individual plants observed up until today. (fig. 2) 'The Rhodo Workhome' will collect the Rhododendron bushes from both, two highly densified areas near Evergem and Wetteren as well as densified areas within the city centre of Ghent, in which it is situated.

\section{Secondly, this species} was chosen because of its physical properties, which have as a consequence that there are no traditional timber applications possible. To be more specific, this plant is a shrubbery with thin irregular, tortuous branches. Therefore, commonly used applications like timber beams for construction or furniture are out of the question. Alternative wood-based materials like MDF or OSB are optional, but were rejected for the following reasons. Firstly, creating MDF from Rhododendron has already been investigated in the study 'Manufacture of medium density fibreboard (mdf) panels From Rhododendron'8 which proved that MDF made from Rhododendron should be mixed with other hardwoods, to create a qualitative and competitive product. Secondly, it was an important requirement form the start of this project that the residents of 'The Rhodo Workhome' could preserve their current occupations and freedom, while processing the materials from home. For this reason, the material should be created within a low-maintenance production process. MDF and OSB require a more industrialised manufacturing process, which is not applicable to this design-exercise in which the residents are living together with 'the process of making'. Thus, the challenge in this research was to find alternative 
applications for the species which can be created in a non-industrialised and lowmaintenance manufacturing process. In addition, the wasted plant should be recovered into bio-based materials within a sustainable and circular approach.

Considering the requirements mentioned above, several organic and compostable materials were tested. (fig. 3) After testing, it was decided that the program of this co-housing project would include a yearly sequence in the production of mycelium, bioplastic, natural dyes and paper. The choice to make different materials was made in order to design the most diverse annual programme possible. The different products are each accompanied by their own type of process that varies in length, intensity, materiality, actions and architectural applications in the house itself.

\section{DESIGN}

\section{METHODOLOGY}

\section{Methodology}

The timing of the production processes has had a substantial agency in the design choices of this architectural project. Therefore, a calendar was created which outlines when a certain product is made and how long the process takes. (fig. 4) In addition, five product-specific graphs were designed, which indicate the workload within each production process.

These graphs integrate both the preliminary steps, which include collecting, drying and storing of the Rhododendron plant material, as well as the more detailed steps within the process. (fig. 4) These graphs are created to ensure that the personal schedule of the residents would not be disrupted too much, in order for them to keep pursuing their jobs and interests.

Site

The site includes five traditional homes in the city centre of Ghent. (fig. 5) The existing houses are being connected by one shared

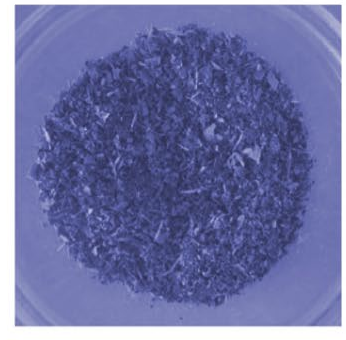

Overnight soaked mixed fresh leaves.
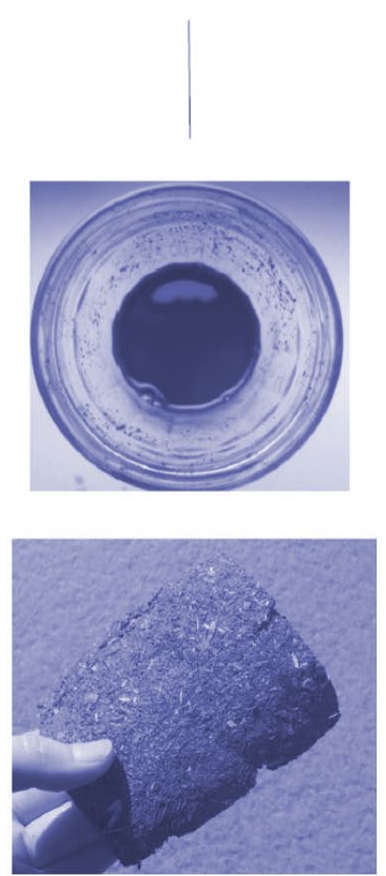

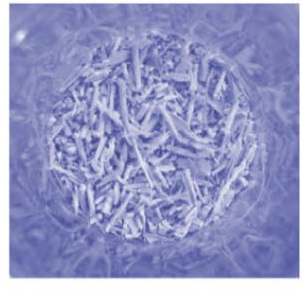

Hard parts of dried leaves that where left unused for bio plastics.
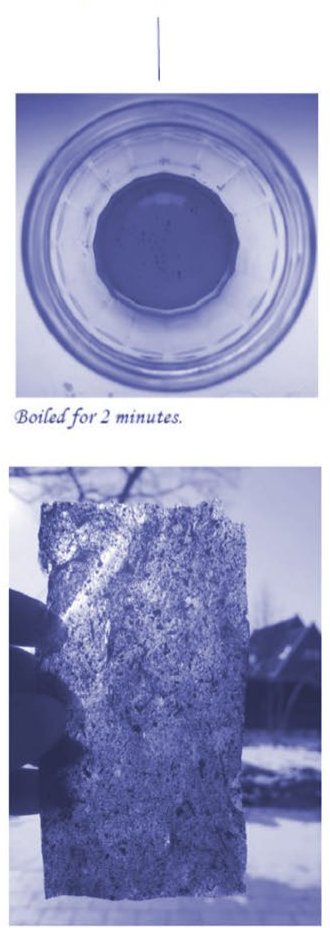
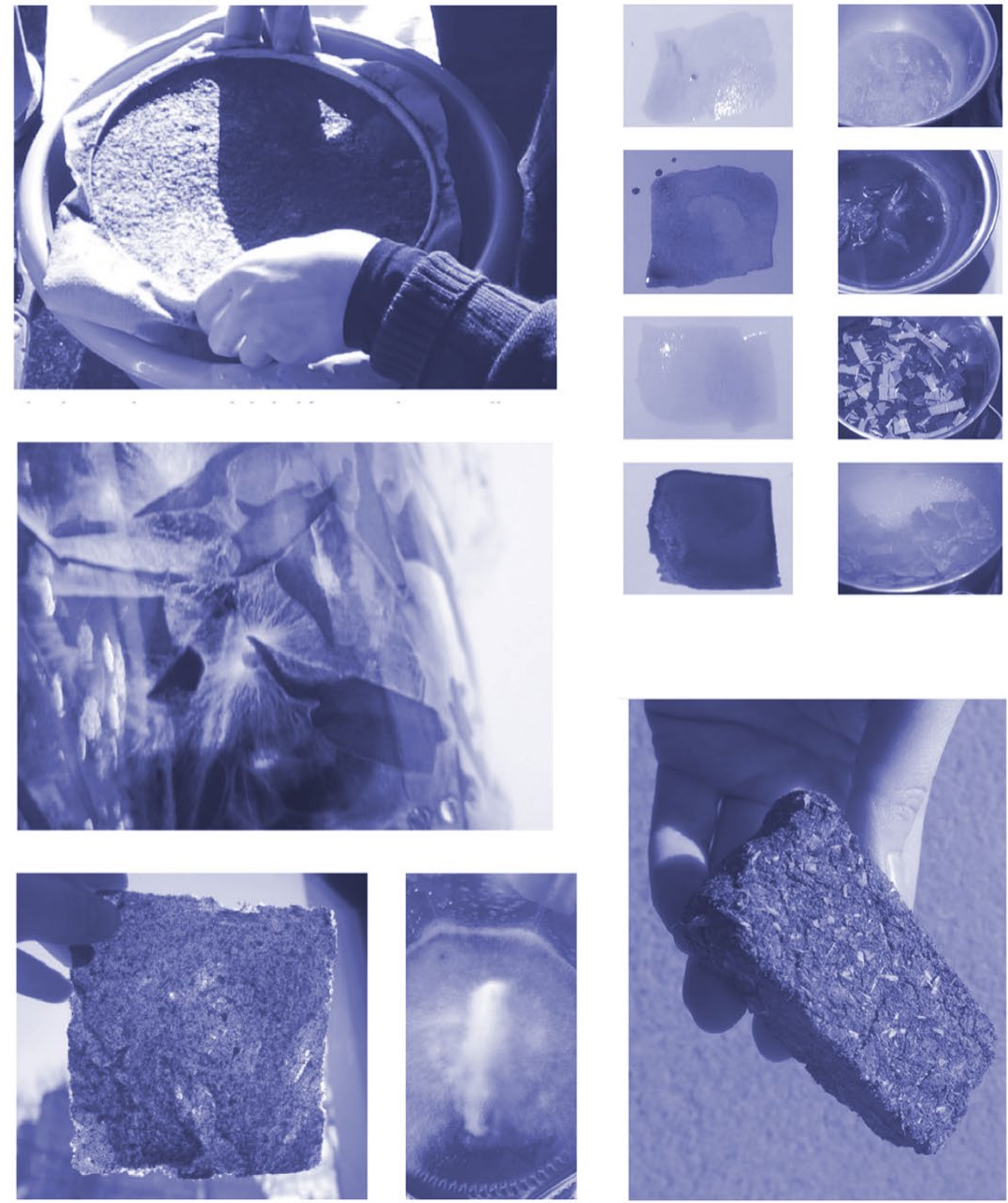

Fig. 3 - Empirical study of organic materials such as, watercolour, paper, bio-plastic and mycelium 
SHIITAKE MYCELIUM

PROCESS OF MAKING - WORKLOAD DIAGRAM

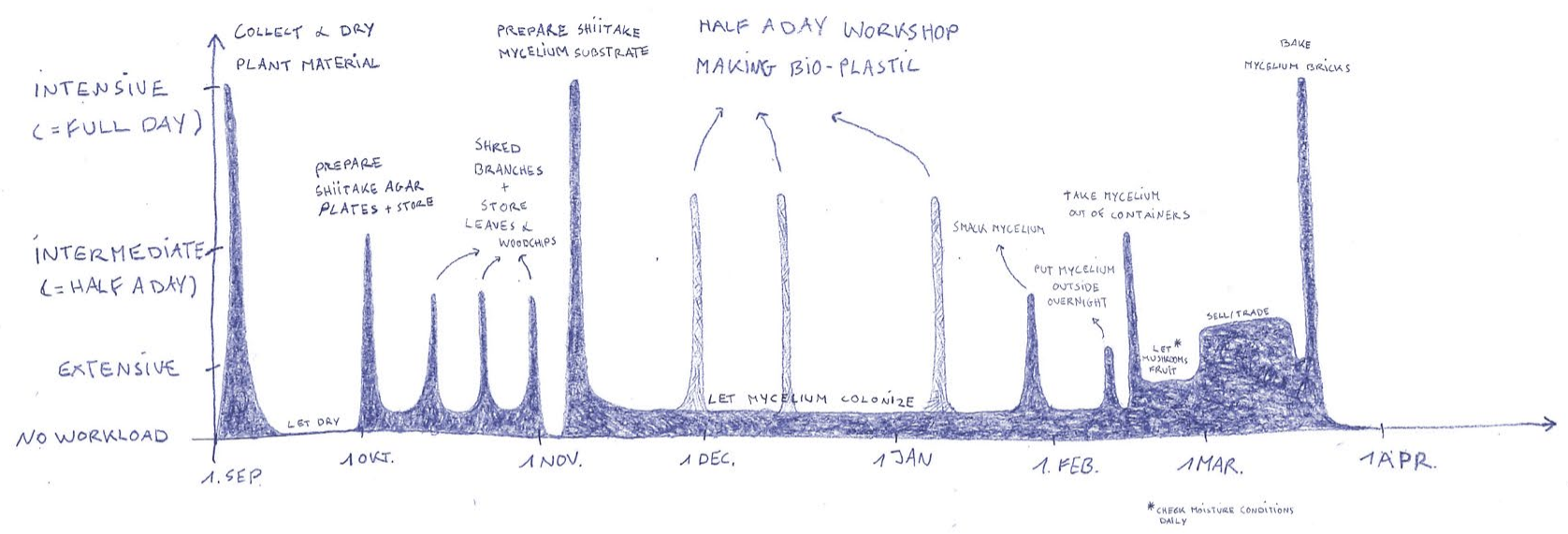

WATER COLOUR
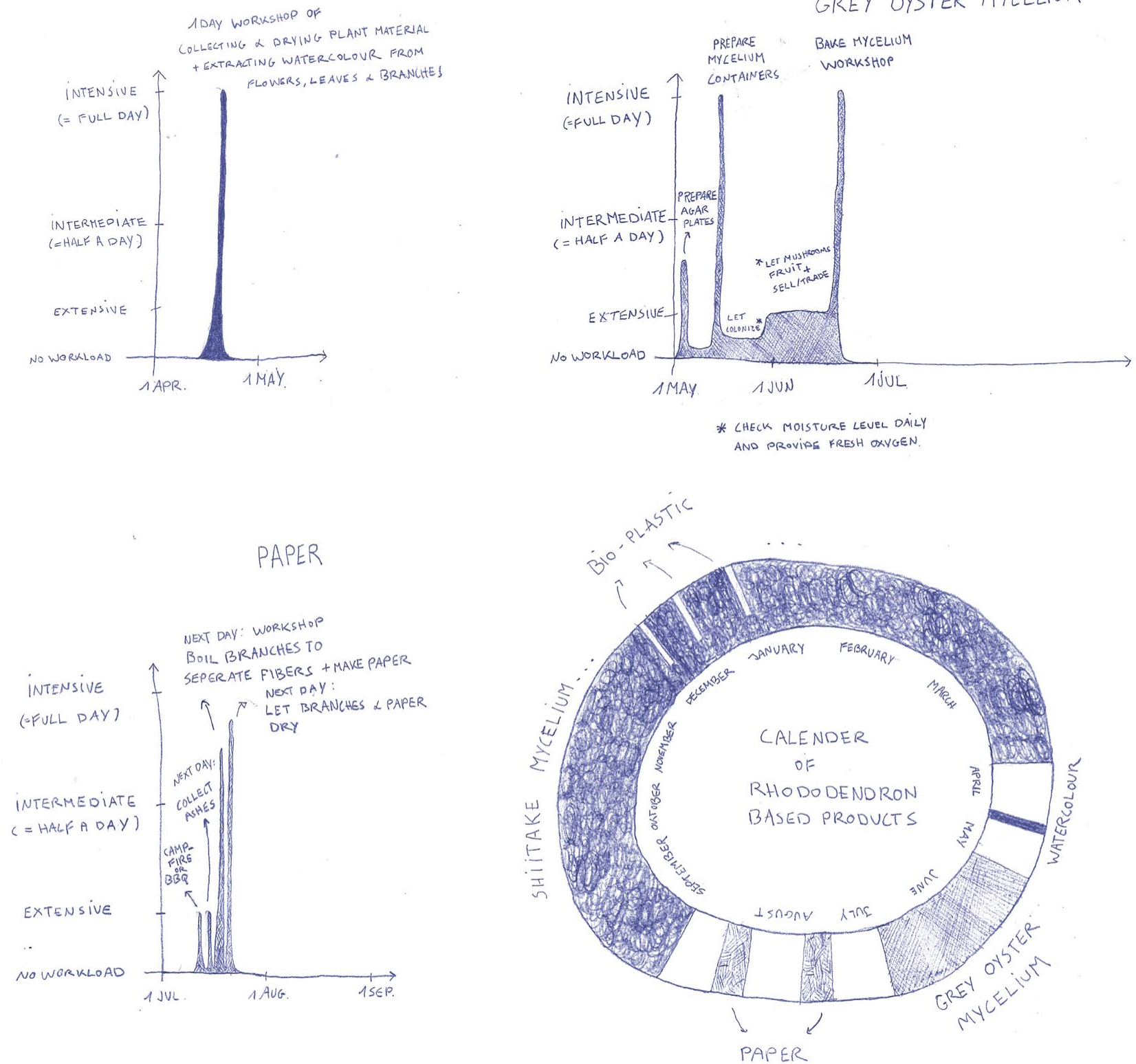

Fig. 4 - Calendar and graphs visualising the different production processes that are carried out in one year. 
courtyard and renovated into an open co-housing project that houses nine people on the north side of the courtyard and eight on the south side. (fig. 5)

The design of the south side will be elaborated upon in this research. The radically open renovation of this co-housing project provides space for on the one hand, the residents to live and work from home, and on the other hand, for the production processes and the Rhododendron-based materials to make architectural interventions.

\section{Design}

The open design of the house creates space for, on the one hand, the residents to change the function and size of the rooms according to their needs. On the other hand, the spacious architecture changes throughout the days, months and seasons according to the different processes of making. How these processes have agency in changing the way the residents live and move inside the house, will be discussed chronologically moving from one production process to
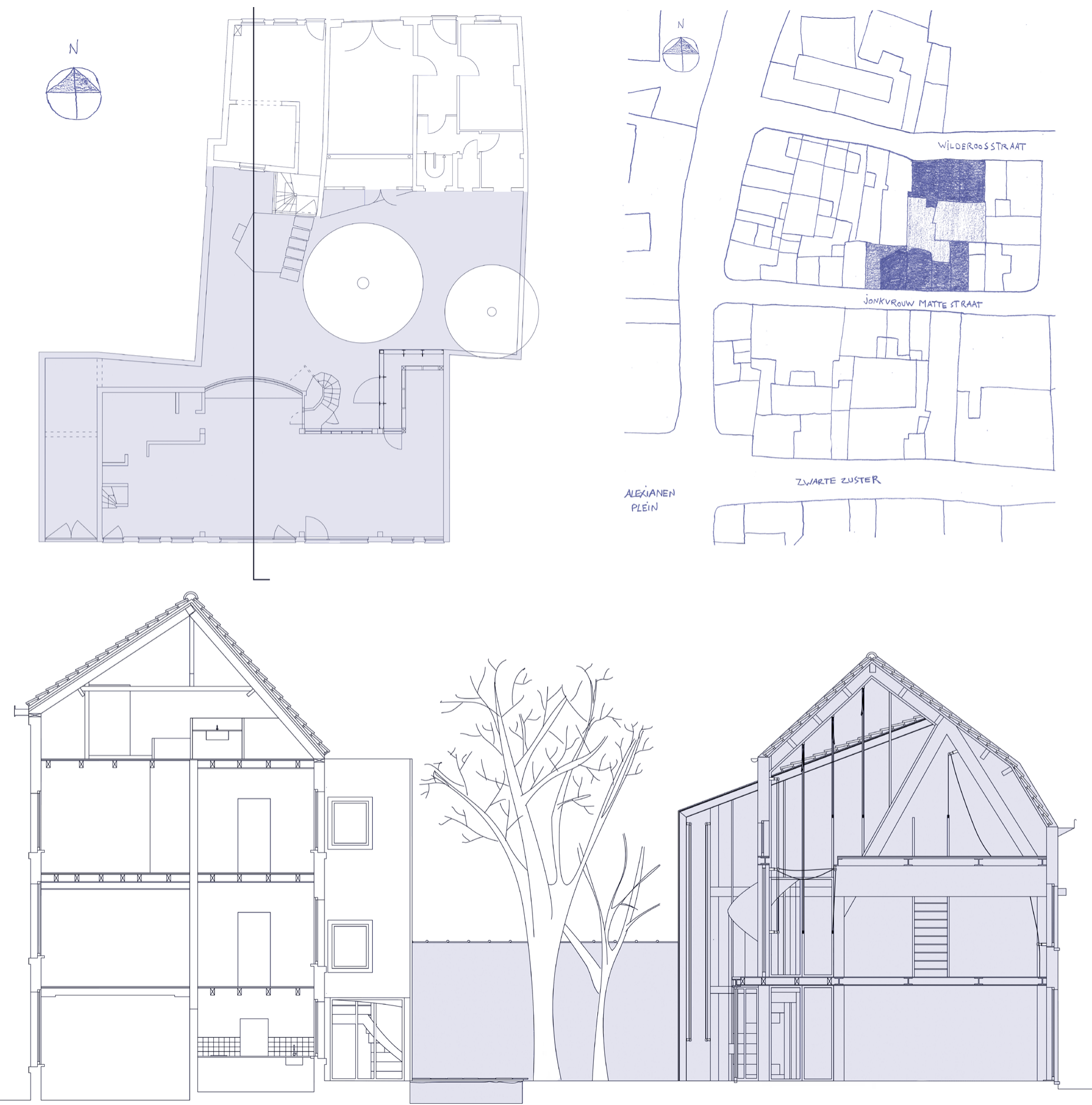

Fig. 5 - Site of 'The Rhodo Workhome' based in the city centre of Ghent 
another.

This is because the different Rhododendron-based products are logically scheduled according to: the temperatures in which they should grow, the seasons in which they should be processed, and the occasions in which they make an intervention inside the house.
This time-line discusses only a limited number of applications possible for the Rhododendron-based products. The design-program invites the residents to, while living at 'The Rhodo Workhome', improve the production processes to their own preference and experiment with the materials to discover new applications and architectural solutions.

\section{One year at 'The Rhodo} Workhome'

September - drying Rhododendron plant material (fig. 6)

The calendar-year at 'The Rhodo workhome' starts in September, when the first batch of Rhododendron ponticum has been removed from the forests in and around Ghent. First, it
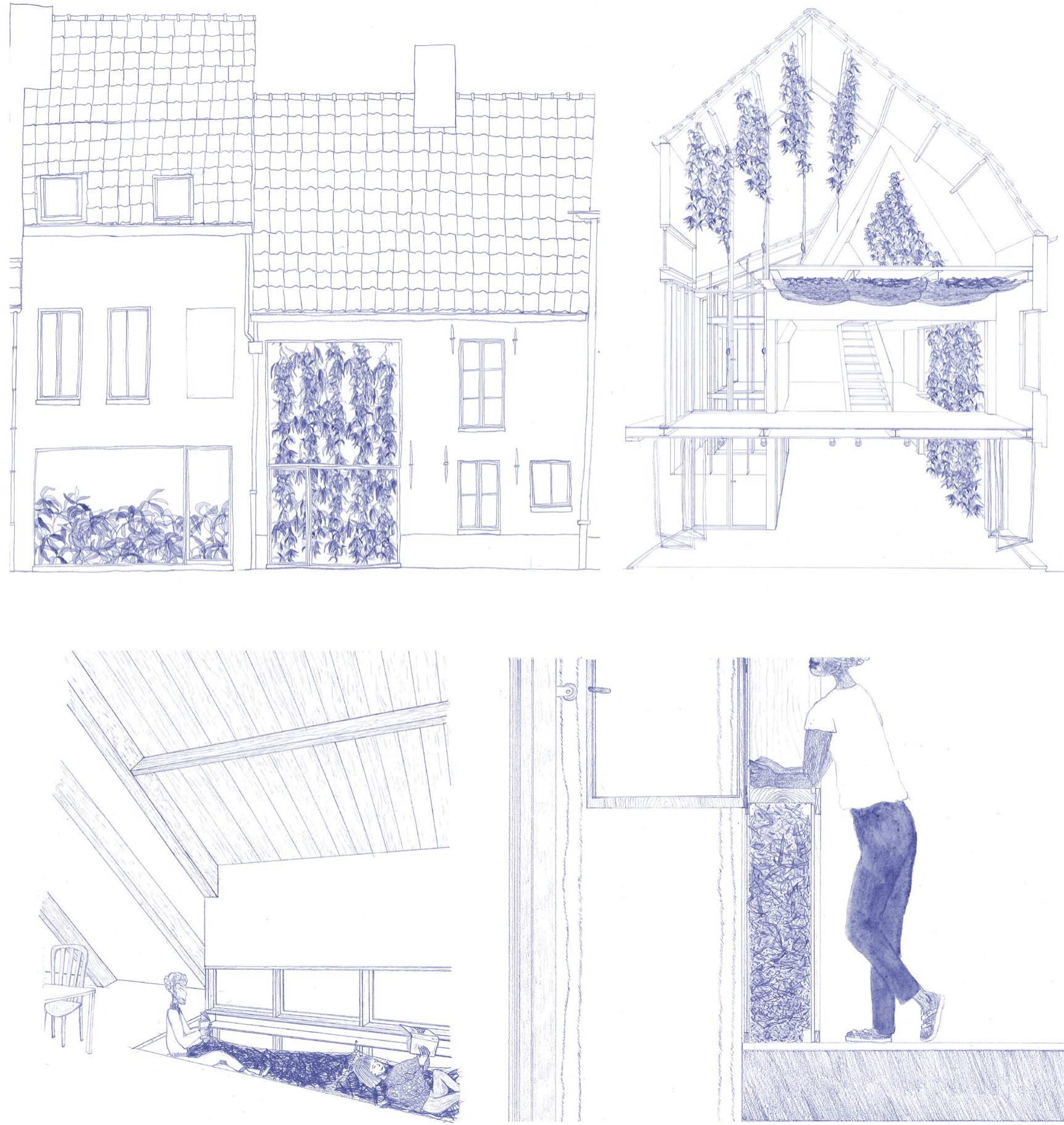

Fig. 6 - Drying and storing Rhododendron plant material 

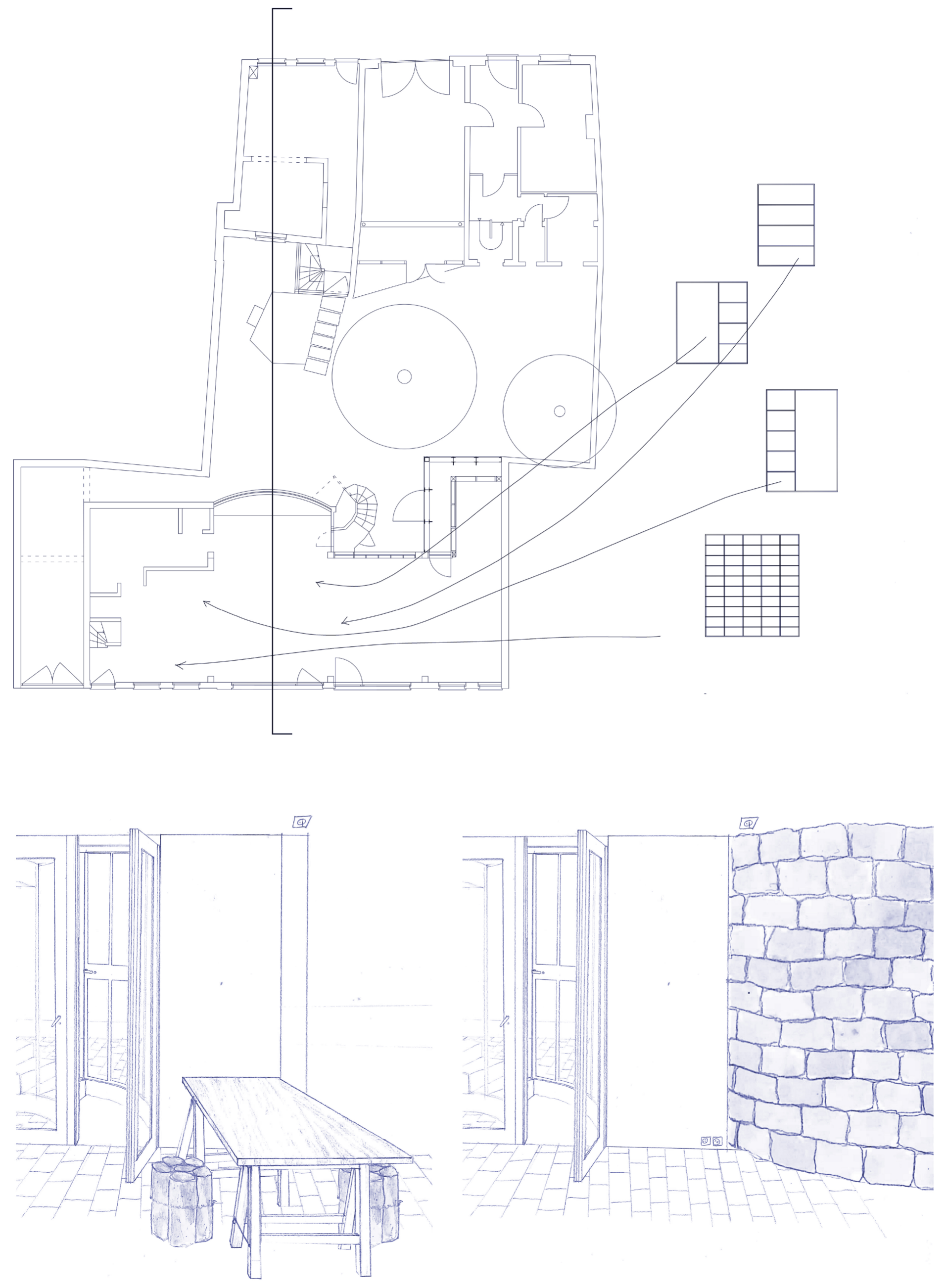


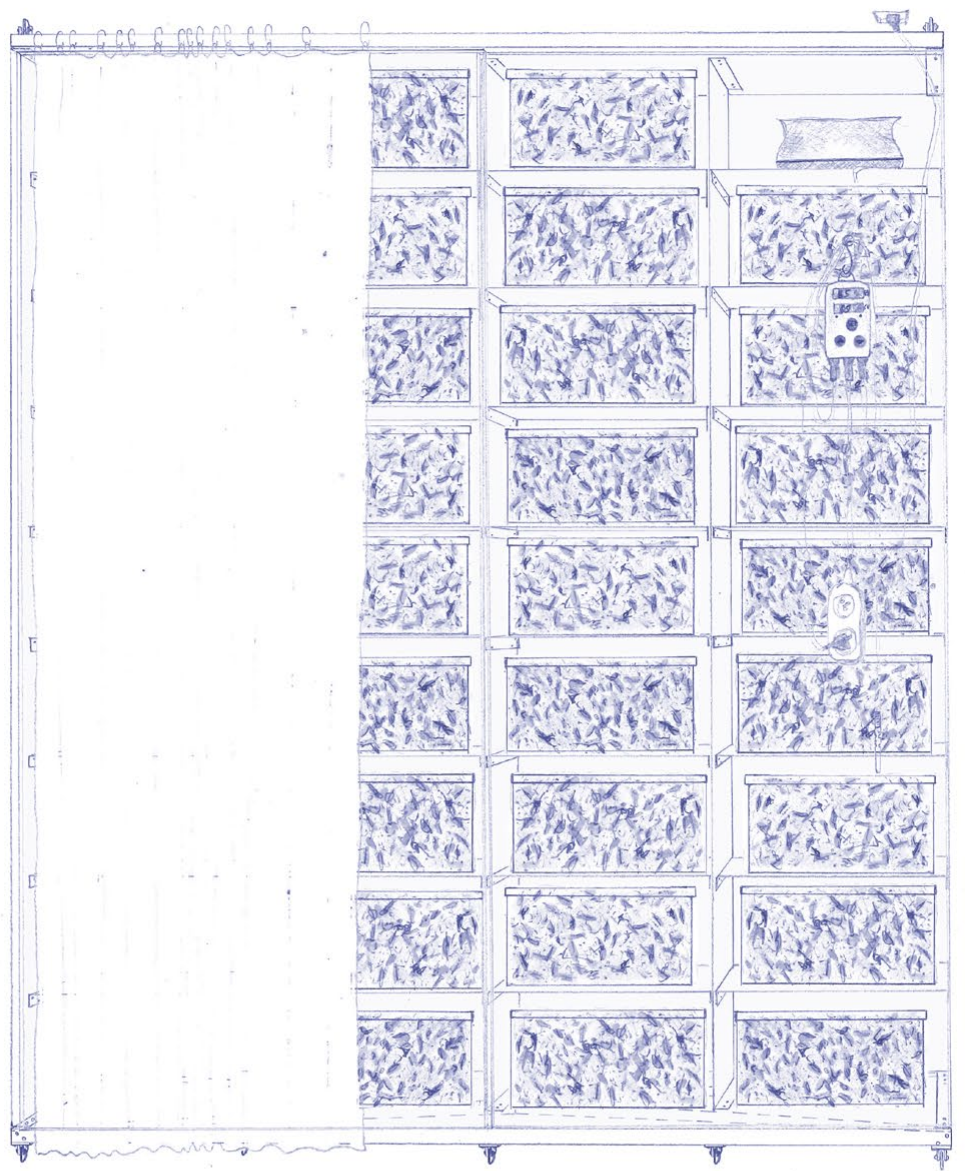

is taken into account how and where the Rhododendron plants are being dried and stored.

The leaves dry on ropes which are raised to the high ceilings, created during the renovation, while the branches are being cut in shorter pieces and dried in nets. The branches that are hung up in the ceiling create a playful mood and improve the acoustic performance of the room. A dense curtain of leaves brings a characteristic musk scent of the forest inside, while creating privacy and sunshade in a natural environment. After approximately four weeks the plant material has dried out. The leaves have been drying in different places with different exposures to sunlight. As a consequence, the leaves changed into different shades of colour. They also shrunk a little, letting in a dappled sunlight.

\section{October - Storing Rhododendron plant material} (fig.6)

At the beginning of November,

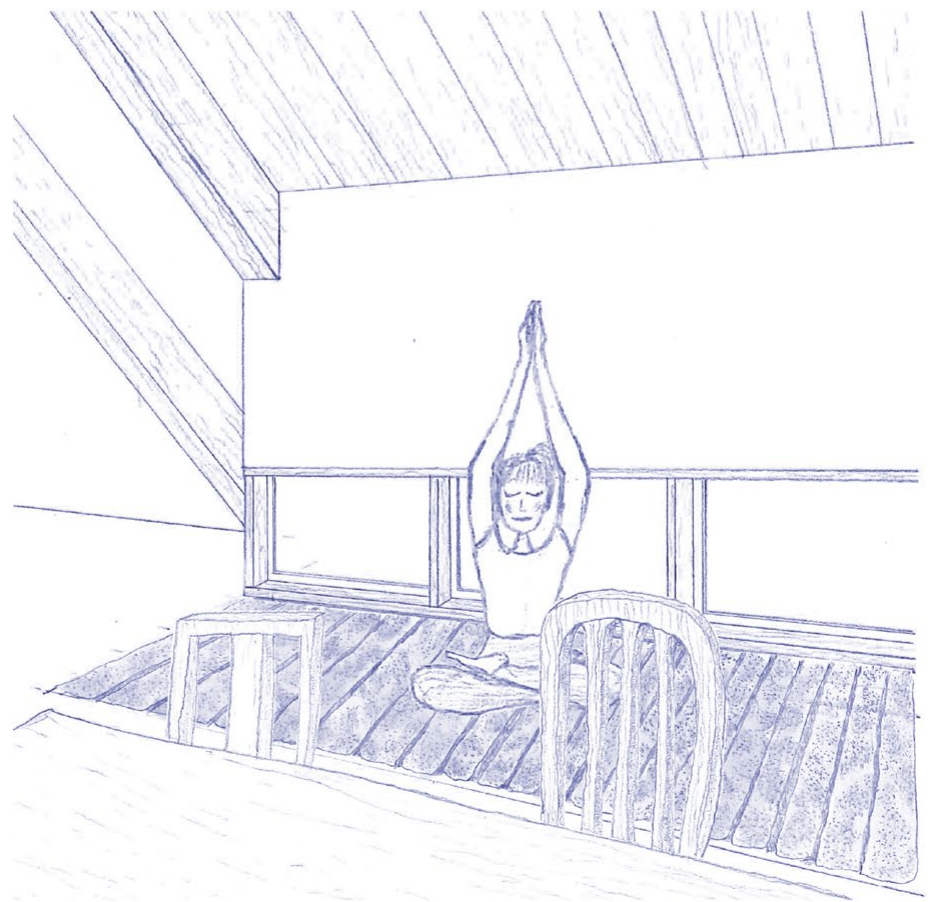
the drying process is finished and 'The Rhodo Community' comes together to shred the branches into woodchips. The dried leaves will be stored in semi-translucent fabric bags, which let through a glimpse of the colours of the leaves inside. These are hung up inbetween two floors and function as hammock-like structures in which the residents can read, chat and relax. The structures create a separation of floors and muffle the sound of the rooms above and below. The leaves will be used later in the year, in December and January to create bioplastic. The woodchips will be stored 


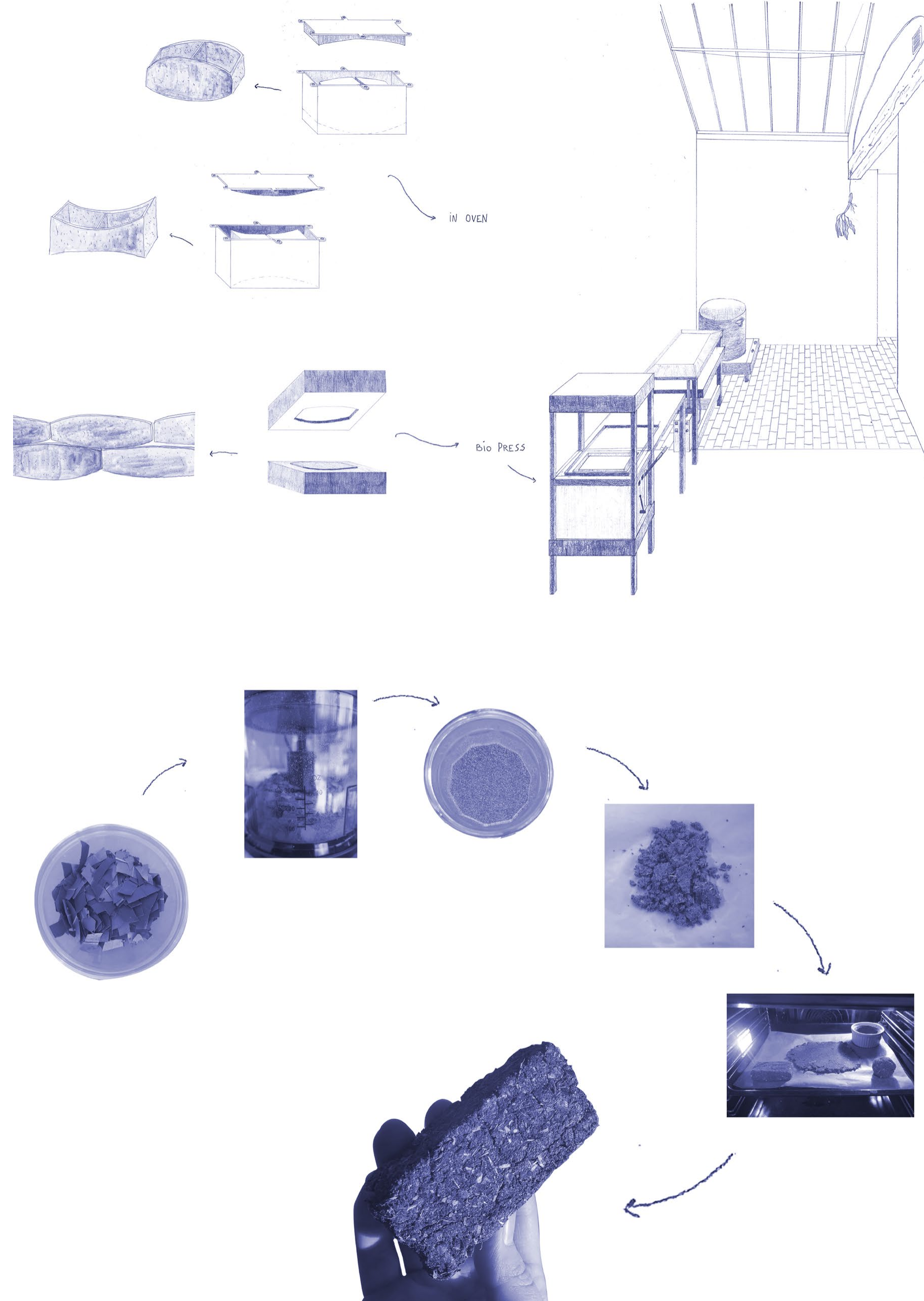

Fig. 8 - Bioplastics workshops 
in the greenhouse at the back of 'The Rhodo Workhome'.

The greenhouse is constructed to let in sunlight and to make it possible to have a light, duplicated timber structure on the inside which accommodates the storage of the woodchips. They function as a flexible type of insulation which creates open ventilated spaces in summer and closed insulated rooms in winter. In this way, the insulating storage of the chips is synchronised with the seasons.

\section{November - growing Shiitake mycelium (fig. 7)}

In November, the growing process of Shiitake mycelium begins. Shiitake mycelium was chosen because of their rich flavour, and low requirements in growth environment. This mushroom species can grow in warm and cold temperatures, but needs a controlled humidity level. The full process of the mycelium takes place in several ceiling-high moving closets. They function as microlaboratories and can be closed with glass to keep them sterile and to monitor the relative humidity level inside.

This is important, in order to have a high success-rate in the creation of the mycelium blocks. The closets are constructed on wheels in order to move to different places, depending if the mycelium needs to be in a dark, light, cold or warm environment. The closets will also be pushed towards the windows facing the street in order to communicate to passers-by what is happening inside 'The Rhodo Workhome'. Because of this modular flexibility, the closets not only serve the needs of the mycelium, but also create a moving interior layout in which the residents can change the function and size of spaces. In this way the residents can improve the co-housing spaces as well as the co-working spaces. For example, the residents can transform a more divided bedroom configuration at night into more open spaces, to work together during the day or to organise workshops during the weekend.

The closets have various divisions and are ceiling-high in order to, on the one hand, grow mycelium in a variety of shapes and, on the other hand, to function as separating walls or as wardrobes, shelf units and door-openings inbetween growing processes. The different mycelium figures will have different architectural applications in 'The Rhodo Workhome'. There are three different shapes: short cylinders $(40 \mathrm{~cm} \times 15 \mathrm{~cm}$ diameter), long beams $(250 \mathrm{~cm} \times 23.5 \mathrm{~cm} \times 23.5 \mathrm{~cm})$, and bricks $(40 \mathrm{~cm} \times 24 \mathrm{~cm} \times 24 \mathrm{xm})$.

The short cylinders are used in a variety of small impact applications such as furniture and insulation. The long beams can be used to assemble straight partitioning walls, insulation and flooring. The bricks are used to create straight and curved partitioning walls.

\section{When the Shiitake growing} period starts, the containers will be kept in the dark. This is needed for the mycelium to be able to inhabit the substrate. The closets will be moved away from the windows and the curtains, attached to the closets, will create a dark environment. This growing process takes two to three months.

\section{December - bioplastics workshops (fig. 8)}

December and January are calm months within the production process of Shiitake mycelium. This is because, the mycelium grows by itself. The only support that needed from the residents is to monitor the moisture level in the closets to a relative humidity of approximately $75-85 \%$.

This gives the residents and volunteers within 'The Rhodo Community' time to organise three workshops. In these workshops, the leaves of the Rhododendron are processed into bioplastic bricks and tiles. These are made with machines designed by the 'Precious Plastic Community's. This organisation is an online open source that shares manuals in which they explain how you can build your own tools at home to shape recycled and bio-plastic materials. In addition, the 'Precious Plastic Community' has a platform that indicates in which city certain machines are present and if they are available for rent or use. 'The Rhodo Workhome' participates in this community and shares its workshop and machines with people on this platform and inside 'The Rhodo Community'. The tiles which are made in this workshop are created from the leaves of the Rhododendron ponticum. These leaves are taken out of their hammock-like storage spaces and are ground into grains of different sizes.

Subsequently, water is added 
to a mix of these grains and compressed in the bio-press under high temperature. The design of the bricks and tiles is inspired by the characteristic lancet-shaped leaves of the Rhododendron ponticum. According to the amount of light, to which the leaves were exposed to when they were drying, the tiles will have different shades of green and yellow. The grain and texture of the bricks and tiles have a wheat-like, grassy appearance and introduce a natural scent and atmosphere inside.

\section{January and February - growing Shiitake mycelium}

After three months, the mycelium has fully inhabited the substrate and the block has turned into a white colour. At this stage, the mycelium will be left to grow for another four to eight weeks. When the substrate has turned from white to brown and bobbly for at least $70 \%$, it is ready to be exposed to fruiting conditions.

\section{March - fruiting Shiitake mycelium}

In March, the mycelium is ready to fruit mushrooms. To activate fruiting, the blocks need to be placed in a cold environment for one night. The growing process of Shiitake mycelium is scheduled this way that, at this time, at the end of February and the beginning of March, it is still quite cold outside. Because of this, the mycelium blocks do not need to be placed in the refrigerator which would take a lot of space and energy, but can be left outside overnight. The closets are pushed out into the courtyard. The day after, the mycelium blocks will be taken out of their containers and will be rinsed thoroughly. Subsequently, they are placed in the closets again, stripped from their reusable boxes, and the closets will be pushed back inside. In order to fruit, the mycelium blocks need to be in a half-shaded place with a controlled humidity level of approximately $80 \%$. This is why the closets will be pushed to the façade facing the street. These movements cause the interior layout of 'The Rhodo Workhome' to shift. As a result, the functionality and experience of the spaces change along with the needs and appearance of the Shiitake mycelium. Replacing the closets can happen in a variety of efficient, spatial combinations and be compatible with a different number of residents. In addition, through the window display, passers-by can follow the growing process of the mushrooms and estimate when the mushrooms will be ready to be picked. Within one week, the mushrooms are full-grown. During this week of fruiting, the residents participate in the process by eating, selling and trading the fruits. The Shiitake mushrooms have a rich and earthy flavour and are a valuable alternative to meat. Together with the process of selling and trading, the residents can also share recipes on cooking, marinating and drying the mushrooms. The dried mushrooms can be kept for at least nine months and be used in a variety of dishes after soaking them in hot water.

After one harvest, the mycelium blocks will be baked. This happens during a workshop, led by a couple of residents. This workshop invites people to learn about the production process of Shiitake mycelium and the way people live inside 'The Rhodo Workhome'. Within this workshop, the participants build partitioning walls inside the house by laying the bricks with compostable cement. These walls will change the interior configuration and make it possible for the residents to change the function and size of the existing rooms. Depending on when the mycelium bricks are baked, before or after fruiting, the colour and texture of the material can vary from almost white and smooth to brown and bobbly. In addition, these bricks can be compressed into tiles to create soft and isolating flooring for winter.

The mycelium and bio-plastic materials have a shorter lifespan compared to traditional durable building materials. The workhome takes advantage of this property by frequently reorganising the indoor spatial configurations through composting and reusing these materials. This makes it possible for the composition of families to change from time to time. (fig. 7)

\section{April - extracting colour from flowers, leaves and branches}

The Rhododendron ponticum blooms in April and May with large lilac flowers. In midApril, a new batch of plant material arrives at 'The Rhodo Workhome'. The residents organise a one-day workshop 

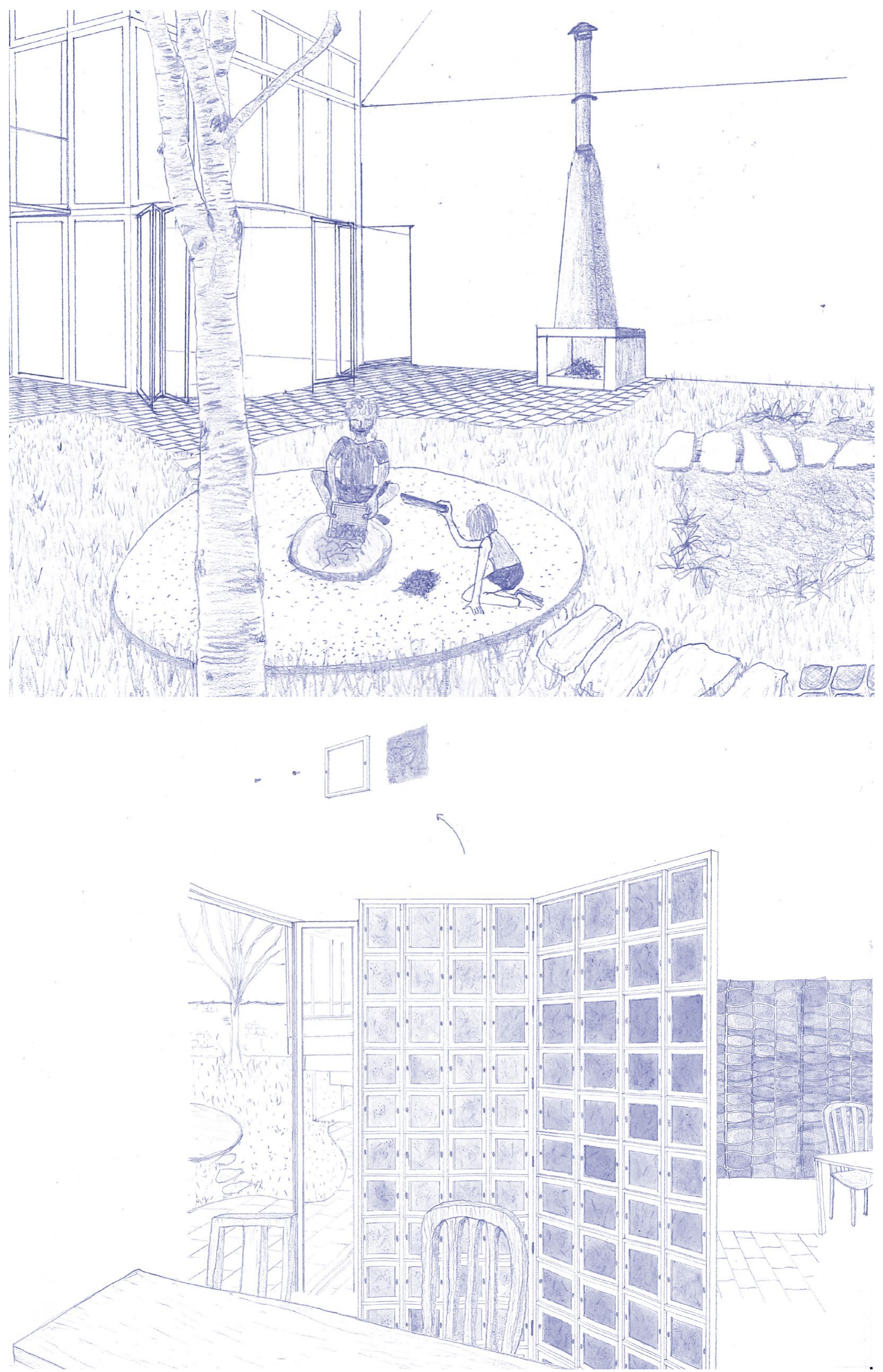


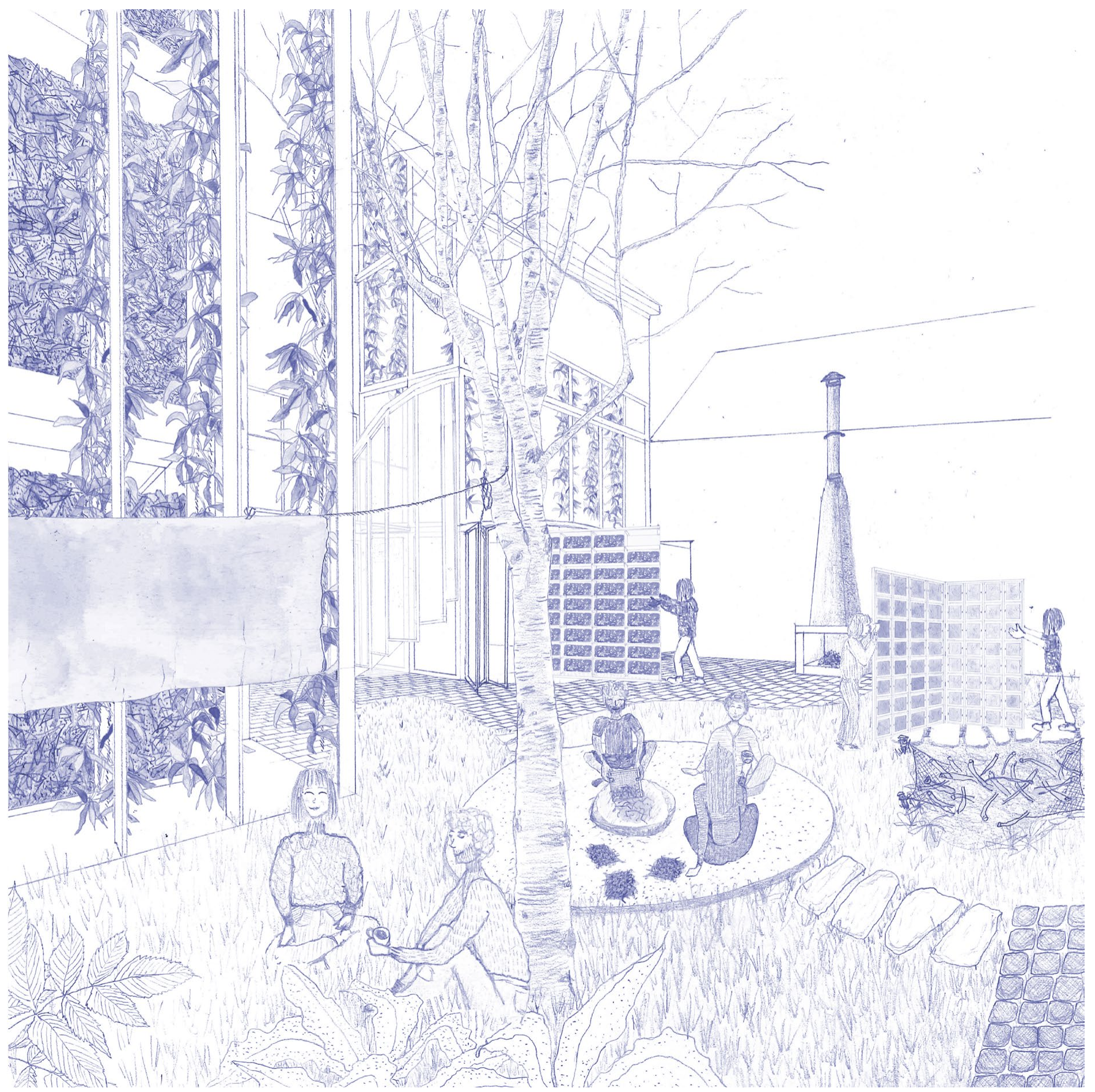


which revolves around extracting colour from the flowers, branches and leaves, which are being used to dye textile and create natural watercolour paint. For the colour extraction, it is important that the temperature of the water does not rise above 95 degrees. This would turn the extracted yellow, green and pink piments of the fresh leaves and flower petals to brown colours only. In addition, soaking the parts of the Rhododendron overnight, will intensify the colours of the extraction process. As a result, the extracted colours can be used to dye curtains, carpets and even clothes. The colours can also be distilled into a more concentrated substances to be used as watercolour paint.

In this same workshop the plant material is dried and stored in a different manner, compared to the previous drying process which takes place in September. Firstly, the number of flowers that are not used in this workshop will be dried in a dark place in order to keep their pigment. Secondly, the branches of the Rhododendron will not be dried this time. On the contrary, they will be soaked in the pond in the courtyard. Soaking the branches is part of the preliminary process of making 'Rhodo paper'.

\section{May and June - Grey oyster mycelium}

In late spring, the woodchips will be taken out of their storage in the greenhouse at the back of 'The Rhodo Workhome'. The chips will be used as substrate for the growth of Grey oyster mycelium. As a result, the timber structure in the greenhouse will be empty when the temperature in Belgium rises and make it possible for the residents to maximize the ventilation of the indoor spaces within the greenhouse. (fig.

6) The Grey oyster mycelium has approximately the same process compared to Shiitake mycelium. The most significant difference here, is that the growth period of Grey oyster mycelium is only 10 to 14 days instead of two to three months, making its process from beginning to end last for only two months instead of six.

\section{July and August - Rhodo paper (fig. 9)}

July and August are more quiet months. In this period, two short processes of making paper of the Rhododendron fibres, are carried out. On a warm summer evening the residents of 'The Rhodo Workhome' come together in the courtyard around a campfire. This might as well be a BBQ in which they grill the tasty fresh Grey oyster mushrooms, which have fruited recently. In addition, they can soak and roast some of the dried Shiitake mushrooms or use them in side dishes. Most importantly, this is a time for the residents to join in the common garden and enjoy their time together. The day after, the ashes of the fire are collected. These are used as binding material to create the 'Rhodo paper'. In the morning the branches, that were left to soak in the pond in April, are boiled until the layer of fibres comes off. These fibres are then smashed together with the ashes to create a flat mass. This method of making paper is inspired by the Japanese technique 'Sekishu-Banshi'10 and results in a sturdy and flexible paper-like sheet material. The paper will be used in wooden frames that function as light, modular partition walls and sunshades. The construction of the timber frames allows the paper to be replaced when damaged. Depending on how intensively the fibres are rinsed, the colour of the paper will vary from dark brown to almost white. The 'Rhodo paper' has a surprisingly fresh and herbal fragrance.

\section{DESIGN IMPACT = A NEW MATERIALITY}

As illustrated within this oneyear timeframe, the processes of making these materials vary in intensity, actions, and architectural interventions. Overall, the processes are mainly extensive and involve a lot of waiting periods: drying and growing. This is very important. Because of this low-maintenance and nonindustrialised process, the residents are able to still live their own lives, practice their jobs and hobbies, while in the meantime, they are surrounded by the colours, smells and textures of the products around them, which are drying, growing and being stored. The people living at the workhome will occasionally free their schedule to prepare a material or to support a certain phase of one of the five manufacturing processes. A new rhythm will turn the daily routines of the residents into a more varied and social post-pandemic way 
of living. This lifestyle values alternative ways of working, together, in addition to the work that the residents deliver separately, during their paid jobs. (fig. 10)

The natural products have agency in creating an adaptable interior, suitable for all residents. They can work together from home, prepare dinner together or choose to live a more separate life for some weeks, months or years.

'The process of making' creates a varying housing structure which makes it possible for the residents to change habits and behaviour according to the seasons, according to the products or according to their mood. This creates an innovative and post-pandemic way of living which is adapted to a variety of social, spatial and natural conditions.

\section{SOCIAL AND \\ ENVIRONMENTAL IMPACT THROUGH COLLABORATIONS}

'The Rhodo Community, designed within this co-housing project, has established various collaborations with researchers, universities, organisations and individuals to increase its environmental and social impact.

\section{Environmental}

More specifically, there is the collaboration with Natuurpunt. An organisation in Flanders which manages landscapes in Belgium. Their aim is to maintain and restore local biodiversity. 'The Rhodo Workhome' cooperates with Natuurpunt by, on the one hand, collecting and recovering the removed Rhododendron plants into biobased materials, and on the other hand, setting up a 'Forest Recovery Model'. In this model 'the removal of the Rhododendron Ponticum' and 'the monitoring of ecological growth' are both incorporated. This program will intervene when the recovery of biodiversity in the forests which are stripped from Rhododendron shrubs, is growing too slowly, when a forest does not recover at all, or when ecosystems are developing into another damaging state. As stated in the article 'When does invasive species removal lead to ecological recovery? Implications for management success'11, different tactics in monitoring an ecological recovery should be used, according to the situation in any particular forest. For example, when removing large volumes of Rhododendron shrubs, open spaces become an opportunity for other invasive species to settle. Another effect of removing the Rhododendron plants could be that a safe haven for a certain native plant or animal species is taken away. As a consequence, environmental conditions created by the shrubberies, that enable certain native species to exist could be altered when the shrubs are removed. This could result in a negative impact on the ecological quality of that site. These exemplary situations explain what is at risk when removing invasive species and not monitoring recovery. The examples prove that we cannot solely rely on the forest's capacity to restore itself into its pre-invaded state. Thus, we can conclude that only taking care of the removal is not sufficient in restoring an ecosystem. A more holistic approach is needed in which seeding programs, frequent site visits, research and maintenance needs to be combined. This 'Forest Recovery Model' will include the investigation of an area, followed by observing which other invasive or dominant species could likely take over the site after the removal of Rhododendron shrubs. Another example of a tactic within this 'Forest Recovery Model' is establishing a list of native species that are present and used to be present at the site. This list will be prepared, in order to start up a seeding scheme, that indicates which seeds should be planted, how and in which season. In addition, this list should state how intensively or extensively the growth of these seeds should be tracked and supported. The previous examples help support the restoration of biodiversity, nevertheless it is not easy or even impossible to estimate or predict nature's reaction after an invasion. As a result, it is necessary to work in close collaboration with foresters and researchers to observe the progress and course of recovery, in order to apply a customized restoration strategy and to avoid undesirable changes in ecosystem processes.

\section{Social}

Through collaborations with individual artists, universities and other organisations 
such as the 'Precious Plastic Community', a wide and diversified group of people is reached. In addition, within the program of 'The Rhodo Workhome', an online platform is designed to create and maintain a clear communication. This website, along with the window displays of the house itself, will announce what is happening inside 'The Rhodo Workhome' and which events and workshops are being organised.

The collaboration with the nearby 'LUCA School of Arts' invites art- and graphic design students to participate in the start of a new production phase by creating the design for its explanatory window display. These changing 'windowscapes' will attract people that walk by and engage them in the changing program of 'The Rhodo Workhome'. Moreover, the program of the house invites students and people from Ghent to use the workspaces, that are being created by the temporary partitioning walls, modular closets and paper-frames. The workspaces are also open for students to test materials in the 'Precious Plastic' machines. In addition, there is a collaboration with the University of $\mathrm{KU}$ Leuven. Their Architecture campus is situated around the corner of 'The Rhodo Workhome', right next to 'LUCA School of Arts'. The university incorporates the workshops organised by 'The Rhodo Workhome' into their curriculum and in this way, creates an opportunity for its students to be involved in learning about a 'new materiality' within the architectural design-practice. REFLECTIONS

\section{Economic value of mycelium products}

'The Rhodo Workhome' does not aim to become a company which produces bio-based materials, instead it still intends to be a home. It does not want to change the lives of its residents drastically, but rather bend and twist them in terms of pace, structure and flexibility.

'The Rhodo Workhome' is designed to create a community rather than a product. It is a place that houses both its residents, its production processes and the community around them. Accordingly, we can conclude that creating a product is far from being the sole purpose of this home.

When it comes to making a product within our current society, an economic value is subsequently associated with it. In contrast to this way of thinking, 'The Rhodo Workhome' is not mainly about creating a profitable product. Rather, it is the altered relation to materials and the lifestyle that it introduces in contrast to our current traditional way of living. Nevertheless, the materials that are produced, are and target to become even more valuable products. In addition, because of their basic shapes, they can be used in different architectural projects. Therefore, these biobased products could optionally be sold or traded by the residents. In addition, creating connections with supermarkets and other local, small design stores could be interesting to expand the impact of 'The
Rhodo Workhome', allowing more people to get to know and use the products.

\section{Impact on biodiversity and innovative design}

There has not yet been much research into the possible uses of the Rhododendron ponticum within the scope of innovative organic materials. Additionally, this plant is invading areas in Europe of considerable size. These two elements make this study relevant within the research subjects concerning 'restoring biodiversity' and 'recovering wasted materials', especially within the discourse of products which are made in a fair, healthy and transparent environment. The techniques that 'The Rhodo Workhome' implements to design these products are low-teach. In addition, the products themselves need more experimenting to make them better. Therefore, a collaboration with research laboratories could be a step forward in order to make innovative design progress in an efficient way.

This article mainly focusses on recovering the Rhododendron ponticum plant material into organic materials. In addition, this research has decided to set Ghent as its case study. Nevertheless, this project can be adapted to various cities in Flanders such as Bruges, Antwerp, Brussels and Hasselt, where the Rhododendron ponticum is also invading many areas. As in Ghent, 'The Rhodo Workhome' could likewise be constructed in these cities. If we were to think even more into the future, 
we could plot what will happen when all the Rhododendron bushes are removed. When this situation occurs, 'The Rhodo Workhomes' will be adapted to a new process of manufacturing, customized to a different invasive species.

For example, the American Oak or Quercus rubra are also invading our forests. In this way 'The Rhodo Workhomes', or in this case 'The Quercus Workhomes', will change name and format according to the invasive species of which they are helping our ecosystems to recover from.

Another, even more efficient method could be, to work our way through damaged ecosystems, not from species to species but, from forest to forest and immediately remove all invasive plants present in one forest, rather than focussing on one type of invasive plant. In this case, different Rhodo-, Quercus- and other- Workhomes should be developed at the same time to host different programs of biobased materials.

\section{Impact on to day's architectural discourse}

There are numerous design aspects of the Rhododendronbased materials, on which this research did not focus. One of these is the fact that mycelium, for example, can be created in many shapes, because it is grown inside a mould.

Therefore, a study on shaping mycelium in order to create more intriguing architectural forms would be an interesting consecutive investigation. Within this prospective study, various building methods could be integrated, such as 'dry connection' building as an alternative method to using compostable cement. Moreover, more research should be established on the structural properties of mycelium and bioplastic depending on their shape and thickness.

In addition, when it comes to mycelium blocks, there was not any information to be found around the different qualities of mycelium blocks depending on if they are baked before or after fruiting. Additionally, this research raises questions about how we treat non-load-bearingwalls in today's architecture. Why are these permanent structures? How could we design partitioning walls differently in the future? Which other (organic) materials could be part of this study?

This research aims to define a new way of living in reaction to how we are experiencing the global pandemic from home. As a result, the project discussed within this research brings together a strong community, a close connection to nature and a flexible architectural system. These three aspects collide through the processes of growing and making Rhododendron-based materials inside a post-pandemic residence called: 'The Rhodo Workhome'.

Firstly, this project includes a strong community through participative architecture, which is designed in order to fight social isolation among homebased workers and individuals in lockdown.
Secondly, 'The Rhodo Workhome' raises awareness around the decrease of local biodiversity which is being caused by the Rhododendron ponticum. This exotic invasive species represents the ideology that lies at the heart of 'The Rhodo Workhome'. Namely, contributing to the restoration of ecosystems and recovering a plant material that would otherwise be thrown away into bio-based products.

Thirdly, the production processes of these materials create a flexible and varying way of living. While their resulting products introduce a new way of treating building materials as temporary and compostable in contrast to the current architectural situation, which builds with ever-lasting, durable materials.

The design of 'The Rhodo Workhome' houses a flexible spatial program which adapts itself to the rhythm and needs of both the residents, as well as the different natural processes which are carried out. This research invites residents to live a more self-sustaining and environmentally conscious life through living together with these naturally grown products.

To conclude, 'The Rhodo Workhome', creates a new materiality of shapes, smells and textures within a new kind of innovative participative residential architecture. In addition, this design exercise introduces a post-pandemic way of living, which is adapted to a variety of social, spatial and natural conditions. 


\section{NOTES}

${ }^{1}$ Bio-based materials are made from organic sources only and are compostable.

2PANCANI, Luca and others. Forced Social Isolation and Mental Health: A Study on 1,006 Italians Under COVID-19 Lockdown. In: frontiers in psychology [online]. Milan: 21 May 2021. [viewed date: 30 May 2021] DOI: https://doi.org/10.3389/ fpsyg.2021.663799

${ }^{3} \mathrm{SMITH}$, Constance. All in this together? Isolation and housing in 'lockdown London'. In: Social Anthropology. n.p.: Wiley Public Health Emergency Collection, 9 May 2020, Vol. 28, issue 2, pp. 357-358. DOI: https://doi.org/10.1111/14698676.12874

${ }^{4}$ PANCANI, Luca and others. Forced Social Isolation and Mental Health: A Study on 1,006 Italians Under COVID-19 Lockdown. In: frontiers in psychology [online]. Milan: 21 May 2021. [viewed date: 30 May 2021] DOI: https://doi.org/10.3389/ fpsyg.2021.663799

${ }^{5}$ HOLLISS, Frances. Conclusion. In: HOLLISS, Frances. Beyond live / The architecture of home-based work. n.p.: Routledge, March 2015, pp. 169. DOI:10.4324/9781315738048

${ }^{6}$ WOUTERS, A. Exotenbestrijding om biodiversiteit te behouden. In: Wouters, A. Agentschap voor Natuur en Bos [online]. 24 August 2018. [viewed date: 10 December 2013]. Available from: https:// natuurenbos.be/persnieuws/nieuws/ exotenbestrijding-om-biodiversiteit-tebehouden

${ }^{7}$ BERTO, Rita, Giuseppe BARBIERO. How the Psychological Benefits Associated with Exposure to Nature Can Affect Pro-Environmental Behavior. In: Annals of Cognitive Science. n.p.: scholars.direct, 2017, Vol. 1, issue 1, pp. 16-20. DOI: 10.36959/447/336

${ }^{8}$ AKGUL, M., Çamlibel, O. Manufacture of medium density fiberboard (mdf) panels From Rhododendron (R. Ponticum L.) biomass. Elsevier: Building and Environment [online]. Turkey: Abant Izzet Baysal University, 7 January 2017, 43(4), 438-443. [viewed date: 26 December 2020]. Available from: https://doi.org/10.1016/j. buildenv.2007.01.003

${ }^{9}$ PRECIOUS PLASTIC

COMMUNITY. Beyond Plastic

- Researching biodegradable alternatives to plastic [online]. 1 Jan 2020. Available from: https:// community.preciousplastic.com/ academy/research/beyondplastic

${ }^{10}$ FRANSWORTH, Donald. A Guide To Japanese Papermaking. 3rd Edition. Oakland: Magnolia Editions, 2018. ISBN: 978-0-9799164-8-9

${ }^{11} \mathrm{PRIOR}$, Kirsten. M., Damian C. ADAMS, Kier D. KLEPZIG, Jiri HULCR. When does invasive species removal lead to ecological recovery? Implications for management success. In: Biological Invasions. n.p., 4 Sept 2017, 20, 2, 267-283. https://doi. org/10.1007/s10530-017-1542-x

\section{FIGURES}

Fig.1 - W., Koen, Rhododendron ponticum bushes in Wetteren - Den Blakken [online]. Photograph. Ghent: Waarnemingen.be, 1 January 2021. Available from: https://waarnemingen. be/species/7312/photos/?after date=1993-01-01\&before_date $=2021$ 06-05\&province $=16 \&$ search $=$ wetteren \&likes=\&user=\&location=\&sex=\&type $=\&$ life_stage $=\&$ activity $=\&$ method $=$

Fig.2 - ROELS, Marie. 2021. Rhododendron ponticum, map of expansion in Belgium and Ghent.

Fig.3 - ROELS, Marie. 2021. Empirical study of organic materials: watercolour, paper, bio-plastic and mycelium.

Fig.4 - ROELS, Marie. 2021. Calendar and graphs visualising the different production processes that are carried out in one year.

Fig.5 - ROELS, Marie. 2021. Site of 'The Rhodo Workhome' based in the city centre of Ghent.

Fig.6 - ROELS, Marie. 2021. Drying and storing Rhododendron plant material.

Fig.7 - ROELS, Marie. 2021.

Shiitake mycelium.

Fig.8 - ROELS, Marie. 2021. Bioplastics workshops.

Fig.9 - ROELS, Marie. 2021. Rhodo paper.
Fig.10 - ROELS, Marie. 2021. A post-pandemic lifestyle. 


\section{Portable
Ecologies}

\section{Dialogues with the Architecture from the Anthropocene}

posthumano ecologías pedagógicas producción de pensamiento crítico reinterpretaciones propositivas posthuman pedagogical ecologies critical thinking production propositional reinterpretations

\section{Marcos Torró, María José 1}

1Department of Graphic Expression, Design and Projects / Alicante University, Spain http://orcid.org/0000-0002-3753-2508

mariajose@magicarch.es

Citation: Marcos Torró, M.J. (2021). Portable ecologies. Dialogues with the Architecture from the Anthropocene. UOU scientific journal \#01, 72-83.

ISSN: 2697-1518. https://doi.org/10.14198/UOU.2021.1.07

This document is under a Creative Commons Attribution 4.0 International license (CC BY 4.0) 


\title{
Ecologías Portátiles
}

\author{
Diálogos con la Arquitectura \\ desde el Antropoceno
}

Este texto muestra una lectura sobre las ecologías comunes de varios edificios de la Historia de la Arquitectura, experimentando desde la construcción de dispositivos que revisitan estos edificios y construyen nuevas experiencias actualizadas. Teoriza dos metodologías de reinterpretación y abre nuevos diálogos sobre las ecologías con las que convivimos o que provocamos, desde una revisita contemporánea a estas Arquitecturas icónicas. Estos diálogos abren preguntas como las divergencias del Antropoceno, las cuestiones posthumanas que acontecen a su alrededor 0 incluso las tecnófilas transhumanas. Su reconstrucción y su escenificación establecen estas nuevas lecturas que abren estas miradas propositivas de la Arquitectura, que sean capaces de articular nuevos presentes. La producción de estos dispositivos críticos se apoya en las posibilidades que nos concede la arquitectura avanzada y el parametricismo. Estas historias de estos edificios ocurren a través de un cuerpo orgánico que los escenifica y que performa con cada uno de los dispositivos, desenvolviéndose cada historia entre paisajes virtuales antropizados y conformando una nueva mirada híbrida y ecológica de estas arquitecturas.
This text shows a reading of the common ecologies of several buildings in the History of Architecture, experimenting from the construction of devices which revisit these buildings and build new updated experiences. It theorizes two methodologies of reinterpretation and opens new dialogues about the ecologies we live with or provoke, from a contemporary revisiting of these iconic architectures. These dialogues open questions such as the divergences of the Anthropocene, the posthuman issues that occur around them, or even of transhuman technophiles. Their reconstruction and staging establish these new readings that open up these propositional views of Architecture, which are capable of articulating new presences. The production of these critical devices is based on the possibilities granted by advanced architecture and parametricism. The stories of these buildings occur through an organic body that stages and performs them with each of the devices, each story unfolding between anthropized virtual landscapes and forming a new hybrid and ecological view of these architectures. 


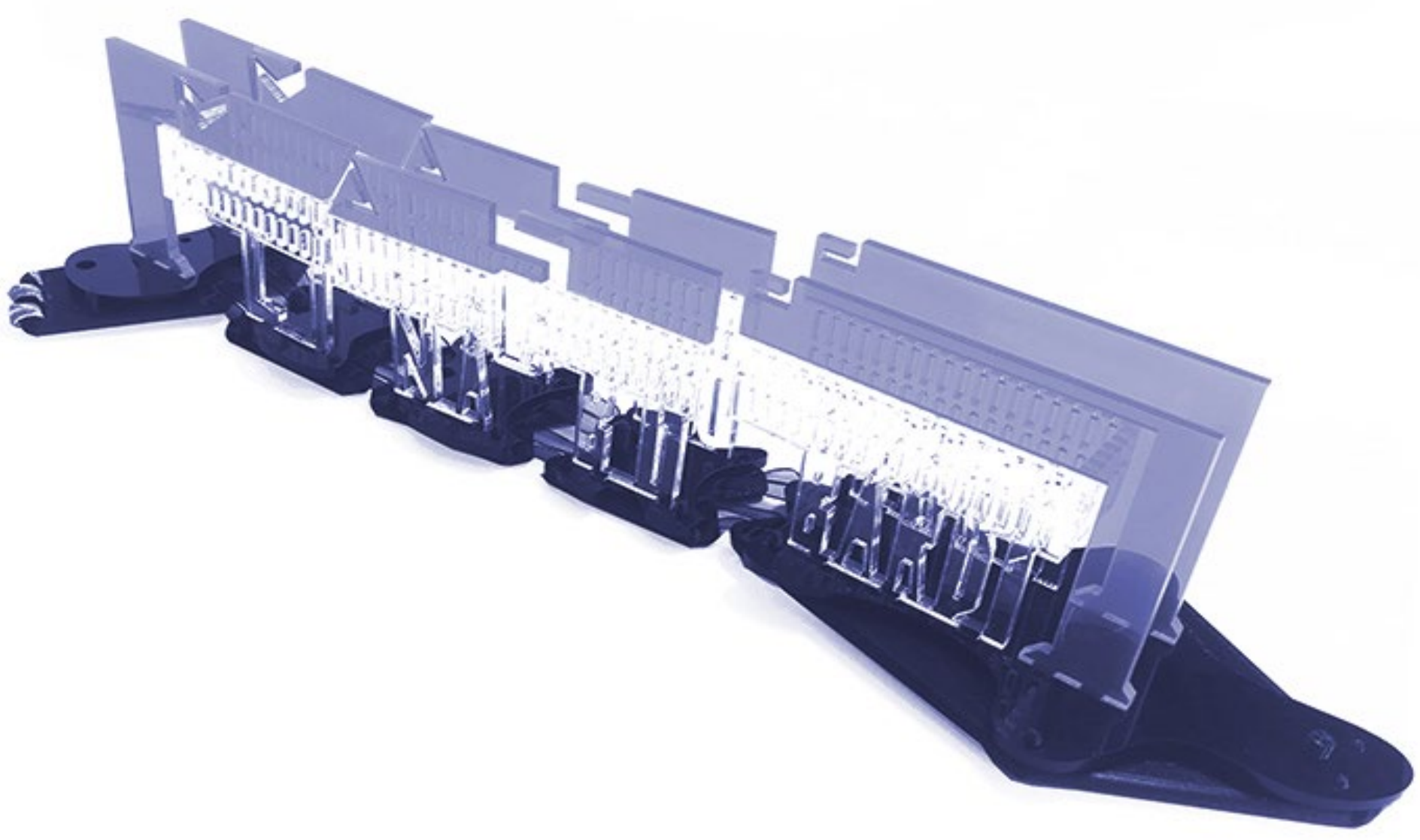

Fig. 1 Interactive Device about the building MASP (Museu de Arte de Sau Paulo) in Brazil designed by Lina Bo Bardi in 1957.

\section{PERFORMING COMMON ECOLOGIES}

With this article I am interested in finding the Common Ecologies from my current positioning of Architecture. In a planetary view, which is already evolving towards a post-Anthropocene, we can question the urgency of re-reading past Ecologies that have affected architectural negotiations and creations. By looking at the means by which energy is distributed, or how resources arrive, by establishing readings on interspecies, the ethical normalization of 'Dolly the sheep', or how planned obsolescence is becoming a matter of political design, by reading these past ecologies we can articulate new interests from the common Ecologies.

In this article I am also interested in bringing out the value of reinterpretations and their propositional value in an architectural project. A question that I will explore in depth relating two highly propositive project methodologies that work from the reinterpretation of the existing, such as the Roman fictions of Piranesi or the domesticity of the New York buildings of Viesendrop. And in the second chapter I will examine in depth twelve ecoreflections of several buildings of the History of Architecture. (Fig. 1)

\section{Architectural Redrawings and theilr Interpretations}

In the History of Architecture there are several assertive reinterpretations that have become 'Manifestos'. Those assertive reinterpretations reenact icons of Architecture by approaching them from new scales. For example, Madelon Viesendrop and Rem Koolhaas humanize legendary buildings in New York and place them in domestic spaces, creating intimate scenographies, while Piranesi de-anthropizes monumental buildings in Rome with his engravings, returning them to Nature. In the following two sections, I will somewhat unpack the interest related to 'Portable Ecologies' that I find 
in these two examples, from the point of view of a change of scale in the architectures, and their caricaturization in the case of the artist Viesendrop, and then from the point of view of the reinterpretation of ecology when I write about the archaeologist and architect Piranesi.

\section{Manifesto of Humanized} Architectures by Madelon Viesendrop

The Dutch artist Madelon Viesendrop draws a sequence of icons of New York City architecture, which she reinterprets through her chromatic illustrations. In this example, for her reinterpretation of the buildings, she edits and builds domesticated scenes, inside a dwelling, where the buildings perform different human scenes.

In her early research, Viesendrop together with her former partner Rem Koolhaas, collected more than 8000 postcards of New York City. In several videos and exhibitions where she shows her suitcases full of postcards, hundreds of views of the Chrysler, or the Empire State, or the Rockefeller Center buildings appear, which she later includes as protagonists of her scenes. These postcards show a superficial and static image of how the city is shown to tourists or visitors. Viesendrop however, shows the most emotional side of the buildings, as she puts them to bed to talk about them, and to interpret their weaknesses or vulnerability, to discuss the conflicts and possibilities of these buildings that, after all, are milestones in the history of architecture.

The cover illustration of the book 'Delirious New York'

(Fig. 2) is one of these famous scenes of buildings which are given feelings and which are suffering emotions. This cover narrates the scene entitled by the author as 'flagrant délit', the Empire State Building is in bed lying next to the Chrysler Building, when the Rockefeller Center bursts into the room discovering the crime, a crime that becomes the spectacle of hundreds of other humanized buildings on the island of Manhattan staring in concentration through the window.

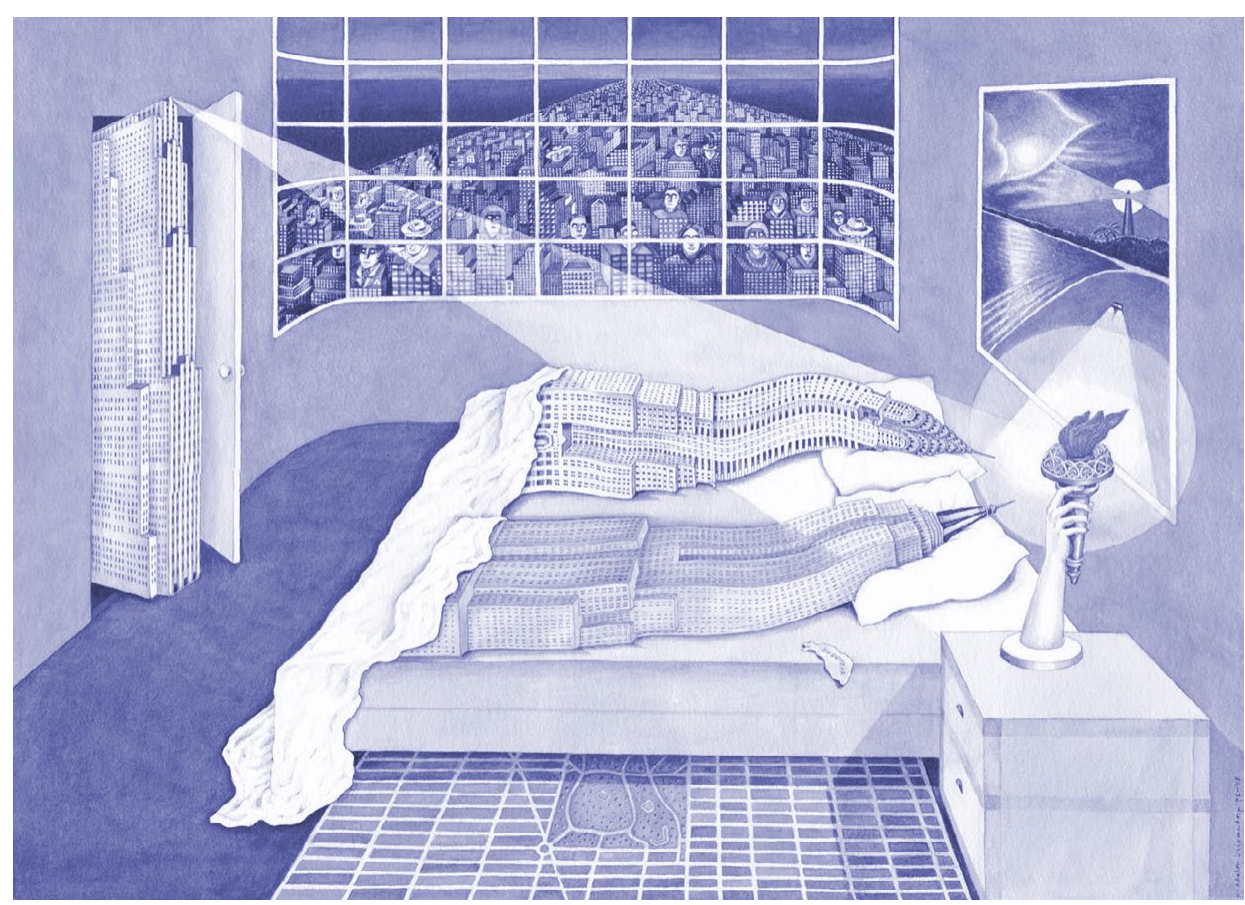

Fig. 2 Cover of the book 'Delirious New York' published in 1978.

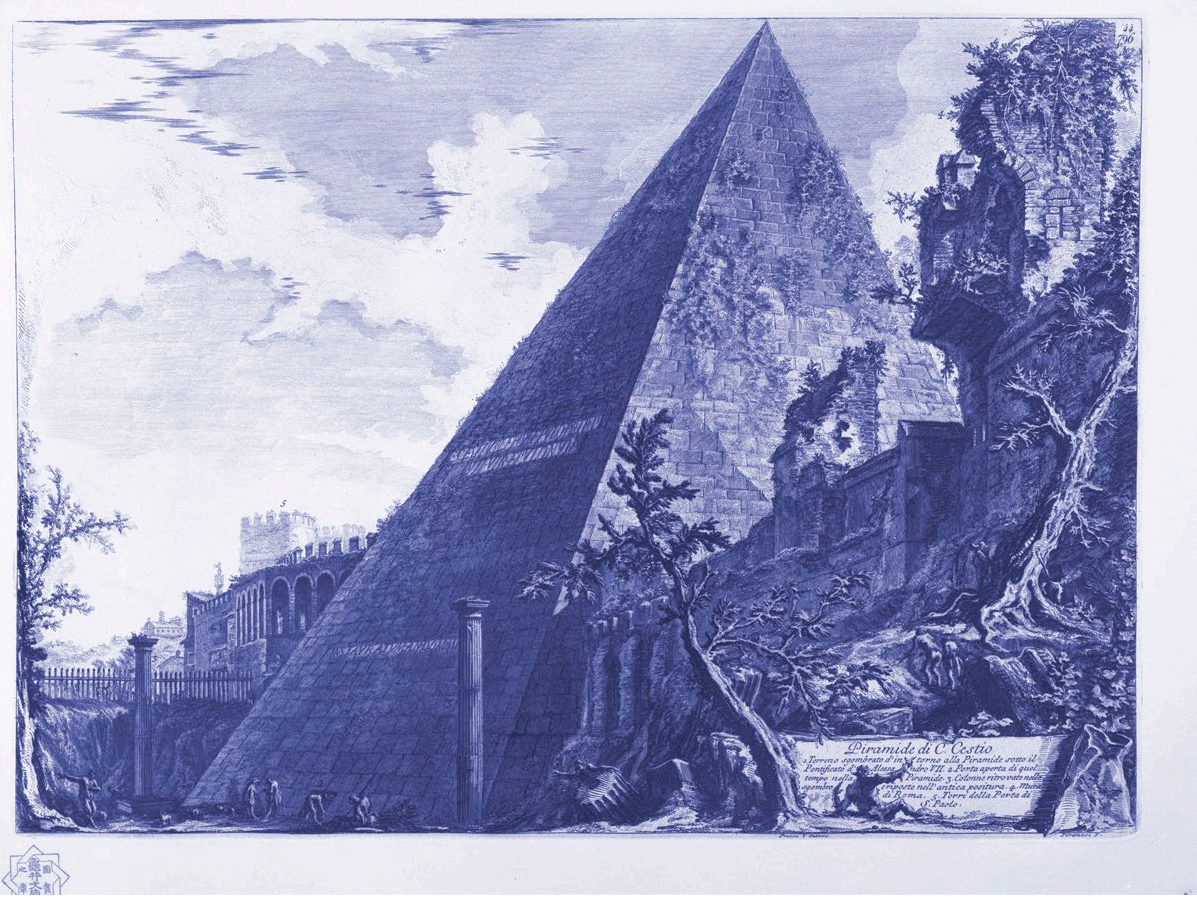

Fig. 3 Piranesi's engraving of the Pyramid of Cestius. 


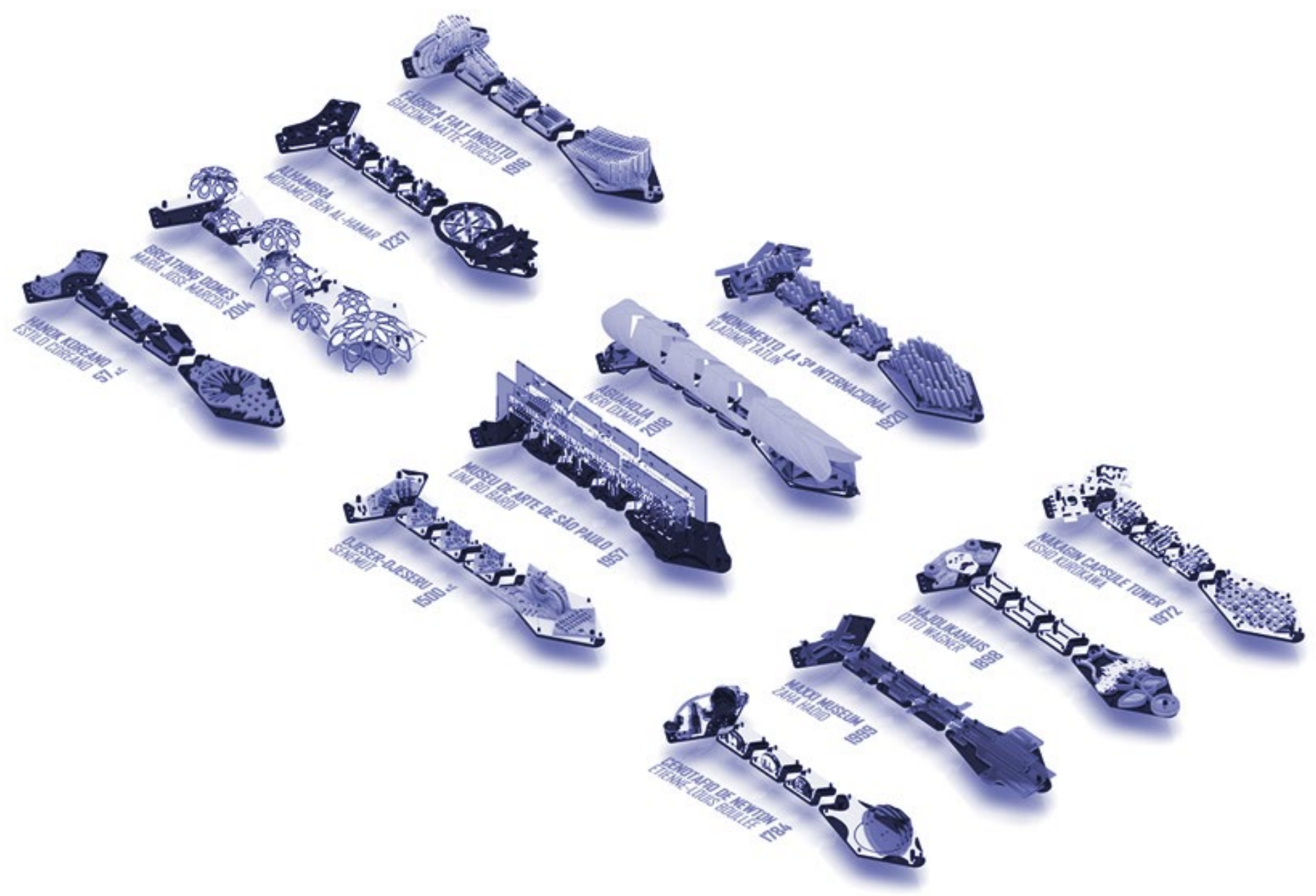

Fig. 4 Collection of the twelve devices that make up the project 'Portable Architectures'.

The reinterpretation of Viesendrop's domestic illustrations narrate new interpretations of the human qualities of cities as they change scale and show their character and are put into a crisis situation with a rigor that can only bring out the humor that emerges from each scene; the tragicomedy grants and validates its legitimacy.

\section{Giovanni Battista Piranesi's Manifesto of Ecologized Archaeology}

In the year 1750, archaeology was not yet a very strict, rigorous or defined science, and for this reason the Venetian architect Giovanni Battista Piranesi immortalized each of his archaeological findings through a creative and unexpected interpretation of history. He had this creative freedom, since there were no dogmas or weight to the emerging discipline. Thus, the interpretation that he carried out in his archaeological engravings was outside of what today would be considered appropriate in the discipline, but this validation was achieved through the precision and hyperrealism of his engravings.

It is true that his rigor in the discipline is born of the major influence of Palladio and Vitruvius during the years he studied in Venice, an influence that gives him a disproportionate fulness, and the rigor in defining and creating architectural drafts, drafts that he projected through hundreds of engravings. Although the most surprising aspect of his work is his enthusiasm for turning the Monumental ruins back to Nature, particularly in his 135 engravings of Rome, there is a draft where the naturalization of architectural spaces and their colonization by animals and plants coexist in a radical way with the contemporary Rome that he wants to show. There are even natural dunes created by the wind that appear in the engraving of the 'Veduta di Campo Vaccino'.

The de-anthropization happens when Piranesi 
denies men and women as protagonists in the appearance of his engravings, since they are hardly the priority in the reinterpretation of his scenes of Rome, an updated reinterpretation of the city where fiction plays an important role in the character of his proposals. When humans appear in the engravings, they sometimes appear as shadows or small, the predominance instead showing how the wind, rain or other means deteriorate the architectures as shown in the engraving of 'Veduta del Pantheon di Agrippa', for example, or how plants grow between the cracks or pediments of the monuments in works such as 'Veduta dell Arco di Tito' or the 'Piramide di C. Cestio' (Fig. 3). We could say that Piranesi's reinterpretations relate his vision of the future of the city, a city extremely linked to natural processes and its shared reading.

\section{PORTABLE}

\section{ECOLOG\|ES}

This second chapter is mainly based on a series of eco-reflections upon the collection of the twelve architectural devices that make up the 'Portable Architectures' project (Fig. 4). The article is based on a theorization of this project that was initiated in 2018 and re-edited to be exhibited at the 17th Mostra International of Architecture of the Venice Biennale in 2021. The project was developed by my architecture studio MAGICARCH and in collaboration with the digital fabrication labs, FaBlab L.A.D. and FaBlab Alicante. The aim of 'Portable Architectures', is to build a reinterpretation of some landmarks of architecture, the project was raised as devices from which to discuss this ecoreflection.

The devices are ties of approximately 30 centimeters produced entirely in the nearby factories of the FaBlaB and

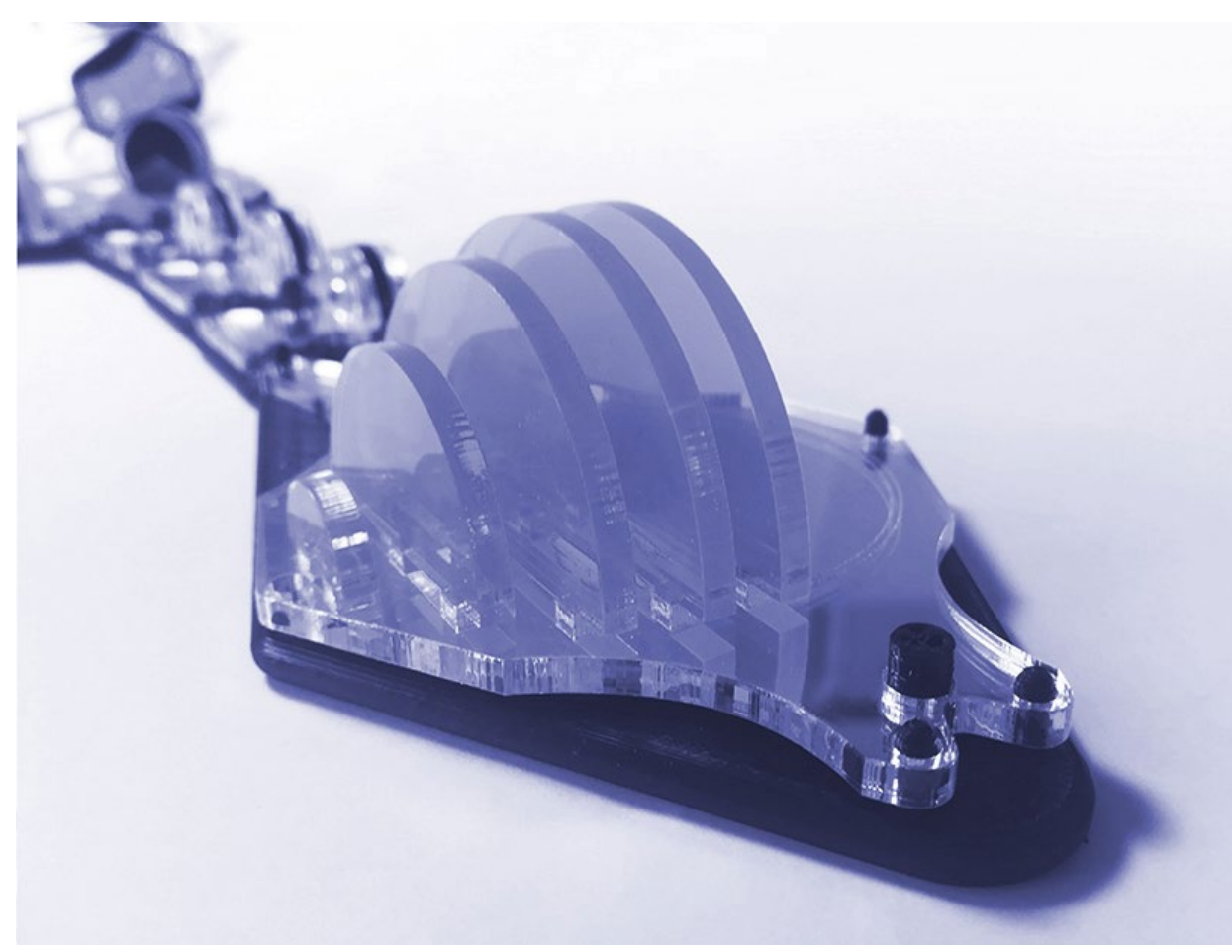

Fig. 5 Interactive Device about Newton's Cenotafio, Étienne-Louis Boullée,1784.

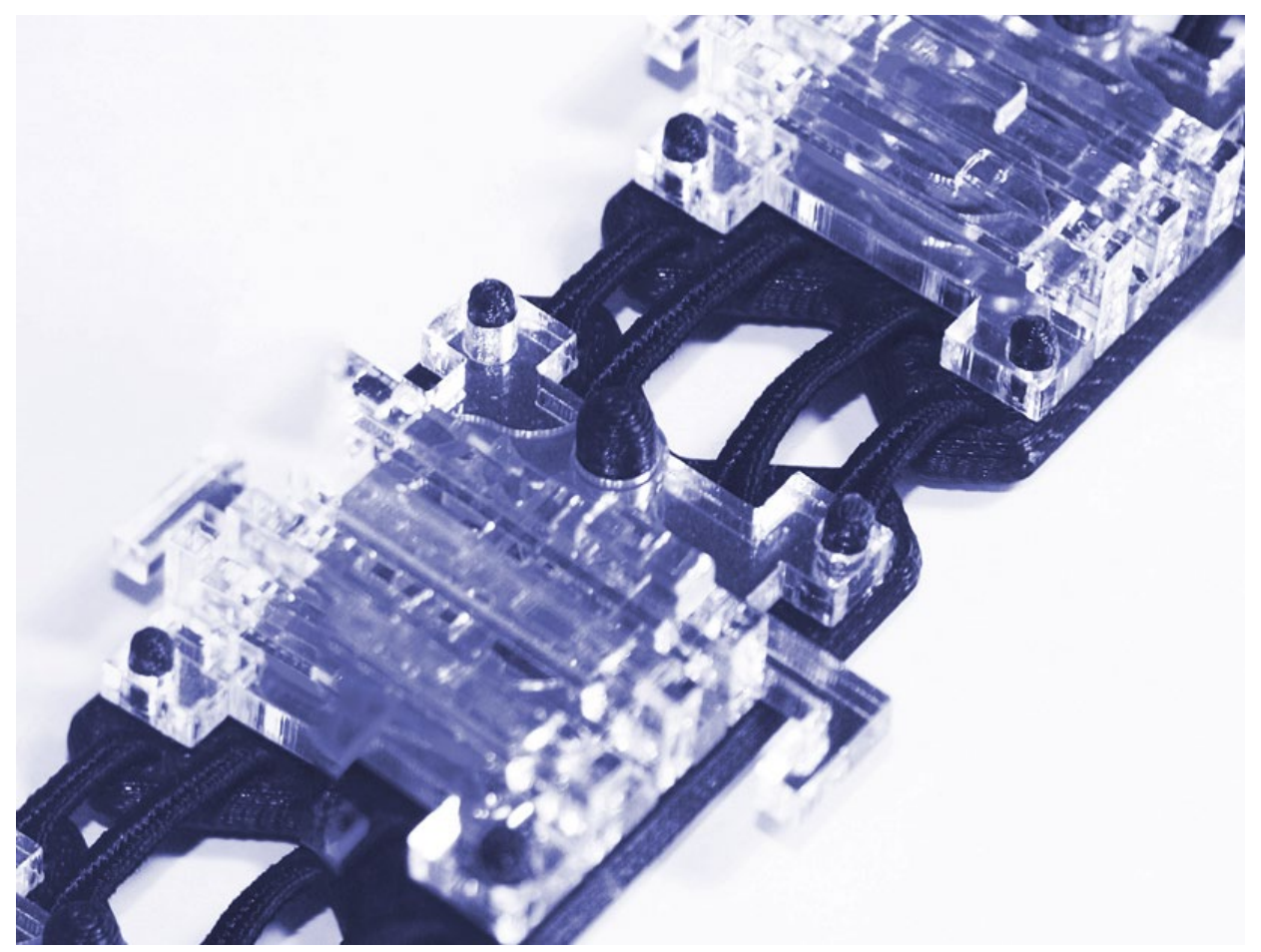

Fig. 6 Interactive Device about Nakagin Kisho Kurokaga, Japan, 1972 experimenting with parametric tools. Through them, various buildings from the History of Architecture are revisited, such as Lina Bo Bardi's MASP, Giacomo Matte Trucco's Fiat Factory in Lingotto, Zaha Hadid's Maxxi Museum or Neri Oxman's Aguahoja. These 


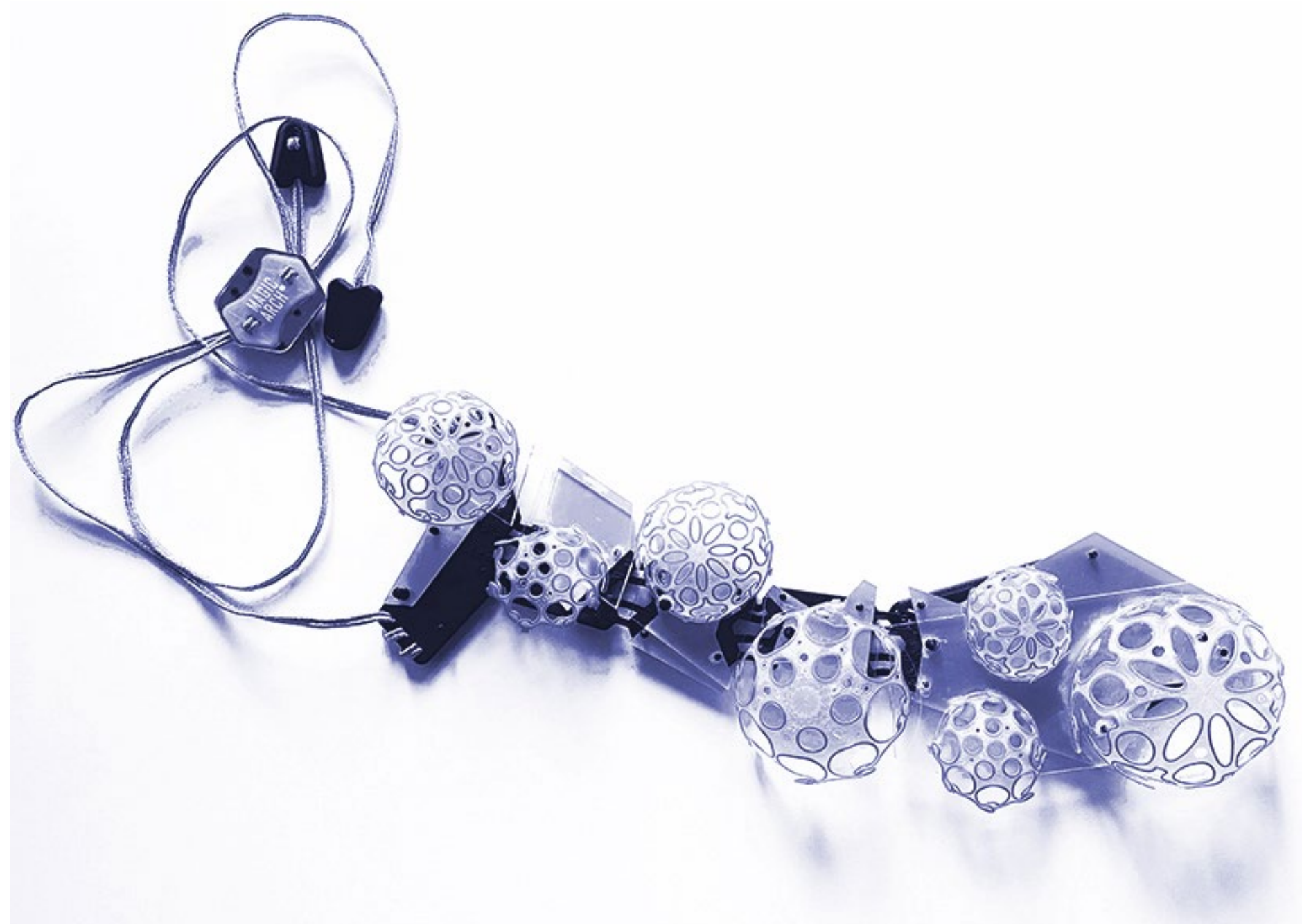

Fig. 7 Interactive Device about Breathing Domes, project in Afghanistan 2017.

portable devices show new readings of these cultural icons, approaching and showing their ecologies and raising questions of the architectural intelligentsia of a universal and pedagogical interest. From a sequence of audiovisuals of anthropized virtual landscapes, counterpositions are established that place these buildings in antagonistic scenarios relating to their scale or their historical moment, new readings are arranged from which to continue learning about the cultural value of each one of these works of architecture.

The twelve devices that become the object of study are based on the following twelve buildings:

- Interactive Device1. Corean Hanok, Joseon Dinasty, South Korea 57 a.C.

- Interactive Device 2. Majolikahaus design by Otto Wagner, Austria 1898

- InteractiveDevice 3. Alhambra. Granada 1237

- InteractiveDevice 4. DjeserDjeseru. Templo Funerario Hatshepsut. Senemut. Egypt 1500 a.C.

- InteractiveDevice 5. MASP Sau Paulo, Lina Bo Bardi, 1957

- InteractiveDevice 6. Fiat Factory Lingotto, Giacomo

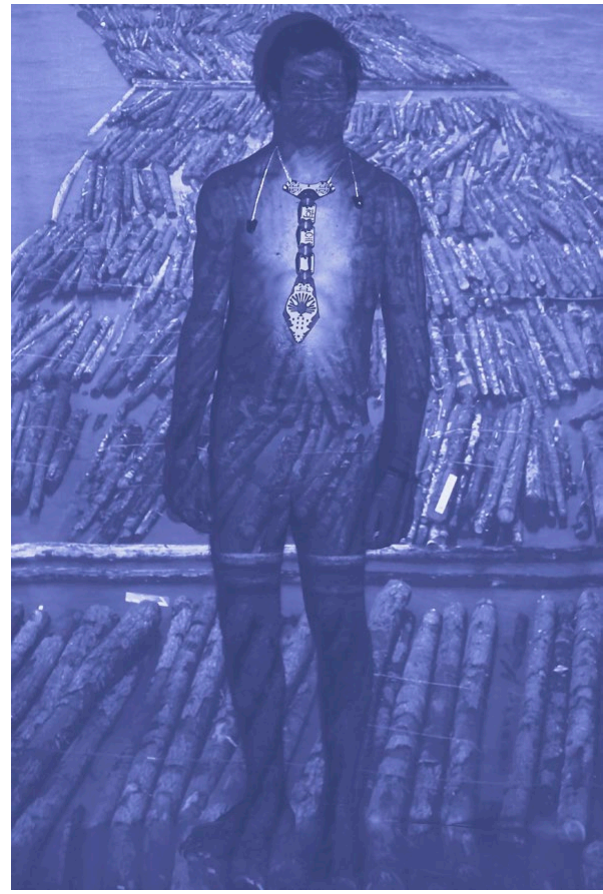

Fig. 8 Landscape of a timber yard carried by the sea projected onto the Korean Hanok device. 
Matte Trucco, Italy 1916

- InteractiveDevice 7.

Cenotafio of Newton, ÉtienneLouis Boullée, 1784

- InteractiveDevice 8.

Aguahoja, Neri xoman, 2018

- InteractiveDevice 9. Maxxi Museum, Zaha Hadid, Italia. 1999

- Interactive Device 10. Tatlin Tower. Vladimir Tatlin, Rusia, 1920

- Interactive Device 11. Nakagin Kisho Kurokaga, Japan, 1972

- Interactive Device 12.

Breathing Domes, Afghanistan. 2014

I am interested in reinterpretations, like those of Piranesi or Viesendrop, reinterpretations that other creators at different moments in history produced as a propositional methodology to elaborate and narrate the cultural and intellectual moments in which we find

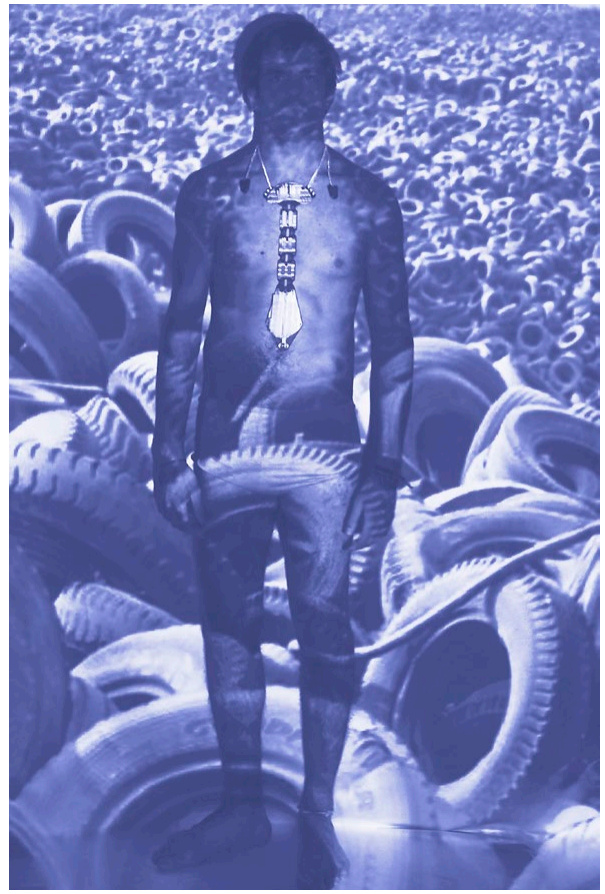

Fig. 9 Anthropised landscape of a tyre dump, projected on the Lingotto Factory site. ourselves. That is why in this project of 'Portable

Architectures' I am interested in revisiting these reinterpretations in order to talk about Ecology and about Common Ecologies. Above all, to be able to examine questions of Ecology updated and adapted to our times. I am trying to summarise this in few words, through the twelve points that I am developing in relation to the twelve devices. Thus, in each of the following sections I narrate a minimal story of this architecture building and which constructs these targets of common ecologies and which are no more than the summary of another, more extensive investigation.

The detail of these twelve Eco-reflections would be listed as follows:

- Eco-reflection Adaptive Ecologies

- Eco-reflection Deanthropised Landscapes

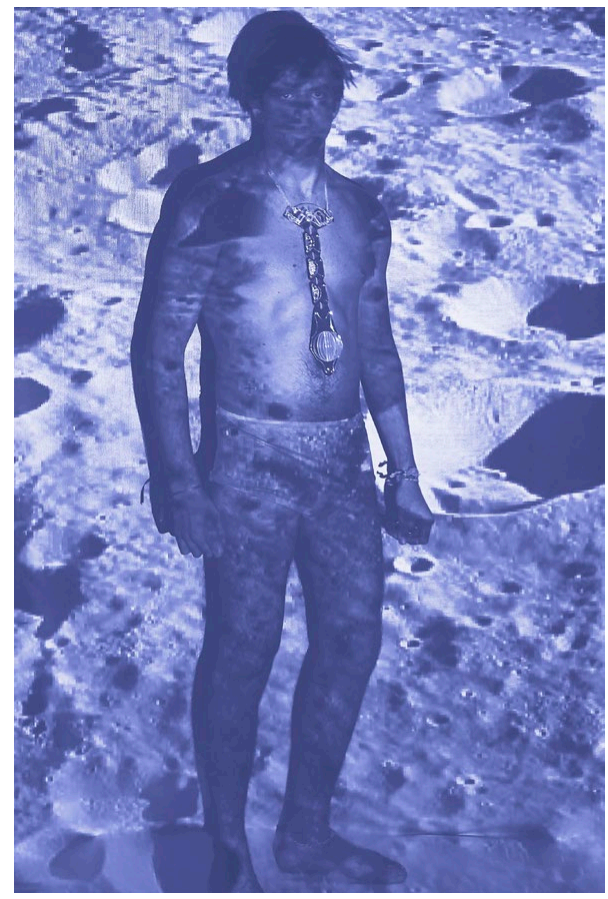

Fig. 10 Lunar landscape projected on the device of the Newton Cenotaph by Étienne-Louis Boullée
- Eco-reflection Ecosophy

- Eco-reflection Biopolitics and its biomediated contradictions

- Eco-reflection Cultural Mapping Device

- Eco-reflection on the obsolescence of $612.000 \mathrm{~m} 3$ of rubber

- Eco-reflection Acceleration of techno-science

- Eco-reflection The interspecies

- Eco-reflection on Bio-

Parametricism

- Eco-reflection Evolutionary Geometries and Multinaturities

- Eco-reflection Dancing among cyborgs and other metabolisms

- Eco-Reflection Breathing with Biodesign

TWELVE ECOREFLECTIONS

\section{Eco-reflection Adaptive Ecologies}

This reflection focuses on the static nature of the Korean Hanok 57 BCE. The

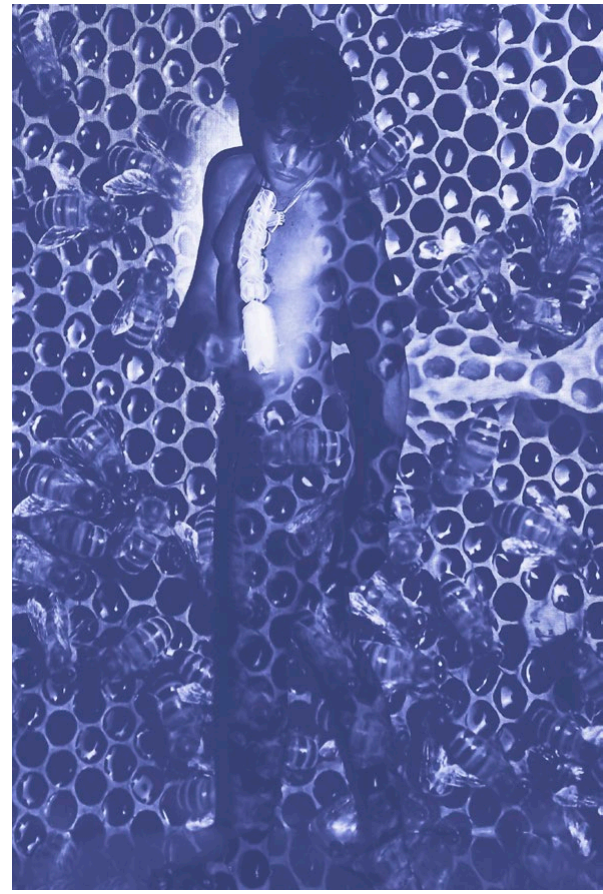

Fig. 11 Hive landscape projected onto Neri Oxman's Aguahoja device. 


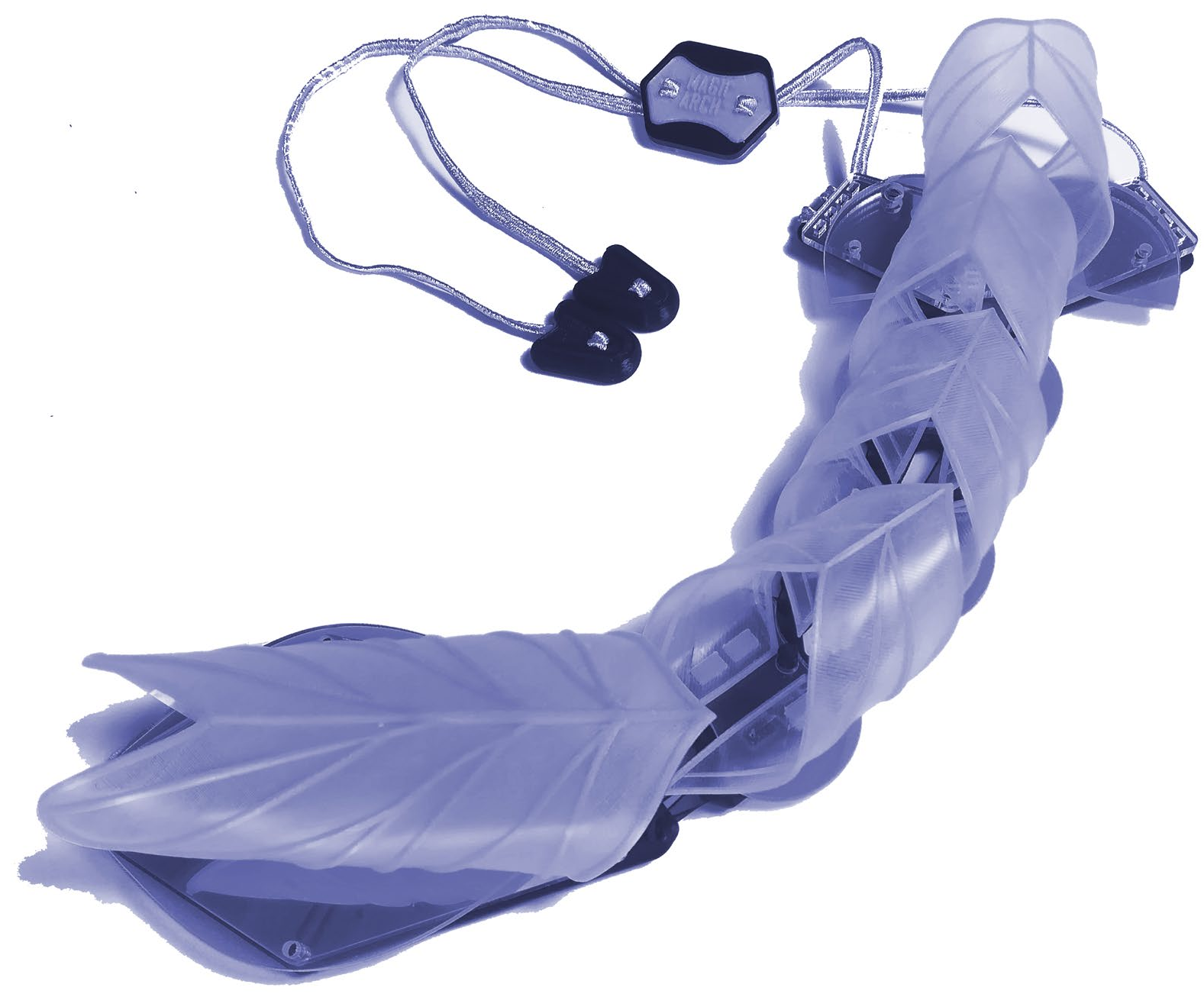

Fig. 12 Interactive Device about Aguahoja at MIT designed by Neri Oxman in 2017

Hanok is one of the most adaptive architectures in the history of architecture, for throughout our anthropised history, the Hanok endures and remains immovable. This pre-Darwinian adaptability is already evolutionary since it emerged in Korea in 57 BCE. It emerged even before the Asian nation itself existed. The concept of Hanok is a precursor to many pre-Darwinian theories and even a precursor to the understanding of cosmopolitics. Yet it has multiple readings such that it could be called common evolutionary ecology. Beyond the cosmopolitics and from the climatic point of view, the Hanok is articulated as a way of life close to the earth, an earth heated by the 'ondol' and where the politics of life can be constantly reorganised throughout the seasons, the politics of life are evolutionary and the Hanok enables them to be adaptive, thus adapting through the years since there is no fixed element in this heated ground, in this ondol. Their material and design make it possible for such climatic adaptation.

\section{Eco-reflection De- anthropised landscapes}

This paragraph reflects upon the common ecology that can be interpreted from Otto Wagner's Majolikahaus, which was built in Austria in 1898. Wagner aimed to introduce de- anthropised landscapes into the Majolikahaus, a building he designed to be quite severe. It established one of the iconic triggers of the Viennese secession and forms the centre of the ensemble of three apartment buildings that make up a unit. On its façade, the Majolikahaus has bunches of roses that bloom on its surface and among which wild lions run. It is this scene of a highly chromatic, de-anthropised landscape that the creator of the project chose to incorporate in view of the plainness of the construction.

\section{Eco-reflection Ecosophy}

If we establish a reading of the 'eco-sophical' stream and 
pay attention to the theatrical effects of the Alhambra, we can find that its gardens and hydrology set up a highly ecological and pedagogical network. The Alhambra, located in the Spanish city of Granada, has remained climatically habitable, becoming a focus of habitable design wisdom, or climate-smart design, thus insightfully and atmospherically adapted to the planet. This eco-sophy is evident in each of its architectural elements, in each of its fountains, vaults and above all in its gardens, but also in the birds and insects that inhabit it and in the constant sound of water, whatever the time of year.

\section{Biopolitical eco-reflection and its biomediated contradictions}

In terms of the modes of dying described by Rosi Braidotti, the Funerary Temple of Hatshepsut of Senemut, completed in Egypt in 1500 BCE, displays an extension of the social contradictions and conflicts of our anthropised world. The temple known as DjeserDjeseru may become a bio-power device of the once biomediating and highly eroticized pharaoh Hatshepsut. The posthuman is not an enemy of the human, but an extension of its bio-mediated contradictions for, according to Braidotti, 'the control of bodies has changed from the advent of the cyborg to renewed forms of vulnerability'. This funerary architecture unfolds new conversations of current necro-politics.

\section{Eco-reflection Cultural mapping device}

Cultural identities, and the production of Museu de Arte de Sao Paulo MASP as an activating device, are linked to issues of anti-colonialist and colonialist discourse, in what Haraway calls an antagonistic dualism. The architect Lina Bo Bardi completed the Museu de Arte de Sao Paulo MASP in 1957 , a name that is also the fruit of the cultural consensus it symbolizes. These questions of antagonistic dualism that construct the anti-colonialist contradiction, are developed in an advanced time frame during the decade that the Italian-Brazilian architect spent negotiating and building MASP. This modern landmark contrasts the language of domination with the new cultural cartography she draws under its flying beams. The multiple situations that have taken place under these beams refer to this.

\section{Eco-reflection on the obsolescence of $612,000 \mathrm{~m} 3$ of rubber}

In the inter-war period around 1931 , one of the car models produced in the $153,000 \mathrm{~m}^{2}$ Lingotto factory was the Fiat 515. Giacomo Matte Trucco completed the Fiat Lingotto factory in Italy in 1916. During one year at least 300 cars of the Fiat 515 car model were built in the factory and left the factory with five wheels, four service wheels and one spare wheel. Each of these wheels was tested with the cars on the extremely steep curves of the circuit, a test for their tyre casing. These 1500 tyres, after rolling on the streets of Turin or Milan, would end their useful life and occupy a volume of $11,250 \mathrm{~m} 3$, which in less than six years would be equivalent to filling the volume of the Lingotto building full of rubber tyres. This would be equivalent to the thickness of some Anthropocene layer filling a volume of $612,000 \mathrm{~m} 3$ of rubber tyres.

\section{Eco-reflection Acceleration of technoscience}

The armillary sphere with which paid homage to Newton in his design for a Cenotaph to Newton became the standard-bearer of French revolutionary architecture in 1784. These fantastic designs suggested new techno-scientific horizons of Architecture, which highlighted the accelerating powers of technology. Boullée established his planetary approach through the a representation of the law of universal gravitation; what techno-scientific horizons would the architect Boullée be able to incorporate into the Architecture of our days, architecture that is immersed in the current technosphere? How would Boullée interpret techno-objects such as the iphone, the roomba or the nanoscience?

\section{Eco-reflection The interspecies}

\section{From a posthuman}

perspective, Neri Oxman makes her building Aguahoja grow; after multiple investigations she recently presented it and blurs the limits of its permanence. The architect links to a new way of decentralizing the axis of dominating relevance of the human species towards a broader view of organic planetary life. With her proposals for changing buildings according to the 
needs of insects, she poses a series of dilemmas of interspecies issues. This work methodology establishes more egalitarian dynamics with the rest of the species, sharing the cycle of life and entering into the politics of being that bring us closer to the non-human.

\section{Eco-reflection Bio- \\ Parametricism}

In the words of Zaha Hadid when explaining her 1999 MaxxiMuseum building, she tells how 'the chaotic fluidity of modern life' converges in this museum that also produces art. The extreme fluidity of parametricism could be an extension of biodesign, in the ten years it took to erect this masterpiece, the common issues of parametricism that link questions of selforganization of Architecture emerge.

\section{Eco-reflection Evolutionary} geometries and multi-natures

Irregular architecture is moving away from controlled forms towards new, unprecedented transitions that embrace multinatures. The Tatlin Tower, which was the Monument to the 3rd International in Russia was created by these evolving geometries, which are eccentrically positioned to establish transitions. Transitions in geometries that don't have beginning or end, and that give rise to new architectural species and new avantgardes. In 1920, the architect Vladimir Tatlin designed an inclined spiral within a twisted structure. If we draw from the emptiness of the ground plan of this irregular spiral of the
Tatlin Tower, would we be able to draw the course of the water that floods a seashell?

\section{Eco-reflection Dancing among cyborgs and other metabolisms}

The constant threat of Nakagin's demolition is a reality, and it is beyond the environmental ecology due to the evidences of its weakness to incorporate social ecology. In the Japan of 1972 Kisho Kurokaga built this metabolic architecture, which once metabolised but now must actualize a constant organic change, just like the organic change that the Nexus Rachael needs in order to remain organically and emotionally autonomous. However, Nagakin, like Rachael, needs to continue in cybernetic bondage, as his technology does not stand the test of time and dilutes his metabolism.

\section{Eco-reflection Breathing with Biodesign}

Knowledge of planetary bioevolution will lead us to the adaptation of the anthropised landscape. This eco-reflection identifies biodesign as an opportunity for self-sufficiency in architecture, so through biodesign in Magicarch's 'Breathing Domes' project, breathing domes were designed for a cultural centre in Afghanistan. These breathing domes oxygenate the vaulted spaces with a passive climatic design, without the need to incorporate any further added energy. Breathing Domes, a project of vaults that breathe and regulate humidity, challenges the scarcity of energy resources with an eye towards energy self-sufficiency, advocating a new climate design discourse that embraces the experimental horizons of biodesign.

\section{ON THE RELEVANCE OF TO BE WEARABLE IN ORDER TO ACTIVATE REINTERPRETATION}

On the theme of common ecologies, which raise new questions of these twelve transportable, wearable devices have been designed that stage twelve buildings from the History of Architecture, twelve buildings that constantly reoccur among my references. The portability and performativity of this micro-architecture is the key to the proposal of this article, an article of ecological pedagogy and architectural cultural transfer. For we currently live connected in a technosphere with an infinity of virtual information that blurs our access to knowledge, leading us to an increasingly virtual and less empirically considered social behavior. The pandemic and its virtual synonyms have further exacerbated the deficiencies produced by the diminished presence of the physical. Thus, each device, and the body that stages them in the photo-reportage, re-enacts new versions that make transparent questions of political ecology, hence becoming a new material interface of cultural transference, a physical device, a pedagogical sculpture, a tangible tie, a wearable building, you can activate from your own experience. 


\section{BIBLIOGRAPHY}

BRAIDOTTI, Rosi. Lo posthumano.

Ediciones Gedisa, 2015

BRAIDOTTI, Rosi. HLAVAJOVA,

Maria. Posthuman Glossary (Theory in the New Humanities). Editorial

Bloomsbury 3PL. 2018

BRAUNGART Michael /

MCDONOUGH William, Cradle to cradle. Redesigning the way we do things. Publisher: McGraw-Hill, Madrid, 2005

DARWIN, Charles, Theory of Evolution. Ediciones Península. Barcelona. 1975

HARAWAY, D. Staying with the Trouble, making kin in the Chthulucene. Translated by Helen Torres. Bilbao: Consonni, 2019

STENGERS, I. Introductory notes on an ecology of practices. Cultural Studies Review, vol. 11, no. 1, 2005. 


\section{Coccapani \\ Planetary Garden}

\section{A transgenerational, common, possible learning space}

spazio educativo comune

natura e apprendimento

giardino planetario educativo ppazio di apprendimento possibile architettura dell'apprendimento common educational space nature and learning educational planetary garden possible learning space learning architecture

\section{Sigillo, Bruna ${ }^{1}$}

${ }^{1}$ DiARC Department of Architecture / University of Naples Federico II, Naples, Italy https://orcid.org/0000-0002-8140-8950

bruna.sigillo@unina.it 


\section{Giardino}

\section{Planetario Coccapani}

Uno spazio di apprendimento possibile, transgenerazionale, comune

Gilles Clément ci ha insegnato a guardare il giardino come un pianeta. Insetti, uccelli, piante, alberi, ossigeno, acqua convivono sinergicamente in un giardino. E chi si occupa del giardino? I Giardinieri planetari. Questa metafora diventa il cuore del progetto vincitore del concorso internazionale Next Landmark 2020 indetto dalla Fondazione Iris Group, che si traduce in un intervento leggero nel rigoroso rispetto della struttura esistente aggiungendo valore attraverso l'inserimento di pochi elementi. II bordo urbano, all'ingresso, si arricchisce di una nuova facciata verde; il parterre è concepito come un parco giochi. Dall'accesso, il nuovo passo carrabile accoglie un inserto colorato (per agevolare anche le disabilità) che guida i percorsi interni; l'area verde del giardino si amplia. È definito da un grande anello interattivo. Le linee ideali che collegano gli alberi proteggono le aree e suggeriscono i loro usi con lievi cambiamenti di superfici e materiali, sempre naturali. Le attrezzature vengono inserite tra piccoli arbusti, a misura di bambino, e le chiome degli alberi diventano tetti per le aule esterne. Come può il giardino di una scuola dell'infanzia diventare un bellissimo spazio comune in cui vivere tutti? II progetto cerca di rispondere alle possibili esigenze degli utenti, aprendosi anche alla città: per i genitori che aspettano seduti a chiacchierare tra piante e fiori. Un posto funzionale e gradevole per gli insegnanti che vi lavorano; per il vicinato di tutte le età; per i bambini, radici della società, per formarli a diventare i giardinieri planetari del futuro.
Gilles Clément taught us to look at the garden like a planet. Insects, birds, plants, trees, oxygen and water co-exist in a garden in synergy. And who takes care of the garden? Planetary gardeners. This metaphor becomes the heart of the winning project of the Next Landmark 2020 international contest announced by the Iris Group Foundation, which translates into a very light intervention that respects the existing structure, but it adds value through the insertion of a few elements: the urban edge, at the entrance, is enhanced with a new green façade; the parterre is designed as a playground. From the access, the new driveway holds a coloured insert (also to facilitate disabilities) that acts as a guide to the internal paths; the "green" area expands. It is defined by a large interactive ring. The ideal lines that connect the trees protect the areas and suggest their uses with slight changes of surfaces and materials, always natural. The equipment is inserted between small shrubs, child friendly, and the canopies become roofs for the classrooms. How can the garden of a kindergarten become a beautiful common space for everyone to live in? This project tries to respond to the possible needs of users, also opening up to the city: i.e., for parents who wait. It would be nice to sit and chat among plants and flowers. A good place for teachers; for the neighbourhood of all ages; for children, the roots of society, to train them to become the planetary gardeners of the future. 

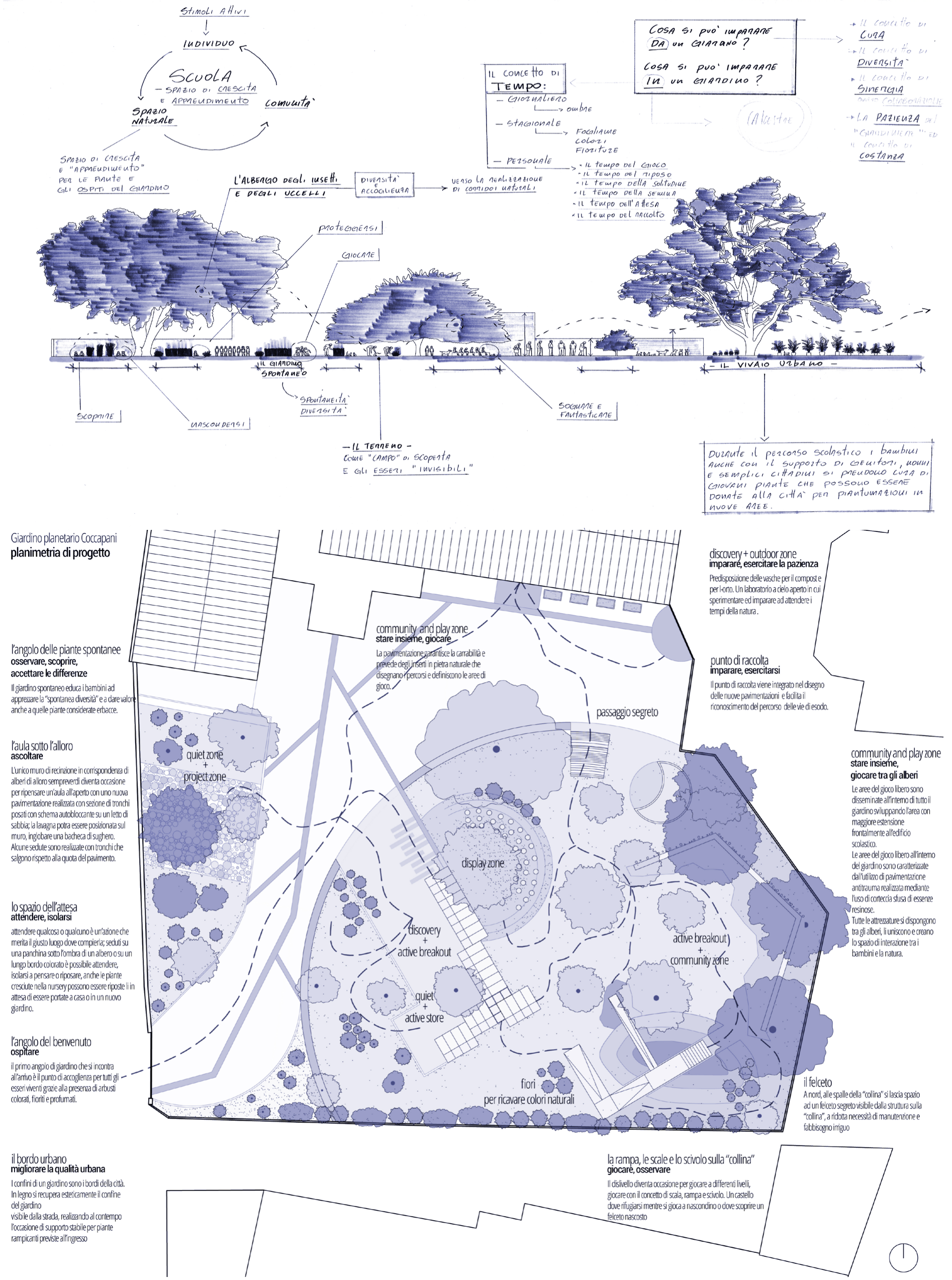

Fig. 1 - Philosophy of the project Coccapani Planetary Garden and Fig. 2 - Plan of the project Coccapani Planetary Garden. 
COCCAPANI

\section{PLANETARY GARDEN}

Tackling the theme of places destined for education in the planning field attests to the profound influence that architecture exercises on generations, because it concerns the community both in the private and public spheres. The role of school architecture in Italy is in fact currently at the centre of important debates that aim to open new frontiers onto a renewed way of living in school spaces, implementing the role of design through the multidisciplinary dialogue between pedagogy, sociology, and neuroscience.

The ninth edition of the Next Landmark international architecture and design competition, titled An Educational Garden in Fiorano Modenese, was dedicated to young architects and designers who graduated from 2010 onwards, and who were asked to submit a redevelopment project for outdoor areas of the Casa Coccapani nursery school in Fiorano Modenese (MO). The project was then carried out in collaboration with the Luigi Coccapani Foundation and the Municipality of Fiorano Modenese. The Next Landmark invitation offered a precious opportunity for international discussion on the role of the pedagogical garden, inviting people to propose design ideas for the Coccapani kindergarten ${ }^{1}$.

The external areas belonging to schools represent learning environments that are very often marginal or completely unused. In place of this, it would be very important to carry out pedagogical activities to the point of them becoming spaces for reconnection with nature, especially in urban settings. It is from a very broad idea of garden enhancement and from contextualized, careful and multidisciplinary research that Coccapani Planetary Garden ${ }^{2}$, the winning project, takes shape (Fig.1). The jury rewarded this project with first prize because the proposal comprehensively addressed the challenge balanced manner to preserve the peculiar features of the existing with a set of delicate interventions without missing the opportunity to provide a new identity to the Coccapani kindergarten outdoor spaces. The project narrative unfolds according to a sequence of frames, each featuring a pedagogical purpose and a spatial unity designed to explore nature, others and self. The project offers to the young members of the Coccapani community an open palimpsest on which, they and their educators, staff and families, can write their stories and grow together. Designed for making nature a driving force in the development of the child, the Planetary Garden is the proposal that best encompassed the competition's targets and that demonstrated its economic, social and environmental sustainability through accurate metrics.

The design of the space arises from the desire to trigger a process in which the school becomes a space for growth and learning. Three dimensions gravitate and interact around it: individual, collective, natural. Social, cultural, technological and economic aspects also come into play. The garden opens up to the community and supports care processes which, in a sustainable approach, not only increase the participatory value for the actors, but also decrease the related maintenance costs. In this way, the garden in itself and the educational garden becomes an opportunity to gather natural and human ecosystems: different species and different generations in a common and shared space (Fig.2).

The project also seeks to redefine a new idea of plant beauty by also include selfseeding plants, which reiterates and accompanies respect for diversity as a sustainable action. Can today's children become the future gardeners of the world of tomorrow? From this question emerges the hypothesis that the school can become an urban nursery, where young plants can be grown that can be used to plant new public spaces at low cost. Architecture supports this social and cultural process by generating suitable spatial environments through the use of materials of natural origin; permeable flooring, the recovery of rainwater, and expanding the green area that invites people to cross and discover. The shape of the space, the choice of materials, colours and new sensory experiences, are inspired by pedagogical and free play principles according to the Convention on the Rights of the Child. In this way, it is possible to imagine a place where children play and learn from nature and its little wild creatures, releasing 
a vital energy that crosses the school fence and makes a dialogue with the surroundings, with people, and with the architecture.

Planetary Garden is also a tribute and clear reference to Gilles Clément, the Master who taught us to look at the garden as a planet. Whether small or large, insects, birds, plants and trees co-inhabit a garden, and planetary gardeners take care of the garden. This metaphor becomes the heart of the project that translates into a very delicate intervention that does not distort the existing structure but enhances it through the inclusion of a few elements:

- the urban border at the entrance, which is embellished with a new façade made of wooden slats designed to accommodate the green of the climbing plants. The school enclosure protects but addresses the context to invite people to take care of the border wall between the school and the street; it also shows that something has changed.

- the parterre is designed as a single large playground in which the asphalt is replaced with permeable flooring. From the entrance, the driveway becomes an opportunity for a coloured concrete insert (to facilitate visual and motor disabilities) that directs the internal paths towards the entrance to the school by way of different material and chromatic consistency.

- the green area expands and is defined by a large, inhabited ring, achievable in coloured concrete, which embraces the space, becoming

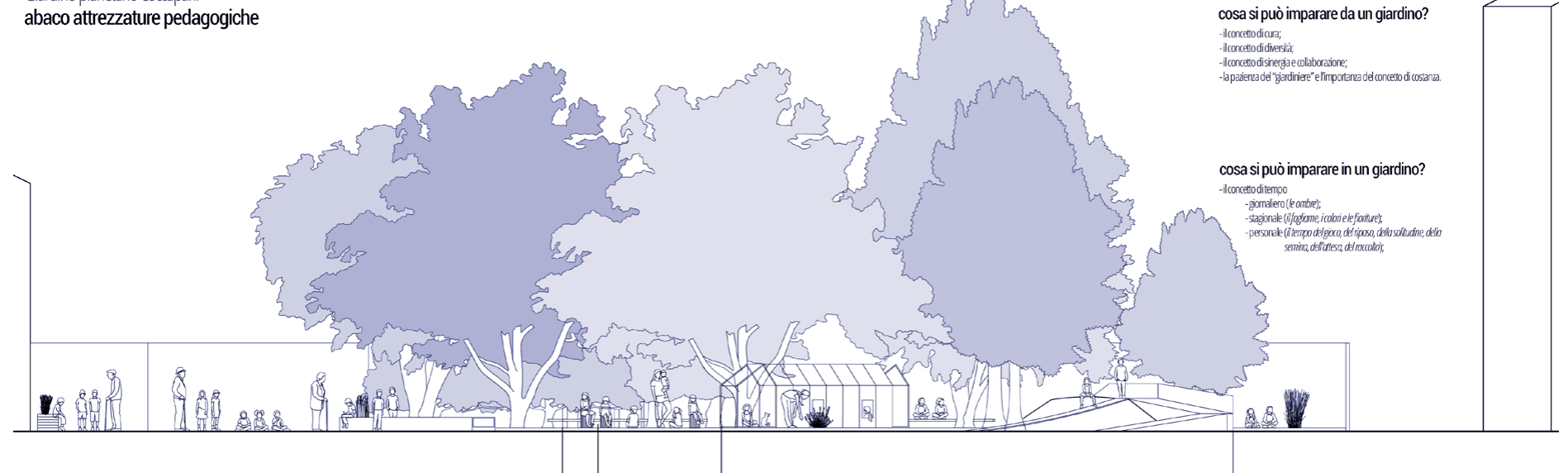

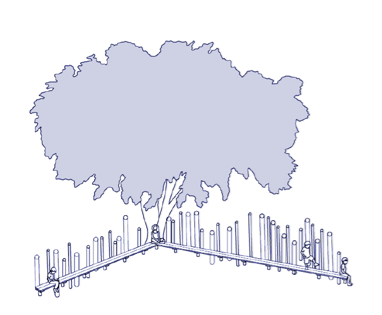

a conoscenzadel mondo Una grande U abbraccia gli a blberi allatlema di 35 mdaterra cosidad diventare una pance peri momenticonviäli, doves puòr rccontare un stoiza, far merenddal'/2perto. Ma anche superficies un aui bambinin possono oesercitare "equilibrio, aiutandosi con i ronchi positionat per agerolarei passi.

Secondo le Indiczioni Nazionali, il bambino, sperimentando questo campo di esperienza, nesce a colloca correttamentenello spazio se

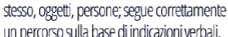
un percosos sulla based dindicazoniviverbal.
siorientane tempo delaviza quodidana Si o oienta ne tempo della vita quodidiana
Rferisce eentid del passoto recente Riferisce eventi del passato recente
dimostando conssperolema della ll lor dimostrando consaperoletza della l I
collocazionetemporale; formula collocazionetemporale, formula correttamententerfessionieconsis alfutroimmeciave prossino

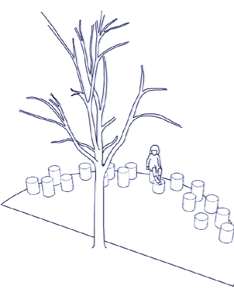

idiscorsie le parole

Una superficiecomposta da morbide contecce, sedute ricuate da tronchie lombradi un grand guardare piccoli spettacoli, celebazioni o micro eventi.

Secondo e Indicazoni inaionali, inquesto campo diesperenzai bambinosiluppa ficucice motivazione nellesprimere comunicare agi a le proprieemojoni, le propriedomande, i propi agionamentie i propri pensien attraverso linguagio verbale.
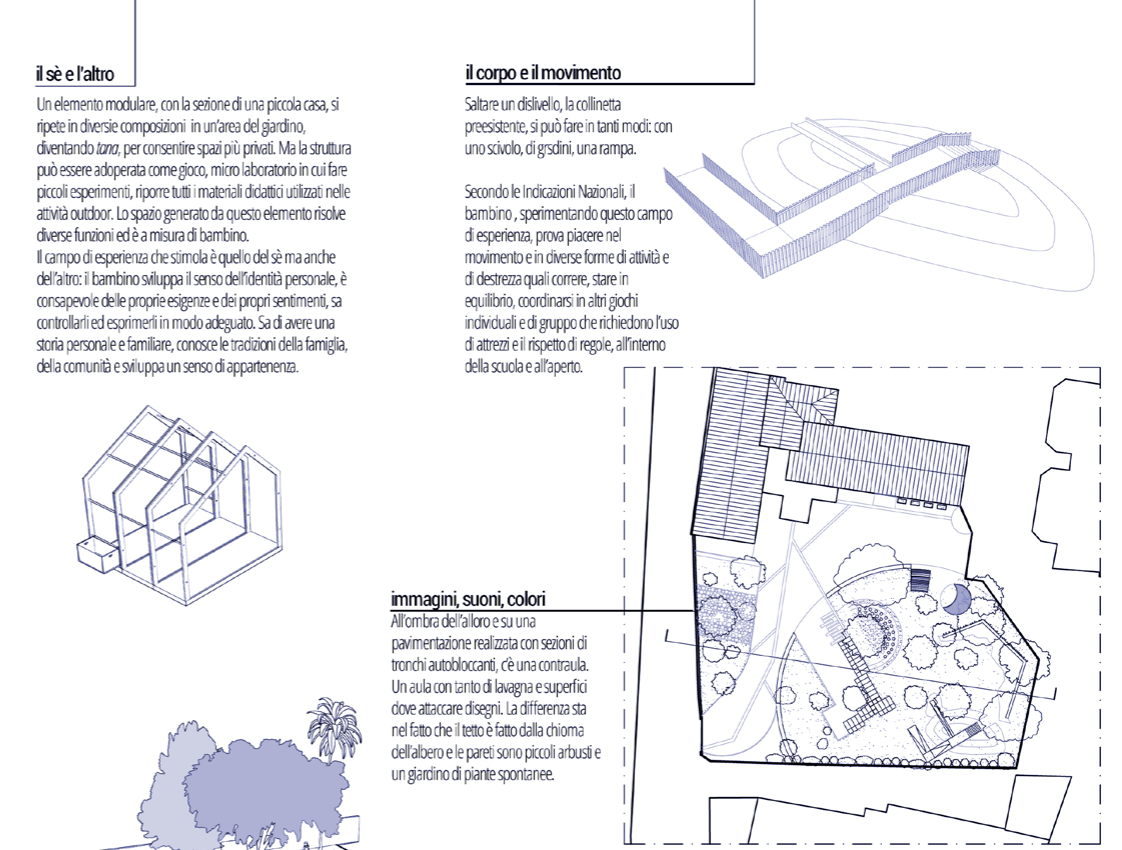

(1)

Fig. 3 - Abacus of pedagogical elements of the project Coccapani Planetary Garden. 
seat, threshold - according to different heights - and inviting people to cross and discover. The ideal lines that unite the trees define the areas for games, and suggest their uses by slight changes of surfaces and materials, always natural. Equipment is inserted between small shrubs, suitable for children, and the foliage acts as a roof for external classrooms and the various pedagogical areas (Fig.3).

How can a kindergarten garden become a beautiful common space for everyone to live in?

The idea that guides the project tries to respond to the possible needs of users, but also opening up to the city: for parents and grandparents who accompany, wait for, and participate in their children's activities. Everything is also designed for adults who accompany the children so that they can pleasantly hold back and admire the beauty of the flowers, sit and chat among plants and trees. For teachers the project facilitates the implementation of teaching, thanks to the introduction of equipment designed to respond to the National Guidelines of the five Fields of Experience. Logs, bark or gravel floors are transformed into chairs and carpets, and they can read fairy tales outdoors, for example. Small shows and performances can take place in an arena under the large plane tree. The floor becomes the book of shadows, and hour after hour they move and draw trees in motion. For all ages of the neighbourhood, they can enjoy the new space and contribute to sharing the garden when ready

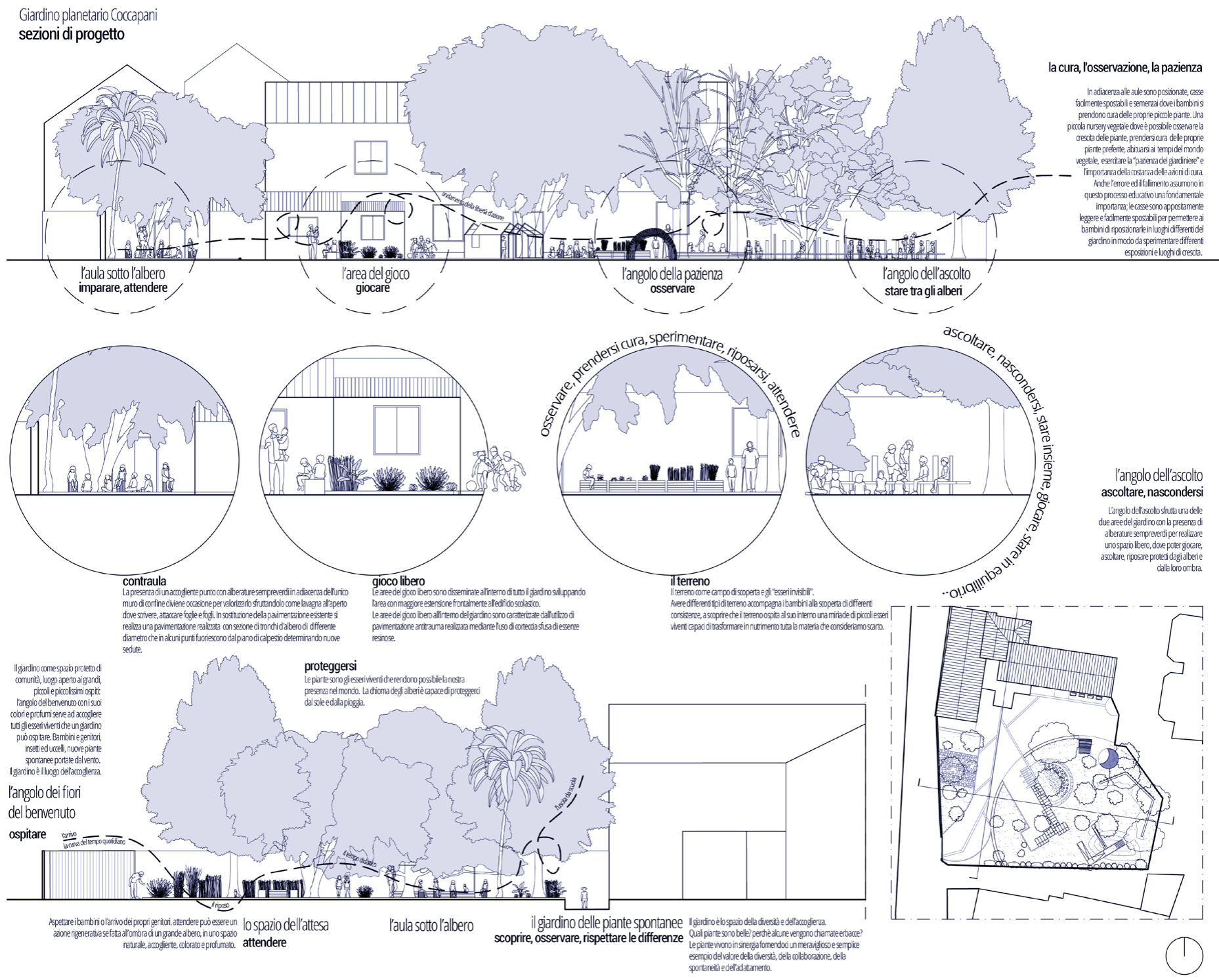

Fig. 4 - Sections of the project Coccapani Planetary Garden. 

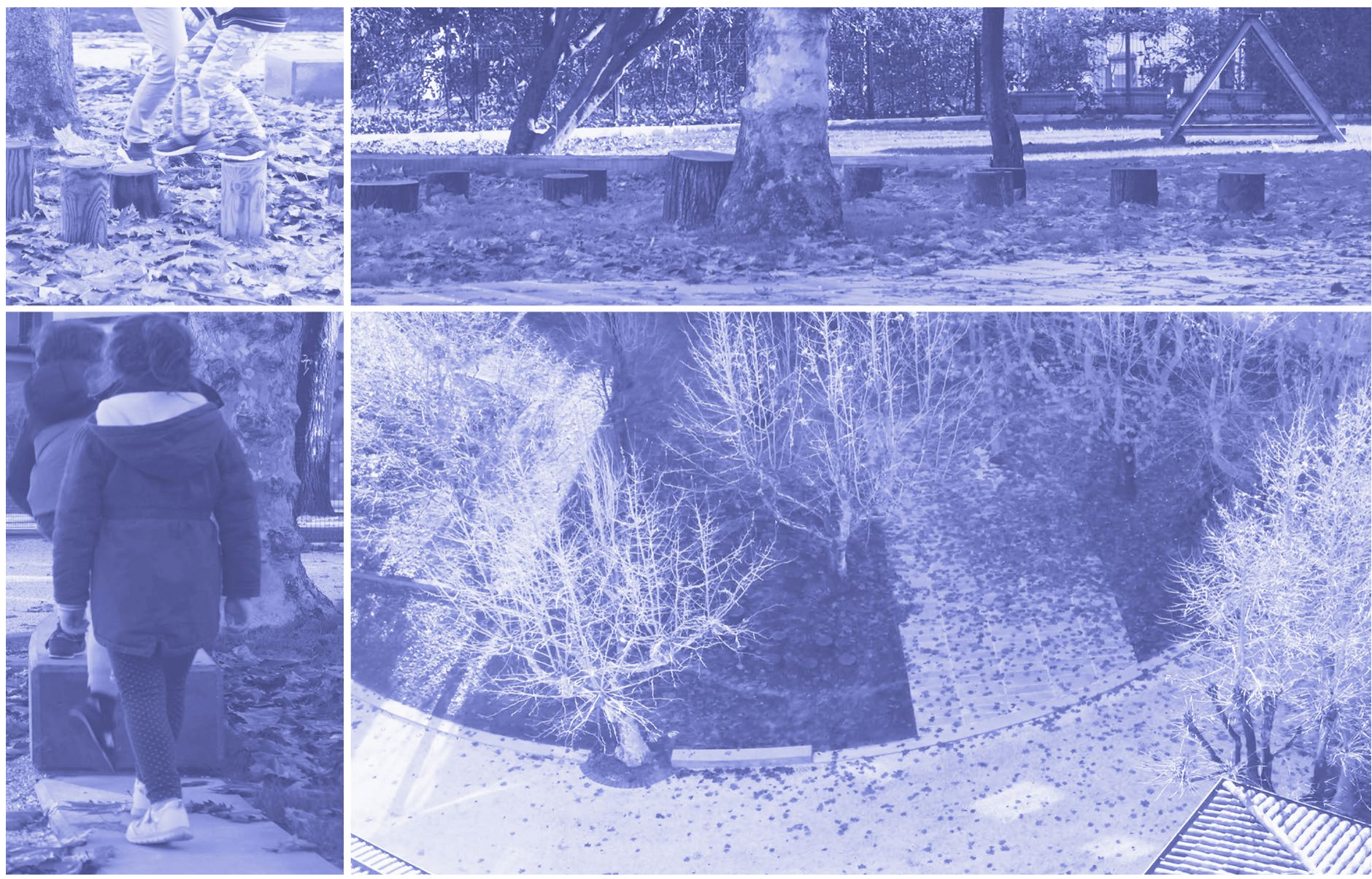

Fig. 5 - Realized Coccapani Planetary Garden project. Pictures of Iris Ceramica Group. to be an urban nursery, where to exchange plants, donate seeds and knowledge during opening occasions to the city (Fig.4).

But first of all, the garden is for children, the roots of society, to whom a special space must be reserved where every day they can be protagonists of new adventures and train themselves to become, in the broadest and deepest sense of the term, the planetary gardeners of the future.

\section{From an early age they} can grow in harmony with all living creatures, guardians of principles of respect and sharing.

Can all this happen in a garden? Probably yes, if it is a planetary garden.
It is important to look at the living dimension of these spaces, and not only at the interiors we are familiar with: even the external spaces must be a concrete part of the architecture of the school. Consequently, it must be equipped and used in order to become a succession of areas in which to experiment, learn and grow together, and that above all does not end in the miniaturization of furniture and objects according to age. The future of school architecture must also enhance the role of schools as spaces open to the city and communities, rediscovering their multiple possible uses and potentials, as they are among the only public buildings currently left in the neighbourhood (Fig.5).

The project was realized and thanks to the feedback from the teachers and management, it was possible to understand how the space has come to be used. The garden is currently the space of the classroom for educational and recreational activities outside, it supports the functions made necessary by the Pandemic, and lends itself to welcoming the principles of sharing expressed in the design idea with which it was conceived.

The theme of the common space, designed and built with, and in nature, translates the projects objective of educating children to beauty, increasing the qualitative aspects of schools, and accustoming children to the processes of care for the common space so that they can become the citizens of tomorrow. 


\section{NOTES}

${ }^{1}$ Except from the motivations of the jury https://www.floornature.com/ nextlandmark/2020edition/

${ }^{2}$ Planetary Garden is the title of the winning project of the Next Landmark 2020 competition designed by architect Bruna Sigillo. The name is inspired by the renowned landscape architect Gilles Clément, a prestigious cultural reference. http://www. gillesclement.com/cat-jardinplanetairetit-Le-Jardin-Planetaire.

\section{BIBLIOGRAPHY}

FAIFERRI, Massimo, S. BARTOCCI, F. PUSCEDDU. Innovative Learning Spaces. List, Trento, 2018. ISBN 8899854408

HUGHES, Hilary, J. FRANZ, J. WILLIS. School spaces for Student Wellbeing and Learning. Springer Nature, Singapore, 2019. ISBN 9789811360923

INGOLD, Tim. Ecologia della cultura. Meltemi, Milano, 2001. ISBN 9788869162091

MONDAINI, Gianluigi. Spazio e formazione. Edilstampa, Roma, 2018. ISBN 8878641324

PALOMA, Filippo Gomez. Embodiment\& School. Pensa Multimedia, Lecce, 2020. ISBN 9788867607648

REMOTTI, Francesco. Contro l'identità. Laterza, Roma, 1996. ISBN 8842048887

WEYLAND, Beate, U. STADLERALTMANN, A. GALLETTI, K. PREY. Scuole in movimento. Progettare insieme tra pedagogia, architettura e design. Franco Angeli, Milano, 2019. ISBN 9788891792426

WEYLAND, Beate, K. PREY.

Ridisegnare la scuola tra didattica archietttura e design. Guerini, Milano, 2020. ISBN 9788881074419 



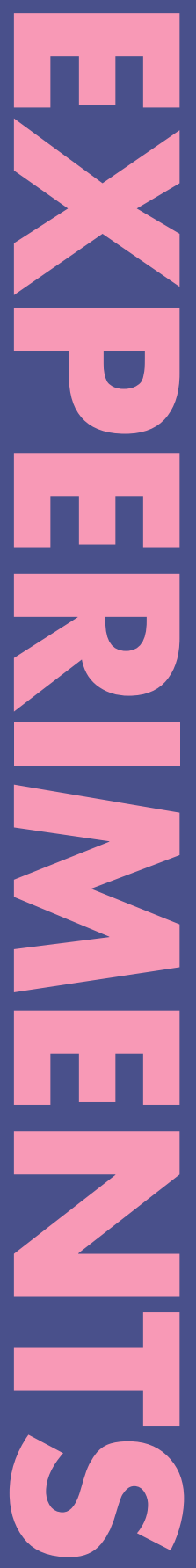




\section{Conventional \\ Complacency in British Housing}

\section{The Explanations Behind Britain's Community Self-Build Absence in Comparison to the Netherlands}

\section{self-build community unconventional political architecture}

\section{Davies, Emma ${ }^{1}$}

${ }^{1}$ Lincoln School of Architecture and the Built Environment / University of Lincoln, England https://orcid.org/0000-0001-9527-1599

emmadaviesr@gmail.com 
Can self-build projects truly become the new "common" within British housing? Self-build schemes can be vital in understanding issues within architecture. However, in 21st century Britain, housing has become an economic system rather than fulfilling dwellings for users, raising concerns about power distribution. Architecture shapes society's culture and Britain has revealed architectural limits with conventional clichés, disregarding the political, social and environmental impacts. Standard, identical building blocks can often create alienation within architecture between the building and the dweller. A reverse of the architect's role to a facilitator could create contextually relevant dwellings, as this would cater for individual sensitivity. This is active within self-build methods, which seems simple as a concept. However, self-build is not the standardised way of living compared to Britain's neighbouring countries, such as the Netherlands. This paper aimed to discover reasons for the absence of self-build in Britain in comparison to the Netherlands, as this method can be an agency to solving political, social and environmental issues. This paper concludes this research question by interviewing British and Dutch experts within the field of self-build. This shone a light on the absence of self-build in Britain against the existing literature data, showing the benefits and drawbacks when implementing these schemes in Britain. This paper revealed the notion of value within British housing. 
WHAT IS SELF=BUILD?

According to the National Custom and Self-Build Association (NaCSBA) and the self-build housing sector, community self-build methods are potential solutions to prevailing social, environmental, and political problems within housing (NACSBA, 2021). Morton's definition of self-build is where an individual or a community have serious input into the design and construction of a home (Morton, 2013, 8). Not to be thrown off by the luxurious schemes seen on Grand Designs, Barlow describes self-build methods as "simple and collaborative", where the participation of the occupants is largely encouraged in the physical construction process or the construction arrangements of their home (Barlow et al, 2001). Hopkins describes this as an "umbrella term" for many schemes: community self-build, co-housing and housing cooperatives (Hopkins, 2021). Wainwright states this has been proven to be admired globally (Wainwright, 2016), but the question is whether these schemes are as "simple" as they are advertised?

Self-build is important because providing people with alternative dwellings to standardised blocks can offer flexibility for all societal groups through its community enhancing advantages (Morton, 2013, 4-5). Morton, Head of House Planning in Britain, believes our housing system is "broken", but communities could form strong connections with self-built dwellings (Ibid). By changing the role of the architect, this realignment of the relationship between residents and the houses they occupy contributes to responsive housing (Holland, 2017, 104). Bossuyt suggests this method highlights the social issues prevailing from the housing crisis: ownership, affordability and sustainability (Bossuyt et al., 2018, 525). Self-build stems from the use of locally sourced materials. This is not only environmentally sustainable, but it also tends to be "cheap to build", explained by a strawbased architectural firm called Straw Works (Smith, 2021).

Despite the "simple" and appealing description of selfbuild from article writers, it has not been significantly implemented in Britain since its conception in comparison to other neighbouring countries. Community self-build is high up on Britons' aspirations list, though Ipsos MORI says that it has failed to develop into a conventional housing solution in Britain (Ipsos MORI, 2014). Morton shows that the percentage of self-build in the UK had only risen to 10 per cent in 2013, whilst Europe's percentage is now over 50 per cent (Morton, 2013, 8). Fig. 1 shows the UK as the lowest achieving self-build territory in 2011 (HM Government, 2011).

Faced with bureaucratic hurdles and unavailability of land, many self-build schemes in Britain are left abandoned (Collinson, 2011).

This paper explores why community self-build schemes are currently disregarded in Britain. The literature research, based on anarchist literature, official bodies, online newspapers, authors of selfbuild articles and existing selfbuild schemes, outlines the advantages and constraints that make self-build less relevant within our society today. Historical literature informed the contextual and political relevance of the self-build method. The second section of this paper will analyse primary data against secondary data, exploring social relations and constraints within the public and the investors. This will illuminate gaps within existing knowledge and experiences to reach conclusions on the lack of self-build. By researching

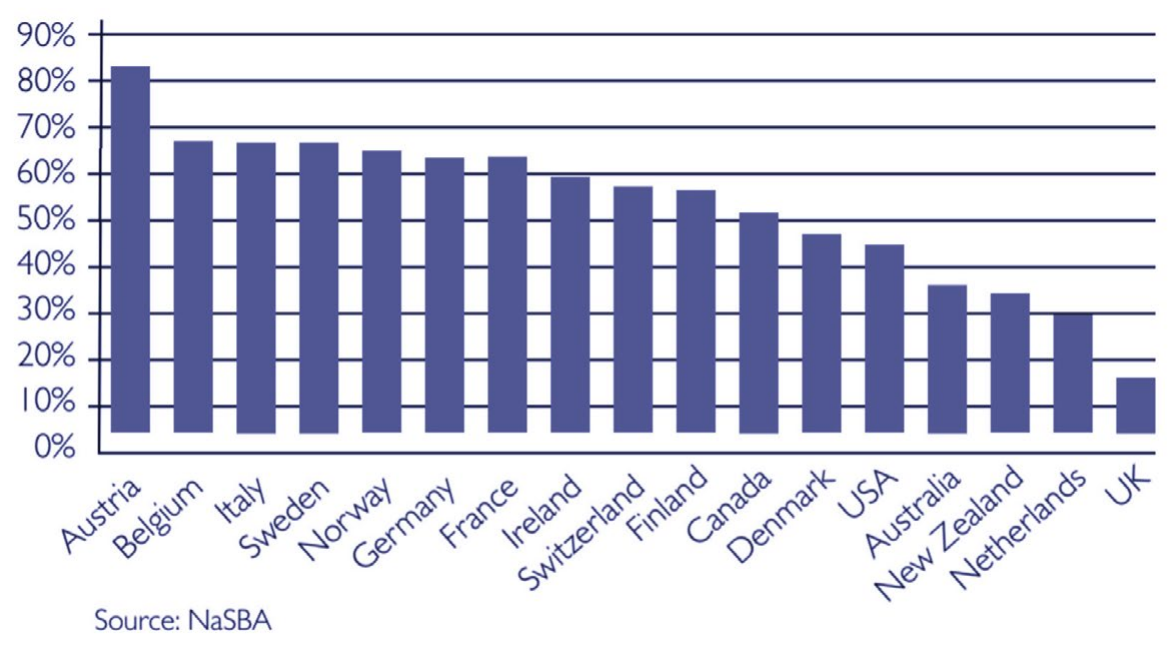

Fig. 1- Illustration taken from HM Government report 'Laying the Foundations: A Housing Strategy for England' by NaCSBA 


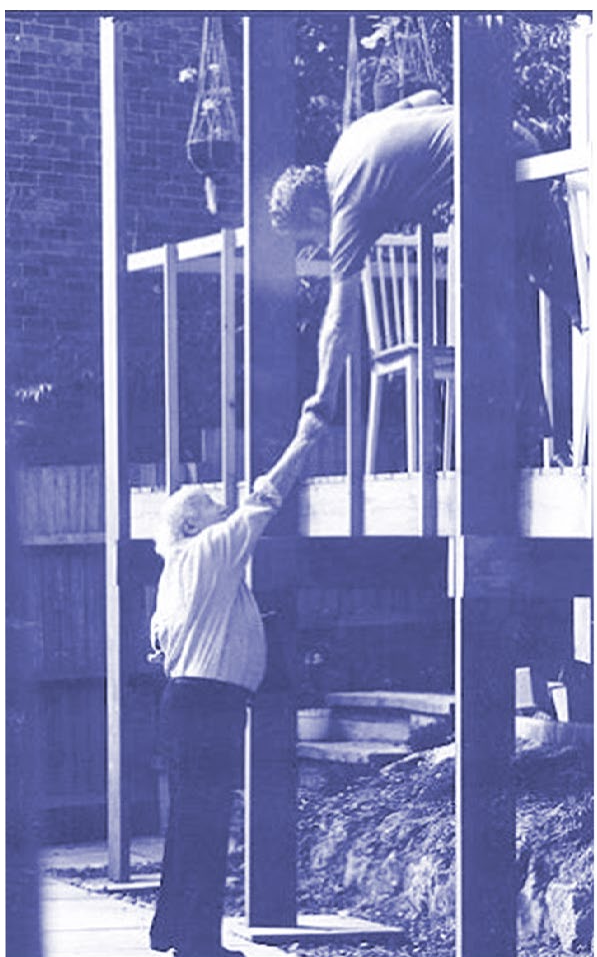

Fig. 2- Segal being the 'facilitator' on site of Walter's Way. Photography by Phil Sayer,

1987

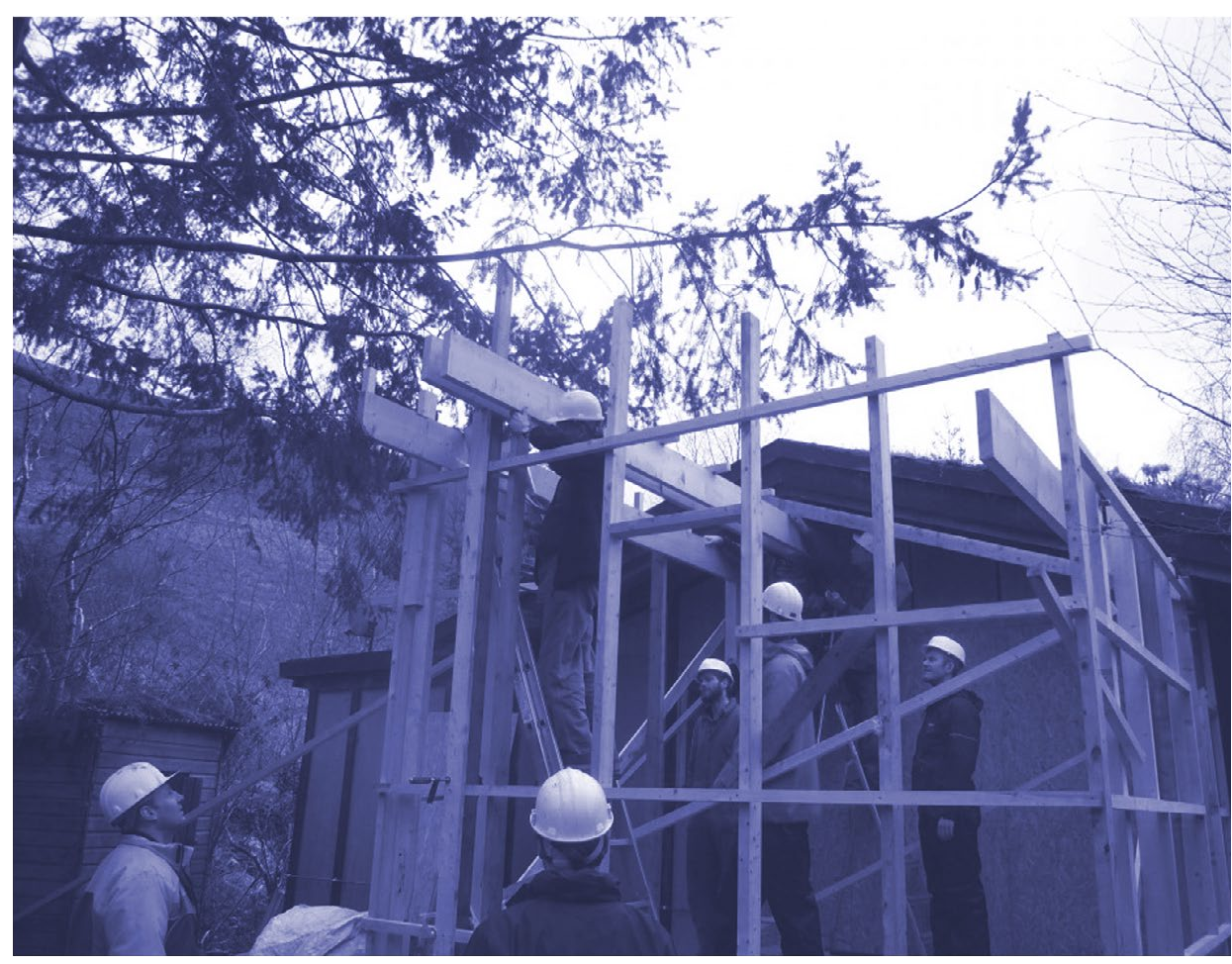

Fig. 3. Contemporary example of the Segal construction method in use. Photography by Cay Green practices and individuals within the Netherlands, this investigation will help ascertain why Britain is unable to implement self-build as efficiently.

\section{AN INTRODUCTION TO SELF-BUILD \\ LITERATURE- WALTER SEGAL'S ROLE AS FACILITATOR}

The first, well-known paradigm of collaborative architecture in Britain came from the architect Walter Segal. Segal set out to provide a new paradigm of architecture when he moved to London in 1930 from the Netherlands (Shaw, 2016). He aimed to promote a different concept of building social dwellings, but as anarchist Colin Ward describes, it always should have been "the normal way and not the remarkable expectation" (Ward,
1990, 122).

Segal housed 14 people who had been on the waiting list for council housing in Lewisham (Broome, 1986), hoping to help those affected by the privatisation of social housing. With Lewisham Council's approval, the encouragement of freedom and community enabled all 14 dwellers to build and retain their own affordable home on Walter's Way in 1978 (lbid). Segal wanted to invent an architectural system where communities can physically engage by allowing freedom with the layout of their house and the liberty to build with neighbours (Kołakowski, 2020), whilst reducing the role of the architect to merely a facilitator or engineer, as shown in Fig. 2.

To empower the residents, Segal gave the neighbours a standardised modular model after deciding their personal layout, involving timber postbeam systems (Broome, 1986). In these documents, Segal provided the neighbours with building instructions (Ibid). Anyone could easily purchase off-the-shelf materials, such as softwood (Ibid), therefore making it readily available. The post-beam construction system accommodated easy modifications, facilitating any developing lifestyle changes (Marriott, 2016, 20).

Kołakowski describes the building process like an "IKEA system", so that everyone can become involved (Kołakowski, 2020). Crouch portrays Segal's idea as "building community cohesion" (Crouch, 2017), as the neighbours also built relationships through collaborative construction (Wallace et al, 2013). This was achieved through crossed frames with rigid joints that were constructed flat on the 
ground before being raised up into place in collaboration with neighbours, shown in Fig. 3.

Holland says this control by the dweller helps define and create communities within neighbourhoods, which is a positive attribute that would not have been established through traditional construction procurement (Holland, 2017). Marriott believed that this created contextually and socially relevant housing for each dweller (Marriott, 2016, 20).

Segal set out to destroy the "alienation within architecture" (Ward, 1990, 11) which occurs between architects, dwellers and the building. Ward believes that there should be meaningful connections between housing and the dwellers, creating a feeling of "dweller control" (lbid). Narrowing the architect's power down to an "enabler", as Bono describes it, helps to satisfy the client (Bono, 2019). Samuel argues against this, claiming architects can bring a project on time and within a budget (Samuel, 2018). However, Holland suggests in Wild Architecture that the ambitions of architects often conflict with the tastes and lifestyles of clients (Holland, 2017, 104).

\section{Coates believes removing} the traditional architect-client relationship would create better social housing for people, rather than the social housing of people (Coates, 2015, 16-20). Kołakowski summarised the Segal system as a process which proved that "architecture can contribute to satisfying the human need for cooperation and creation" (Kołakowski, 2004).

\section{Enthusiasts of Walter Segal- Participation}

Colin Ward was an architect and a well-known figure of the UK anarchist movement, particularly on issues of housing and planning (Spatial Agency, 2021). His political philosophy rejected dominant power structures where "one group of people make decisions, exercise control, and limits choices" (Ward, 1996). He admired Segal, viewing his selfbuilding system as exemplary of such an approach to housing, promoting participation and "dweller control" (Ward, 1990, 11). Segal set out a solution for freedom in Britain's social housing planning in the 1970s, influencing Ward's concerns with the people and their right to freedom (Grahame, 2015). Segal generated participation through architecture to ultimately end the 'one-sizefits-all' position that has caused many contextually irrelevant buildings.

Segal had many admirers. As Broome mentions, Lewisham Council allowed Segal to accomplish his self-build system (Broome, 1986), which demonstrates that people believed that his housing strategies could work. Architecture firms were also inspired by him. For example, Architype produced Britain's Diggers and Hedgehog selfbuild scheme using simple timber frame methods initiated by Segal (Architype, 2021). Overall, Segal's method became a blueprint for many community-led housing schemes, with benefits such as dweller control, sustainability and community cohesion, forming part of the earliest lowcost self-build projects in Britain (Hughes, 2004).

\section{British Projects Supporting Initiative - LILAC's \\ Sustainable Co-housing}

The cooperative lifestyle originated in Denmark and spread throughout Europe in the 1970s (Cummings \& Kropf, 2020). The Low Impact Living Affordable Community (LILAC) in Leeds was inspired by the Homeruskwartier's model in Almere (Feary, 2015). Strawbale, solar panels, community shared gardens and communal houses produced three benefits to this scheme (Downer, 2014): low impact, affordability and community (Chatterton, 2013, 4). Founder Paul Chatterton said straw-bale is available in abundance in Britain, allowing them to complete a quick, affordable building (Chatterton, 2014). It offers efficient insulation U-Values, which are effectively below the maximum building regulation requirements (Style, 2014). Straw-bale allowed a hands-on approach with the community, encouraging social interaction (Chatterton, 2014).

\section{Self-Build Constraints- Governmental Guidelines}

Despite the benefits, obstacles restricting the self-build movement can be ascertained from national trends, statistics and governmental guidelines.

Even though Lewisham Council accepted Segal's scheme, other local councils 
remain averse to change. Morton explains how councils avoid allocating land for selfbuilders and oppose any unconventional proposals brought by the local residents (Morton, 2013, 6). Freedom, in terms of housing, is often restricted by governing bodies who do not wish to deviate from the conventional planning system (Holland, 2017, 108).

Kieran Toms suggested that Britain's planning system needs to change, as he believes it should be easier to self-build (Toms, 2018). However, Grant Schapps, England's Secretary of State, declared Homeruskwartier as a workable model, seeing a marked difference when councils offered help to aspiring self-builders (GOV.UK, 2013).

Schapps dedicated a $£ 30$ million fund to self-builders, however Brenton explains that this is insufficient (Brenton, 2021).

Conversely, Dutch policymakers considered it appropriate to revive traditional self-build in the Netherlands, therefore the 2001 Dutch National Housing Report provided a political impetus for self-build. This stated that onethird of Dutch housing should be self-built by 2040 , increasing the demand for self-build schemes (Ministry of Housing et al., 2006).

\section{Lack of Land in Britain for Self-Builders}

A study, carried out by the University of York, found stasticical data on the different types of land obtained by self-builders in Britain and the difficulties inherent in the

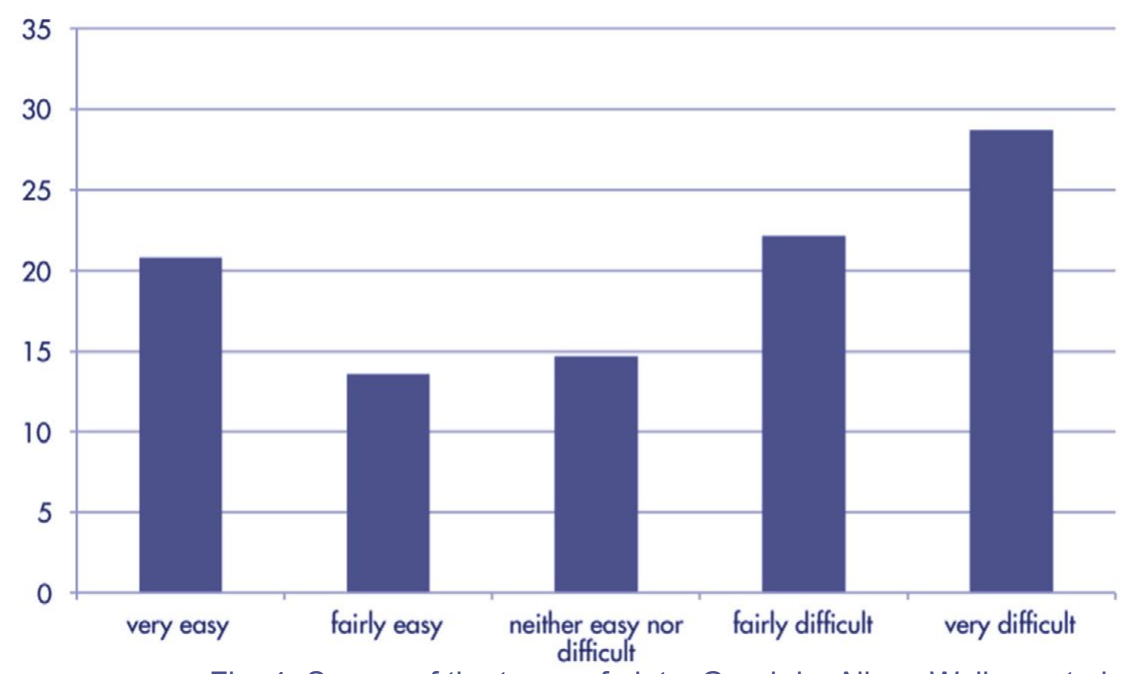

Fig. 4- Survey of the types of plots. Graph by Alison Wallace et al, 2013

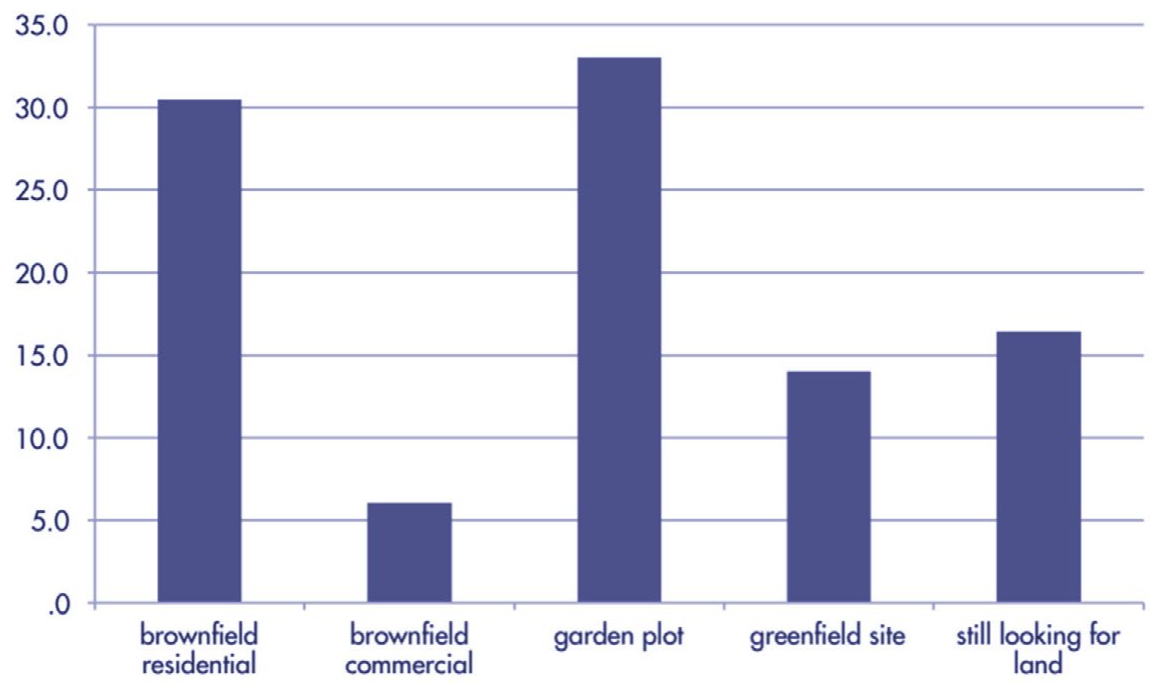

Fig. 5- Survey of difficulties obtaining land in the UK. Graph by Alison Wallace et al, 2013

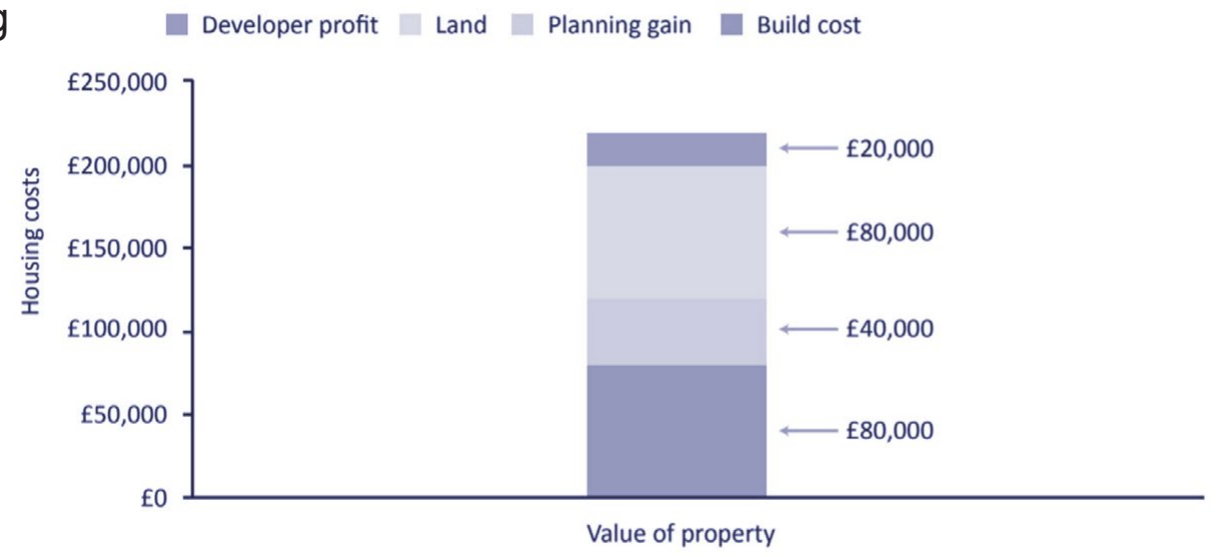

Fig. 6- What makes up the cost of a new $£ 220,000$ home? Graph from Alex Morton, 2013 


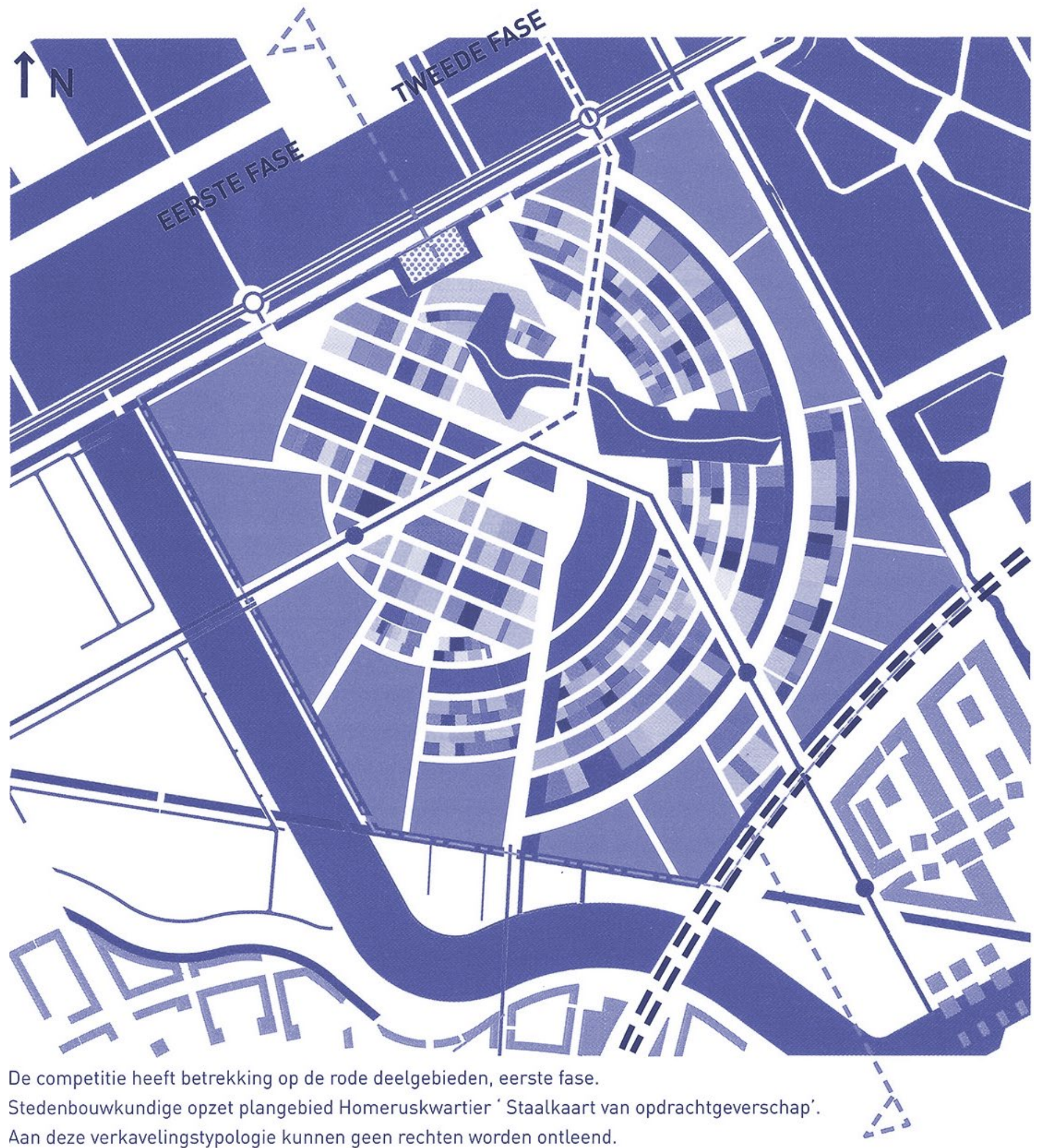

Aan deze verkavelingstypologie kunnen geen rechten worden ontleend.

institutioneel

IIII 1 particulier/collectief

centrum voorzieningen

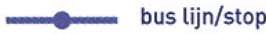

$50 \mathrm{~m} 100 \mathrm{~m}=300 \mathrm{~m}$ 


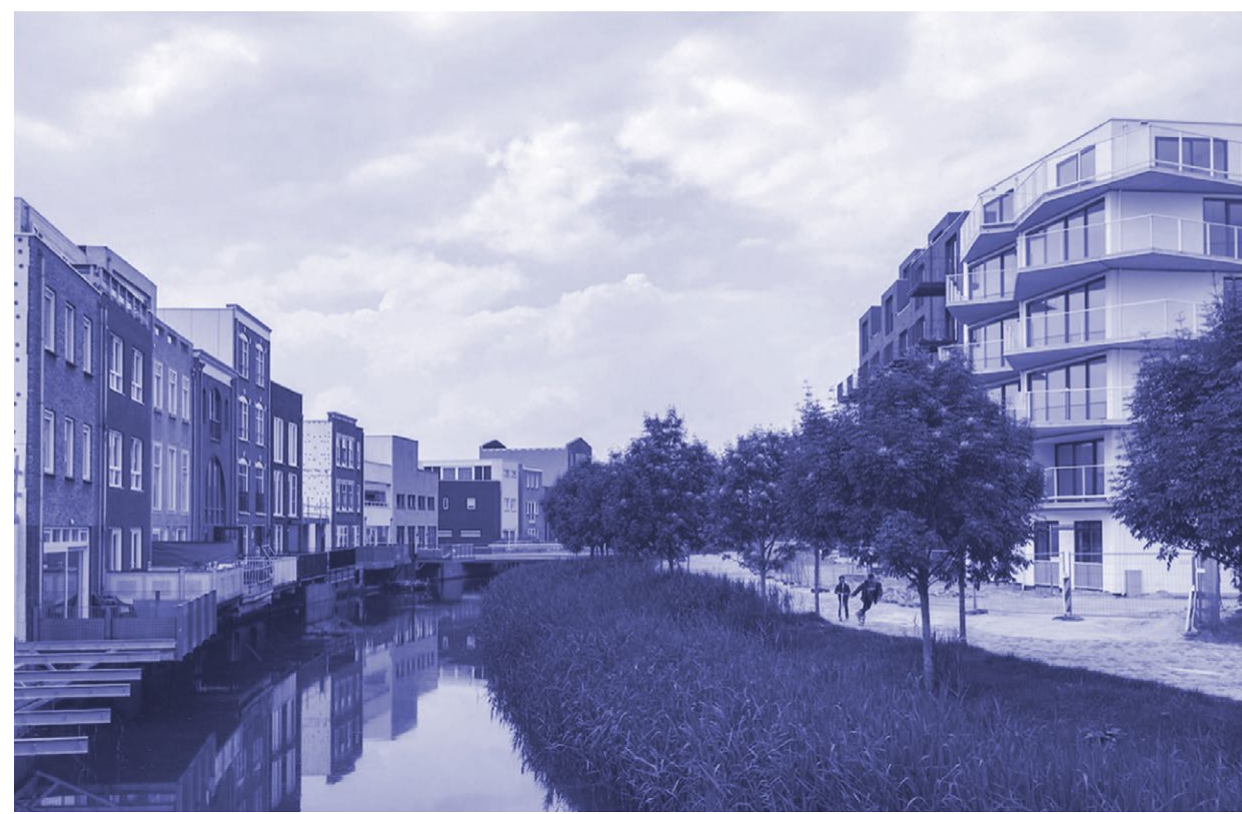

Fig. 8- Homerus quarter: self-build on a revolutionary scale. Photography by Adrienne Norman, 2019

process of finding this land (Wallace et al., 2013). Fig. 4 is taken from their study, which illustrates that over $15 \%$ of self-builders were still looking for land in 2013, supporting NaCBSA's argument regarding the unavailability of land in Britain (NaCBSA, 2021).

Fig. 5 also shows that the majority of the survey group found it 'very difficult' to obtain land (Wallace et al., 2013).

\section{Another study by Morton} shows the costs of obtaining land are on par with building the home in Fig. 6, which further illustrates the difficulties (Morton, 2013, 16). Slower development on allocated sites results in difficult distribution of further sites. Even once the land is allocated, councils can slow development or block planning applications (Ibid, 18).

Contrastingly, municipalities in the Netherlands possess little to no land. With this lack of availability of land, it is difficult for politicians to justify allocating plots specifically for self-build schemes (Tellinga, 2021). Facing similar impediments to Britain, this raises the question why there is little self-build in Britain?

\section{Homeruskwartier- the Affordable Self-Build Model in Almere, the Netherlands}

The analysis between the Netherlands and Britain has been chosen because the Dutch are not too far ahead with the self-build movement, explained in figure 1 , but ahead enough to see a difference. Therefore, analysis and conclusions can be closely refined, as there would be similarities and differences within experiences. Europe, in comparison to Britain, has adopted more selfbuild schemes. In Britain, more than $80 \%$ of housing is built by the same large developers, consolidating a monopoly over the housing market (Hamiduddin et al., 2016, 1). In the Netherlands, three in ten houses are self- built, compared to Britain's one in ten (Collinson, 2011). Bossuyt explains that more Dutch citizens want to contribute to their urban environment (Bossuyt et al., 2018). The analysis between the Netherlands and Britain has been chosen is because the Dutch are not too much ahead in terms of self-build, but enough to see a difference. Therefore, analysis and conclusions can be closely refined, where there would be similarities and differences.

Homeruskwartier began before peak of the 2008 financial crisis. (Feary, 2015). Interestingly, the plan predates the financial crisis so during the crisis, which no one could have predicted, the selfbuilders continued to build, while the developers stopped building (Tellinga, 2021). The financial crisis had profound effects on the Dutch property development industry, however NaCSBA explains that self-build proved to be less vulnerable to its effects (NaCSBA, 2021). Homeruskwartier targeted affordable housing for lowincome households of $€ 20,000$ $(£ 14,500)$ a year, because of the cost savings of self-build compared with conventional dwellings (Lloyd et al., 2012, 24). Therefore in 2007, the smallest $86 \mathrm{~m} 2$ plot cost around $£ 25,000$ whilst a $1000 \mathrm{~m} 2$ plot cost $£ 290,000$ (NaCSBA, 2021). Tellinga explains the reason why self-building was so successful during the financial crisis was because a single home could be bult based on the income of one household (Tellinga, 2021). Contrastingly, developers needed at least 
$70 \%$ presale and a loan from the bank (Ibid). The inclusivity of plots can be seen in (Fig. 7).

Homeruskwartier celebrates individual desire: you decide how to behave and how to use your space, which is shaped to your own liking (Oosterwold, 2021). This resolves Ward's criticism of "alienation with architecture" within the housing system, where the power of the architect often conflicts with individuality (Ward, 1990, 11), therefore creating variety within housing, seen in (Fig. 8).

Homeruskwartier established a strong blueprint for residential innovation (Russell, 2002), providing a source of inspiration for projects like LILAC Grove in Leeds (Feary, 2015) and $\mathrm{OWCH}$ in London (Brenton, 2021). Many community-led schemes in the Netherlands influenced alternative ways of living in Britain because of their unconventional benefits.

For example, Maria Brenton presented the concept of senior cohousing, as developed in the Netherlands, to an audience of older women in London (Brenton, 2021). This presentation generated long lasting success, as in 2016 it resulted in the Older Women Co Housing (Ibid).

\section{METHODOLOGY}

The methodology is set out to illuminate existing research and discover the benefits and obstacles to self-build schemes through primary data to draw current conclusions. There were existing articles based on the benefits to these schemes, however the literature did not provide answers to whether these obstacles truly prevent self-build from becoming the new "common" in British housing. Carrying out qualitative, semi-structured interviews with housing developers and individuals, who have been actively involved in community self-build projects, enabled rich and relevant primary data. Qualitative analysis was important in linking individual experiences with an understanding of the social, economic, and political processes (Knigge and Cope, 2006, 2022).

\section{A purposeful sampling} strategy of interviewees was carried out to ensure diverse viewpoints. These individuals were approached separately through their email addresses.

This selection included:

- A Housing Developer, based in London

- Director of the Greater Manchester Community Led Housing Hub

- A project manager of Homeruskwartier, based in the Netherlands

- The Leader of the Abundant Earth Community, promoting self-build in Lincoln

- Director of an architecture firm specialising in strawbale self-build, based in Britain anonymised to "Smith"

- Secretary at Yorspace, based in York

- Project consultant for Older Women Co-housing (OWCH), based in North London

- Director of HugrHomes, based in Cumbria

A Dutch perspective was obtained to draw comparisons with the Netherlands. They were approached by email, which was translated into Dutch. This method generated insights and reflections that align or contrast with Britain.

Interviews were conducted and recorded on Zoom and Microsoft Teams due to COVID-19. In-depth interviews lasted 11-50 minutes, where they reflected on personal experiences with self-build and community integrated projects. Additionally, they were asked to reflect on the positives and negatives of selfbuild schemes or, for housing developers, reasons for the lack of implementation of these schemes.

\section{Grounded Theory}

In this paper, grounded theory was used to codify the procedures for qualitative data (Glaser and Strauss, 1967).

This was useful to compare key consistencies and irregularities between the Netherlands and Britain (Knigge and Cope, 2006, 2024). Thematic context analysis was conducted through coding these interviews (Assarroudi et al., 2018) to determine word patterns for substantial amounts of textual data and identify common themes in the materials (Canary, 2019). This was categorised into obstructions and experiences within the subject of community self-build. This approach was chosen as there was no available theory to explain the lack of self-build in Britain, therefore investigating and understanding the experiences and mechanisms that obstruct the movement will help propose comparative answers. This enables a more extensive idea of whether selfbuild could potentially become the new common in Britain, 


\begin{tabular}{|c|c|c|c|}
\hline Person & Response & Word Coding & Theme \\
\hline Higginson & $\begin{array}{c}\text { "During the } 2007 \text { financial problems, small regional builders were wiped } \\
\text { out from the market by dominant housing developers. Those small, local } \\
\text { builders never came back to the market. There is a demand for self-build, } \\
\text { but there is a difference between walking around an exhibition and } \\
\text { buying a plot of land. There is a big drop-out rate because people cannot } \\
\text { find plots" }\end{array}$ & $\begin{array}{c}\text { Financial crisis, market, } \\
\text { domination, housing } \\
\text { developers, difficult }\end{array}$ & Land \\
\hline Chandler & $\begin{array}{l}\text { "The cost of land in this country prioritises the delivery of housings on } \\
\text { brownfield sites, which come with complications. Housing associations } \\
\text { have a lot of small, difficult infill sites. At the same time, they are } \\
\text { attractive to us because we own them and London is incredibly } \\
\text { expensive. If you can generate enough housing on that land, it is good } \\
\text { proposition" }\end{array}$ & $\begin{array}{l}\text { Expensive, difficult, } \\
\text { brownfield sites }\end{array}$ & Land \\
\hline Tellinga & $\begin{array}{l}\text { "When the financial crisis ended, it became more interesting for housing } \\
\text { developers to enter that market again...the Netherlands and the UK do } \\
\text { not put the market out to individuals. It is not in the developer's interest } \\
\text { to have self-builders within their scheme: they do not earn anything from } \\
\text { it" }\end{array}$ & $\begin{array}{c}\text { Financial crisis, housing } \\
\text { developers, difficult, } \\
\text { market }\end{array}$ & Land \\
\hline
\end{tabular}

and if not, what it is that is obstructing the movement.

\section{Limitations and Obstacles}

The first obstacle was accessing primary data. The aim was to analyse existing literature in conjunction with the primary data to explore the obstacles in further detail. This was overcome by asking the first set of interviewees if they knew individuals in the field who would be willing to participate. This approach increased active participants from two to eight. The lack of response from selected councils: Lincoln, Warrington and Lewisham limited the scope of the data.

\section{Ethical Considerations}

The participants were informed of the motivation behind the interviews. All participants signed a research consent form, which contained the option to request data removal. All participants accepted the use of their information and opinions to spread the word of unconventional living.

\section{FINDINGS}

\section{Theme 1 - Lack of Land}

All eight particpants stated their difficulties obtaining plots of land when they were asked about the obstacles of selfbuild. They all agreed that housing developers dominate the British housing market. Higginson sells plots of land to self-builders in Britain, because self-builders struggled to reenter the housing market after the financial crisis of 2008 (Higginson, 2021). London housing developer Chandler confirmed Higginson's point when asked about the problems that come with self-build. He believes the "availability of land is challenging" (Chandler, 2021).

This correlated with the

Fig. 9- Theme of land. By Author, 2021

views from the director of a strawbale architecture firm, who specalises in sustainable selfbuild. Smith believes that in the English system:

"only the wealthy can obtain land on their own because the politics around land in the UK is excluding.... if you are not wealthy then that is your own fault" (Smith, 2021).

She summarised this issue as "ridiculous" and the "absolute biggest reason why we do not have self-build" (Ibid). She has experience with clients who have been waiting for land for 5 years (Ibid).

However, Jacqueline Tellinga, urban planner and project manager of Homeruskwartier in the Netherlands, explained that Dutch municipalities also had difficulties finding plots of land, meaning few schemes were implemented after Homeruskwatier. She described the "oligopoly process of real 


\begin{tabular}{|c|c|c|c|}
\hline Person & Response & Word coding & Theme \\
\hline Peaceful Warrior & $\begin{array}{l}\text { "Working with people is not the easiest thing in the world, not everyone is } \\
\text { going to see it progressing in the same way and speed" }\end{array}$ & $\begin{array}{l}\text { Hard, people, work, } \\
\text { disagreement }\end{array}$ & People \\
\hline Higginson & $\begin{array}{l}\text { "Finally, there are those at the end of the spectrum 'who are scared stiff by } \\
\text { programmes like Grand Designs'. These people have watched Grand Designs } \\
\text { and want to build their own house. They think it is a great idea, but they } \\
\text { watch Grand Designs but see that it goes wrong. They want to do it but are } \\
\text { scared...when we have someone who wants to buy a plot from us but is scared } \\
\text { of what to do, we can put a comfort blanket around them and deliver the } \\
\text { project for them. From their point of view they get to drink champagne and } \\
\text { tell their friends how they have built their own house, whereas in reality we } \\
\text { have done it for them" }\end{array}$ & $\begin{array}{l}\text { Grand Designs, scared, } \\
\text { comforting, people, } \\
\text { ambitions }\end{array}$ & People \\
\hline Brenton & $\begin{array}{c}\text { "The group went on all sorts of weekend trips, cycling along canals, theatre } \\
\text { visits. They got to know each other really well before becoming a co-housing } \\
\text { group of } 45 \text { " }\end{array}$ & $\begin{array}{l}\text { Bonding, community, } \\
\text { people, relationships, } \\
\text { success }\end{array}$ & People \\
\hline Chandler & $\begin{array}{l}\text { "Only one family lasted the course because they had all fallen away and they } \\
\text { had not appreciated the efforts that would be required to get it up and } \\
\text { running. They did not have the camaraderie that my group had. There were } \\
\text { tough times, long and cold winter nights. Our group had bonded, so they } \\
\text { carried on. I would never advertise for random families" }\end{array}$ & $\begin{array}{l}\text { Hard work, bonding, } \\
\text { broken, community, } \\
\text { group, relationships, } \\
\text { tough }\end{array}$ & People \\
\hline
\end{tabular}

Fig. 10- Theme of people. By Author, 2021

\begin{tabular}{|c|c|c|c|}
\hline Person & Response & Word coding & Theme \\
\hline Gibbard & $\begin{array}{c}\text { "We have existed for 7 vears and have only just completed the stages of } \\
\text { negotiation with the council. All that is left to do it raise the last bit of } \\
\text { money that we need in order to build the houses" }\end{array}$ & Time, difficult, process & Time \\
\hline Chandler & $\begin{array}{c}\text { "The time it took to complete was three or four times more than what } \\
\text { we had allowed. The problem was through the funding requirements } \\
\text { with regulators and if we do not meet these deadlines, we will lose our } \\
\text { funding. They were miles off finishing so we had to get builders in to help } \\
\text { them finish" }\end{array}$ & Time, difficult, help & Time \\
\hline
\end{tabular}

Fig. 11- Theme of time. By Author, 2021

estate companies who have access to land unequally pushing self-builders behind" (Tellinga, 2021). However, in the Homeruskwartier project, she ensured small plots of land were available and affordable for the low income sector (Ibid). Tellinga compared this to Britain, where schemes are "aimed at middle to highincome people" (Tellinga,
2021).

Chandler helped develop a self-build project in 2010 with one of his old residents "who lived in over-crowded accommodation" (Chandler, 2021). Chandler was questioned as to why his company had not implemented self-build schemes since 2010. He explained since 2010 , the company was never approached regarding selfbuild and their priorities as a housing association are "to house people in need quickly, as they do not want to be given a piece of land and told to build their house themselves" (Ibid). As the company's assets, the houses are at a greater risk with self-build schemes as they could be built to a poorer quality, thus reducing their value (Ibid).

Brenton, founder of the $\mathrm{OWCH}$ co-housing project, went through eight different housing associations. The association that fulfilled the project never came to its opening and have not been involved in unconventional projects since (Brenton, 2021). Brenton highlighted the "lack of interest" as a whole from housing developers, who are the ones that dominate and influence the housing market (Ibid). Gibbard emphasised this with her struggle in finding a plot of land for Yorspace, as they were set on a space which the council "ultimately sold it to the highest bidder" (Gibbard, 2021).

Hopkins emphasised that the absence of self-build goes beyond the unavailability of land (Hopkins, 2021). He believes the availability of "land is individual to every region of the country" and says "land is not the issue: it is about motivation" (Hopkins, 2021). Gibbard, secretary of the YorSpace in York, echos this sentiment. She describes the process of finding land full of "torture, twists and turns", clarifying that "Yorkshire is booming with alternative ways of living" so she is "hopeful" 
about their future (Gibbard, 2021). These results show that the lack of self-build is deeperrooted than the unavailability of land.

\section{Theme 2 - The People}

Hopkins' reference to a lack of "motivation" introduced the second theme behind the lack of self-build in Britain, reflected in the results. When asked about the difficulties of self-build schemes, six out of eight interviewees referenced the dwellers when it comes to motivation, relationships and skill set. Tellinga says how we pick our own food, so why not make our own decision from scratch when it comes to housing (Tellinga, 2021).

Hopkins, director of Greater Manchester Community Housing Hub, emphasised the long-term responsibilities that accompany self-build, highlighting that "sometimes the people do not have motivation to maintain them", which fails to nuture longevity (Hopkins, 2021). This aligned with selfbuild advocate Guilhem Dumas (Peaceful Warrior), as his then 'Abundant Earth Community' ended due to its members not being able to fully pledge their time because of other life commitments (Dumas, 2021). He also considered self-build schemes to have a perception as "overwhelming" (lbid). However, he has not given up on the idea and explained that he has plans to move to a European country to start a new unconventional housing project (Ibid). Higginson has also experienced clients' perceptions of self-build as overwhelming, as they lack construction skills and are "scared stiff by programmes like Grand Designs" that portray self-build as complicated and expensive (Higginson, 2021). Higginson's company sometimes offers a "comfort blanket" to inexperienced, nervous clients by delivering the construction for them (lbid). Gibbard also has experience with people believing that these schemes are "too hard" and not wanting to support them (Gibbard, 2021). She revealed how people refrain from asking about their financial projections, which shows how Yorspace is going to be affordable in the long term. Instead, they receive criticism where they are referred to as "hippies" and "moochers" (lbid).

However, some self-build projects have established success due to strong connections and commitments between the dwellers. Brenton found that the OWCH project was a success because their group had bonded over weekend trips before intiating the building process (Brenton, 2021). Chandler emphasised on the importance of having "ready-made groups" (Chandler, 2021). He had known of previous self-build projects that were implemented by other housing associations where the residents did not have close relationships and fell

\begin{tabular}{|c|c|c|c|}
\hline Person & Response & Word coding & Theme \\
\hline Tellinga & $\begin{array}{l}\text { "It is merely up to the local governments to perform. They tried and were } \\
\text { willing to help here. Not all of them do this. It depends on the council. } \\
\text { Without the explicit support of the city council, a scheme like this would never } \\
\text { happen" }\end{array}$ & $\begin{array}{l}\text { Government, council, } \\
\text { help, variation }\end{array}$ & Council \\
\hline Brenton & $\begin{array}{l}\text { "We are a self-satisfied, post-imperial basket case. You can find really good } \\
\text { local authorities and really bad ones. They are variable and pretty imperviable } \\
\text { whether they are bad or good. In the name of so called "freedom" of action, } \\
\text { we do not get a say. Local authorities are pretty ossified on the whole and it is } \\
\text { very difficult for an ordinary person to penetrate them, unless you know } \\
\text { them" }\end{array}$ & $\begin{array}{l}\text { Self-satisfied, local } \\
\text { authorities, bad, good, } \\
\text { variable, ossified, } \\
\text { stubborn }\end{array}$ & Council \\
\hline Gibbard & $\begin{array}{l}\text { "There was some push back in terms of planning permission because we are } \\
\text { doing something that is untested in this council. We approach this by trying to } \\
\text { get them excited about being the first early adopter and leader of these } \\
\text { schemes" }\end{array}$ & $\begin{array}{l}\text { Planning permission, } \\
\text { hindering, council }\end{array}$ & Council \\
\hline Smith & $\begin{array}{l}\text { "The Welsh and Scottish Government promote self-build much more than the } \\
\text { English Government. I tell my clients to move over there because they will } \\
\text { have an easier time with it. I have } 6 \text { project going on over there at the } \\
\text { moment as they manage to get planning permission" }\end{array}$ & $\begin{array}{l}\text { Hard, English, Welsh, } \\
\text { Scottish, government, } \\
\text { planning permission, }\end{array}$ & Council \\
\hline Brenton & $\begin{array}{l}\text { "What the UK Government is trying to do at the moment is regulate planning } \\
\text { abysmally; the local people will not be able to stop developments plastering } \\
\text { identical boxes. In the Netherlands they introduced a piece of legislation } \\
\text { around } 2005 \text { which made provincial funding available to small builders and } \\
\text { groups. This was to challenge the uniformity and self-builders could get funds. } \\
\text { What is to stop us doing that in the UK? But, we have to build orthodoxes" }\end{array}$ & $\begin{array}{l}\text { Abysmally, identical, } \\
\text { orthodox, lack of control, } \\
\text { government, legislation }\end{array}$ & Council \\
\hline Peaceful Warrior & $\begin{array}{l}\text { "The difficulties come with the council. I think they are naive and have } \\
\text { backward thinking. We are boiled down to adhering to the building codes and } \\
\text { planning permissions, which are completely disproportional in relevance to } \\
\text { safety. It cost someone } f 600 \text { for a tree survey. I am very disappointed that the } \\
\text { council did not take on some of the enthusiam that I had with developing } \\
\text { community planning. That was the biggest stumbling block with my project" }\end{array}$ & $\begin{array}{c}\text { Difficulties, council, naive, } \\
\text { backwards, planning } \\
\text { permission, } \\
\text { disproportionate, }\end{array}$ & Council \\
\hline
\end{tabular}




\begin{tabular}{|c|c|c|c|}
\hline Person & Response & Word coding & Theme \\
\hline Brenton & $\begin{array}{l}\text { "I think the deepest level is cultural problems. It is so different from the } \\
\text { Netherlands, there is so much variety. I Iave never been able to put my finger } \\
\text { on it. The Netherlands are more democractic; they like to be involved. A girl } \\
\text { who moved over from there to the UK was named the most impertinent girl in } \\
\text { the school because she would always ask questions. Our culture could not } \\
\text { tolerate it, whereas in other cultures, children are consulted and encouraged } \\
\text { to share responsibility. In our culture that's sheer impertinence" }\end{array}$ & $\begin{array}{l}\text { Variety, culture, } \\
\text { responsibility, }\end{array}$ & Culture \\
\hline Peaceful Warrior & $\begin{array}{l}\text { "I have lived in Spain for several years and the way of community there is so } \\
\text { different to the UK. They will have a community hub under where you } \\
\text { physically live, so community is brought right to where you live. In the UK, we } \\
\text { do not have integrated design in terms of where you live is where you } \\
\text { associate community" }\end{array}$ & $\begin{array}{l}\text { Different, community, } \\
\text { intergrated }\end{array}$ & Culture \\
\hline Peaceful Warrior & $\begin{array}{l}\text { "I proposed a design for this land, suggesting to put a boat pontoon at every } \\
\text { dwelling because it was on a floodplain and you are going to have to build the } \\
\text { house on stilts like in the Netherlands. The Dutch have been doing this for } \\
\text { centuries- living on flooding land. They did not even respond" }\end{array}$ & Dutch, proposal, rejection & Culture \\
\hline Chandler & $\begin{array}{l}\text { "It is a cultural thing as well I would wage it. People do not think it is } \\
\text { something they could or would want to do. They would think they could } \\
\text { refurbish it but then they watch Grand Designs which focuses only on } \\
\text { expensive and incredibly challenging developments which might put them off. } \\
\text { When the easiest thing to do in the UK is to buy a home from the many house } \\
\text { builders" }\end{array}$ & $\begin{array}{l}\text { Cultural, challenging, } \\
\text { misjudgement }\end{array}$ & Culture \\
\hline
\end{tabular}

Fig. 13- Theme of culture. By Author, 2021

apart, unlike the the group he had managed, who had known and trusted each other for two years (Ibid). When interviewees were asked how they would advertise these schemes to facilitate success, seven participants explained that they advertise them on social media and wait for ready-made groups to approach them.

\section{Tellinga explains, from a} Dutch perspective, that "we cannot say we do not have the skills anymore" (Tellinga, 2021), so the results generated further reasonings behind the lack of self-build in Britain rather than just the dwellers' inexperience, relationships and lack of drive.

\section{Theme 3 - Time}

The third theme was the time it requires to complete self-build schemes. All seven partcipants based in Britain acknowledged the long process of selfbuild. Tellinga, based in the
Netherlands, did not touch upon this theme. Brenton described how impressed she was at the commitment of her co-housing community, as their project "took 18 years to complete" (Brenton, 2021).

Dumas explains that the "time involved in dealing with self-build is quite considerable" which can be perceived as off-putting (Dumas, 2021). He believes self-build is more attractive to younger people, as he had the most engagement from students and lecturers (lbid).

\section{Chandler explains the} importance of construction skills when carrying out selfbuild projects, as it could lead to a shorter process (Chandler, 2021). He described his selfbuild project as a "self-finish" rather than a self-build, as the group only completed basic tasks such as fittings and decorating due to time constraints (Ibid). Chandler contacted builders to finish the advanced elements of the construction in order to meet the timeframe (Ibid).

Interviewees suggested that the time taken to complete a self-build project is also affected by government guidelines and local councils who delay selfbuilders' progression.

\section{Theme 4 - Councils and Planning Permission}

When questioned about the biggest hurdles of self-build, all seven British participants discussed their frustrations with the council and planning permission. Whilst Tellinga did not face any set backs with her local council in Almere, she acknowledged they were supportive. She recognises that is not always the case and city councils are "not interested in endless discussions" regarding unconvential living (Tellinga, 2021).

The British participants further explained the disinterest from the council regarding unconventional living. Brenton explains how you have to entice the council as they are "ossified" (Brenton, 2021). Gibbard represents York Council as less obstructive. Although she did have some setbacks with the council, they were more open to Yorspace's unconventional scheme (Gibbard, 2021). Gibbard further explained the reason her local council are more interested in unconventional schemes is because York City Council have a community-led housing officer, unlike other councils (Ibid). 


\begin{tabular}{|c|c|c|}
\hline Difficulty with Self-Build & Britain & The Netherlands \\
\hline Difficulty- Finding Land & Yes & Yes \\
\hline $\begin{array}{c}\text { Difficulty- Councils and Planning } \\
\text { Permission }\end{array}$ & Yes & Sometimes \\
\hline $\begin{array}{c}\text { Difficulty- Culture } \\
\text { Difficulty- the People }\end{array}$ & Yes & No \\
\hline & Yes & No \\
\hline Difficulty- Time & Yes & No \\
\hline
\end{tabular}

Fig. 14- Comparative table for the difficulties of self-build mentioned in both areas. By Author, 2021

\begin{tabular}{|c|c|c|}
\hline Positives with Self-Build & Britain & The Netherlands \\
\hline Positives- Cheap Solution & No & Yes \\
\hline Positives- Personal Pride & Yes & Yes \\
\hline Positives- Variety & Yes & Yes \\
\hline Positives- Community & Yes & Not mentioned \\
\hline Positives- Sustainable & Yes & Not mentioned \\
\hline
\end{tabular}

Fig. 15- Comparative table for the positives of self-build mentioned in both areas. By Author, 2021

Smith believes that European countries have a greater amount of self-build schemes than Britain, as she works with European partners to promote straw panelling structures (Smith, 2021). Smith also believes there is a political impetus in Europe to establish self-build schemes and they generally want to succeed to the Head of Planning at Lincoln City Council, who were originally amazed and said they need more housing like this (Dumas, 2021). However, he was sceptical of the council's excitement, as his unconventional project was not profitable (Ibid).

Tellinga considered the UK's Right to Buy Scheme as a successful model to replicate in the Netherlands (Tellinga, 2021). However, Higginson demonstrated that some British local authorities put the selfbuild register on their website, but others will conceal it, as it makes it hard for the public to find and sign. Therefore, the true demand of self-build is not representative and they would not have to act upon the demand. "While they have an obligation to do it, they do not really want to do it" (Higginson, 2021).

\section{Theme 5 - Cullture}

Four out of seven British participants mentioned cultural issues when they were questioned about the absence of self-build in Britain. For half of the interview, Brenton spoke of cultural issues, as she had experience of travelling to the Netherlands regularly to produce a co-housing model and write reports for Homes England housing corporation (Brenton, 2021). Consequently, she is familiar with both cultures and discovered a distinctive cultural difference between the two. She repeatedly described the Dutch as "flexible, inclusive and civic minded" when compared to Britain (Ibid).

Dumas experienced other cultures, so he explained how 
communities are different in other countries compared to Britain. He has presented design proposals to Lincoln City Council for resolving local floodplain sites, similar to the Dutch way of living (Dumas, 2021). However, this was ignored. Housing developer Chandler also agreed that the lack of self-build is due to cultural issues (Chandler, 2021).

When asked why there are fewer self-builds in Britain compared to the Netherlands, Tellinga initially struggled to identify a reason, "I do not know why there is not many in Britain" (Tellinga, 2021).

Two tables were generated from the interview responses to compare both the advantages and disadvantages of each area.

\section{DISCUSSION}

The results obtained from the diverse range of primary sources in Britain further highlighted these obstacles to self-build, with all sharing very similar experiences. The research also generated a Dutch perspective. This was important to the scope of the research as it identified the themes which were specific to Britain and the themes that also correlated with the Netherlands.

The overarching question is whether community self-build is as "simple" and "collaborative" as Barlow describes it (Barlow et al, 2001). The review on Segal analysed the potential for simple self-build construction models (Marriott, 2016, 20), which rules out over-complexity as the main reason for self-build vacancy in Britain. The role of the architect, as facilitator, can also produce more responsive and contextually relevant buildings (Holland, 2017, 104). The primary results within this paper are important to the research, because they reveal the aspects of community selfbuild that are not so "simple", which did not emerge from the literature review. In the literature review, unavailability of land and issues with British local authorities were deemed, in reports and articles, to be the main obstructions of self-build (Wallace et al., 2013).

The theme of unavailability of land correlated with Wallace's statistical data in the review (Ibid). Tellinga said that there is also a lack of available land in the Netherlands (Tellinga, 2021). Therefore, if the Dutch also experience the same perceived obstacle as Britain, yet have had success in self-build schemes, then the absence of self-build must be attributed to another cause. The effect of the 2008 financial crisis was recognised as a hinderance to self-builders, as large housing developers started to dominate the market once again, preventing self-builders from gaining a foothold. However, Tellinga's project commenced before this financial crisis, so they did not experience as much competition for land within the market in the beginning (Tellinga, 2021). After the effects of the financial crisis had eroded, Tellinga was faced with a hinderance as developments carried on (ibid), showing the correlation of hurdles between both Britain and the Netherlands. However, Tellinga's project was inclusive, as she provided smaller plots of land within her scheme that people of low income could afford, compared to Britain, where plots of land are only affordable for people on middle to high incomes. Therefore, her project appears to be more accessible.

Six interviewees mentioned the motivation, construction skills and weak relationships between the people involved in these projects as a reason why these schemes were difficult.

Segal created community cohesion with the 14 strangers on Lewisham's waiting list, which was a successful element. Chandler believed the key to a successful selfbuild project relies within the community's relationships (Chandler, 2021), as this would support them through the challenging days. Brenton was the only participant who approached people about self-build, rather than waiting for ready-made groups to approach her. However, she made sure that the group connected before they started working together, evidencing the importance of relationships for success.

\section{Segal's role as faciliator} helped any inexperienced selfbuilders in Lewisham, however Chandler raised the issue with this in his profession. Chandler said that working as a facilitator can be challenging within the house development profession, as you do not have complete control over the quality and time of your building projects, which can be a big risk. This can prevent or block any progess 
made by Segal in the self-build movement, as this role might not suit all self-build situations. Chandler spoke about how long his self-build project took to complete. However, time restrictions were put in place by other external bodies within his housing association. In other cases, as when self-builders own the home, time restrictions would be dictated by the selfbuilders themselves. This might relieve some of the pressure that comes with self-build.

The next obstacle that emerged is the role of the council, who can often delay self-build projects further. Dumas explains that you can spend "five years fighting with the council" before you even start building your home (Dumas, 2021). In the review, Holland says the obstacles of self-build are the obstructions from local authorities (Holland, 2017), rejecting unconventional design proposals against planning permission regulations. Ward's anarchist views correlated with some of the primary responses, as they were all passionate about dweller control rather than governmental control that normally eliminates freedom when it comes to building dwellings. On the other hand, Tellinga could not provide an answer as to why Britain was so behind in these schemes compared to the Netherlands. This indicates that Britain has no reason to be behind, as both states seem to face similar obstacles. However, whilst all seven British participants found difficulties in dealing with the hurdle of the council, Tellinga did not seem to have any frustration with her local council. She recognises that this is not always the case, therefore "dweller control" and unconventional aspirations can be limited in housing when there are political barriers that block that personal control. This can make any self-build ambition challenging.

The results and review show the Netherlands' willingness to build unconventionally in order to tackle housing issues, such as living on a floodplain. Brenton states that Britain has a "backwards" culture, as Britain is reluctant to develop new ways of living when problems arise. Instead, Britons stick to conventional housing, which is not always fit for purpose. Brenton, through her experience in the Netherlands, believes they are more supportive and open to new ideas, which is attested to by Tellinga's experience of receiving support from her local council (Tellinga, 2021). This reflects the wide variety of housing in the Netherlands. The literature review did not uncover culture as a barrier to self-build schemes. Political conservatism and bureaucracy, at all levels of the housing process, often prevent or stall realisation of unconventional schemes. The councils tend to adopt a risk-adverse approach, shown by Dumas' difficulty in getting a response from Lincoln Council in his proposal for boat pontoons and houses on stilts for a floodplain site, similar to the Netherlands. In his presentation to the council, he had proved that unconventional housing can be achieved safely. His scheme was rejected due to its inability to generate high enough profits, as designs are often implemented due to their potential for financial reward. This shows that housing is viewed as a commerical enterprise rather than a direct benefit to the community. (Dumas, 2021). With a bit of unconventional thinking, councils could generate self-build schemes for a fraction of the price of a non self-build scheme. This was demonstrated in LILAC where they use locally-sourced straw material that was cheap and easy to install. A focus on sustainable, unconventional housing could produce long term benefits, but the councils do not seem to view it in this way, leading to overlooked possibilities.

Limitations in the methodology included the councils' lack of response to both emails and telephone calls. This correlates with the theme of the council being the biggest hurdle to selfbuilders in Britain, as they were difficult to contact. This could cause a delay to self-build projects. In future research, conducting interviews with the council would be valuable to determine why they are so intransigent, as this research cannot provide the councils' perspective on self-build.

This would reveal a new, unexplored area in the research, not covered by the perspective of a housing developer and a European self-build project manager. However, as Brenton describes, without connections to the local government, it is difficult for a normal person to gain access (Brenton, 2021). 


\section{CONCLUSION}

The self-build method demonstrates community, sustainability and affordability advantages, but when it comes to Britain's priorities, there are cultural differences when compared to the Netherlands. Existing models prove its viability in theory, but the hurdles outlined in the results make the concept of selfbuild difficult to achieve in practice. It is impossible to identify a singular reason for the lack of British self-builders. However, the pervasive culture impacts on, and reflects in, other community selfbuild obstacles, such as the council, land unavailability and peoples' attitudes. Intransigent, conservative outlooks on housing in Britain is entrenched in local councils and planning systems, who have the power to determine whether schemes succeed or not. This attitude results in an excessive focus on conventional dwellings in Britain, as they fail to consider unconventional opportunites that could further benefit society. Conversely in the Netherlands, flexibility is inherent in cultural, political and social attitudes, leading to the creation of unconventional dwellings that are contextually relevant to the dwellers, the councils and the environment. Although Britain has passed legislation to support selfbuilders, such as the Right to Build Scheme, it is the way the legislation was implemented and the tools provided for its execution that are lacking. Segal's self-build work is admired by many. However, the compliance and motivation of local authorities dictate the implementation of self-build, as they can make any strategy difficult to fulfill, even if it is compulsory (Higginson, 2021). As Higginson says, there is a difference between going to an exhibition and buying a plot of land (Ibid). Much like Segal, there is a big gap between admiring his work and applying his work in practice.

This difference in culture offers an explanation as to why Britain and the Netherlands face the same, significant barrier of unavailability of land, yet the Netherlands have managed to successfully deliver self-build schemes and Britain has not. It could be said that Britain are currently failing to propose unconventional living as the new "common" way of living, as this paper has revealled the notion of conservative values and strictness that prevail within current British councils, compared to the Netherlands. It questions the responsibility of their own dwellings, which is often in the hands of others.

This paper can be used by future researchers to further explore the depth of impediment of local councils by interviewing a range of local council members throughout Britain on the reasons of selfbuild vacancy. This is to see whether all local councils contribute equally to this obstruction, or whether it is more regional in nature. Without the support from powers of authority, movements such as the self-build movement can be widely difficult to develop as the new normal within housing.
BIBLIOGRAPHY.

Architype.co.uk. (2021) Architype / Community Self-Build Projects: Hedgehog and Diggers / The UK's Leading Passivhaus, Sustainable Architects. Available from https://www. architype.co.uk/project/hedgehogdiggers-self-build/ [Accessed 18 February 2021]

Assarroudi, A., Heshmati Nabavi, F., Armat, M. R., Ebadi, A. \& Vaismoradi, M. (2018) Directed qualitative content analysis: the description and elaboration of its underpinning methods and data analysis process, Journal of Research in Nursing, 23, 42-55.

Barlow, J., Meike, J. and Jackson, R. (2001) Homes to DIY for: the UK's Self-Build Housing Market in the Twenty-First Century. York: York Publishing Services Ltd.

Bono, C. (2019) New Ways: How An Architect Is Rethinking CustomBuild. [online] The Architects' Journal. Available from https://tinyurl. com/57j5hzjn [Accessed 1 January 2021]

Bossuyt, D., Salet, W. and Majoor, S. (2018) Commissiong as cornerstone of self-build housing. Assessing the constraints and opportunities of self-build in the Netherlands, Land Use Policy, 77 524-533. Available from https://doi. org/10.1016/j.landusepol.2018.06.003 [Accessed 20 Dec 2020]

Brinkley, M. (2013) How Does Self Build in the UK Compare to Germany? - with Mark Brinkley, Author of The Housebuilder's Bible. [podcast] House Planning Help Podcast. Available from https://tinyurl.com/5fxf6sdn [Accessed 5 February 2021]

Broome, J. (1986) The Segal method: special issue'. Architects's Journal, 183 (45), 31-68.

Canary, A. (2019) How to Analyze Interview Transcripts in Qualitative Research - Rev. [online] Rev. Available from https://tinyurl.com/ hynymuys [Accessed 7 February 2021]

Chatterton, P. (2013) Towards an Agenda for Post-carbon Cities: Lessons from Lilac, the UK's First Ecological, Affordable Cohousing Community. International Journal of 
Urban and Regional Research, 37 (5) 1654-1674 Available from http:// eprints.whiterose.ac.uk/74549/6/ chattertonP1.pdf [Accessed 20 January 2021]

Coates, M. (2015) To Hell with Architecture: An Architecture of Anarchism. Anarchist Studies, Lawrence and Wishart, 23 (2) 1-26. Available from http://e-space. mmu.ac.uk/600447/ [Accessed 16 December 2020]

Collinson, P. (2011) Self-build: it's time to go Dutch. The Guardian. Available from https://tinyurl. com/43m3mbfk [Accessed 5 February 2021]

Crouch, D. (2017) Lived Spaces and Planning Anarchy: Theory and Practice of Colin Ward. Planning Theory \& Practice, 18 (4) 684-689. Available from https://doi.org/10.1080 /14649357.2017.1371878 [Accessed 26 December 2020]

Downer, S. (2014) Lilac co-housing: How they did it - NewStart. [online] NewStart. Available from https:// tinyurl.com/5fz2zhxu [Accessed 20 February 2021]

Feary, T. (2015) Inside Almere: the Dutch city that's pioneering alternative housing. [online] The Guardian. Available from https://tinyurl.com/ m5vcj76k [Accessed 14 January 2021]

Glaser, B. and Strauss, A. (1967) The discovery of grounded theory. New Brunswick, United States: AldineTransaction.

GOV.UK (2013) Sustainability and Climate Change: MOD. [online] Available from https://tinyurl. com/9642xfr4 [Accessed 5 March 2021]

Grahame, A. (2015) 'This Isn't At All Like London': Life In Walter Segal's Self-Build 'Anarchist' Estate. [online] the Guardian. Available from https:// tinyurl.com/37as7u9k [Accessed 26 December 2020]

Hamiduddin, I., Gallent, N. (2016) Self-build communities: the rationale and experiences of group-build (Baugruppen) housing development in Germany, Housing Studies, 31 (4) 365-383. Available from https://tinyurl. com/rztcsmjh [Accessed 13 February 2021]
Holland, C. (2017) Wild Architecture: The Potential of Self-Build

Settlements. Architectural Design, 88

(3) 102-109. Available from https://doi. org/10.1002/ad.2307 [Accessed 10 November 2020]

Hughes, H. (2004) Building of the month October 2004 - Walter's Way, Lewisham. C20 Society. Available from https://tinyurl.com/3a5cjuj8 [Accessed 18 February 2021]

Ipsos MORI. (2014) One in seven Britons expect to look into building their own home. [online] Available from https://tinyurl.com/jpneeptk [Accessed 5 February 2021]

Knigge, L. and Cope, M (2006) Grounded Visualization: Integrating the Analysis of Qualitative and Quantitative Data through Grounded Theory and Visualization. Environment and Planning A: Economy and Space, 38(11) 20212037. Available from https://doi. org/10.1068/a37327 [Accessed 1 February 2021]

Kołakowski, M. (2020) Timber Frame Construction [lecture] ABE Technical Specialism - 2021, University of Lincoln, October 2020.

Kołakowski, M. (2004) Wzajemna pomoc i miejska rewolucja,

Architektura i Biznes, 143 (5) 38-43.

Marriott, A. (2016) Homes for People, Not for Profit: The choice to self-build an adaptable house providing an alternative to the developer housing model. PhD. University of Dundee. Available from https://tinyurl.com/2rvwkhwr [Accessed 9 December 2020]

Morton, A. (2013) A right to build. Local homes for local people. London: Policy Exchange.

NaCSBA. (2021) About us | NaCSBA - National Custom \& Self Build Association. [online] Available from https://nacsba.org.uk/aboutnacsba/ [Accessed 1 February 2021]

NaCSBA. (2021) Almere, Holland - Self Build Portal. Available from https://tinyurl.com/8bbhckp3 [Accessed 13 February 2021].

Oosterwold. (2021) Over Oosterwold | Maak Oosterwold. Available from https:// maakoosterwold.nl/over-oosterwold/
[Accessed 9 February 2021]

Russell, James S. (2002) New Housing at Almere. Architectural Record. v190, n10. p 234-237

Samuel, F. (2018) Why Architects Matter: Evidencing and Communicating the Value of Architects. 1st ed. London: Routledge.

Shaw, F. (2016) Walter's Way to solve the Housing Crisis | Local Dialogue. [online] Localdialogue.com. Available from https://tinyurl.com/ wpuen38w [Accessed 15 Nov 2020]

Spatial Agency (2021) Colin Ward. Available from https://tinyurl. com/3c265d77 [Accessed 18 February 2021]

Style, O. (2014) LILAC: Low Impact Living Affordable Community. Construction21. Available from https:// tinyurl.com/a9rfhsj4 [Accessed 20 February 2021]

Toms, K. (2018) If Britain wants more self-build housing, we need to change its planning system City Monitor. Available from https:// tinyurl.com/2ke3dsu7 [Accessed 13 February 2021]

Wainwright, O. (2016) Self-Build Pioneers: The Estate Pointing The Friendly Way Out Of A Housing Crisis. [online] The Guardian. Available from https://tinyurl.com/stf7exa2 [Accessed 12 November 2020]

Wallace, A., Ford, J. and Quilgars, D (2013) Build It Yourself? Understanding The Changing Landscape Of The UK Self Build Market. [online] York: University of York. Available from https:// tinyurl.com/sbe58bw3 [Accessed 6 December 2020]

Wallace, A., Ford, J. and Quilgars, D. (2013) Results of a survey of people engaging with self-build. York: Lloyds Banking Group, 5-22. Available from https://tinyurl.com/37k69kyb [Accessed 20 February 2021]

Ward, C. (1996) Anarchy in Action. 2nd ed. London: Freedom Press.

Ward, C. (1990) Talking Houses: Ten Lectures. London: Freedom Press. 



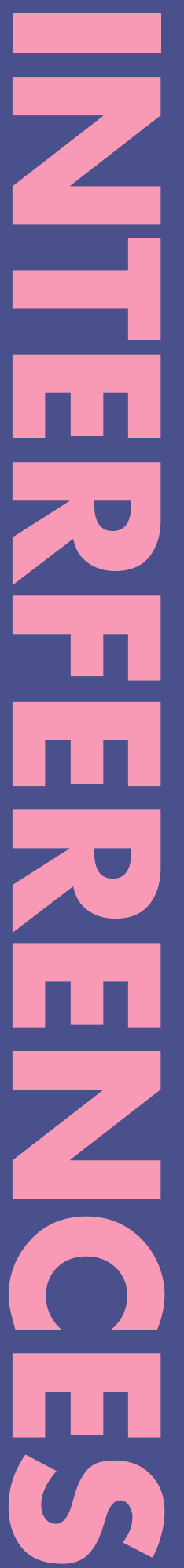




\section{Low-Tech Freedom, Creativity \&. Love \\ Translating Erich Fromm's Psychoanalysis into Analyses of Architecture}

Low-tech

Erich Fromm

narrative

psychoanalysis architectural analysis

\section{Kołakowski, Marcin Mateusz ${ }^{1}$}

${ }^{1}$ Lincoln School of Architecture and the Built Environment / University of Lincoln, England Orcid: 0000-0001-7244-1479

mkolakowski@lincoln.ac.uk 
An attempt to understand the idea of 'commons' in architecture requires analytical tools and a narrative which will refer to 'common values'. Yet the era of Postmodernism taught us mainly the relativism of multitudes of values, standards and paradigms. It made us used to 'it all depends' approach.

Many popular methods of describing architecture are based on analysing it in a historical or cultural context. This paper, however, proposes a perspective that refers to human needs which have arguably been universal for all the people in all historical periods in all cultures. This perspective could be useful particularly while dealing with big contemporary issues of 'commons' in architecture - togetherness, ecology, common places and agendas.

This paper proposes a framework based on the school of 'positive psychology' and in particular on the unappreciated father of the Frankfurt School and critical theory - Erich Fromm who worked all his life on his comprehensive 'theory of needs'. This paper proposes translating the concepts of this theory into architectural analyses and narrative.

If we are to understand the essence of 'commons', we need to refer to people's common needs. These are the key concepts of Fromm's model. This paper is structured around what Fromm described as three basic, common needs: freedom, creativity and love.

The analysis of low-tech movement will serve as an example illustrating how the lens of Erich Fromm's theory allows better understanding of this phenomenon. The objective of this paper is to propose a new definition and narrative of the low-tech movement which will be based on a psychological framework. 


\section{INTRODUCTION}

Low-tech movement is often associated with the use of unprocessed materials such as timber, bamboo, straw bales, unfired earth or recycled products including car tires, bottles, etc. This movement is often also linked with building techniques which encourage self-built or co-operation during the building process.

\section{Interestingly, for many} reasons the movement is often ignored and underresearched, despite the fact that it experiments with the burning issues of the building industry's lack of resources and the link between architectural production and social cohesion.

Also, the definitions and the understanding of this movement have been persistently unclear and unsatisfactory. This paper proposes a way to address these problems by redefining low-tech as a movement. An alternative to current definitions will be proposed and structured according to Erich Fromm's concept of three main needs.

\section{Erich Fromm was a key} founder of the Frankfurt School, later named as one of the most unappreciated thinkers of the 20th century (Durkin, 2014:10). As philosophy historian Neil McLaughlin(1999) revealed, due to political coincidences Fromm was unfairly wiped out from the school of critical theory which he was a founding member of. This paper tests his theory by structuring paragraphs according to his models and concepts, which are translated below into the field of architecture.
UNSATISFACTORY DEFINITIONS

\section{The Ontology of Low-Tech}

The term 'low-tech' in architecture first appeared in the 1970s and referred to 'ingenious but unglamorous design' (Ball, Cox 1982) in a stark contrast with the newly born buzzword 'hightech' - coined by Kron and Slesin's book High-Tech - the Industrial Style (1978). Morgan (1978) started to link the idea of 'low-tech buildings' with "energy conscious design and employing concepts of low embodied energy, use of thermal mass, natural materials and passive heating". In the 1980s, 'low-tech' entered popular culture thanks to the short story Johnny Mnemonic by Gibson (1981), which portrayed a dystopian future in which 'Lo Teks', a group of anti-technology outcasts, fight an unscrupulous 'high-tech' corporation. 'Low-tech' first entered the Oxford English Dictionary in 1989, still as an antithesis of the hightech style, but 10 years later Luchsinger (1998) associated low-tech with "progressive solutions where aims are reached not by accumulating new technological tricks but by avoiding them". Daniels (1999) described low-tech as "passive methods of using the sun and natural environment". In the 1980s, low-tech started to be associated with the approach proposed by Victor Papanek who wrote about low-tech as being more of an "architectural movement" than an architectural formal style (Papanek, 1985). This was acknowledged in the definition included in the Dictionary of Architecture by Curl (1999):

"...involves the recycling of materials and components and the use of traditional construction, insulation, and natural means of heating and ventilation. Low-tech recognizes the environmental damage done by High Tech through excessive use of resources, and has been applied to the circumstances of poverty-stricken areas, where it has been termed 'alternative', 'intermediate' and even 'utopian' technology”.

At the beginning of the new millennium, 'low tech' in architecture ceased to be a pejorative term. In 2001, Jean Dethier, director of Centre Pompidou, made a speech celebrating the meeting of bamboo, paper and earth architects in which he said: "high-tech is the past, the future belongs to low-tech".a Books such as Sustainable Architecture - Low-tech houses (Mostaedi, 2003) and Ultra Low Tech Architecture (Mira, Minguet, 2011) present low-tech projects as those that utilise unprocessed and recycled materials.

\section{Problems of Definitions}

The first problem concerning low-tech's definitions derives from the fact that it is not necessarily rated on materials or techniques only. Unprocessed materials - wood, earth, bamboo or straw - have recently become part of the vocabulary of architects which could hardly be associated with low-tech. Rammed earth walls were designed by Norman Foster at Musée de 
la Romanité in Narbo Via, by Herzog \& de Meuron at the Herb Centre, or Grimshaw Architects in the Eden

Project. Straw became part of mainstream guidelines and is also used in technologically sophisticated prefabrication processes such as those proposed by Modcell. Renzo Piano developed bamboo architecture. Those examples could hardly be called low-tech.

The second problem is linking the movement simply with an eco-friendly architectural response. Even if this is an important part of low-tech narrative, in the 21th century sustainability has become part of an accepted paradigm of the whole mainstream building industry. On the other hand, there are plenty of examples where low-tech is driven by other ideas than sustainability: addressing problems of community or the poor, socially excluded or people affected by natural disasters.

The third problem is that the movement is often defined as a modern trend starting in the 1960s. Yet low-tech could also be presented as not historically specific. The refusal to participate in the latest, most evolved technological conveniences is by no means a recent phenomenon, and not necessarily an architectural one. Advocates of these ideas may be found in different cultures, religions and historical periods: cynics and Diogenes in ancient Greece, Francis of Assisi and his followers in Christianity, Lev Tolstoy and the Tolstoyan movement in Russia, Mahatma Ghandi in Hinduism and a multitude of other movements which promoted a simple life and minimalism and were sceptical of luxury. In his famous book Walden or Life in the Woods, Henry Thoreau strongly identified the link between minimalist lifestyle and architecture creating a blueprint which was used by many low-tech promoters (Thoreau 2018). These timeless, cross cultural and cross historical characteristics of low-tech indicate that the essence of this movement should be sought in a more universal realm of human psychology.

\section{LINES OF \\ INVESTIGATIONS AND METHODOLOGY}

\section{Site visits and interviews}

In order to establish an understanding of the universal character and the essence of the low-tech movement, the author has followed grounded research principles by visiting over 50 workshops and events which promoted low-tech techniques such as various methods of building out of earth, straw bales, bamboo, car-tires and paper

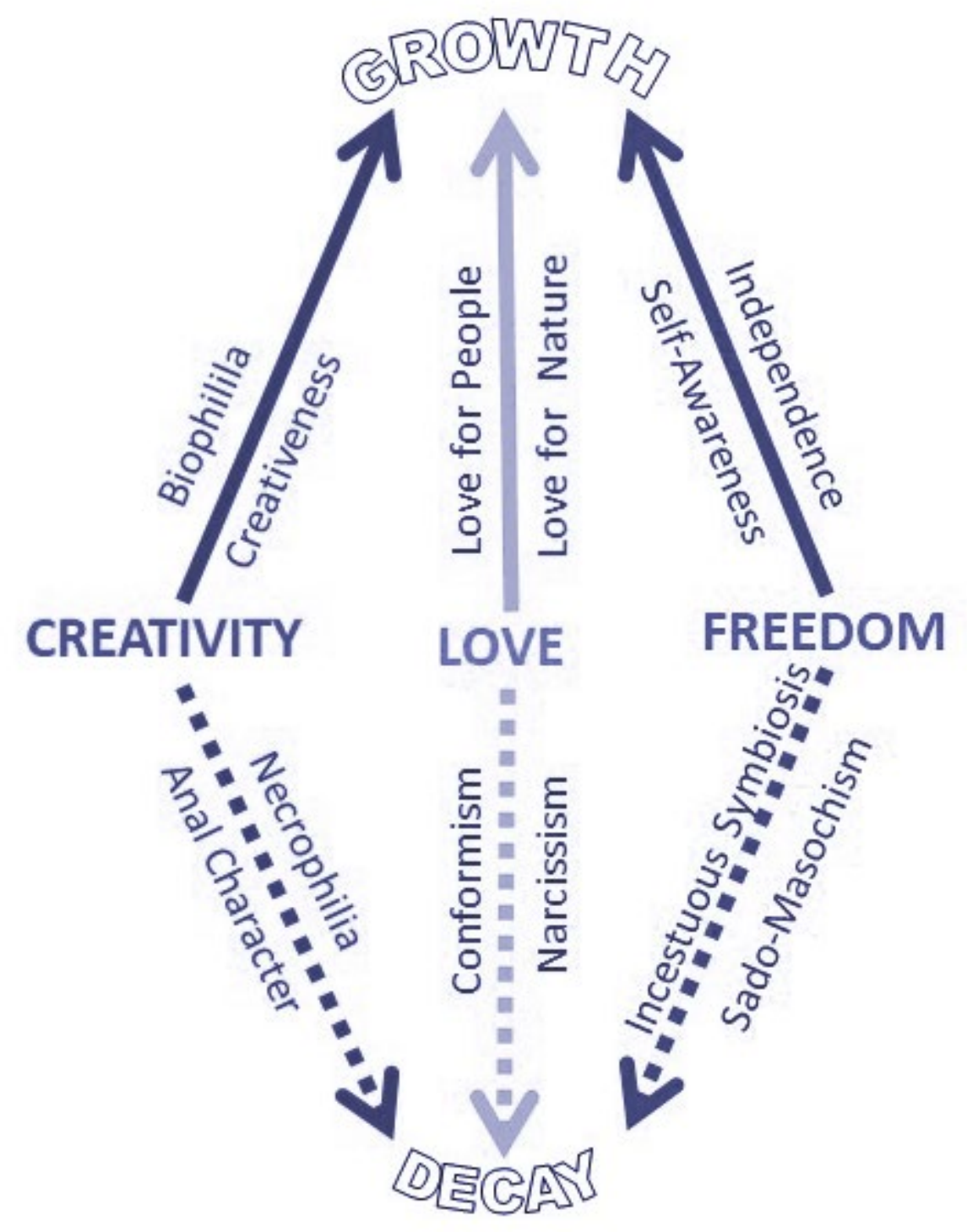

Diagram 1 (by author based on Fromm, 1980: 114) 
tubes. During the events, over 100 structured and semistructured interviews were conducted based mainly on two questions: "What is the main characteristic of the lowtech movement?" and "What made you get involved in the movement?". Those interviews were analysed in order to find the main repeating themes and lines of narrative.

\section{Psychoanalytical modelling}

The second line of investigation was an attempt at creating a model which would compare and contrast paradigms of the movement with other movements, in particular, the mainstream high-tech. The model has been developed based on Erich Fromm's theory of human needs. The hypothesis that 'translation' of the psychological theory into architectural syntax could be useful was suggested because of its universal character that allows bridging technical, social and psychological domains. Fromm proposed the model in The Heart of Man (1980) but was developing it throughout his life in his other works such as: The Anatomy of Human Destructiveness (1973), The Art of Loving (2005), The Fear of Freedom (2010) and others.

In The Heart of Man, Fromm proposed a model whose three key elements are 'freedom' (opportunity to develop one's own potential); 'creativity' (opportunity of active and meaningful interaction with the world) and 'love' (connection with the world and other people). Interestingly, Fromm calls those needs 'fundamental' while Maslow (1943) in his pyramid of needs calls them 'higher' and claims that people would want to fulfil them after the basic needs are satisfied. Fromm claims otherwise, and points out that people are often ready to suffer and even commit suicide not because they are hungry or uncomfortable but because they fight for freedom and desire, love or a meaningful active life.

Fromm's model and hypothesis links the needs of Love, Freedom and Creativity with culture and political systems. He argues that different social systems promote different ways of how the needs could be fulfilled. Fromm distinguishes cultures promoting growth from those which supress it, such as slavery, totalitarianism but also the hierarchical, bureaucratic office culture (which could be 'translated' into an architectural office culture). According to Fromm (2010), in a normal, healthy environment the 'need of freedom' manifests itself in developing one's own potential but if this is impossible, if society/ environment/culture does not support this development, the same need takes the form of oppression, destruction or an apathetic pedantic approach. Analogically, according to Fromm the 'need of love', which in a supporting environment naturally develops itself as togetherness with people and nature, could be transformed by dysfunctional culture into obsessive narcissism or conformism. In a similar way, the 'need of being creative' in a supportive society manifests itself in creativeness and 'biophilia' (the love of life), whereas in a destructive environment it could take the form of 'necrophilia' (love of dead \& controllable objects like machines). Fromm put forward a hypothesis that in a supportive environment every person would rather live in peace with people, be active and be free. However, if these options are not possible because of social conditions, one can fall into the alternative options: conformist, narcissistic and destructive (see Diagram

The question remains whether the Frommian theory could be applied in any useful way in other domains such as architecture? The following paragraphs test the 'translation' of Frommian concepts into a low-tech narrative. Each 'translation' starts by forming a short explanation of one of Fromm's psychological concepts, and then suggests how it could be translated into qualities regarded within this movement as flaws or virtues.

\section{FREEDOM}

\section{Incestuous Ties vs. Oedipus" Rebellion (Following the mainstream vs. escaping it)}

Fromm defines freedom as a condition in which individual potential can be developed (Fromm 2001). Since everyone's potential is different, the same concept of freedom could apply to people regardless of their different qualities. The first step to be free is to realise that one could be free. Fromm claims that in order to develop, one must break 'incestuous ties' 


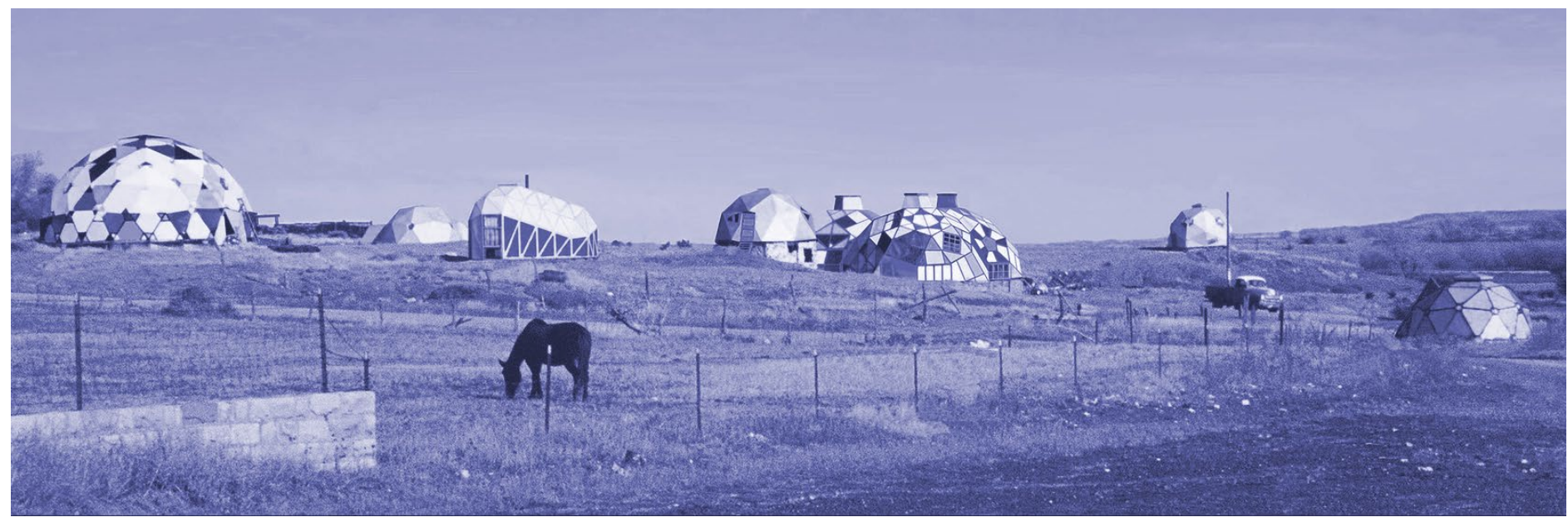

Fig. 1 Drop City - architectural manifestation of low-tech rebellion against establishment: unconventional form, material and organization (Photo: Clark Richert)

- a toddler must realise his/ her own independence from the mother, a teenager from the family. In the world of design, we can extrapolate this into metaphorically breaking incestuous ties between the designer and conventions.

Fromm adopted the Freudian concept of the Oedipal complex, but gave it an unfreudian interpretation. This complex is not so much a negative urge to kill the father, but rather a positive rebellion against authoritarianism which limits one's own development i.e., reinforcing freedom (2003 p. 117-118).

\section{Low-tech Narrative:}

Modern technology promises a lot of freedom but under one condition: keeping strong 'ties' with technocratic manufacturers posing as 'freedom providers'. Fromm's concepts can be translated both as a metaphor and narrative, but they also go deeper. Fromm emphasized the fact that the development of freedom (developing individual potential) is conditioned by exposure to 'external systems' such as culture and the socioeconomic environment. In architecture, it could again be interpreted as relations with clients or the professional architectural milieu, which manifest itself in fashions and social expectations. A hypothesis might be suggested that low-tech creators could be understood as 'oedipal rebels' against 'incestuous ties' imposed by systems. Many lowtech promoters defy authority in their own way. This was the case in 1960s in Drop City (Ebert, 1981) and in today's 'ecovillages' in which young people contribute towards a new culture which is often manifested by alien, unfamiliar architecture. "It was kind of rebellion against important people and totalitarianism" says founder of the Drop City (Grossman 2012).

Many low-tech architects were initially driven by the desire to escape the system which they found oppressive or unfulfilling and, in the process, decided to give up potentially 'successful careers'. Gernot Minke left work at the successful practice of Otto Freib; Hassan Fathy turned away from the path of a respectable modernist architect to later be nicknamed the "mad architect of mud" and Mike Reynolds was attributed the role of an "architectural outlaw" and "Garbage Warrior" (2009). This rebellion towards low-tech represents arguments against mainstream styles, manufacturers and energy suppliers using rational and emotional justification. In these circles everything that is 'off' or 'alternative' becomes a virtue: "off mainstream", "alternative", "off grid", or "autonomous house" all have a positive connotation for creators not only in these circles but often also in wider culture.

Some questions inspired by Fromm's concept of Oedipal Rebellion are: "Does a given technology allow you to rebel - to come out of your comfort zone?"; "Does it encourage you to leave the comfortable nest and fly?" or "Does it tighten the ties and seduce you by 'external potential'?"

\section{Frommian Perspective:}

A hypothesis may thus be suggested that low-tech could perhaps be better understood not as a result of hatred against modern technology as such, but as a longing for independence, the first step to which is the 'oedipal rebellion'. 


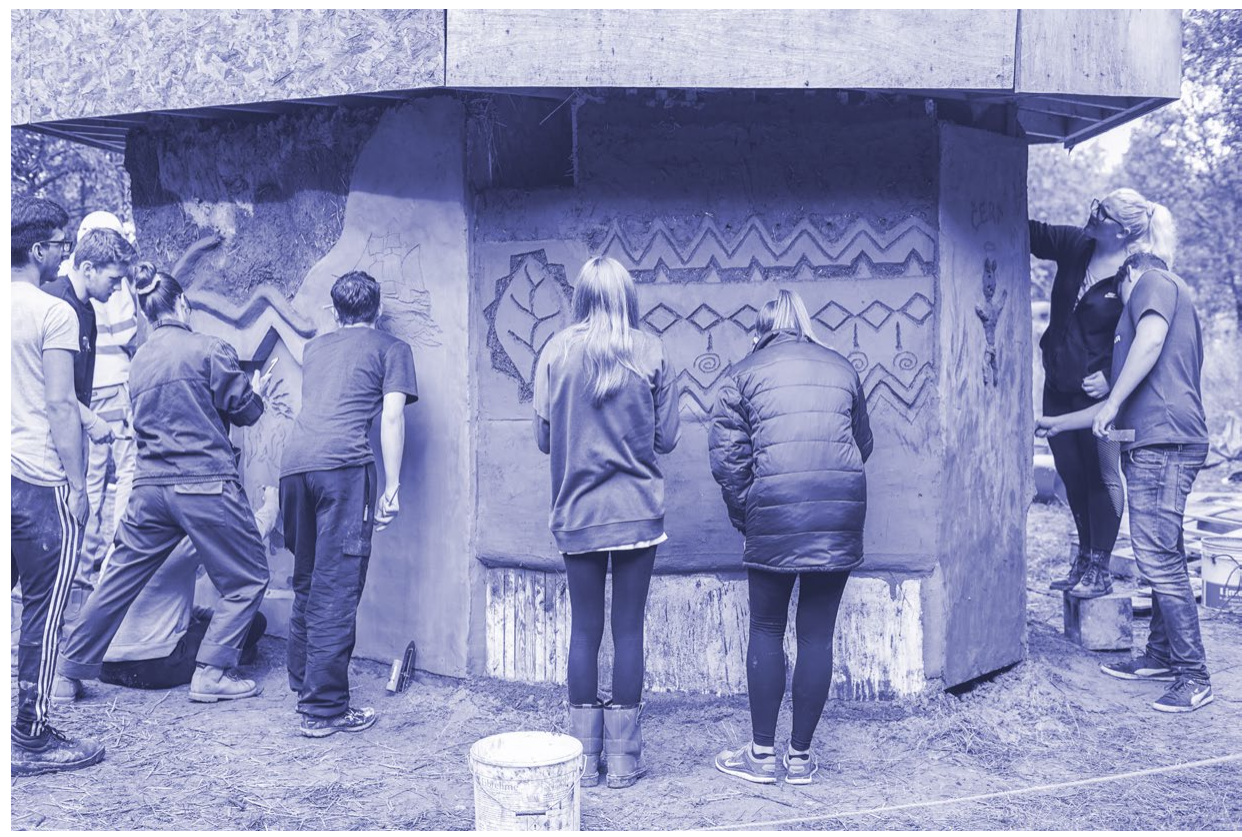

Fig. 2 Construction of Lincoln Hexagonium: each builder makes their own mark. This is what makes this building unique and what is a unique value of low-tech

Identification vs. Identity (Identification with Fashion and Techno-culture vs.

Identity Through Unique \& Contextual Design)

Fromm claims that an individual that has already managed to detach themselves from "incestuous ties" (mother, family, conventions etc.) needs to identify that they have - in other words to find their own potential and identity. In Man or Himself (2003), Fromm draws on the humanist tradition to show that the quest for selfconsciousness lies in the core message of thinkers in various cultures: Buddha said 'Be ye lamps unto yourselves (p. I), Master Eckhart 'I am I is only mine and belongs to me and nobody else' (p. 27), Spinoza 'the man is an end-in-himself' (p. 19), and Kant 'man should be an end of himself and never a means only' (p. 90). For Fromm, respect for identity is the sine qua non of freedom: "Man's main task in life is to give birth to himself, to become what he potentially is. The most important product of his effort is his own personality" (p. 177).

\section{Low-tech Narrative:}

In order to draw parallels with the low-tech building movement, it is vital to realise the extent to which modern technology contributes to identity. People are encouraged by adverts and cultural pressure to identify with the latest fashion or high-tech products as a way of creating individual images or improving credibility. Similarly in architecture, the latest technology is used as a way of raising status. Fromm warns against this loss of individual identity and encourages people to search for their own unique faculties.

A collective of testimonies of low-tech creators e.g. Kahn (2000, 2004), Olsen (2012) and others, show that sometimes low-tech is a way for people to find their own identity, value system, or own design path: Hugh Brown, the tree house builder, who decided to move to Honduras to take up what he called a "solitary life sufficiency removed from anywhere especially the United States", was conscious this trip was not the aim but only a means of finding his identity: "I knew I would not spend the rest of my life there... When the time came I returned" (Khan 2000, p. 94). Exactly such enjoyment of simple work as a way of developing one's own skills was a key concept of the archcritic of modern technology and Fromm's collaborator - Ivan Illitch (2001).

The involvement with lowtech is described by almost all professionals as a personal turning point and a relief from the bureaucratic environment in office work: "My psychosomatic hatred to office work was so bad that once they had to call an ambulance. After this incident, I decided to spend several months in Asia studying Tibetan construction techniques. After returning to Europe, I found straw bale movement which encapsulated for me a similar respect to nature."

Simple materials such as earth or straw also allow every creator to make their individual marks in the form of ornamentation or personalized solutions. Paulina Wojciechowska, founder of "Earth Hands and Houses", and author of Building with Earth, sees this as a particularly significant value of natural architecture and encourages every participating builder/ volunteer "to feel joy, play and make such a mark on her buildings" (Wojciechowska 
2001, p.148).

In Fromm's psychological perspective, respecting one's own identity goes hand-in-hand with respecting the identity of others. This explains why such importance is accorded to respecting the surroundings in low-tech. Christopher Day (2002) calls it the 'Spirit of the Place'. The use of simple local materials and vernacular techniques helps to emphasize the identity of the surroundings. This attitude contrasts strikingly with the approach of modern architecture and prefabrication, which imposes external systems and coordinates indifferent to the spirit of a place.

\section{Frommian Perspective:}

For Fromm, the 'need for identity' is common to all people, but it can be substituted by identification with external logos, gadgetry, and fashions for the latest technology. It may be argued that it is the aversion to those 'fashions', and not to technological development itself which is a characteristic of lowtech movement.

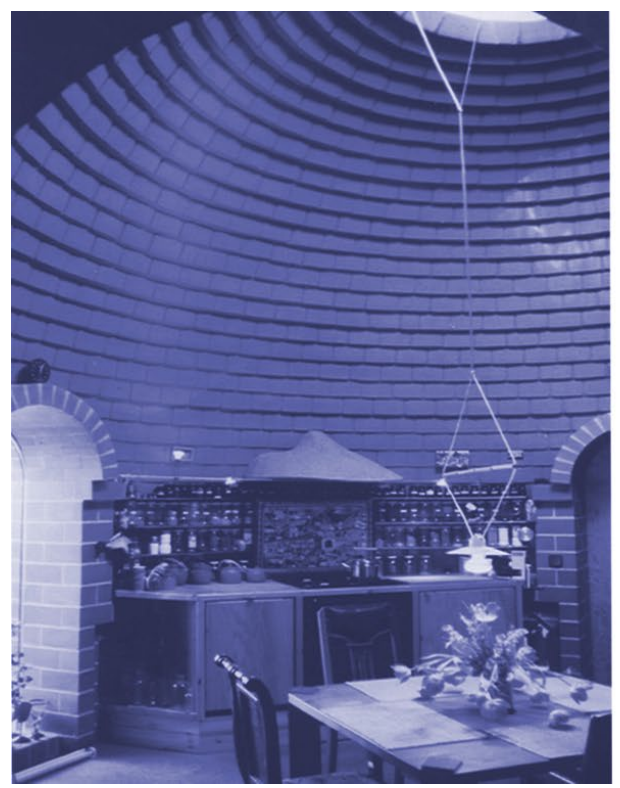

'Freedom from' vs 'Freedom to' (Decadent design vs. Developing human potential)

In The Fear of Freedom (2001), Fromm analysed the history of the concept of 'freedom' from the Renaissance, when the idea started to play a crucial role in Western culture, up until the 20th century, when central Europe gave up freedom by embracing fascism. In this seminal work, Fromm introduced a key distinction between the concept of 'freedom to', which gives meaning and makes it possible to develop one's own potential, and 'freedom from', which only frees a human from various ties and obligations. According to Fromm, the former could lead to passion, the latter to fears and anxiety, which could push people to accepting dependence and authoritarianism.

Using this differentiation, it may be argued that modern sophisticated technology promises freedom from dangers, toil and others, but
Fromm asks 'what does it offer instead?' Freedom from constraints could be interpreted as 'decadent design' ('know how' without 'knowing what for').

\section{Low-tech Narrative:}

Many low-tech promoters are sceptical about technology offering 'freedom from' toil without developing meaningful independence. "I am happy that I do not need all those new materials to feel free and creative," said Professor Gernot Minke.b

If we agree with Fromm that freedom is a 'possibility to develop individual potential', then we can also make sense of the main drawcard that attracts people to low-tech workshops. These events are orientated largely towards developing individual skills, knowledge, and networking. The testimonies of self-builders show that they are often convinced that the greatest freedom comes from satisfying the basic needs of here-andnow (such as dwelling). "People think of the word 'primitive' as

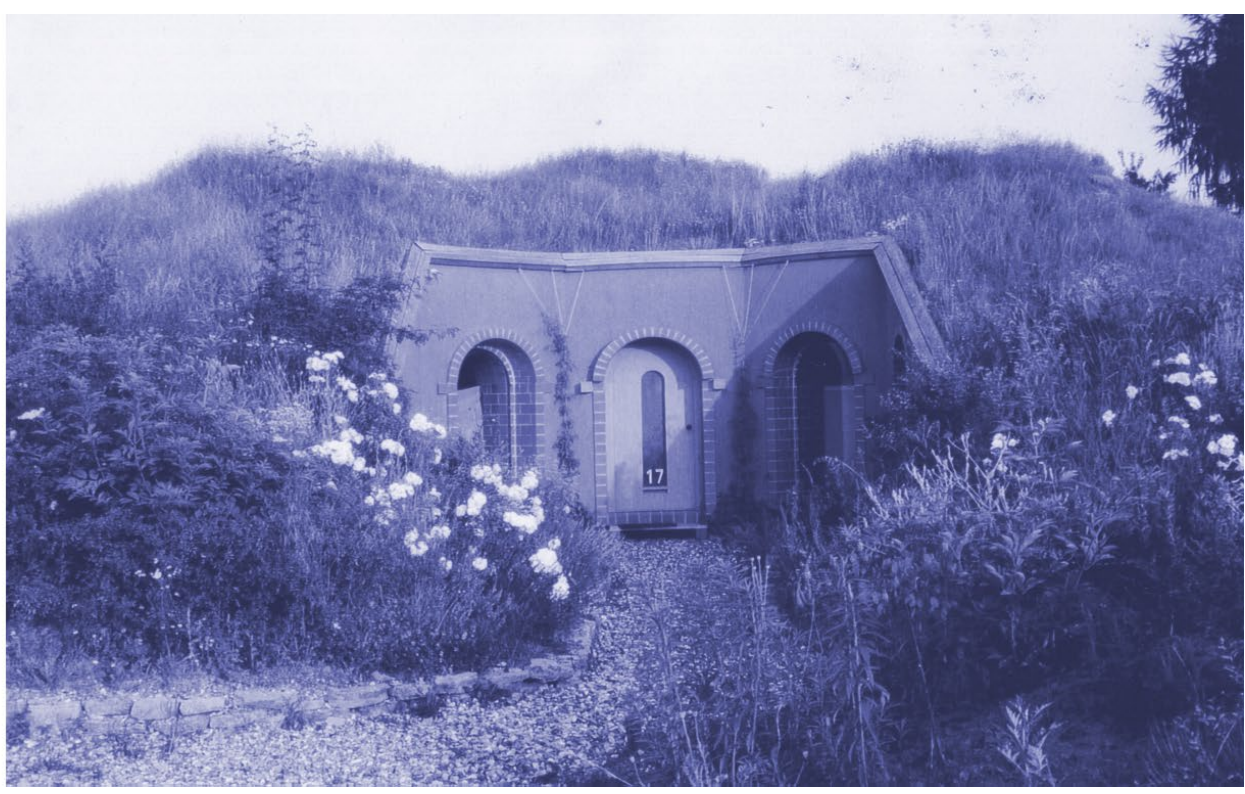

Fig. 3 Interior and exterior of a private house designed by Gernot Minke for himself which encapsulates the low-tech idea if independence from processed materials. "I am happy that I do not need all those new materials to feel free and creative".[b] 
derogative. For me it derives from 'prime', fundamental and if a building has good foundations then you can be free and creative and you can sculpture the walls as you want," said Paulina Wojciechowska.[d]

\section{Frommian Perspective:}

Thus, the reluctance towards sophisticated technology in the low-tech movement may not really be a criticism of technology as such, but could rather be understood as reluctance towards technology that makes people dependent on external systems. In this sense, the low-tech paradigm shift would be in the direction of 'freedom to'.

\section{Sadomasochism}

vs. Independence

(Standardisation vs.

Experimentation)

Highly complex technological systems require hierarchically organised processes and structures. Fromm claims that socio-cultural and technological structures in which individuals feel subordinate or superior to others, push the human psyche towards what he calls a 'sadomasochistic character' and thus blocks growth, which needs a balanced partnership.

Low-tech technologies could thus be seen as a direct reaction against this "sadomasochistic dependency" - limiting oneself to simple techniques reduces concerns around access to expensive materials, and reduces the need for external experts and a rigid system of standardisation.

As a result, it encourages experimentation and direct contact. It reduces the distance between the creator and the object of design: it allows for touching and feeling the material. At the same time, it is worth noting that such a close relationship between the designer and the environment could positively impact the 'ecology of design' if, indeed,

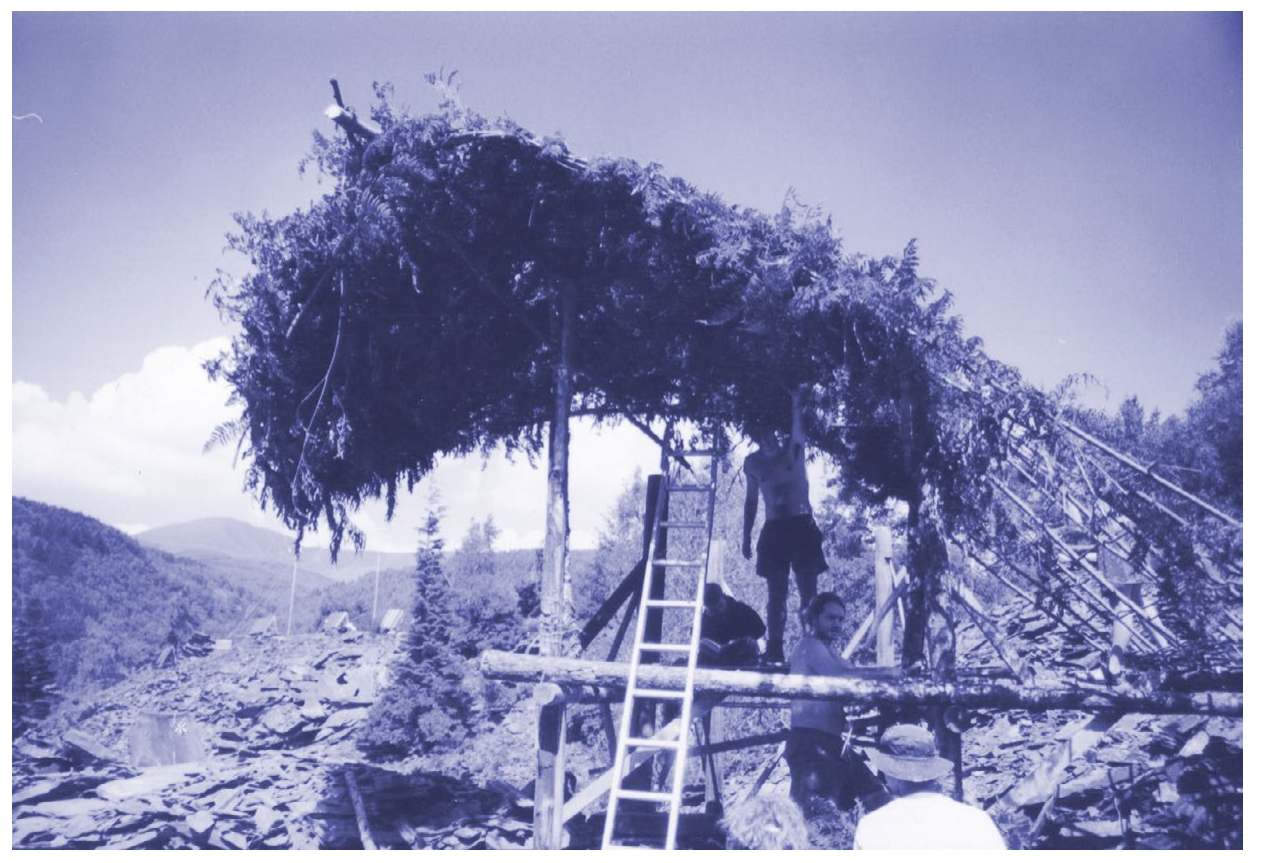

Fig. 4 Workshop 'Unfamiliar Materials and Structures' at the Centre for Alternative Technology in the UK run by Maurice Mitchell, who values the fact that low-tech materials invite unpredictable solutions which could unleash hidden architectural skill of their creators.

ecology is understood as a derivative of a 'relationship'.

\section{Low-tech Narrative:}

In promoting untypical building methods, low-tech approaches could encourage cooperation and partnership. Sarah Wigglesworth, the architect of Stock Orchard Street office in London, famous for her use of untypical materials, claimed in an interview that the "introduction of those techniques deconstructs macho relationships on the building site and encourages cooperative problem solving".d Maurice Mitchell (1998) seems to agree with her when he says that "technology using unfamiliar materials" has a power to generate skills, techniques and understanding of other cultures. Mitchell claims that experimenting is an effective way of developing individual potential.

The value of such experiments could be illustrated by a designer who said: "It is not important if the objects are low- or high-tech. I am interested in voyage, experimentation. Mistakes help me to discover new paths".[f] $\mathrm{He}$ is by no means motivated by an aversion to sophisticated technology, rather the low-tech approach allows him to be more creative.

\section{In Anatomy of Human}

Destructiveness, Fromm introduced the concept of a sadomasochistic relationship, which resulted from a mindset of people for whom everything needed to be in a strict hierarchy and each thing had to be subordinated to another, preventing partnership. 

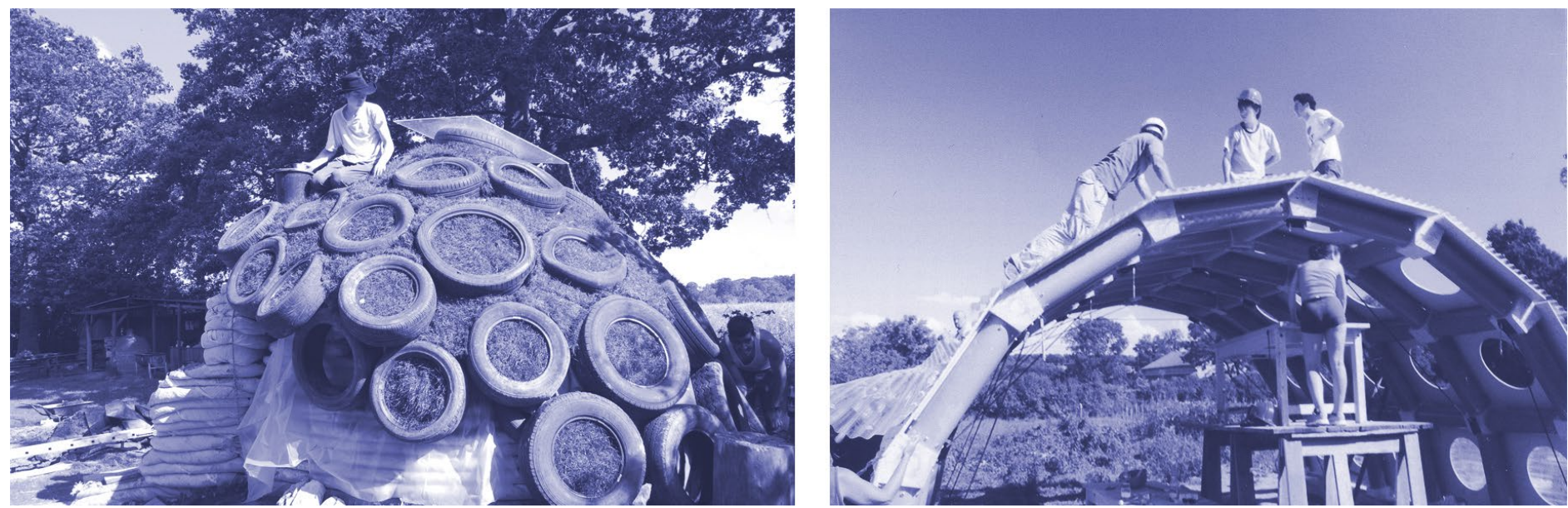

Figure 5 Earth Dome in Hill-Holt Wood covered in car tires and a vault by Shigeru Ban supported by paper tubes. Both projects were possible because of low-tech's distinctive feature which is encouragement of self-built and experimentation with cheap non-standard materials.

\section{Frommian Perspective:}

Thus, it could be suggested that low-tech practitioners avoid highly technological processes not because they do not appreciate technology as such, but because they try to avoid hierarchical environments, which Fromm relates to sadomasochistic culture ("either you tell me what to do or I tell you what to do").

\section{CREATIVITY}

\section{Workaholism vs. Active Life (Mass-produced off-shelf architecture vs. self-builld)}

When talking about 'creativeness', Fromm referred to the state of being active as an ability to change the environment and one's own self (2002: 35-37). In Creative Attitude, he emphasized that creativity is an attitude to life and not merely an artistic endeavour: "To be creative means to consider the whole process of life as a process of birth and not to take any stage of life as a final stage" (Fromm 1959: 44).

The technology that has been developed since the Industrial
Revolution never fulfilled the promise of liberating mankind from mentally unsatisfying labour. Work that is alienating and 'deprived of joy' has been criticised by critics of technology from John Ruskin (2004) to Ivan Illitch (2001). Fromm discusses the problem of workaholism, which he describes as an antithesis of creativity - a result of stress and anxiety. Comments of architects who changed their environment from conventional to low-tech often emphasize the lack of creativity in mainstream practices: "Being creative' is merely a privilege of a very small number of well-publicised individuals (e.g., star architects) whilst the stress related to deadlines, quality, finance, or increasing productivity are typical factors affecting other more general architectural workers." In the Frommian sense, despite the fact that it 'creates' objects, this type of production perpetuates the social status quo and cannot develop 'creative' people.

\section{Low-tech Narrative:}

Low-tech is not merely dedicated to the production of objects, but it often aims to 'produce' social change. The promotion of building techniques for everyone, activating people and 'the democratisation of technology' lies at the heart of lowtech and the Open Source Movement as is spelt out in the self-repair manifesto: "if you can't fix it, you don't own it" (Fixit, 2021). This explains the contrast between the popular paradigm of exclusive technology promoted as 'easy' and the low-tech virtue of 'work intensive' but accessible building methods. Most lowtech techniques allow for the participation of unqualified people or even children in an environment in which everyone can feel like a creator (Minke 2006).

Because of their simplicity and low price, low-tech techniques, unlike high-tech, also encourage modifications during habitation. In a concrete building, the user must be very determined to introduce changes, whereas in a simple timber frame construction adaptation of the layout and structure is available using basic DIY measures. 

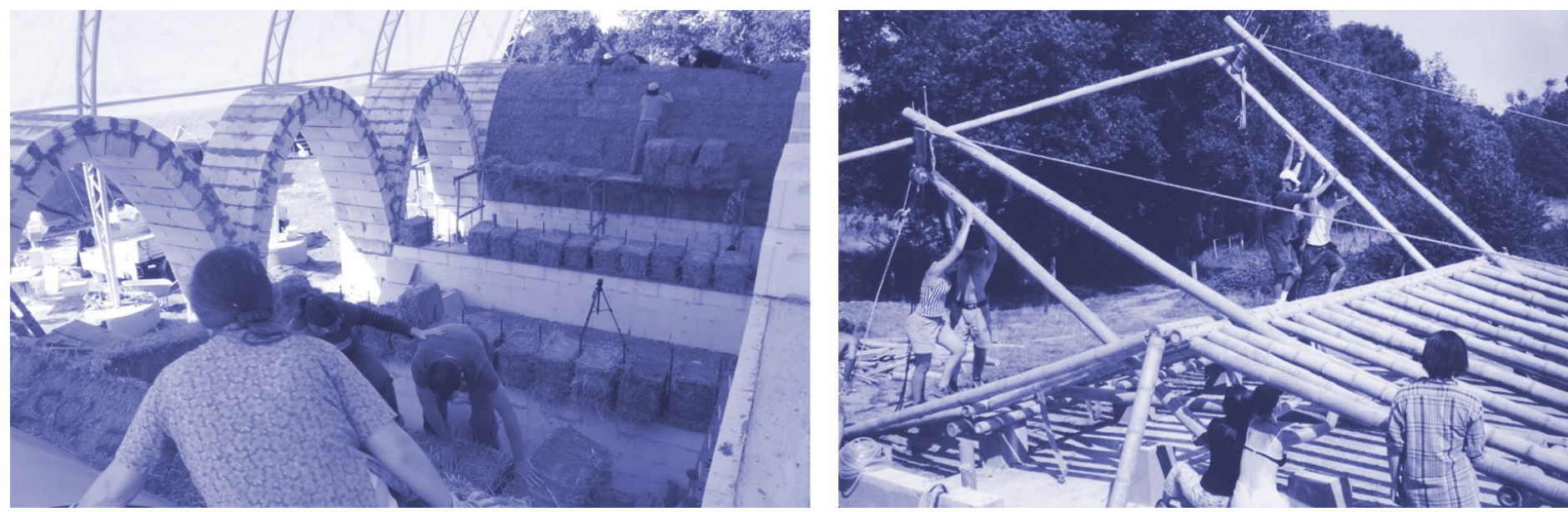

Figure 6. Straw vaults in Wangelin (by Gernot Minke) and Bamboo House in Boisbuchet (by Simon Velez). Those projects, like many other low-tech projects, were possible because volunteers are attracted to natural building sites.

\section{Frommian Perspective:}

It seems likely that the low-tech movement attracts people who are disappointed with the building methods that limit one's own initiative. Perhaps in order to understand the essence of low-tech, we need to understand the sheer pleasure and joy of work and being active?

\section{Necrophillia vs. Biophilia (Dynamism of Machine vs. Dynamism of Life)}

Biophilia is a core concept coined by Fromm, which emerges as an interdisciplinary framework for investigating human affiliation with nature, life and life processes, such as dynamism, change, unpredictability and complexity. Fromm claims that socioeconomic systems influence biophilia. "Love for life will develop the most in a society where there is: security in the sense that the basic material conditions for dignified life are not threatened, justice in the sense that nobody can be an end for purpose of another, and freedom in the sense that each man has the possibility to be an active and responsible member of society" (Fromm 1964: 53). The question remains then as to the means by which different societies and different 'architectural communities' influence this dynamism in different ways.

\section{Low-tech Narrative:}

Dynamism and change are a trade mark of modern mainstream architecture. This, however, begs the question: dynamism 'of what' or 'of whom'? The glorification of dynamism was introduced into European culture in 1909 by Futurists with their famous Manifesto (Marinetti 2009) praising speed, machine, brutality, anti-feminism and war. Analysing this text, Fromm wrote: "Here we see essential elements of necrophilia: worship of speed and the machine; glorification of war destruction [...] that characterise Nazism, Mussolini and Hitler [...] They had no genuinely creative ideas, nor did they accomplish any significant changes for man. They lacked the essential criterion of the revolutionary spirit: love of life" (Fromm 1973, p. 345). For Fromm 'necrophilia' (love of dead objects and fear of life processes) was a concept identifying the key attitude of a technocratic culture praising objects, machines, and predictable systems.

Significantly, in this respect low-tech offers a paradigm shift. Its promoters are often driven by the ambition of empowering life: people, communities and nature (Naess, 1993). Dynamism in the low-tech environment often relates more to boosting self-reliance and aims at changing public opinion and lifestyle. In Architecture for the Poor, Fathy talks about vernacular techniques not as an end in themselves but as a means to combat unemployment and improve the low self-esteem of local population: "So the peasants at once begin to look on their own products with pride" (Fathy, 1976: 43). John Smith, builder of the Universal Hall in Findhorn Foundation - Scottish 'Mecca' of low-tech architecture - said "we didn't build the hall, but the building built us." [g] It is one of the recurring themes among low-tech builders (Dethier 2002). 


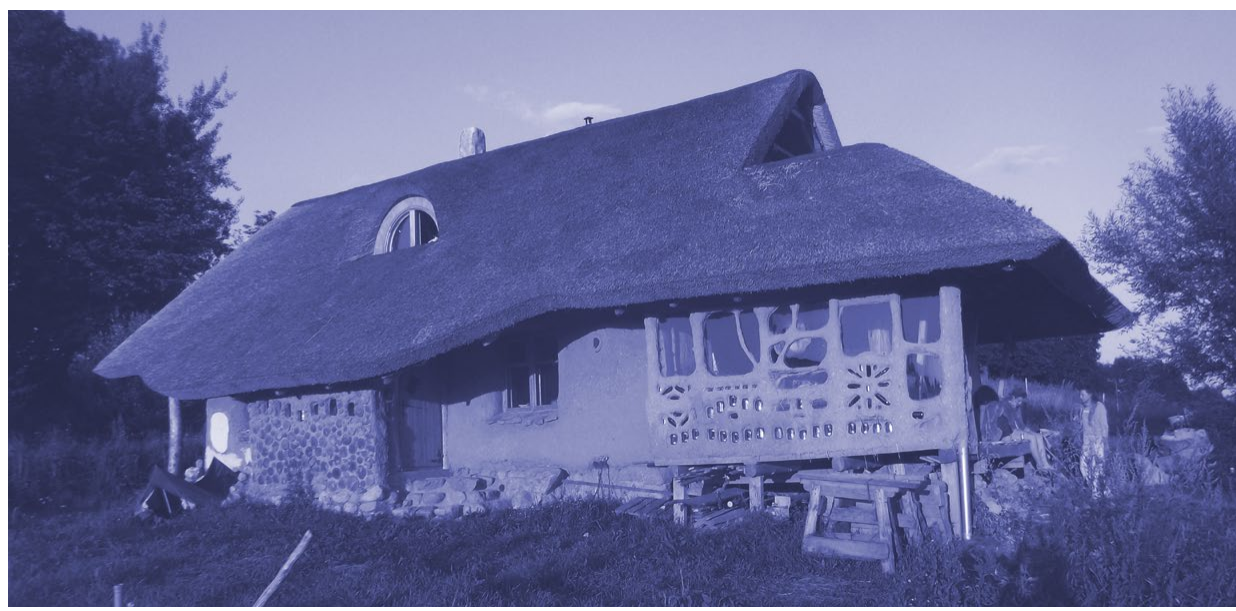

Figure 7 'Beauty on imperfection' is for many the most attractive feature of low-tech. Straw bale house in Przełomka (by Paulina Wojciechowska)

Further, according to Fromm's model, affiliation with nature is a natural consequence of the biophilic attitude. This mindset can often be observed in low-tech creators who strive to harmonise with nature by incorporating green roofs and walls and contextualizing buildings in their natural setting. Self-imposed technological constraints could be seen as a reflection of the natural limits of biological-growth, which is a characteristic of every living being (Kennedy 1995).

\section{Frommian Perspective:}

Given the above, one could perhaps ask whether it is not the machines as such that low-tech architects are in fact repelled by, but the lack of this biophilic appreciation of life and a necrophiliac fascination with dead objects that suppress creativity?

\section{"Anal Complex" vs Complex Stimulation (Obsession with Control \& Pedantry vs. Beauty of Imperfection)}

Fromm used the concept of the 'anal complex' to explain why attitudes such as orderliness so often go together with an authoritarian character suppressing spontaneous creativity. "[...] The tendency to control and possess is only one aspect of anal character, but milder and less malignant than hate against life" (Fromm 1973, 462). Compulsive cleanness is thus a symptom of fear of life which by its nature is "messy" and not predictive.

The 'anal character', craving for cleanliness, and fear of 'touching' anything dirty could describe modern technology and high-tech architecture spotless but cold, unpleasant to touch, uncompromisingly precise and at the same time often struggling to cohabitate with nature which is too unkempt in a media environment which requires images of clean cut, crisp buildings.

\section{Low-tech Narrative:}

At the same time, low-tech can often be located on the other side of the spectrum in terms of aesthetics. "Look at the cold glass and steel building. How unpleasant it is to touch it. Why would anyone want to design an untouchable building?", I was once asked by an earth builder, Henning Schmitt. h Low-tech embraces what the Spanish describe as 'belleza de la imperfección - the beauty of imperfection, and the Japanese as wabisabi - cherishing the look of unfinished artefacts.

The architect Rhen August Benson thus describes this contrast: "Low tech vs. high tech; tactile vs. slick; real vs. ideal; form and light take precedence over material and finish; intuitive vs. rational and logical; natural vs. manufactured; simple without austerity or pretence" (Benson, 2021) Hundertwasser was convinced that an ecological artist should avoid straight lines (Hundertwasser, 1986), whilst Papanek valued the beauty of slightly worn down objects over brand new: "all the scratches are just beginning to give it character, making it unique" (1995, 142).

The imprecise nature of lowtech often results in it being rejected by the wider audience or other potential clients. However, this is a characteristic of this movement that deserves being investigated particularly in contrast with the mainstream 'anal' tendencies. Lack of accuracy derives from the employment of simple methods. Despite this, Fromm's interpretation encourages research into a correlation between this low-tech inclination and its ecological ideals.

\section{Frommian Perspective:}

Thus, it is suggested that this aspect of low-tech is not denying the benefits of technology but merely 


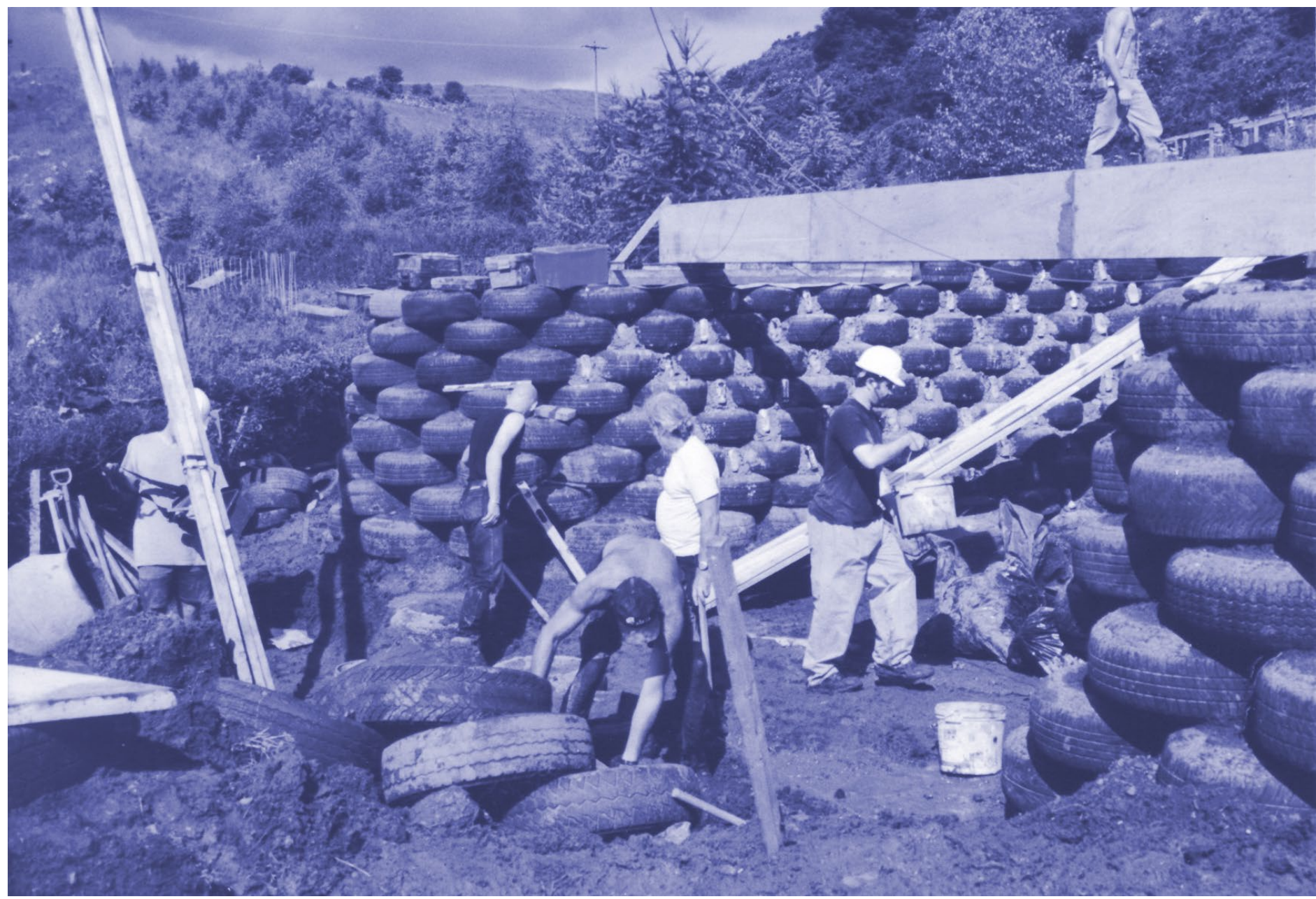

Figure 8. Earthship construction by Michael Reynolds, who like other low-tech architects developed a cheap construction for poorer parts of the society

a subconscious reaction against those types of modern technology which cannot find a way to support life.

\section{LOVE}

Narcissism vs. Togetherness (Competition vs.

Cooperation)

In The Art of Loving,

Fromm described love in the socio-political context as a "development of interest, care, responsibility, respect and knowledge" toward the environment (Fromm 1956, p. 32-33).

If the need for loving is blocked, however, human beings often push themselves towards decay in the form of conformism or narcissism.

\section{Low-tech Narrative:}

Narcissism, both of society in general and of the architectural profession specifically, might explain the problems in Modernist buildings' failure to relate to the context. Modern cities with shopping centres which turn their backs to any kind of integration with the local surroundings, or megalomaniac edifices that overshadow the neighbouring city fabric are only some examples of narcissism in architecture. A contemporary capitalist society's glorification of competition and egoism (without care, responsibility, respect or knowledge) goes hand-in-hand with the conformism of maintaining standardised products, styles and approaches.
Thus, the contrast of this attitude with the low-tech paradigm could not be more striking. Cooperation, mutual help, sharing and open-source are concepts deeply embedded in the ethos of the low-tech movement. Most straw-bale constructions have been erected as a group effort of volunteers and enthusiasts. Catarina Pinto, straw and earth builder, said: "If you want to build a house, you either need a lot of money or a lot of friends" i. Limitation and simplification encourages alternative self-build by friends, neighbours or communities. Settlements designed by Walter Segal in Lewisham (Towers, 1995: p. 82-85) or Michael Reynolds in Taos (Reynolds, 


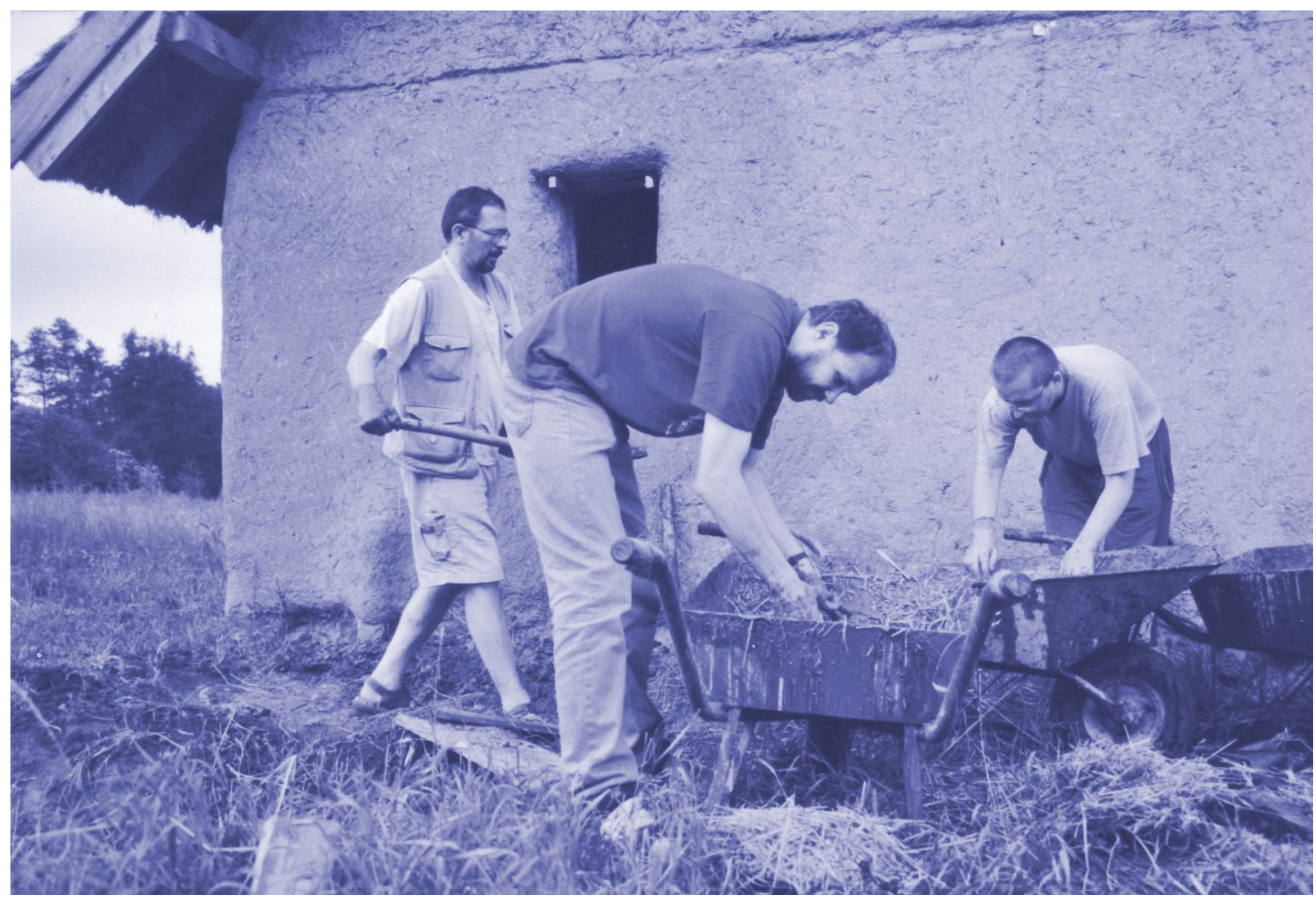

Figure 9. Direct contact with material and building processes is a characteristic of many low-tech constructions. In the picture: the author (in the forefront) mixing cob for Kadłubówka first Polish straw-house design by Paulina Wojciechowska

2000) were possible not only thanks to simple techniques but also because members of the community helped each other.

\section{Frommian Perspective:}

A hypothesis may be suggested that the people who experience the pleasure of cooperation in low-tech construction might be repelled by high-tech because of an anxiety related to competition and predictability associated with the conformism of established systems.

Inrelatediness vs.

Relatedness (Indirect vs. direct contact with the builling process)

Fromm redefined Freud's core concept of libido into his perception of loving as "active striving and inner relatedness" (Fromm, 2005: 99).

Sophisticated technology often introduces tools, interfaces and procedures which disassociate the user away from the subject. At times, this indirectness could be perceived as a loss of relationship with the environment or with the subject of creation.

\section{Low-tech Narrative:}

Paulina Wojciechowska said "Sometimes when I work on a computer, I can see a yellow line, a green line and I feel like I am losing contact with the building and the design. It is so liberating to touch the building with your own hands, to feel it and smell it. There is nothing better than the touch of earth while are you plastering a wall with your own hands and being able to shape it with every move of your palm".d

Many volunteers participating in low-tech constructions emphasize the pleasure of direct contact with materials and processes. Low-tech methods, more than any others, enable close direct contact with materials. The urge to be closer to the site and its workers, makes some designers move away from office work. Simon Velez said "My office is where the building site is, and by being close to my workers, all I need is an A4 sheet to explain any aspect of the project". 


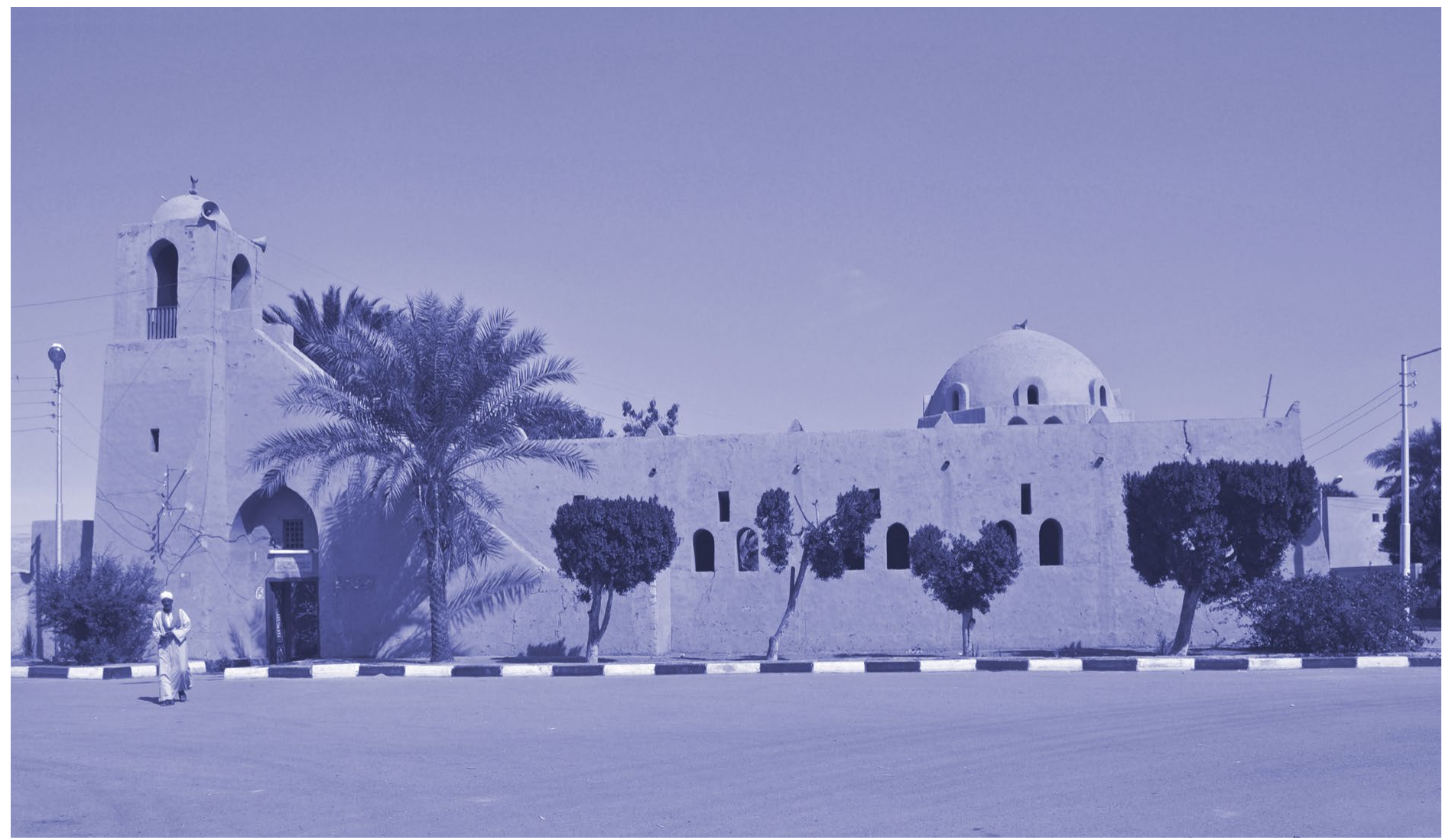

Figure 10. Many low-tech architects were driven by the idea of helping the poorest parts of society. In the picture: New Gourna designed from earth by Hassan Fathy (photo by Marc Ryckaert)

\section{Frommian Perspective:}

Thus, a hypothesis may be suggested that lowtech creators do not wish to oppose a society that develops technology, but instead to enrich technological development with a more direct and tangible relationship to materials and people.

\section{Care vs. Carelessness (Care vs carelessness in architecture)}

Fromm decided to reclaim love from naïve pop culture. In The Art of Loving (1956), he described love in the psychological but also socio-political context as a development toward "interest, care, responsibility, respect and knowledge of environment" (Fromm: 32-33).

Modern technology often makes it possible to fulfil our needs (and wants) without having any care, knowledge or responsibility. Users of sophisticated technology are rarely encouraged to consider the whole life cycle of a product or what happens to it once it has been used. As Giles Slade (2006) claims in his Make to break, planned obsolescence became part of advanced technology - "Out of sight, out of mind". Jealously guarded knowledge in hightech culture is legally reinforced by intellectual property rights, copyright and often embedded in products deliberately designed as incompatible with products made by other manufacturers.

\section{Low-tech Narrative:}

In a series of interviews conducted at the European Straw Bale Gathering [k], accusations of the irresponsibility of modern technology were expressed by more than half of interlocutors. Due to limited resources, low-tech approaches compel builders to understand, appreciate and study the laws of nature, limitations of materials and the potential of local environment and vernacular architecture. Gernot Minke, one of the world's most prominent researchers of natural construction, said: "When I visited Middle America and saw villages with poorly designed architecture, I realized that by combining their vernacular tradition with construction knowledge which I had as an architect, I could make a much bigger change to the world than in fancy modern architecture".[c] Encouraging knowledge, educational values and information sharing play an important role in low-tech 
architecture. Low-tech blogs, books, meetings or workshops are usually connected with a mission of popularising knowledge. Some institutions, such as the Centre for Alternative Technology, started as informal groups dedicated to the promotion of knowledge, before they developed towards becoming an organiser of formal education courses in cooperation with universities (Harper, 1995).

\section{Frommian Perspective:}

Rehabilitating the concept of 'love' makes it possible to see a strong connection between psychological needs and the low-tech movement. Architecture observed through this lens inspires one to pose the question: perhaps what really fuels low-tech is not techniques but the dissatisfaction with carelessness, and the need for love?

\section{TRANSLATING PSYCHOANALYSIS INTO ARCHITECTURE}

In the previous paragraphs, Erich Fromm's concepts were translated into the domain of architectural narratives and analyses. These translations make it possible to identify and systematise the characteristics of low-tech that distinguish the movement from others. The narrative allows presentation of the main qualities of this movement not as merely related to techniques, tools or materials, but rather as emanating from a more significant psychological position.

In this paper, the elements of Fromm's theory presented in Diagram 1 were 'translated' into key architectural concepts which could be visualised in Diagram 2.

It is worth noting that Diagrams 1 and 2 indicate the interdependency of the 'needs axes'. This model emphasizes that it is not enough to nurture only one aspect of growth: Love without freedom turns into overprotectiveness paralysing personal development;
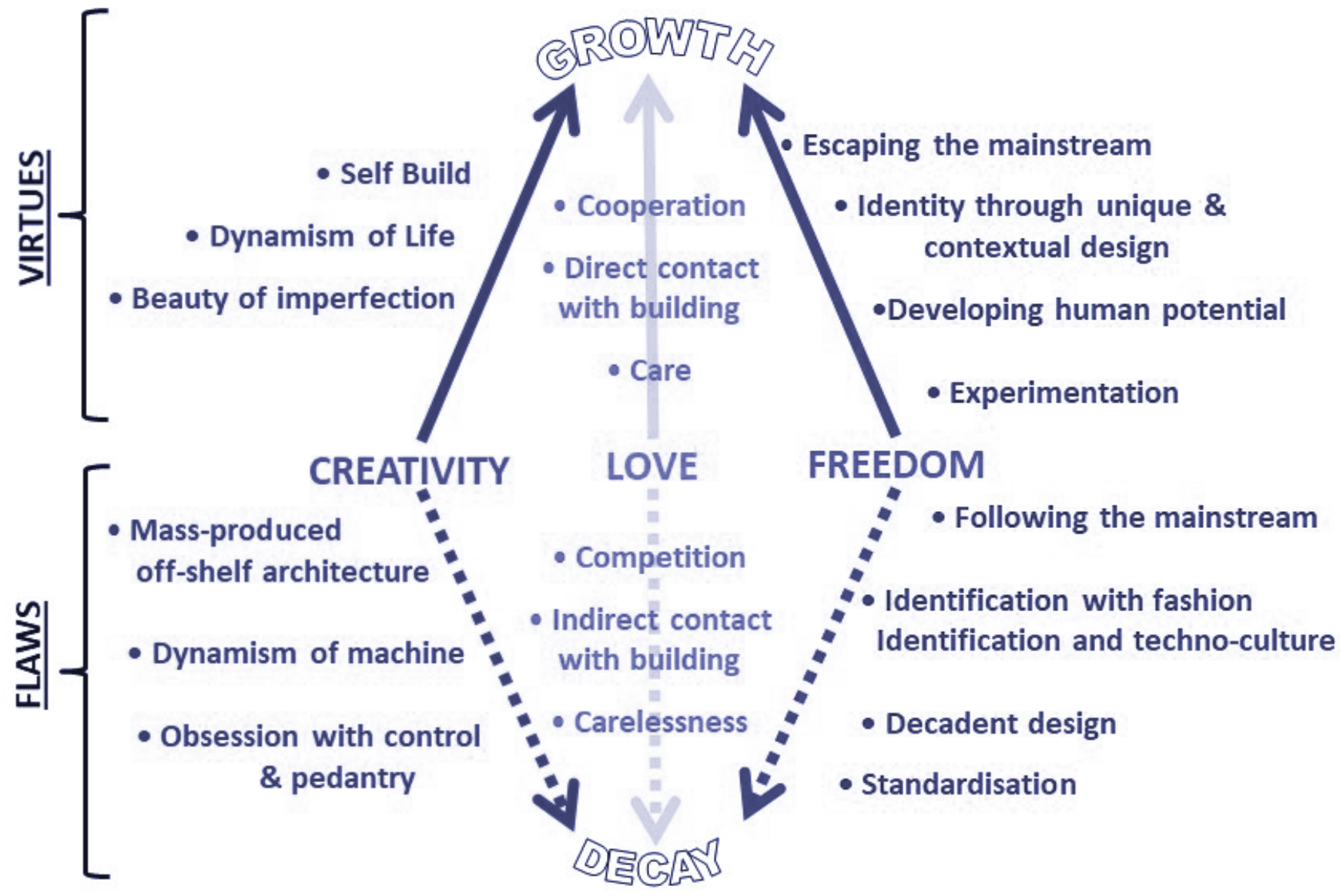
freedom without creativity is not constructive, and creativity without love may turn into decadent design. In order to assess the attitudes and paradigms of creators, aspects of love, freedom and creativity should not be assessed separately but they should be triangulated. Diagrams 1 and 2 could also be useful in describing architectural creation by indicating the intensity/ potential on each axis.

\section{CONCLUSIONS}

The movement of low-tech is under-researched and not without organisational and ideological challenges. Yet, it deserves particular attention because it tests answers to vital questions concerning our technological civilisation - in material, technological and narrative sense - our relationship to the 'commons': the benefits of social collaboration, lack of resources, potential for reducing the use of energy, but most of all - the role of technology in personal and social development.

\section{Literature on low-tech} has so far not managed to develop a satisfying definition encapsulating the characteristics of the movement. Low-tech cannot be described merely by analysing technical aspects of this movement. The 'translation' of Fromm's theory into architecture proposed in this paper offers a narrative and a research platform which relates to the attitudes of creators and links it with the socio-economic culture. This perspective makes it possible to redefine 'lowtech' as a movement which could be characterised by voluntary refusal of available sophisticated technology and replacing it by innovations driven by ambitions for reshaping the role of technology towards processes that would respect the humanistic, psychological, environmental or social values. Translation of Frommian concepts helps to analyse those ambitions as an attempt to support 'construction process culture' which will nurture personal growth.

The narrative suggested in this paper helps to see the problems of a sustainable building industry not merely from the perspective of tools, indicators, measurements of $\mathrm{CO} 2$ and KW/h etc. Attitudes of designers, builders and users have their psychological dimension. A building could be designed or presented theoretically as sustainable, but all of this would be in vain if the process is not supported by and harmonised with culture and psychological attitudes of designers, builders and users.

This problem is identified, for example, by research on the well-known problem of 'performance gap' - where a disparity is found between the sustainability predicted at the design stage and that in operation.

The key to sustainability which would truly respect 'common' resources, spaces and values lies in the psychological attitudes and aspirations of designers, builders, promoters and users. This is why the humanistic perspective and narrative of technology is so important. Translations proposed in this paper could be one way of constructing a narrative which bridges the technical and humanistic perspective.

The remodeling of the architectural analytical toolkit proposed in this paper suggests different 'measuring strategies' which refer to love, creativity and freedom. Are we able and ready to translate those humanistic values into architectural narrative and analyses?

\section{NOTES / REFERENCES TO INTERVIEWS CONDUCTED BY THE AUTHOR}

[a] Interview with Jean Dethier, Boisbuchet Vitra Museum Centre, France, 21.07.2002

[b] Interview with Gernot Minke, Wangelin Germany, 2011.09.01

[c] Interview with Jakub Wihan. Bridport, UK. 2012.06.20,

[d] Interview with Paulina Wojciechowska, Przełomka, Poland 2007. 08.17.

[e] Telephone Interview with Sarah Wigglesworth 2008.02.20

[f] Interview with Peter Rollings. Lincoln 2014.05.14

[g] Interview with John Smyth (one of the builders of Universal Hall in Findhorn), Findhorn Foundation 06.06.2002

[h] Interview with Henning Schmitt Berlin, Conference Lehm 17.11.2000

[i] Interview with Catarina Pinto Wangelin, 30082014

[j] Interview with Simon Velez, 21 July 2000. Boisbuchet, France

[k] Series of 20 interviews. European Straw bale Gathering 2013.09, Łódź, Poland

[l] Interview with Gernot Minke, Wangelin, Germany, 28 Aug 2011 
BALL, Rick, COX Paul, Low-Tech.

Fast Furniture for next to Nothing.

London: Century Publishing,. 1982.

BENSON Rhen. Technology manifesto. [viewed date: 2021.04.29]. $<$ rhenaugustbenson.com>

CURL, James., The Dictionary of Architecture. Oxford: Oxford University Press, 1999.

DANIELS, Klaus. Low-tech, Light-tech, High-tech. In: Deutsche Bauzeitung. 1999. December, 55-66.

Dethier Jean and others., Grow Your Own House: Simon Velez and Bamboo Architecture. Weil am Rhein: Vitra Design Museum, 2002.

DICKSON, David. Alternative Technology and Politics of Technical Change. Glasgow: Fontana/Collons, 1974.

DAY, Christopher. Spirit \& Place. Oxford: Architectural Oxford Press,. 2002.

DURKIN, Kieran. The Radical Humanism of Erich Fromm. Palgrave Macmillan, 2014.

ELIZABETH, Lynne. ADAMS, Cassandra.,. Alternative Construction: Contemporary Natural Building Methods. John Wiley\& Sons Inc, Toronto.

FATHY Hassan., Architecture For the Poor. London: The University of Chicago Press. 1976.

FIXIT. Repair Manifesto. [viewed date: 2021.05.29]. <https://www.ifixit. com/Manifesto>

FROMM, Erich. The Heart of Man. London: Harper Colophon Books,. 1980.

FROMM, Erich. The Anatomy of Human Destructiveness. New York: Holt, Reinhart and Winston, 1973.

FROMM, Erich. The Fear of

Freedom. London: Routledge. 2010.

FROMM, Erich. The Art of Loving. London: Thorsons, . 2005.

Garbage Warrior, directed by HODGE Oliver [Film], UK: Rachel Wexler. 2009

Grossman, Drop City 2012 directed by GROSSMAN Joan [Film], US: 2012
Gibson W., 1981. Johnny

Mnemonic. Omni Magazine, May, 44-55.

HUNDERTWASSER Friedensreich., Humaniesierung der städtishen Umwelt -Kehrtwertung. In: KENNEDY Margritt (ed.) Öko -Stadt. Band 2.

Berlin: Fischer Tashenbuch, 1986, pp. 56-57

ILLICH, Ivan. Tools for Conviviality. London: Marion Boyars, 2001.

KAHN, Lloyd. Shelter. Bolinas: Shelter Publication Inc., 2000.

KENNEDY Margrit.. Interest and Inflation Free Money. Michigan: SEVA International Okemos, 1995.

Kellert Stephen., Wilson Edward. The Biophilia Hypothesis. Washington: Island Press, 1995.

KENNEDY, Joseph, and others.. Natural Building: Construction, Resources. Gabriola Island: New Society Publisher:. 2002.

KRON, Joan SLESIN, Suzanne.. High-Tech. New. York: Viking Press, 1978

LUCHSINGER, Christoph. Hightech als Low-tech. In: Werk + Bauen Wohnen,.1998. Januar-Februar no1-2, pp. 30-36

MAHLKE Friedemann,. Schwerelos erdverbunden: Vom Leichtbau zum Lehmbau: Das Werk des Architekten Gernot Minke. Staufen im Breisgau: Ökobuch Verlag, 2007.

MASLOW Abraham.,. Theory Of Human Motivation. In: Psychological Review, 1943, v50,pp. 370-396.

McLAUGHLIN Neil,. Origin Myths in the Social Sciences: Fromm, the Frankfurt School and the Emergence of Critical Theory. In: Canadian Journal of Sociology 1999. 24 (1), pp. 109-39.

MIRA, Oscar MINGUET, Josep. Ultra Low Tech Architecture.

Barcelona: Monsa, 2011.

MITCHELL, Maurice. The Lemonade Stand: Exploring the Unfamiliar by Building Largescale Models. Machynlleth: C.A.T Publications, 1998.

MOSTAEDI, Arian. Sustainable Architecture: Low-tech Houses. Barcelona: Carles Broto \& Josep Ma Minguet,. 2003.
NAESS Arne. Spinoza and the deep ecology movement. Delft: Eburon, 1993.

PAPANEK, Victor, Design for the real World, Human Ecology and Social Change. London: Thames and Hudson, 1985.

ROUSSEAU Jean-Jacques. Discourse on the Sciences and the Arts. In: Jean-Jacques Rousseau Basic Political Writings. Cambridge: Hackett Publishing, 1987.

RUSKIN John, On Art And Life. London: Penguin, 2004.

MARINETTI, Filippo. Futurist Manifesto 1909. In: RAINEY, Lawrence (ed.). Futurism: An Anthology. London: Yale University Press, 2009.

MINKE, Gernot. Building with Earth: Design and Technology of a Sustainable Architecture. Berlin: Birkhäuser, 2006.

MORGAN, Jim., 1978. Low-tech Building. In: House \& Garden, Oct. 42-46.

OLSEN Richard, Handmade Houses: A Century of Earth-Friendly Home Design. London: Rizzoli, 2012.

REYNOLDS Michael, Comfort in Any Climate. Taos, US: Solar Survival Architecture, 2000.

SLADE, Giles., Made to Break: Technology and Obsolescence in America. London: Harvard University Press 2006.

THOREAU Henry., Walden and Civil Disobedience. New York: William Collins, 2018.

TOWERS Graham. Building Democracy. Community Architecture in the Inner Cities. London: UCL Press, 1995.

World Commission on Environment and Development. Our Common Future. Oxford: Oxford University Press ,1987.

WOJCIECHOWSKA Paulina, Building with Earth: A Guide to Flexible-form Earthbag Construction. London: Chelsea Green Pub Co, 2001. 


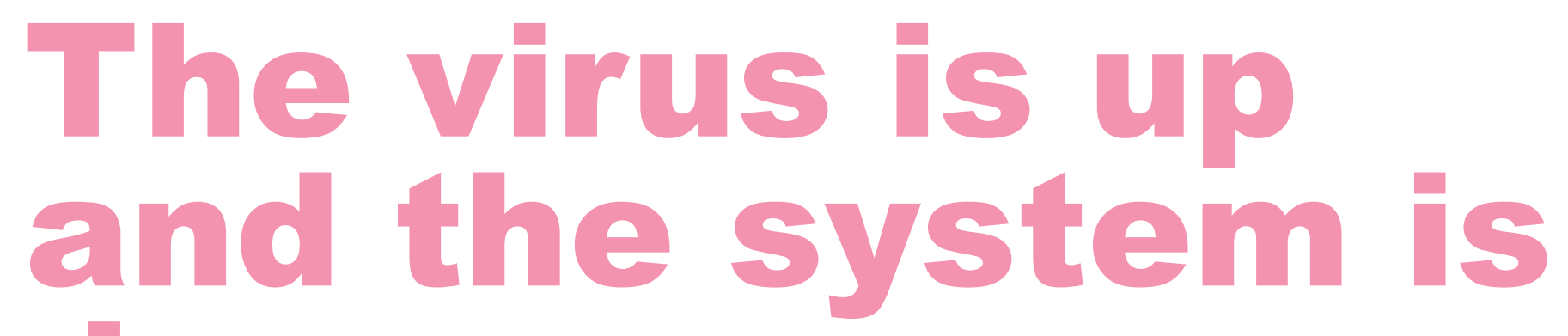

down

A Peruvian case for cosmopolitics in urban studies

Covid-19 cosmopolitica

Lima

no humano

diseño urbano

Covid-19 cosmopolitics

Lima

non-humans

urban design

\section{Chichizola, Bruno Enrico1}

${ }^{1}$ Independent researcher

https://orcid.org/0000-0001-5229-8476

b.chichizola@alumni.ucl.ac.uk

Citation: Chichizola, B. E. (2021). The virus is up and the system is down. A Peruvian case for cosmopolitics in

Date of reception: 29/03/2021 urban studies. UOU scientific journal \#01, 132-141.

ISSN: 2697-1518. https://doi.org/10.14198/UOU.2021.1.11

This document is under a Creative Commons Attribution 4.0 International license (CC BY 4.0) 


\section{El virus está arriba y el sistema abajo}

Un caso peruano para la cosmopolítica en estudios urbanos

The social distancing that the Covid-19 pandemic has forced upon humans demonstrates that a common space can be forged through virtual means. Exploring further a conceptualisation of 'common' - which has been defined as all peoples common needs - that can encompass nature and dwelling, I draw attention to embracing a conceptualisation of 'common' rooted in a cosmopolitical approach.

Following an auto-ethnography methodological approach, I exemplify how non-human actors (software systems and the SARS-CoV-2 virus) intervene in the human experiences of the city of Lima. I will argue that urban design could benefit by taking into consideration the constant reconfiguration and co-constitution of nature and culture to embrace a broader understanding of dwelling. This means to design with a cosmopolitical approach.

The social distancing that the Covid-19 pandemic has forced upon humans demonstrates that a common space can be forged through virtual means. Exploring further a conceptualisation of 'common' - which has been defined as all peoples common needs - that can encompass nature and dwelling, I draw attention to embracing a conceptualisation of 'common' rooted in a cosmopolitical approach.

Following an auto-ethnography methodological approach, I exemplify how non-human actors (software systems and the SARS-CoV-2 virus) intervene in the human experiences of the city of Lima. I will argue that urban design could benefit by taking into consideration the constant reconfiguration and co-constitution of nature and culture to embrace a broader understanding of dwelling. This means to design with a cosmopolitical approach. 


\section{INTRODUCTION}

The Covid-19 pandemic has pushed organisations and professionals to rearrange the way of doing things. Travelling without moving and learning from each other has been feasible through the creation of common virtual spaces. A testament to this is precisely the collaboration from which this journal has originated. Drawing from Isabel Stengers' concept of cosmopolitics, I want to draw attention to, and reflect upon, what a common space might mean and the role of non-human actors in the process of shaping it. This is all the more important to reflect on because, under the current social distancing measures, the importance of technology making our common world possible has intensified.

To understand what cosmopolitics is about, it is important to briefly state what role do non-humans play in it. Non-humans are not a synonym for nature, understood as the passive backdrop to human interactions. A cosmopolitical approach is based on the recognition that non-humans take part with us in the creation of reality regardless of their figuration. Hence, when we are talking about non-humans, we are effectively talking about an aggregation of individuals both human and non-humans - whether humans intervened in their creation or not. This makes it necessary to take a post-humanist perspective on social sciences that forces us to open up our understanding of what can be considered an actor. It could be argued that the central idea of this post -humanist approach is "shifting the focus away from the internal analysis of social conventions and institutions and toward the interactions of humans with (and between) animals, plants, physical processes, artifacts, images, and other forms of beings" (Descola, 2014 p. 268).

Cosmopolitics derives from a fear of the climate crisis and an understanding that culture - what human society makes - and nature - not created by humans - cannot be thought of as separate (Stengers, 2018). To take a conscious decision that can affect the survival of human and nonhumans requires looking for all intervening actors gathered around topics that are guided by complexity and constant change, much like the matters of concern coined by Latour (2004c). This requires hearing them speak - even if they can only vicariously - and taking into consideration the threats to the existence of any of them. This is the central task of cosmopolitics. Latour discusses Stengers' creation of cosmopolitics as follows:

'The presence of cosmos in cosmopolitics resists the tendency of politics to mean the give-and-take in an exclusive human club. The presence of politics in cosmopolitics resists the tendency of cosmos to mean a finite list of entities that must be taken into account. Cosmos protects against the premature closure of politics, and politics against the premature closure of cosmos' (Latour, 2004b p. 454).

Cosmopolitics has been addressed in a number of areas of study. Here I focus on how some authors in urban and design studies have dealt with it to discuss a central idea: there is no specific domain or particular matter of what we have commonly known as "social" as opposed to natural. Within the area of architectural design, some have focused on rethinking what design is. Among other interests, cosmopolitics has been used here to challenge the conception of separating culture and nature, which points towards the ever-present reconstruction of architectural activity when interacting with the rest of what constitutes the urban (Zaera-Polo and Yaneva, 2015). In the case of urban studies, some have used cosmopolitics to be able to explore and name some of the emerging combinations of culture and nature that could exist (Blok and Farias, 2016). This use of cosmopolitics looks at the politics in urban connections without replacing grounded phenomena with inbuilt explanations based on analytical frameworks. In both cases, there is a clear disruption of what can be considered socially and naturally constructed. Both approaches find that such difference is one to be considered only after conducting a due exploration of the dynamics holding together the matter concerned. Following Latour (2005), it could be argued that for both cases a central interest is to provide a description of where all actors do something in a way that does not require the addition of a "social explanation". The only explanation possible is the one 
affirming that some other actor needs to be considered, so it is the description that needs to be extended.

The next section will introduce the particular case presented in this article. Building on the importance of description explained above, I will present it in the form of a description of my own experiences. That means that the language and way of presenting things will change because it will not be written necessarily to match or connect to intellectual debates. For that, I will wait for the last section of this article. However, I would say that it is absolutely important to stay committed to description because otherwise, we could fall into the false illusion that cosmos - in cosmopolitics implies transcendence. Instead, cosmos implies a grounded practice that refuses an a priori difference between what counts and what does not as a valid order of things. It could be argued, this idea is grounded on the belief that objective truth is not what humans see from diverse viewpoints; is the thing - non-human actors themselves - we are observing unfolding as multiple (Latour, 2005). This approach gives important possibilities to understand the city because it considers unexpected ways of experiencing it.

The following example will explore further the possible advantages of taking a cosmopolitical approach to urban design. I am going to use an auto-ethnographic example to reflect on connections between human and non-humans that shape my experience of Lima while briefly reflecting on philosophical arguments around cosmopolitics.

\section{THE CASE}

Peru is one of the twenty countries currently most affected by COVID-19 worldwide (Johns Hopkins University, 2021). I will expand on the dynamics of Peru's capital city of Lima to understand how is this possible. It will bring to the fore how queuing could be understood as a political activity by discussing how it was a key infection site primarily affecting marginalised populations.

Peru can be described as a highly unequal and diverse country in which racist practices have permeated the way society works (De la Cadena, 2000, Zapata and Rojas, 2013). But doing this would certainly frame our discussion in all-human terms. Under the context of the current pandemic and climate crisis, it is clear for all of us that human societies are not just related to nonhumans. We depend on them as much as they depend on us (Latour, 2004a). A tiny virus can mobilise the whole world reconfiguring the use and experience of the city. This situation puts into question the necessity of organising the world into human and nonhuman realms. By the same token, this requires thinking about the ways the built environment is connected to the wider environment. From this perspective it is possible to argue that 'What we study is not 'the city' as such, but multiple, open-ended, and often conflictual urban assemblages' (Blok and Farias, 2016 p. 227).

After years of living in England, Spain and Australia, about a year ago I came back to Peru. The country where I was born and raised. Of course, I am glad to have the opportunity to come back and see my friends and family but I almost forgot how chaotic the city of Lima feels like. A city of around eleven million people. Located between the Pacific Ocean and the Andes, Lima is one of the few capital cities in the world located on a desert which, among other factors, contributes to the disparities of access to water in the city (Ziegler and Morales, 2020). Since the 30 s barriadas emerging and vibrant shanty towns - have made visible how Lima has been overwhelmed due to it concentrating the life opportunities of the country (Matos Mar, 2012). To be clear, I am not saying that barriadas are the problem of the city. I mean that historical inequalities have impacted negatively on life opportunities for the majority of people living in them and that barriadas are a proxy to understand the city as overwhelmed.

Among the many things that catch my attention in Lima, the culture around queuing strikes me in particular. In Lima you queue at, to mention some examples, the phone company, markets, government buildings and, of course, at the bank. Queuing in Lima - and other parts of the country - is not just about the time you spend waiting and the opportunities lost that it entails. During the pandemic, it has become a 
matter of life or death (Pighi, 2020). Queuing was considered to be a dangerous activity as it is difficult to maintain social distancing. You may perhaps wonder why this is so. In Peru, many people are still either afraid or incapable because of lack of technology or the knowledge to use it - of accessing technological tools, which creates a significant digital divide in the country (Tello, 2019). Furthermore, the informal business activities sustaining seventy-three per cent of Peruvians (ILO, 2019) made them particularly vulnerable to the economic impacts of the virus and in need of support. Hence, when the government started to pay allowances, instead of waiting for an online transfer to your bank account many people had to queue to get it.

A couple of weeks ago I had to go to the bank. Throughout the pandemic, the government has implemented a number of online tools for people to keep socially distant while dealing with paperwork. Sometimes it could work wonderfully, sometimes it fails. It is a sort of 'black box' for many people like me that has no background in IT. However, I can confirm that it behaves much like the kind of actors that Bruno Latour has identified as mediators. These actors, unlike intermediaries, "transform, distort, and modify the meaning or the elements they are supposed to carry" (Latour, 2005 p. 39). Sometimes they work as expected and sometimes they might surprise you with a different outcome and in turn, make you do things.
In my case, it failed. I paid online for a document that was never delivered and to get the refund, instead of wiring back the money, I had to go physically to the bank. Despite the irony of this story, I set aside a whole morning just for it. I knew it was going to take some time and I also knew that I might not even be successful in my attempt. I spent about three hours only to get to the counter and be given a fairly common answer: I am sorry the system is down. Please come back another day. The system failed twice: it did not deliver my document and neither let me get my refund. It is clear then that the system, an otherwise considered black box, is central to my experience with the bank, both virtually and physically.
The experience of going to the bank in a city like Lima seems to exceed what could normally be attributed to two separate spaces, the virtual and the physical. Instead, the way I experienced "going" to the bank was more like a continuum in which the story unfolded. So I kept thinking about how urban design could plan better to improve this tiresome and almost neverending experience? In what follows I will provide some insights about my experience of queuing to give you a flavour of what one might want to take into consideration.

It cannot be denied that we humans rely on technology to get things done. But at the same time, it is important to say that such technology

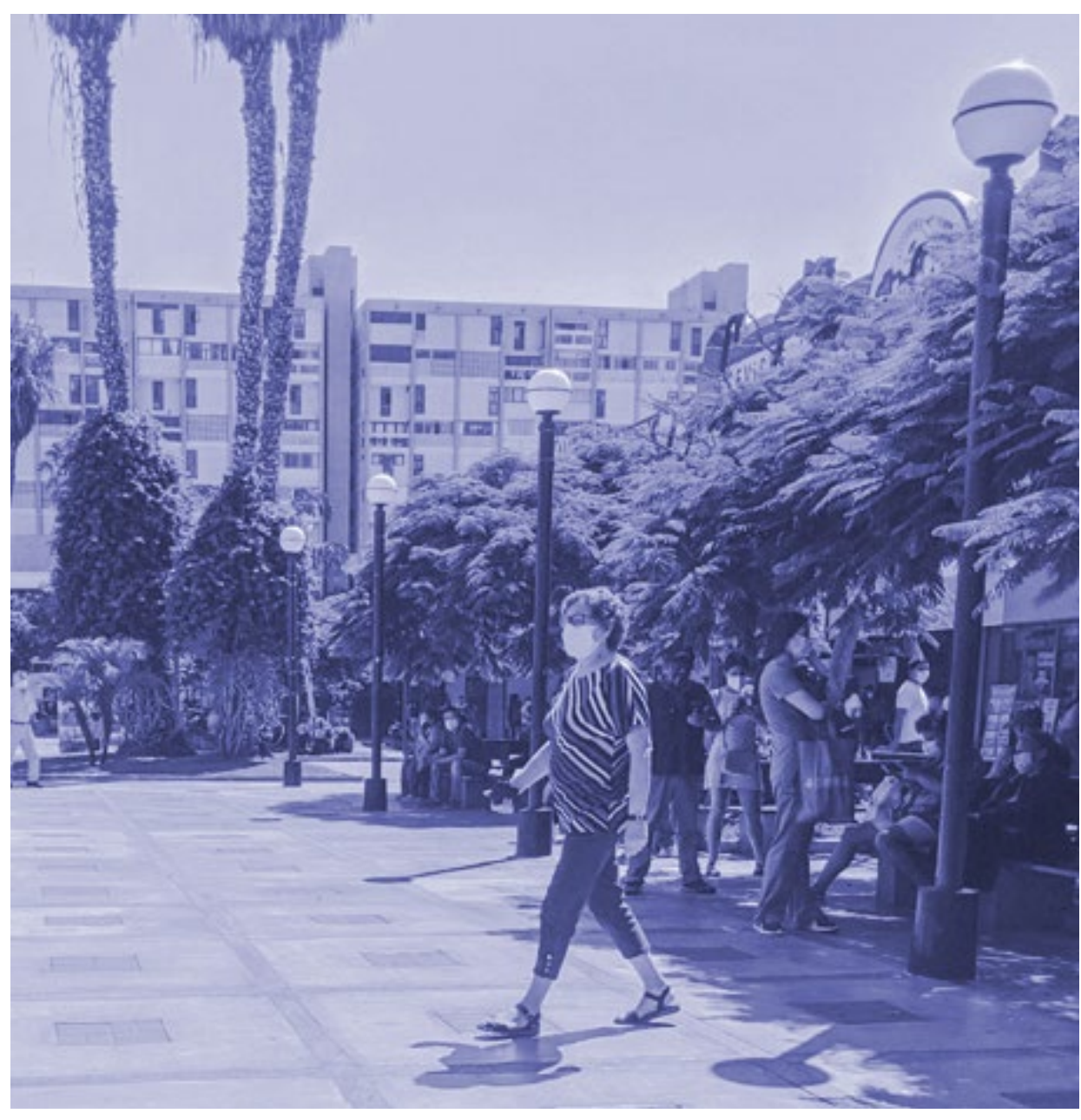

Fig. 1 - A woman walking away from the queue. 
impacts on the shape of human societies (Latour, 1990). While queuing, I saw a myriad of things that made me reflect on how it has always been part of a Peruvian tradition of dealing with private and public institutions. This may also be the case in other countries. But what I am saying is that here it seems like nobody questions the existence of a queue. If sometimes somebody commented on how inefficient some institutions are it is rarely the case that the system is blamed. If it is a fault of the system, it is most likely somebody not doing their job properly. But it is never a problem of an otherwise "flawless and cold" system. Well, let me tell you how the system is pretty much a shaping actor in the experience of going to the bank in Lima and how my experience made me question the imaginary separation between nature and dwelling.

The queue was approximately forty people in a straight line that, aiming to respect social distancing, extended for around eighty meters. While I was walking to the end of the queue one of the bank members goes up and down the line informing people that the system is slow and so the waiting time is going to be longer than normal. Despite being the middle of summer and without proper protection from the sun - as we are standing outside the bank in an open public square nobody seems to say anything, it seems like a normal thing to expect. Only a few, considering how daunting the task was, decided to leave the queue.

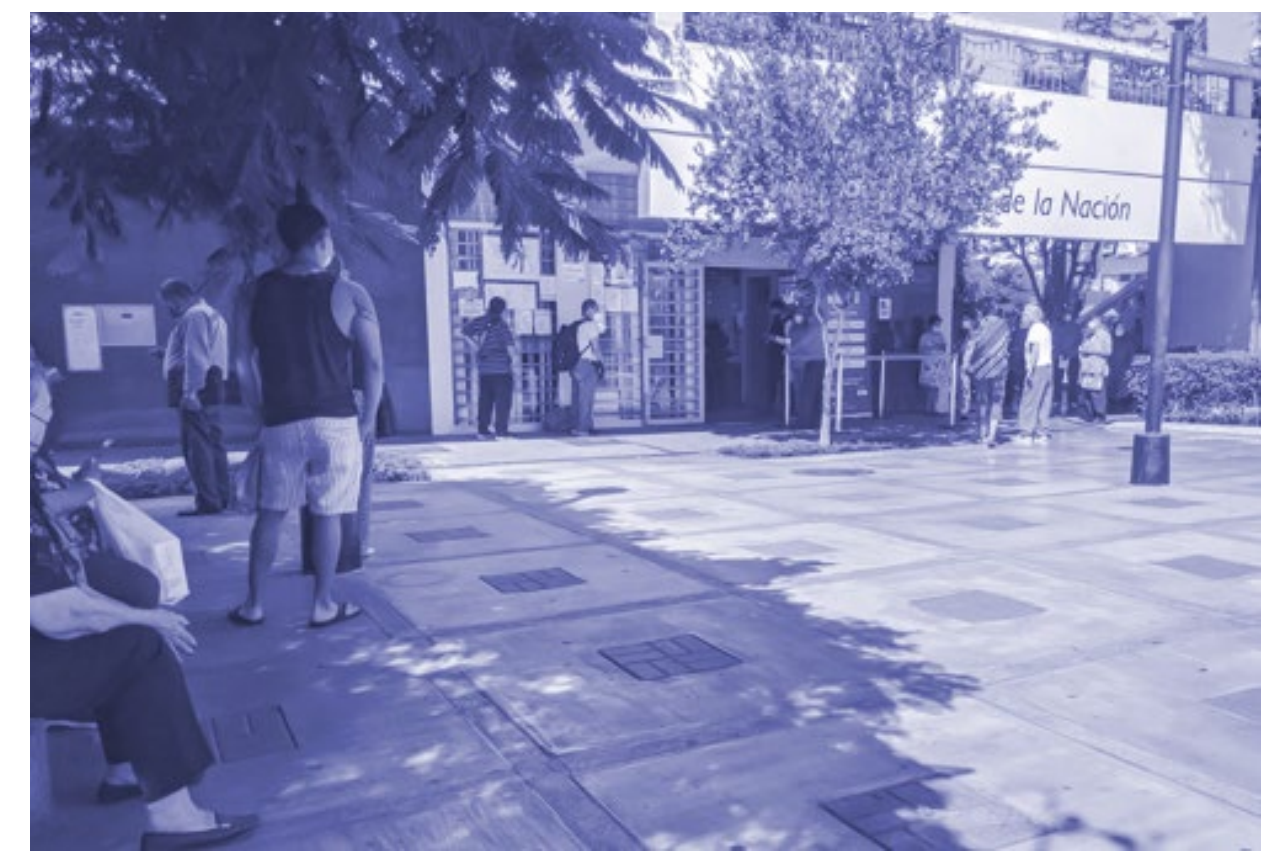

Fig. 2 - A few meters away from the bank's entrance some people use the tree shadow to protect themselves from the sun while keep waiting in line.

Figure. 1 on the left shows precisely that moment.

Ten minutes into the queue a little girl dressed in typical Andean clothes offers candy but nobody even looked at her. After her, a person working to raise funds for a drug addiction campaign tries to sell lottery tickets. No one bought anything. Perhaps nobody had change and did not want to risk losing their position in the queue. After him an old person fell in a tray full of bleach many buildings have started to use them for people to clean their shoes as a protection against Covid-19. Everybody looks at him but nobody seems to care. I wonder what would have happened if all of the people in the queue did not feel that we were each in a struggle of our own by queuing in the middle of summer under the burning sun. Perhaps if people would have had a better experience queuing maybe it would have made it more likely that somebody would help. However, losing your position in the queue makes it not worth trying.

My experience of going to the bank in a city like Lima shows how united it is the separation between nature - non-human developed environment and dwelling - human-built environment. I could see that the bank extended the space occupied by the queue. It went beyond the structural walls that support it and extended to the almost eighty meters long queue of which I was part, and the trees providing shade for the people in it, and the sun burning our bodies, and the complicated ways of computational systems that forced me to experience this. Figure 2 below shows how escaping from the sun under the tree is also part of the experience of going to the bank.

I think that all the people in the queue know that 'going to the bank' means dealing with these non-humans. That is why some prefer to go very 


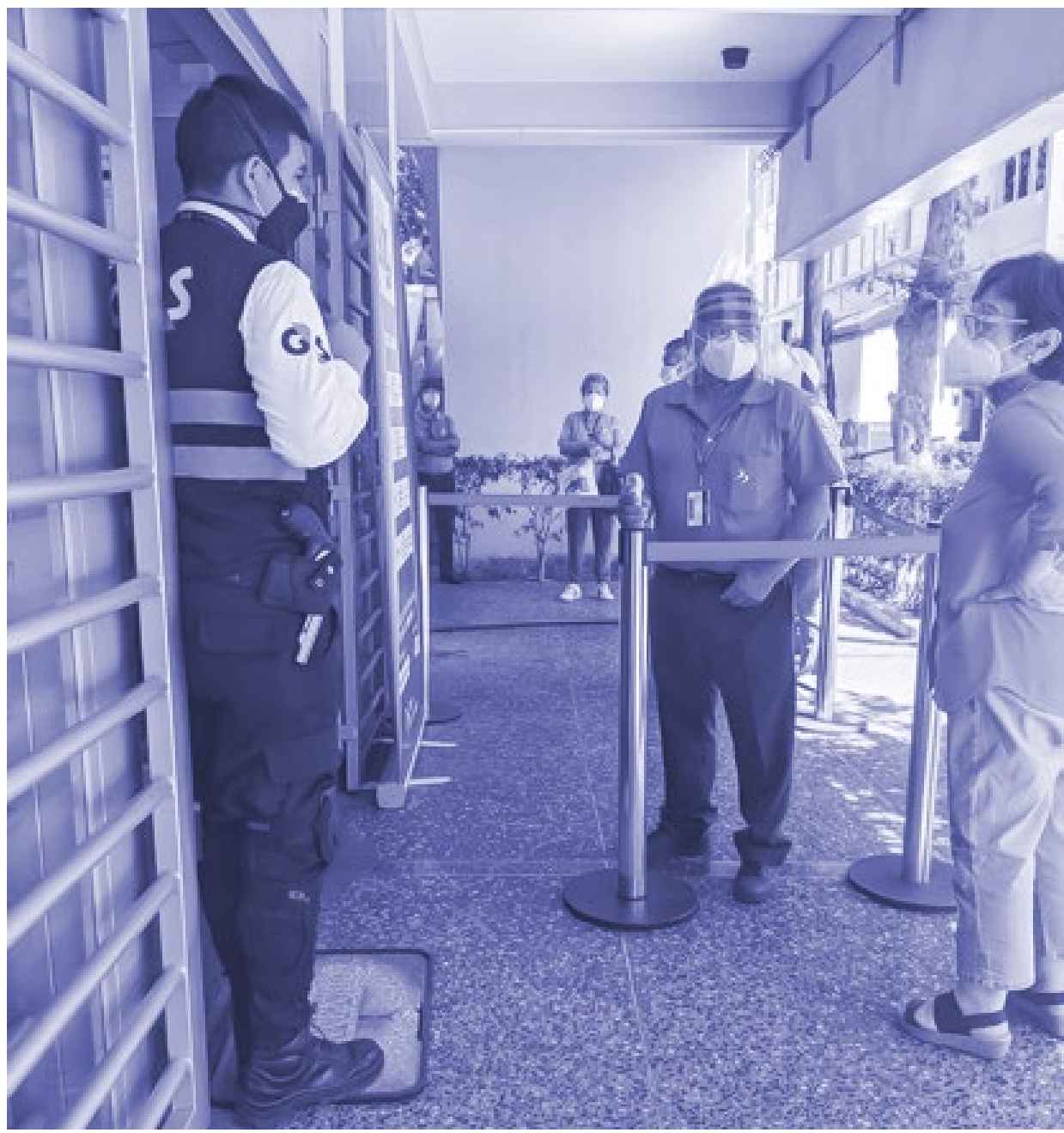

Fig. 3 - The bank security staff recommending costumers to come before the opening time if they want to avoid long queues.

early to avoid queuing, even before the bank opens to the public. At least that was the recommendation of one of the security staff to a client when she asked him what time the bank opens. The Figure 3 below shows precisely that moment.

The system - or the lack of it - makes human societies become ordered in certain ways. For example, queuing has developed some traditions around it. Some people make money by waiting in line for somebody else. While for some it is an opportunity, for some others it is the opposite. While we were waiting in line, a couple of parents with their children came and decided to leave. Which made me wonder how single parents could queue with their little children? Perhaps for them, it is a matter of desperate need to try and make an adventure in doing something like this. I wonder could a better plan could be designed for people with little children? If we think about the bank not just as the physical space but also an extension of it constituted by all the people in the queue, perhaps a children's playground might be considered as part of the design of the bank?

The point here is that, as my experience demonstrates, going to the bank entails a story that reminds us about the broader cosmos. By this, I mean not only all the natural combinations observable from a human perspective. This feature of the cosmos disrupts a purely scientific way of ordering the natural world. It aims to keep open the possibilities of new ways of listening to how nature and culture combine. This requires us to be cautious in our decision making and care more for threats to the existence of some actors; in the context of the climate crisis, this seems an obvious thing to do. From a postmodern/post-development approach this would mean adding multiplicity to a unified world of grand narratives. However, a cosmopolitical perspective understands that multiplicity is a property of the associations of humans and non-humans themselves, not of the humans that interpret things.

A cosmopolitical perspective arises from the idea that there are many ways of assembling the heterogeneous compositions of nature and culture. Hence the importance of maintaining a diplomatic perspective by which new assemblages can be considered valid actors. In my example, I presented how the technological actors and the virus have agency. They shape how humans experience and interact with space. The introduction of "the system" as an actor that nobody fully comprehends what it is or how it works makes the case for taking into consideration associations otherwise considered singularly as black boxes. Whatever constitutes the system is alive as its reactions do not follow a predictable outcome. It makes 
me queue for hours and I am at its mercy. It might allow me to get what I need or not. Hence, it is important to think about the impact of non-humans in the use and experience of space thought of as a cosmos. That it is not private nor public space, nor does it fit within the classification of nature or dwelling. It is both at the same time and more. It is an interwoven connection of purposely imagined material, social and virtual bubbles.

\section{REFLECTIONS}

In this article, I have exemplified how nonhuman actors intervene in the production of human experience of the city of Lima.

The interwoven nature of society and nature allows us to consider that urban design may benefit from a cosmopolitical approach. Some authors have proposed this before (Blok and Farias, 2016, Zaera-Polo and Yaneva, 2015). Hence what this article has tried to do is to provide a brief example to contribute and support a dialogue around it.

A network of non-human actors facilitates the fabrication of society, as most Peruvians know it. A country where leaving home for things that could be considered quotidian - like queuing for the bank - could become a source of adventure or even death - if we consider the number of Covid-19 cases that were connected with queues for the bank. Both technology and the virus effectively re-configure our experience and use of space. This approach expands the concept of dwelling - a room, a building, a city - and makes it necessary to think about 'common' space from a cosmopolitical perspective. Doing so involves rethinking an imagined dichotomy of naturedwelling.

To design under these conditions requires redefining what is commonly associated with nature and society. Nature is not a finite mix of non-human participants as represented by natural scientists. Society is not an exclusively human affair governed by politics and culture. Pursuing this line of thinking allows us to evaluate why we make a distinction between the built environment and the natural environment. To me the question here is not who but how it is being built? This shift in the way of looking at things may help us to think more holistically about space.

But such a holistic approach would not be enough, because there is not a common ground where things have to be ordered. Hence, the real task here is to think about how to develop a conversation about the diversity that exists. This is one of the key tenets of cosmopolitics. It could be useful to think of this 'common' not as a given space but as an outcome. In a cosmopolitical approach, common space becomes the outcome of a process in which all the relevant actors in something that concerns them or matters are heard, and decisions are made acknowledging the positive and negative consequences that our decisions could have for each of them. To that end, the cosmopolitical project brings important conceptual tools to be attentive to and to look for previously unknown assemblages.

An assemblage entails a politically wide description that deploys an accurate description of the complicated possibilities of concrete urban situations. As Rankin (2011) has discussed, assemblages remove the need to look for and explain through the underlying structures of neoliberal political economy that shape inequalities. This type of analysis would lead to me discussing the connections between, for example, the vaccine patent owners and the people queuing at the bank. While not denying there may be some connections, the task here is to trace such connections by observing how they hang together. The proposition for critical thinking here is to detect (not to reveal) 'how many participants are gathered in a thing to make it exist and to maintain its existence' (Latour, 2004c p. 246). The move it performs departs from the idea of facts into the building of such facts in a way that integrates new layers of evidence along with new types of participants. This does not mean to 'get away from matters of facts but closer to them' (Latour, 2004c p. 231).

This type of reasoning is justified in response to, and exemplified by, climate change deniers arguing how facts are produced to destroy hard-won evidence. Latour worries that disbelief in scientific facts which he helped to promote by showing how these are constructed - has come to be used to produce conspiracylike theories among some 
critical studies. He argues that critical researchers, use similar procedures to that mobilised by conspiracy theorists in reaching their conclusions: first, they express disbelief about something, then they introduce several causes from 'deep dark below' to explain what they think is really going on. The argument Latour tries to bring forward is that a 'certain form of critical spirit has sent [academics] down the wrong path, encouraging us to fight the wrong enemies' (Latour, 2004c p. 231). This is relevant at this time when we have witnessed numerous conspiracy theories around the pandemic which have hampered the focus on crucial discussions and instead made us fight against each other (Goodman and Carmichael, 2020).

Based on his approach, critical thinking aims to stop neither studying how facts are produced nor to obliterate their power. His approach entails negating debunking as the ultimate goal of criticism. His criticism aims to keep exploring the many interactions among actors that make it possible for something to exist, including both matters of fact and matters of concern, broadly speaking, products of nature and politics, respectively.

As mentioned in the introduction to this article, a cosmopolitical approach investigates the conventions around the separation of nature and society. This requires undertaking a multi-perspective enquiry that sees objects of research as existing on one large continuum. Latour talks about 'a multifarious inquiry launched with the tools of anthropology, philosophy, metaphysics, history, sociology to detect how many participants are gathered in a thing to make it exist and to maintain its existence' (Latour, 2004c p. 246). This entails also reconstructing our way of seeing how urban power relations and inequalities in the city relate. In a cosmopolitical approach, power is not a given, it is a consequence rather than a cause. Power requires to be explained through the interactions making it possible. The point here is not to disavow how things are assembled and the reality they convey. Instead, it aims to: 'show (and, through the analysis, participate in) how they become real in the layering and knotting of multiple concerns; this equally involves how they derealize as their assemblies scatter or turn contentious' (Blaser, 2016 p. 552). Hence, as Law (2009) puts it "class, nationstate, patriarchy become effects rather than explanatory foundations. This is not to say that they are not real - they may indeed be made real in practice - but they offer no framework for explanation" (p. 147). In this way instead of understanding politics in an already existing factual world, a cosmopolitical approach embraces new assemblages of human and non-human participants to explore "politics concerned with the processes through which a world is being brought into existence" (Blaser, 2016 p. 552).

However, in the process of reconstructing how a world is being brought into existence, the actors and the narratives that could be considered as part of such a world is always contingent on the analytical ability, political will and ontological approach of the researcher, and also on the capacity of vulnerable actors to raise their voice. In this situation, there is a reasonable worry about not being able to account for the voice of vulnerable actors, which could disrupt the extractive oriented political economy and its ontological underpinnings. De la Cadena (2010) exposes a clear example of this by situating how sacred mountains are disavowed from participating in formal political discussions. Hence, some authors have argued to shift from the composition of a common world, to concentrate on differences. This approach is described as a way to identify ontological overlaps and to present and accept their differences without the subordination of either (De la Cadena, 2015, Blaser, 2016).

If we decide for this type of reasoning, I think we could do more for improving the experience of vulnerable populations. By this I mean the people who have been forced to face death by lining up to the bank. By this I also mean the number of non-human species who have been threatened by the expansion of human activities and, in an attempt to survive or pushed by human coercion, have started to mingle with pockets of humans in an interaction that may have lead us to the current pandemic situation (Sharun et al., 2021). 


\section{BIBLIOGRAPHY}

BLASER, M. Is another

Cosmopolitics Possible?. In: Cultural Anthropology. 2016, issue 4 (31), pp. 545-570. ISSN 0886-7356

BLOK, A. and I, FARIAS. (eds.) Urban cosmopolitics: agencements, assemblies, atmospheres. New York: Routledge. 2016. ISBN 9781138813410

De LA CADENA, M. Indigenous Mestizos: the politics of race and culture in Cuzco, Peru, 1919-1991. Durham: Duke UP. 2000. ISBN 978-08223-2420-1

De LA CADENA, M. 'Indigenous Cosmopolitics in the Andes: Conceptual Reflections beyond "Politics", Cultural Anthropology. 2010, issue 25(2), pp. 334-370. ISSN 15481360

De LA CADENA, M. Earth Beings: Ecologies of Practice across Andean Worlds: Ecologies of Practice across Andean Worlds. Duke UP. 2015. ISBN 978-0-8223-5963-0

DESCOLA, P. All too human (still): A comment on Eduardo Kohn's How forest think. In: HAU: Journal of Ethnographic Theory. 2014, 4(2), pp. $267-273$.

GOODMAN, J. and F, CARMICHAEL. Coronavirus: Bill Gates 'microchip' conspiracy theory and other vaccine claims factchecked: BBC Reality Check. 2020 [Accessed: 28/03/2921]. Available at: https://www.bbc.com/news/52847648

ILO. Lima's Gamarra market: The benefits of moving to the formal economy. 2019. [Accessed: 28/03/2021]. Available at: https://www. ilo.org/global/about-the-ilo/newsroom/ news/WCMS_723278/lang--en/index. htm

JOHNS HOPKINS UNIVERSITY. Mortality in the most affected countries. 2021. [Accessed: 26/03/2021]. Available at: https:// coronavirus.jhu.edu/data/mortality

LATOUR, B. 'Technology is Society Made Durable', The Sociological Review. 1990 38. pp. 103-132.

LATOUR, B. Politics of nature : how to bring the sciences into democracy. Cambridge, Mass: Harvard UP. 2004a. ISBN 9780674013476
LATOUR, B. Whose cosmos, which cosmopolitics?: Comments on the Peace Terms of Ulrich Beck. Common knowledge. 2004b, 10(3), pp. 450-462.ISSN:1538-4578

LATOUR, B. Why Has Critique Run out of Steam? From Matters of Fact to Matters of Concern. Critical Inquiry. 2004c, 30(2), pp. 225-48.

LATOUR, B. Reassembling the social: an introduction to actornetwork-theory. Oxford: Oxford UP. 2005. ISBN: 0199256055

LAW, J. Actor Network Theory and Material Semiotics, in Turner, B.S. (ed.) The new Blackwell companion to social theory. London: Wiley Blackwell. 2009. ISBN: 978-1-40516900-4

MATOS MAR, J. Peru. Estado desbordado y sociedad nacional emergente. Lima: U. Ricardo Palma. 2012. ISBN: 978-612-4059-54-4

PIGHi, P. Cuarentena en Perú: 5 factores que explican por qué las medidas de confinamiento no impiden que sea el segundo país de América Latina con más casos de covid-19: BBC News Mundo. 2020. [Accessed: 28/03/2021]. Available at: https://www. bbc.com/mundo/noticias-americalatina-52748764

RANKIN, K. N.'Assemblage and the politics of thick description'. City. 2011. 15(5), pp. 563-569

SHARUN, K., R, TIWARI, S, NATESAN and $K$, DHAMA. SARSCoV-2. Infection in farmed minks, associated zoonotic concerns, and importance of the One Health approach during the ongoing COVID-19 pandemic. The Veterinary quarterly. 2021. 41(1), pp. 50-60.

STENGERS, I. Another Science is Possible: A Manifesto for Slow Science. Polity Press. 2018. ISBN: 150952181X

TELLO, M. La brecha digital en el Perú: Diagnostico, Acceso, Uso e Impactos. Instituto Nacional de Estadística e Informática. 2019. [Accessed: 17/05/2021]. Available at: https://departamento.pucp.edu.pe/ economia/wp-content/uploads/MarioTello.-Brecha-digital.-INEI.pdf

ZAERA-POLO, A. and A, YANEVA (eds.) What Is Cosmopolitical Design? Design, Nature and the Built
Environment. Routledge. 2015. ISBN: 9781138297081

ZAPATA, A. and R, ROJAS. ¿Desiguales desde siempre?: Miradas historias sobre la desigualdad. Lima: Instituto de Estudios Peruanos. 2013. ISBN: 978-9972-51-445-6

ZIEGLER, G. and M, MORALES. Lima lucha contra el coronavirus con aguas turbias: Ojo Público. 2020 [Accessed: 28/03/2021]. Available at: https://ojo-publico.com/especiales/ lima-lucha-contra-coronavirus-conagua-turbia/ 


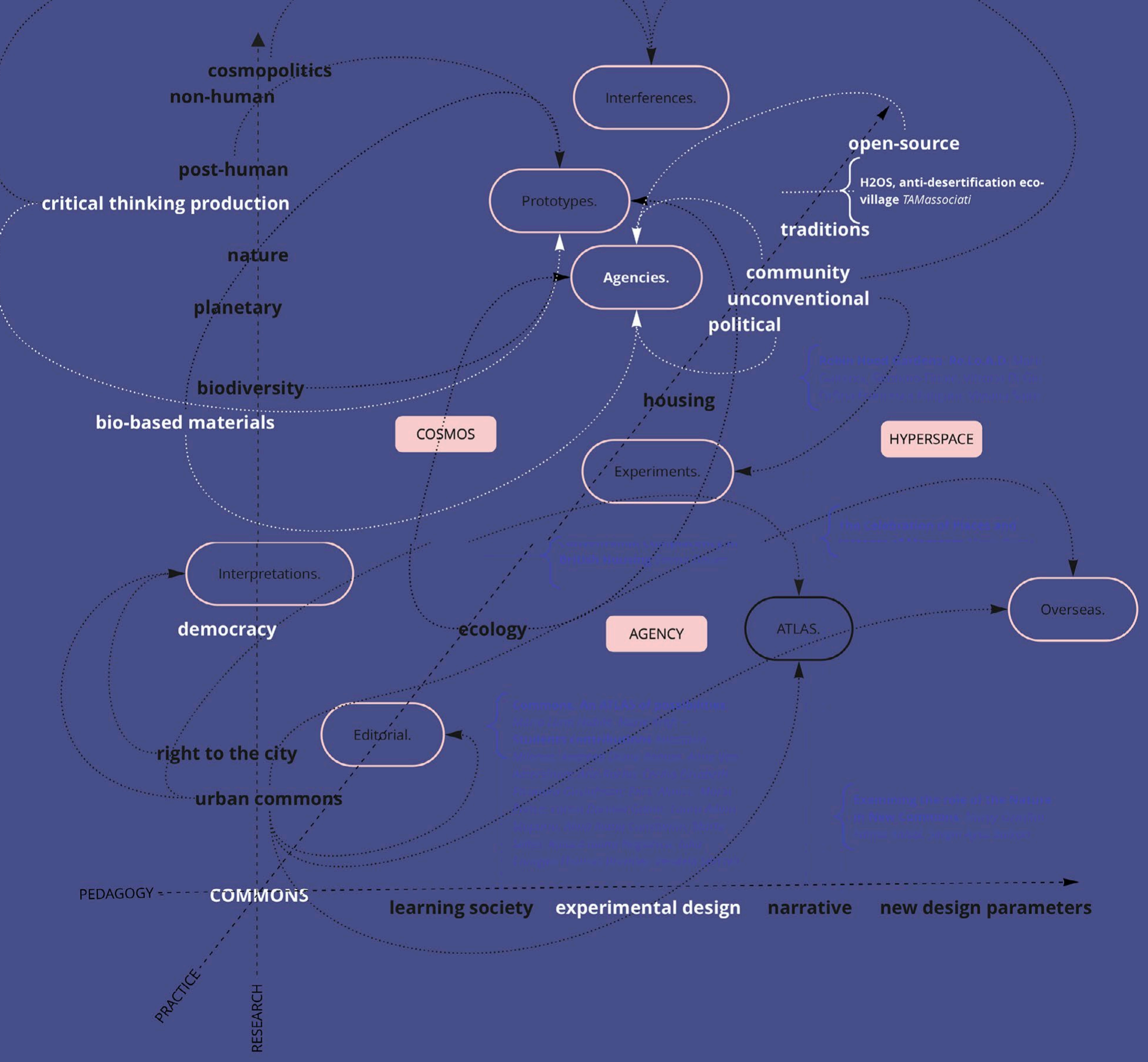




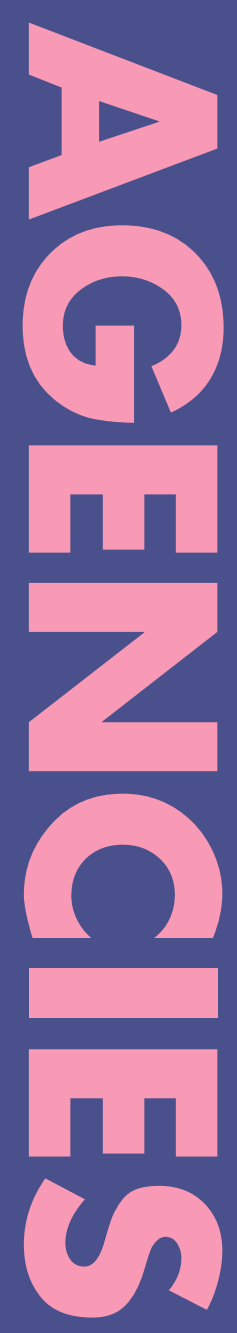




\section{H20S, anti- desertification eco-village in Senegal \\ An open-source, autonomous and sustainable prototype}

\section{TAMassociati ${ }^{1}$}

${ }^{1}$ Massimo Lepore, Raul Pantaleo, Simone Sfriso (cofounders senior partners) Laura Candelpergher, Enrico Vianello (junior partners)

www.tamassociati.org

Citation: TAMassociati (2021). H2OS Anti-desertification eco-village in Senegal. UOU scientific journal \#01,

144-155.

ISSN: 2697-1518. https://doi.org/10.14198/UOU.2021.1.12

This document is under a Creative Commons Attribution 4.0 International license (CC BY 4.0) 


\section{H2OS. Eco-villaggio anti-desertificazione in Senegal}

Un prototipo open-source,
autonomo e sostenibile

Il progetto architettonico e tecnologico di H2OS è concepito e sviluppato da TAMassociati. H2OS è un esperimento di co-sviluppo promosso dal Circolo Sunugal (associazione di migranti senegalesi) di Venezia, sviluppato dalla Onlus Musoco (Venezia) in collaborazione con la Ong USE (Union pur la Solidarité et l'Entraide) di Dakar. Ė finanziato da), CGIL CAAF Nord-Est, 8 per mille Chiesa Valdese, LTA (Livenza Tagliamento Acque) ed è supportato da AUTODESK FOUNDATION (USA). È sostenuto anche da IdRiCo (Idee per Risorse Collettive), finanziato dalla Regione Friuli Venezia Giulia, e dall'associazione provinciale Arci Trieste.

\section{Luogo:}

Keur Bakar Diahité, Senegal

\section{Team:}

Progetto architettonico: studio TAMassociati Ispiratore: Circolo Sunugal APS di Venezia Coordinamento: MUSOCO onlus Mutalità, Solidarietà e Cooperazione / Partner locali: Ong senegalese "Union pour la Solidarité et l'Entraide (USE) Progetto architettonico: studio TAMassociati Partner tecnici: Francesco Steffinlongo, K\&G Progetti

\section{Tempi:}

Percorso partecipato: 2012-2014

Progettazione architettonica: 2014-2015

Realizzazione eco-casa: 2015-2017

Superficie: $280 \mathrm{mq}$

Download the prototype: www.h2os-project.org
The H2OS architectural and technological project is conceived and developed by TAMassociati. It is an experiment in co-development promoted by the Circolo Sunugal (Senegalese Migrant Association) in Venice, developed by Onlus Musoco (Venice) in collaboration with the NGO USE (Union pour Solidarité et l'Entraide) in Dakar. It is funded by CGIL CAAF Nord-Est, 8 per mille Chiesa Valdese, LTA (Livenza Tagliamento Acque), and is supported by AUTODESK FOUNDATION (USA). H2OS is also supported by IdRiCo (Idee per Risorse Collettive), funded by the Friuli Venezia Giulia Region, and by the provincial association Arci Trieste.

\section{Location:}

Keur Bakar Diahité, Senegal

\section{Team:}

Architecture: TAMassociati

Inspired by: Circolo Sunugal APS di Venezia Coordination: MUSOCO onlus Mutalità, Solidarietà e Cooperazione / Local Partner: Ong Union pour la Solidarité et l'Entraide (USE) Technical Partners: Francesco Steffinlongo, K\&G Progetti

\section{Phases:}

Participated process: 2012-2014

Project: 2014-2015

Realization: 2015-2017

Area: $280 \mathrm{mq}$

Download the prototype: www.h2os-project.org 


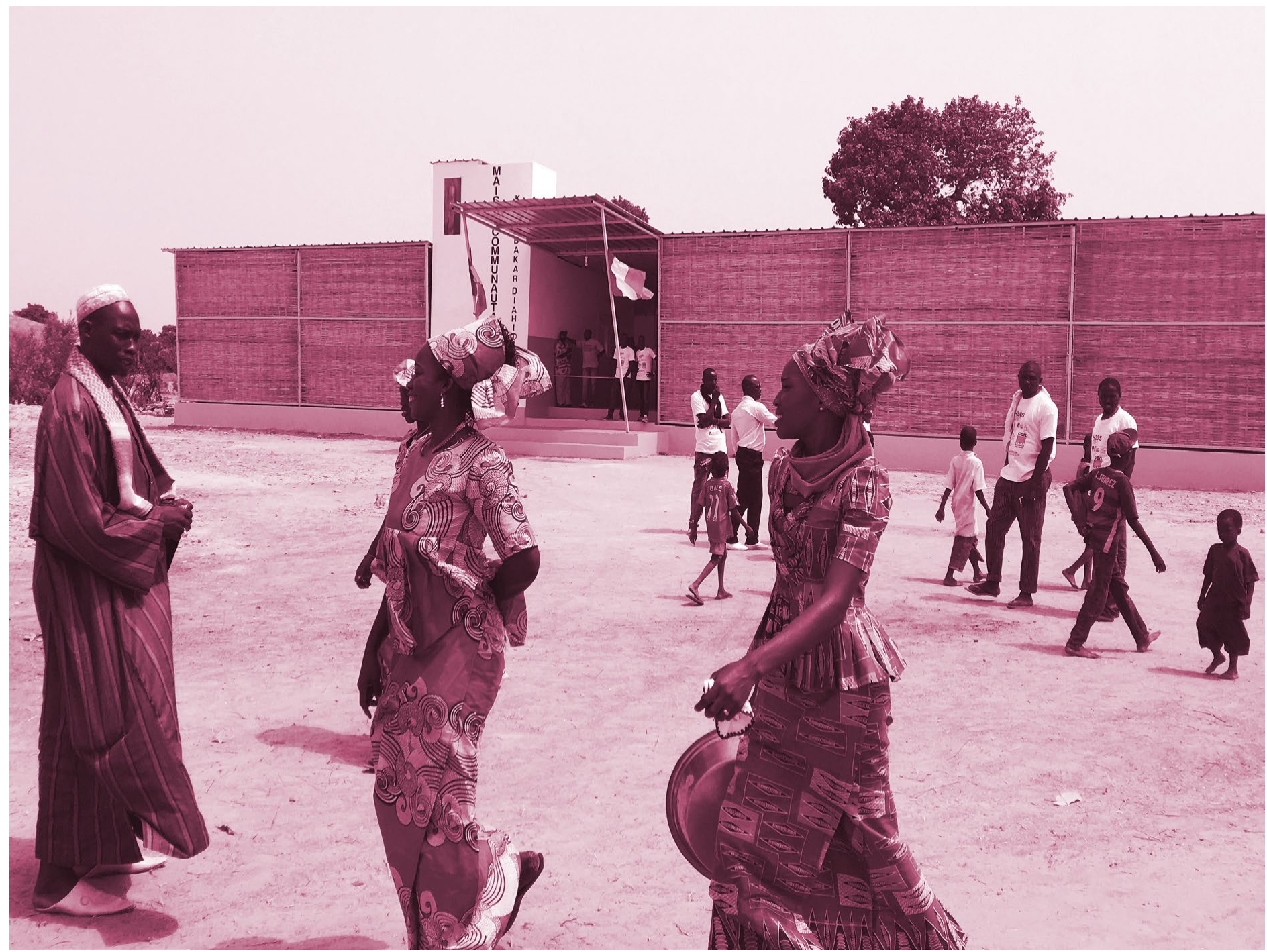

Fig. 1 - TAMassociati, H20S, Keur Bakar Diahité, Senegal, 2017.

\section{A RESEARCH BASED PROJECT}

TAMassociati has inaugurated the 'eco-maison', the first lot of the $\mathrm{H} 2 \mathrm{OS}$ project, which plans the construction of an eco-village in Senegal (at Keur Bakar, 200 km from Dakar) consisting of common spaces and housing modules selfsupporting in energy and water in an area where desertification is inexorably spreading. "Desertification, high dropout rates at school, emigration: $\mathrm{H} 2 \mathrm{OS}$ is a project that aims to give hope to all the peoples of the African Sahel," announce TAMassociati. It is an opensource pilot project, replicable, adaptable and perfectible elsewhere. It is the result of an international collaboration, born from the grass roots and inspired by Sunugal - an association of Senegalese immigrants in Italy - which has won increasing support. And it is destined to become a model of sustainable dwelling for the whole continent, but can be adapted anywhere "

The eco-village will become a symbol of eco-modernity, proportionate to the technical, managerial, and agricultural self-sufficiency of local communities, who are also the protagonists of this project.

The eco-dwellings, organized around the common ecohome technology, will be built of stabilized raw-earth bricks in a self-build system. The most complex elements of the buildings (extremities, services, utilities) are dealt with by specialized technicians who at the same time train the local workforce. 


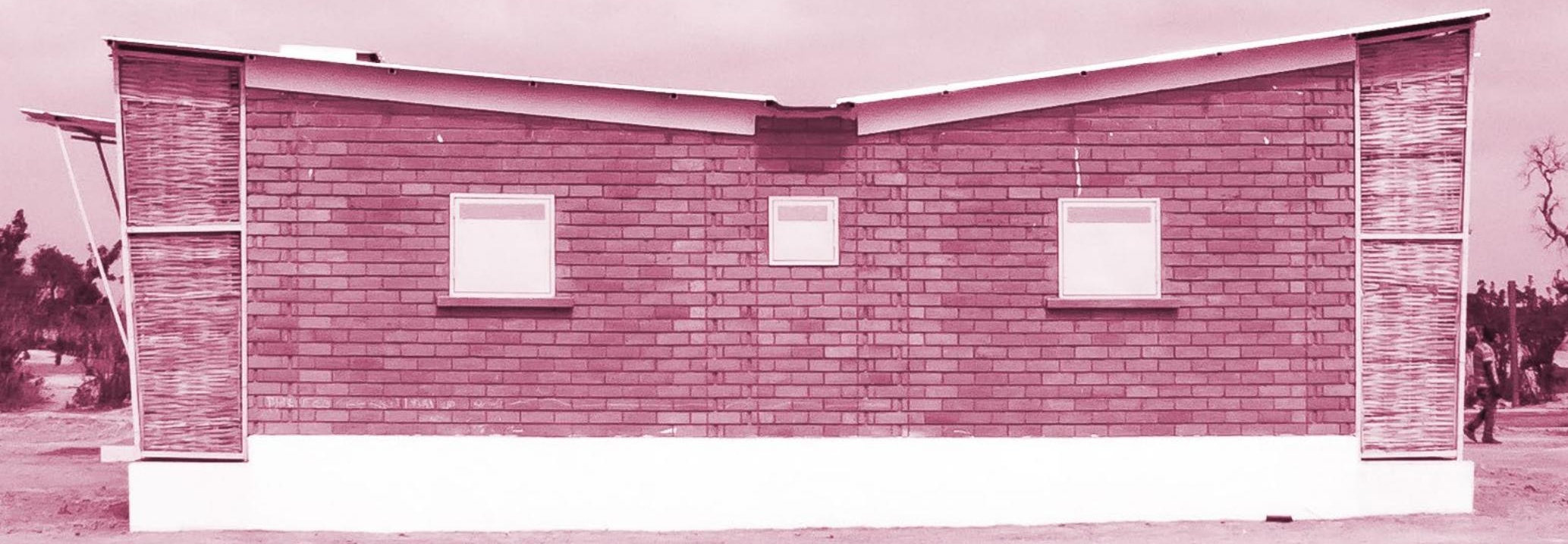

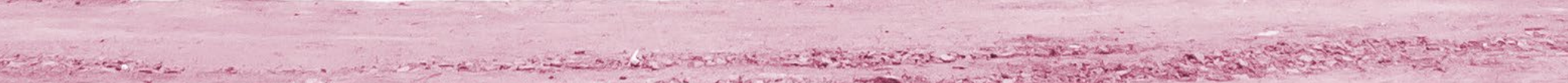

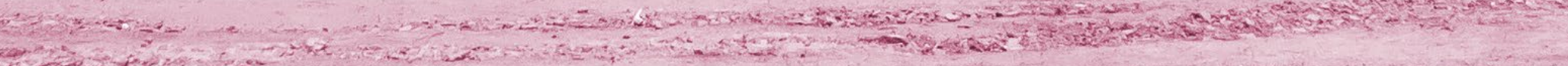

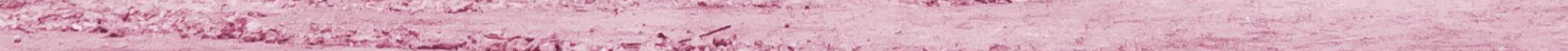


On-site maintenance is part of a broader scenario of selfsufficiency and self-subsistence underlying the project.

Sustainability is also embodied in the cost of the work: less than 200 euros per meter. The village is located in an area without electricity, water or school and health services.

The eco-maison project completes the first phase of the project: "The community ecomaison, the heart of the new village," state TAMassociati "will be a home for the community devoted to research, training, information, arts and crafts workshops, and social life. A public place of sharing, in which the first cornerstones of the ecological project will be shaped: from the recovery of rainwater for sanitary water to systems engineering, the filtration system and natural ventilation, passive building, energy production, phytodepuration of black waters and the photovoltaic circuit.

Next to it are the well, washhouse and a community organic vegetable garden, run largely by women and irrigated by the water recovery system: a true community garden, where farming rests on the principles of environmental compatibility, food and local culture".

The challenge to designers, promoters and partners is clear: the Senegalese project, an African path to ecology, is a new proposal for the new type of modernity required by the continent, concerned to combine self-management, traditions, landscape and social fabric with the opportunities offered by the best international design.

"A non-invasive but participatory design, which will become a bulwark and symbol of rights," conclude TAMassociati, "such as access to water, food, the possibility of living in the place where they were born and moving away voluntarily, not from necessity."

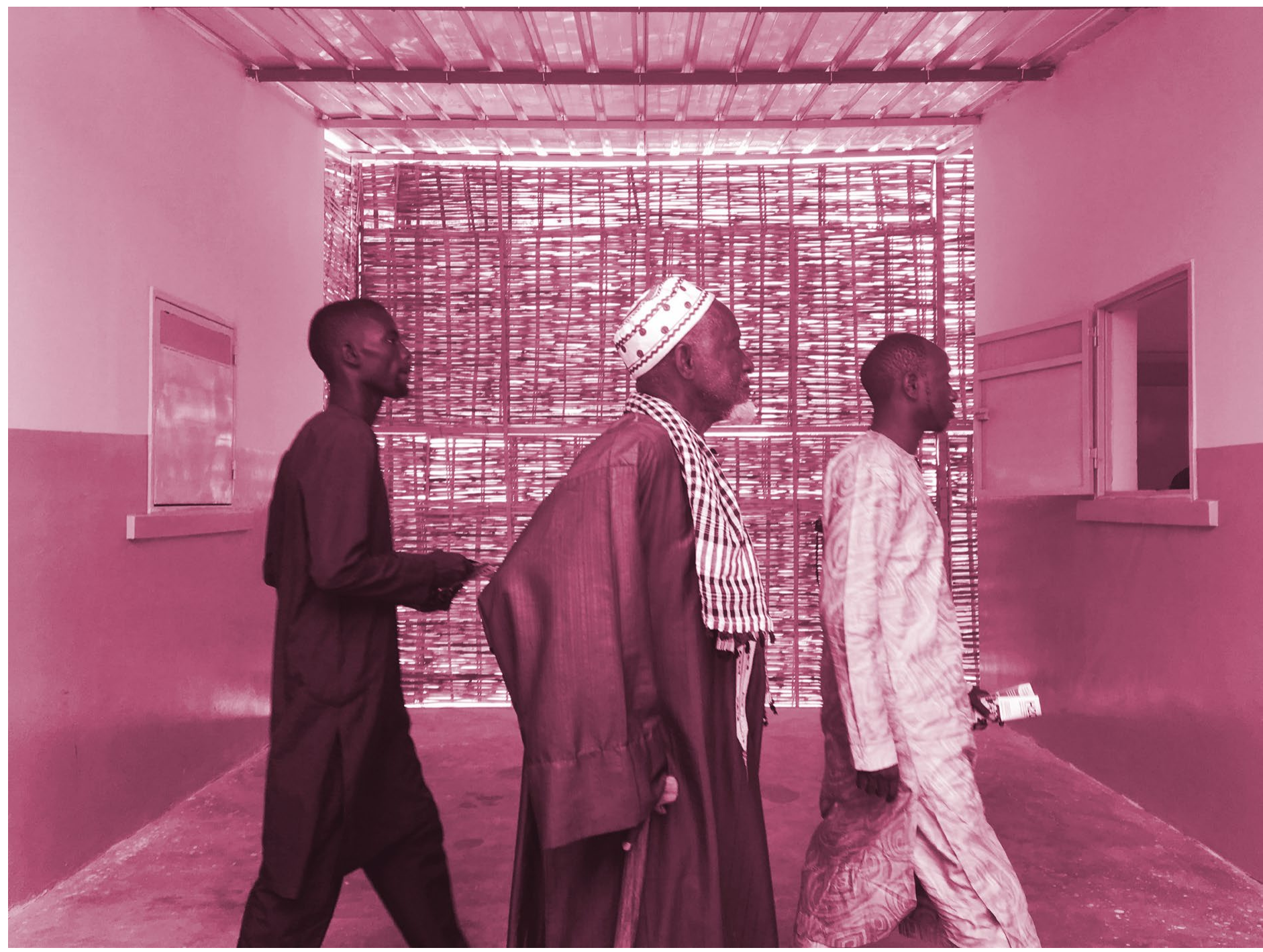



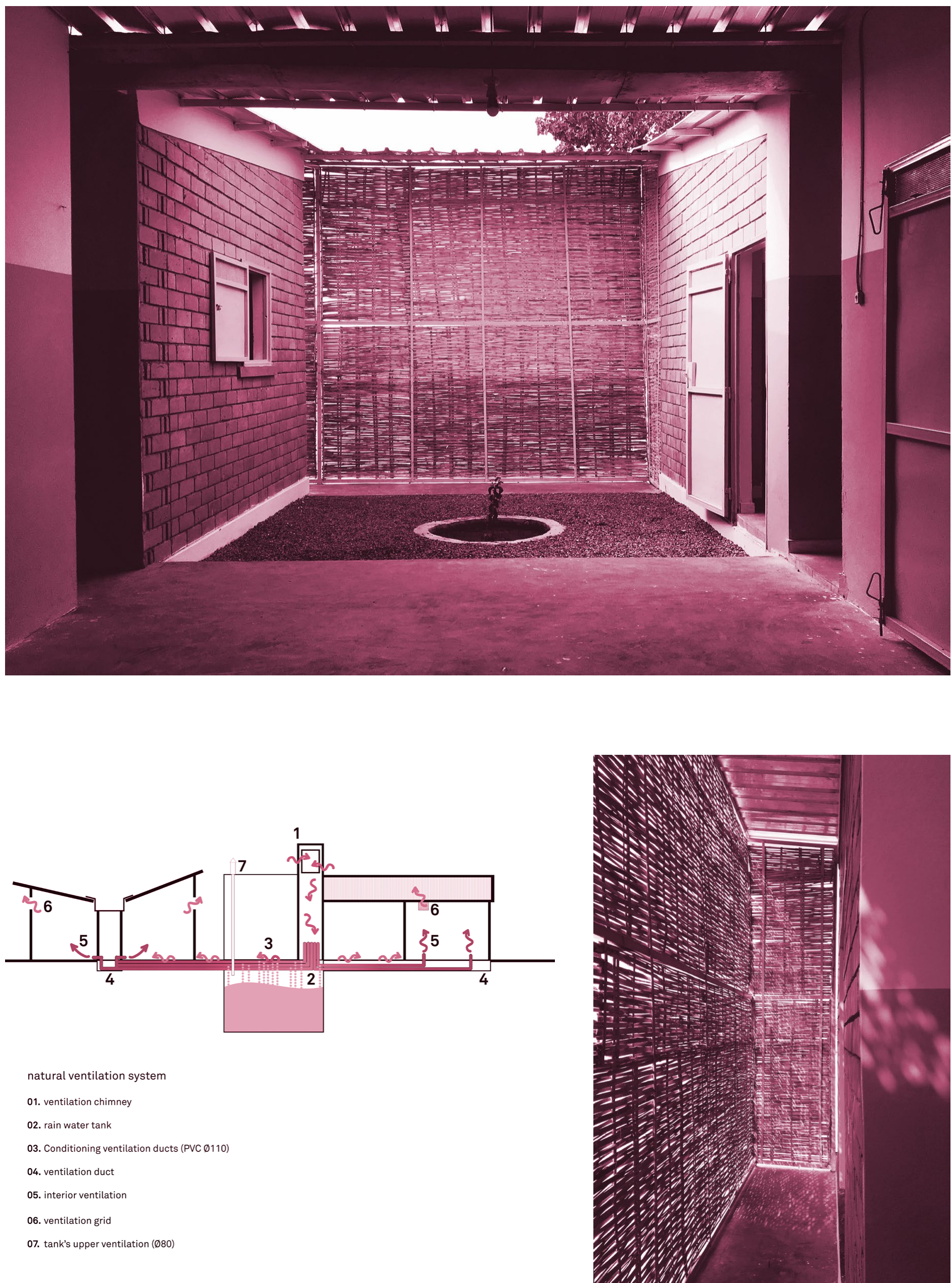

natural ventilation system

01. ventilation chimney

02. rain water tank

03. Conditioning ventilation ducts (PVC Ø110)

04. ventilation duct

05. interior ventilation

06. ventilation grid

07. tank's upper ventilation (ø80) 


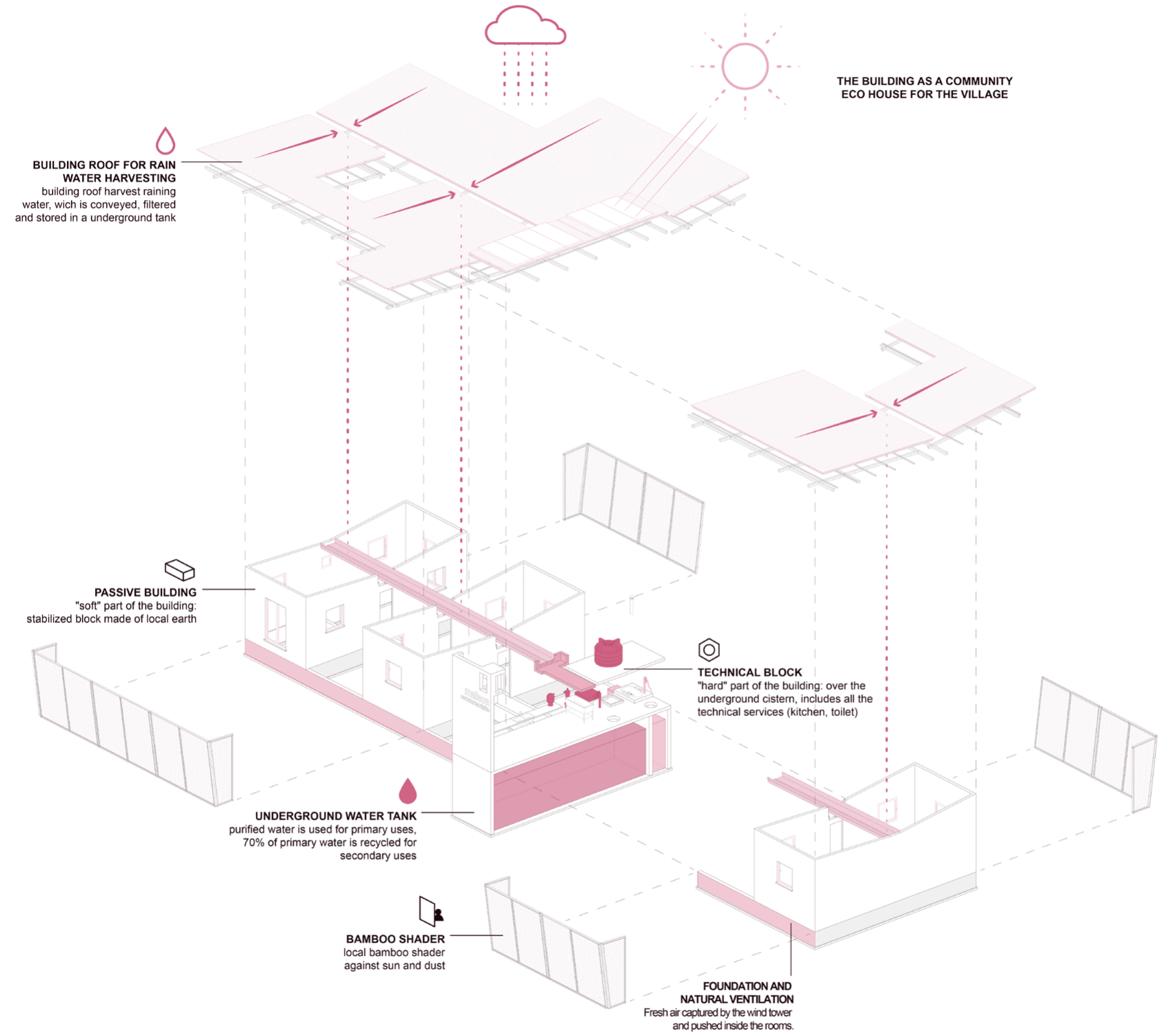

Fig. 7 - TAMassociati, H20S, Keur Bakar Diahité, Senegal, 2017. 

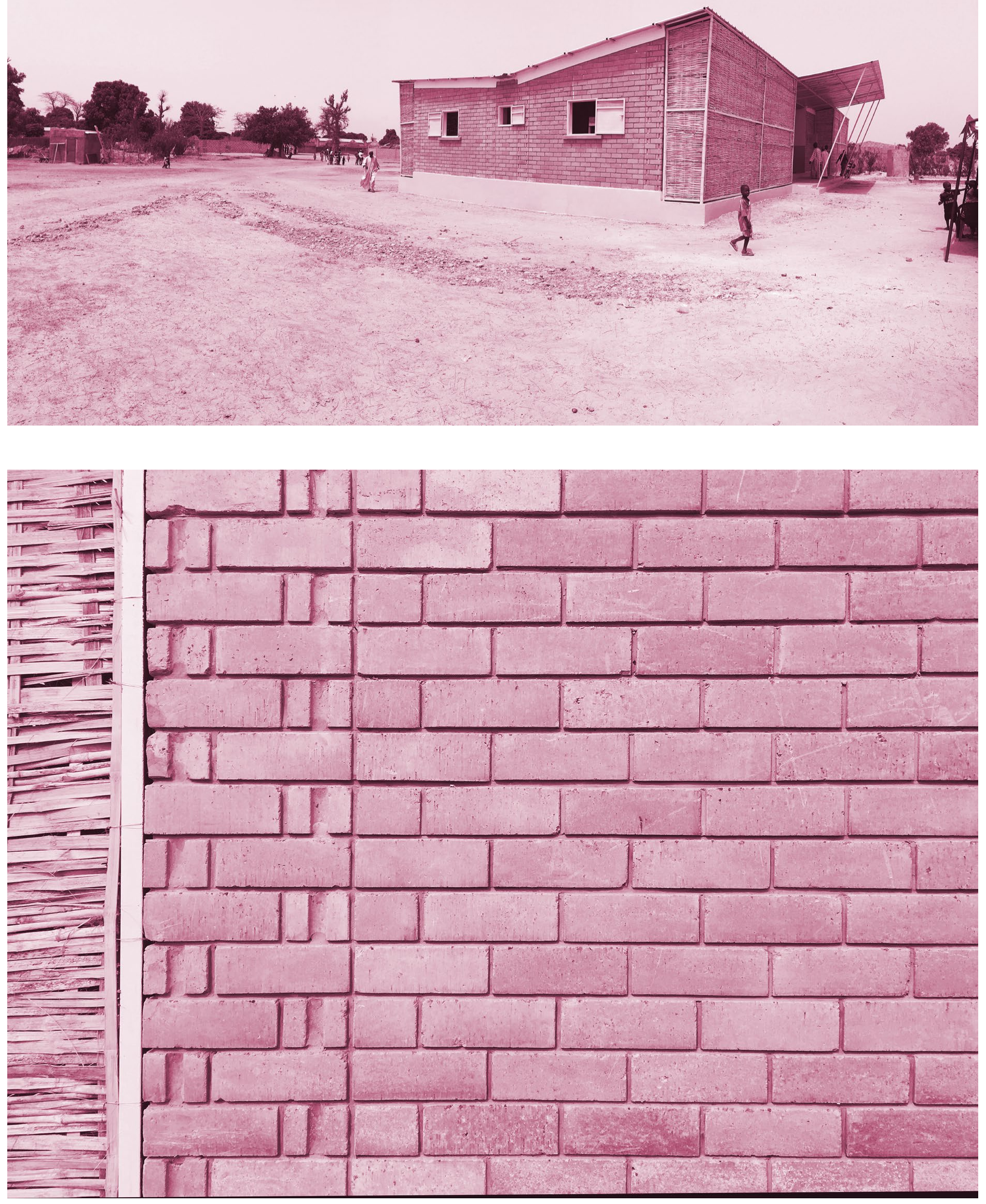

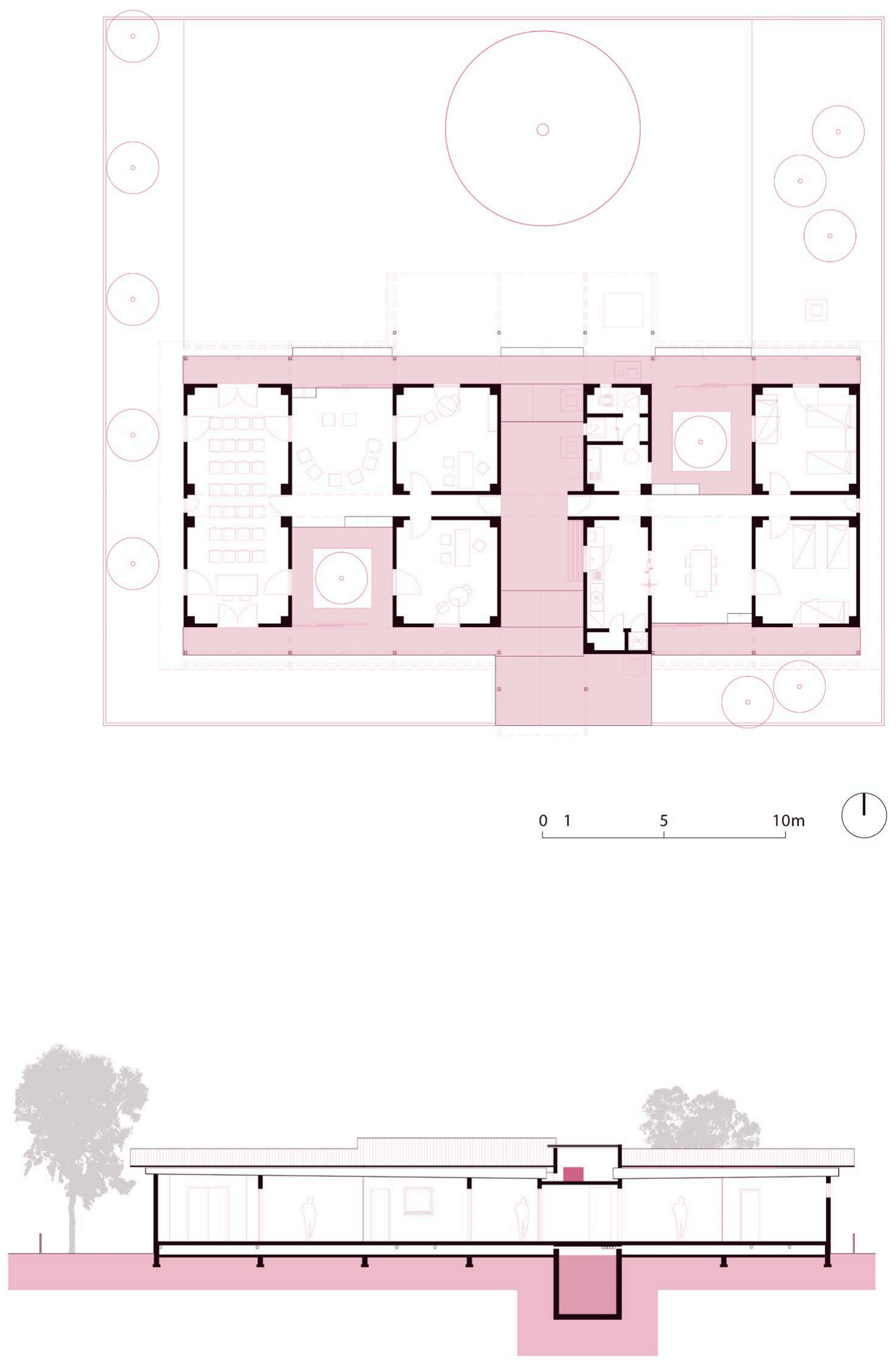

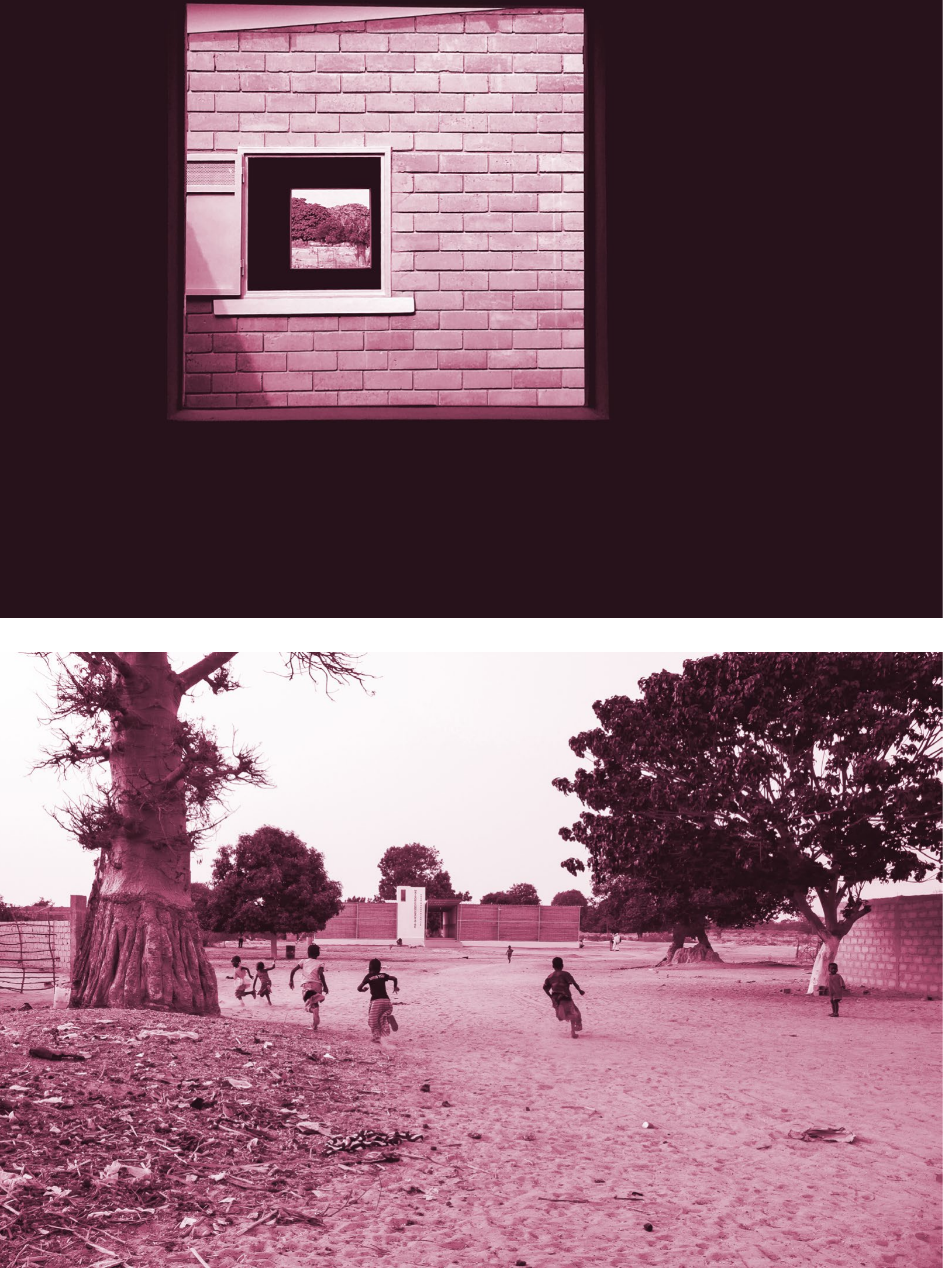


\section{TAMASSOCIATI}

\section{Active in Social Design} internationally since the last millennium, TAMassociati combines a civil and professional commitment, working in sustainable architecture, urban planning, landscape design, participatory and educational processes, graphic design and social communication.

The office has won widespread recognition and numerous prizes: in 2013 it received the Aga Khan Award for Architecture for the excellence represented by the Salam Centre for Cardiac Surgery in Sudan, the international lus-Capocchin prize for construction of the world's most sustainable pediatric hospital (Port
Sudan) and the Curry Stone Design Prize for the overall sustainability (social and environmental) of recent projects built in different parts of the world. In 2014 the practice won the Zumtobel Group Award for innovation and sustainability represented by the pediatric hospital it built in Sudan (Port Sudan). It was named Italian Architect of the year for 2014 "for its ability to enhance the ethical dimension of the profession."

TAMassociati has been the curatorial team of the Italian Pavilion at the 15th International Architecture Exhibition of La Biennale di Venezia "Taking care Designing for the Common good".

Winner of the prize Italian
Architect of the Year 2014, TAMassociati has displayed its works at numerous exhibitions and international events, including Architecture is Life at the Aga Khan University in Karachi, Pakistan, 2014; Five Projects for a Sustainable World, Cité de l'Architecture et du Patrimoine, Paris, 2014; AFRITECTURE Building Social Change at the Pinakothek der Moderne in Munich, 2013; the Triennale di Architettura in Milan, 2012; International Architecture Exhibition of La Biennale di Venezia, 2012 and 2010 editions.

Currently TAMassociati is working in Uganda, Senegal, Italy and Afghanistan. It has offices in Venice, Bologna, Trieste and Paris.

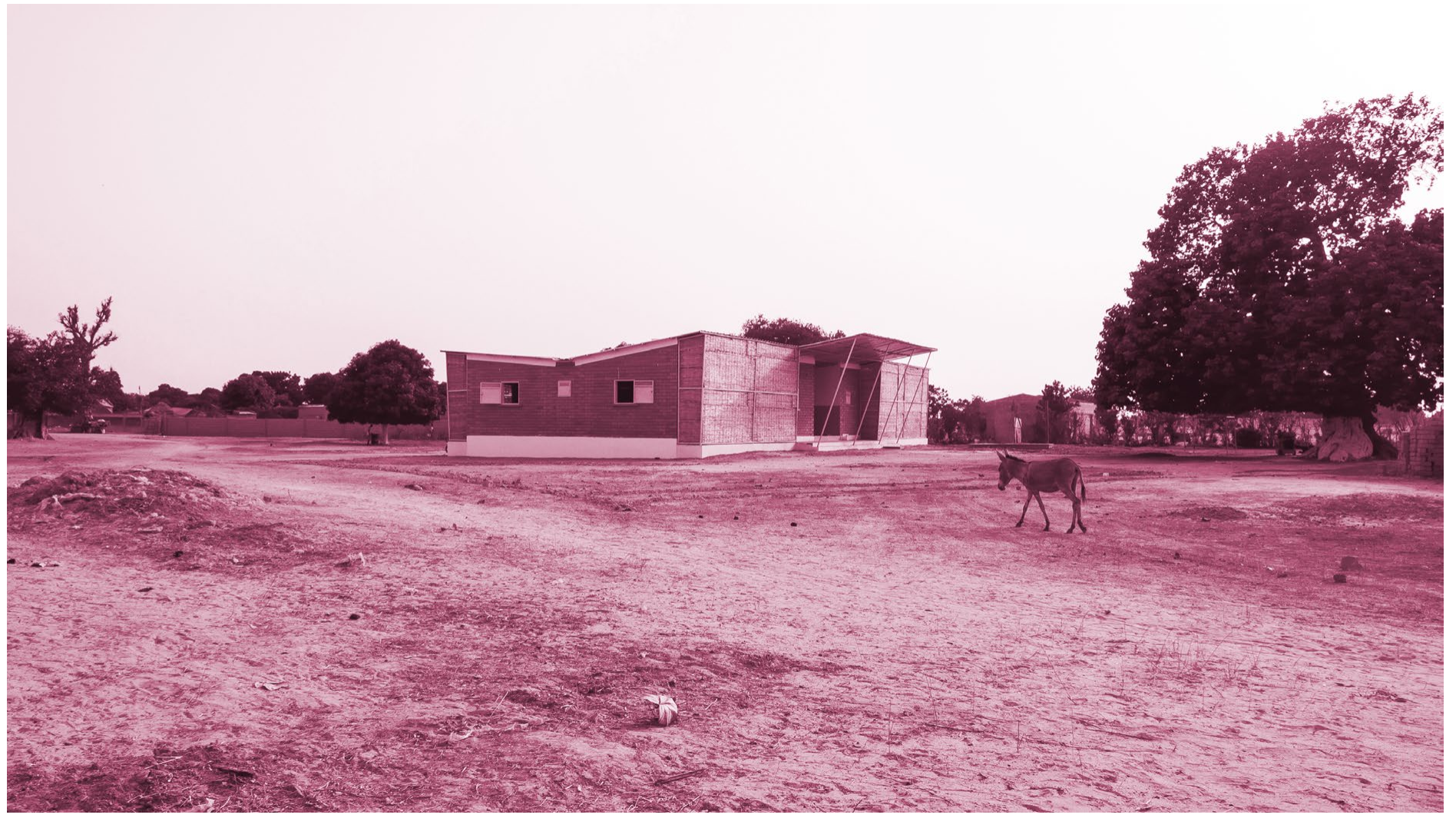



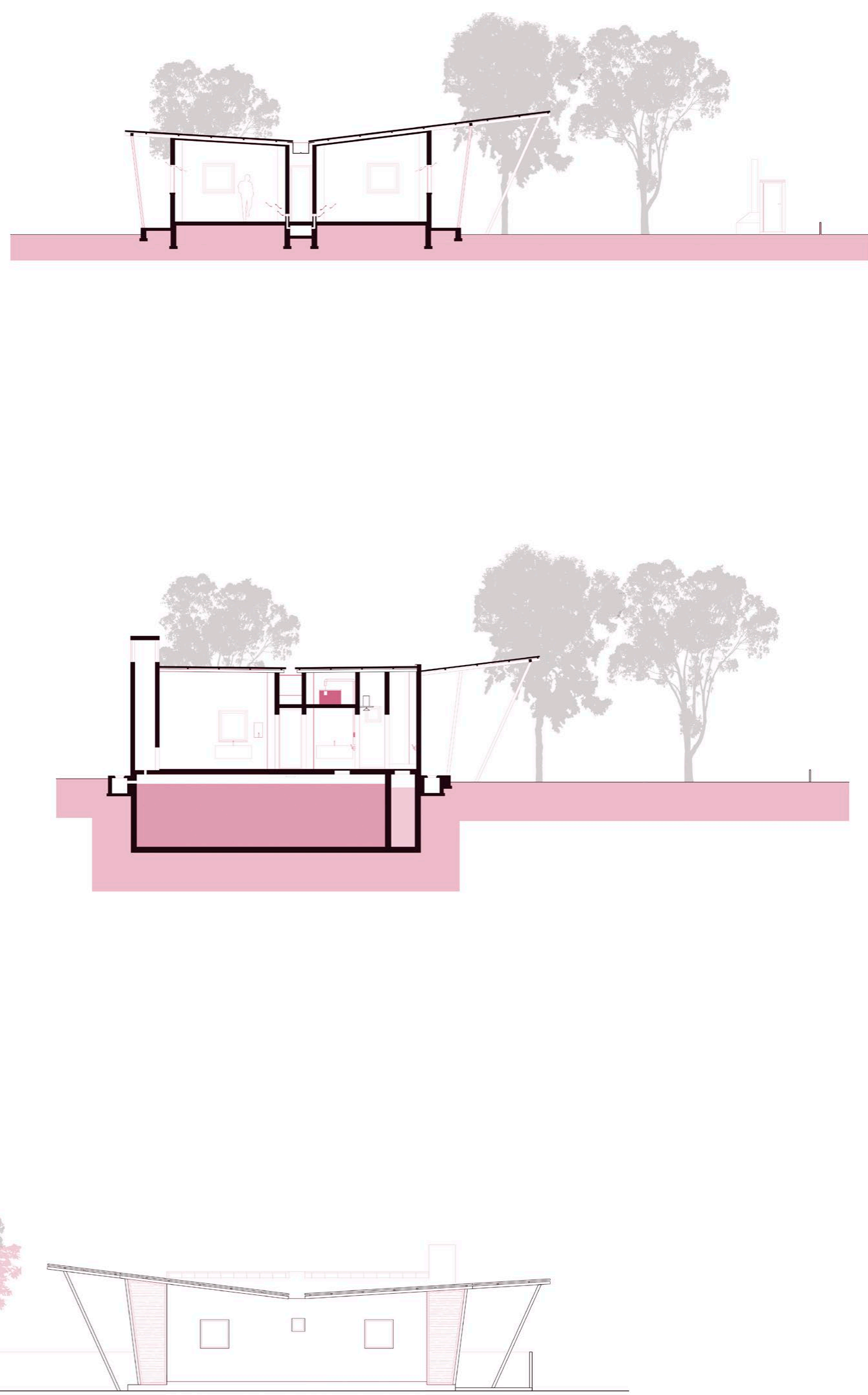


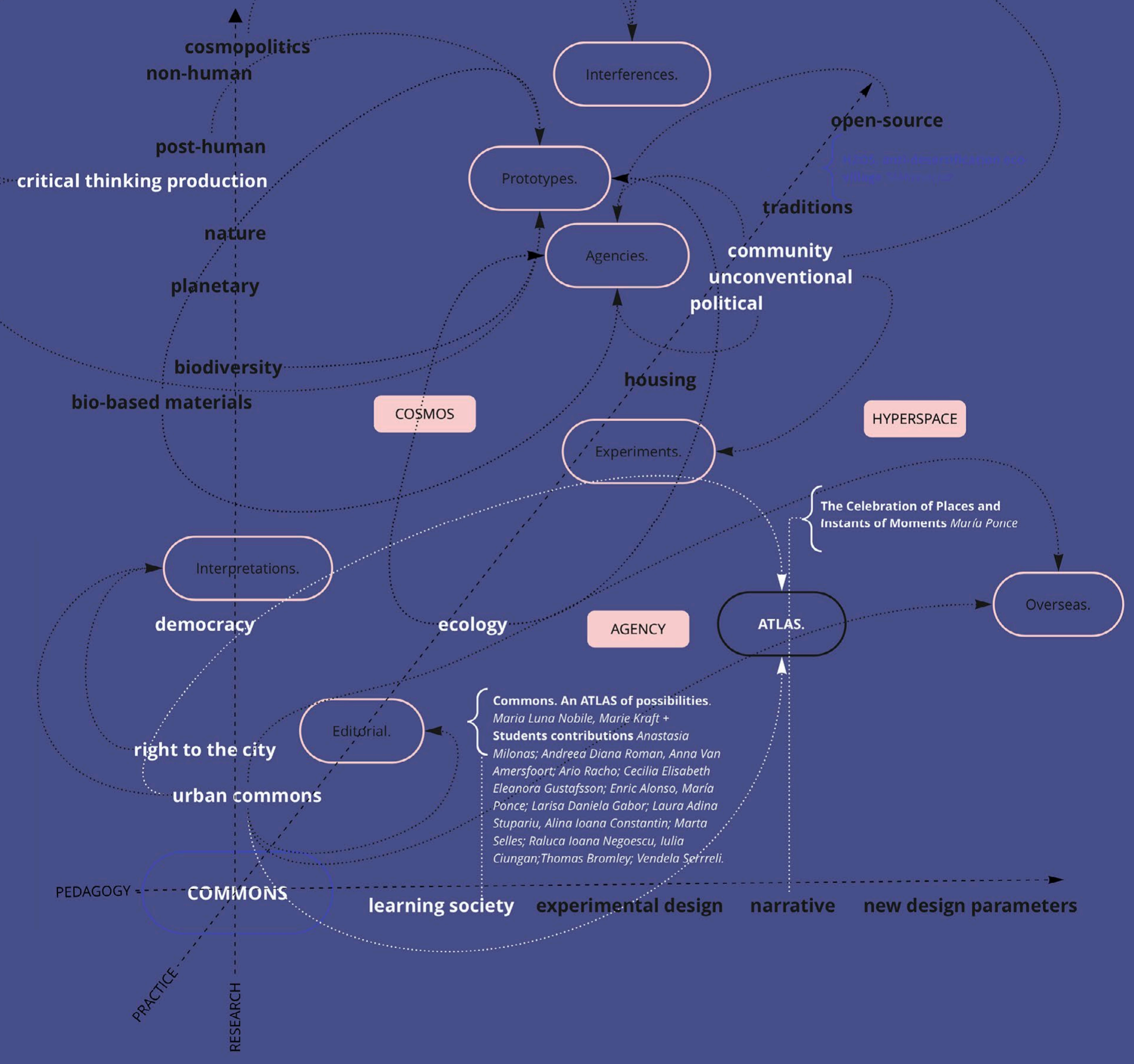




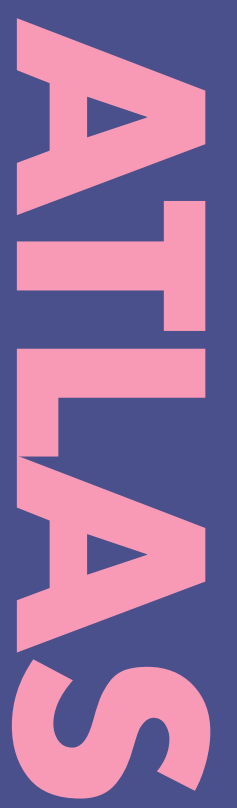




\section{Commons. \\ An ATLAS of \\ possibilities.}

\section{Nobile, Maria Luna ${ }^{1}$; Kraft, Marie ${ }^{2}$}

${ }^{1}$ Umeå School of Architecture / Umeå University, Sweden

${ }^{2}$ Department of Urban Studies / Malmö University, Sweden

Citation: Nobile, M. L.; Kraft, M. (2021). Commons. An atlas of possibilities. UOU scientific journal \#01, 158-189.

ISSN: 2697-1518. https://doi.org/10.14198/UOU.2021.1.13

This document is under a Creative Commons Attribution 4.0 International license (CC BY 4.0)

The concept for "Infinite Places - Building or Making Places?", developed by the Encore Heureux team in the Architecture Biennale of 2018 , presents places produced by new and inventive processes that generate architectural processes of value. This exhibition project highlighted initiatives on the part of civil society and communities that embody a certain free spirit of experimentation and the infinite possibilities opened up by architecture.

The ATLAS presented in this section is the result of a call for students' projects based on the reflections shared during the Workshop \#2 of the Autumn Term of the UOU Project. The Workshop included students from several nationalities and aimed to build a reflection between territories, nations, regions, cities, places, and their own inhabitants, on the topic of the role of the architecture in society: each student identified an Infinite place in their own city.

These were not meant to serve only as sites for the development of a project, but as sources for the elaboration of a trans-national, trans- scalar, trans-disciplinary community starting from the local context, culture and society, and going beyond borders, languages, national regulations.

The students were asked to build an Imaginary Land where architecture could re-conquer its function in revealing the relationship between the humans and the world. (Dorfles 1968) .

The workshop included short talks between tutors from different universities. We have unpacked the city based on the experience of the places, with the aim of finding opportunities in neglected and forgotten area/buildings; we worked with imagination in defining new rules for a collective "Imaginary Land" as a different idea for a trans-national/scalar/disciplinary community; we learned how to contribute to group work and exchange as a small experiment for a learning society.

See more on our ATLAS:

$@$ @university of universities 



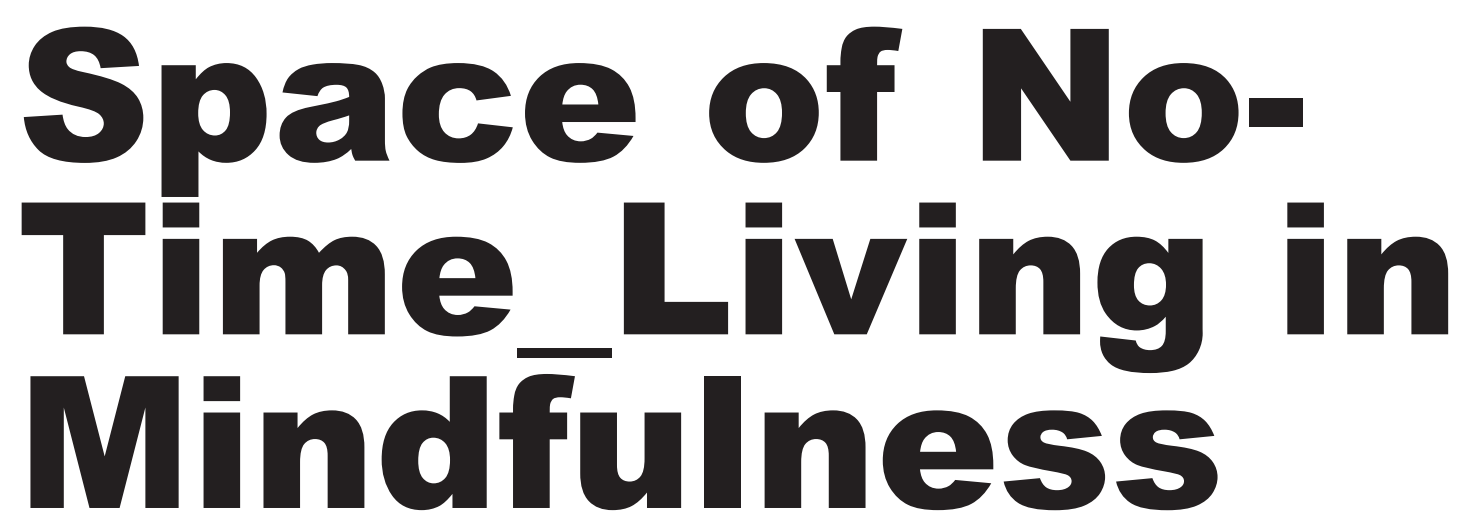

\section{Milonas, Anastasia ${ }^{1}$}

${ }^{1}$ University of Nicosia, Cyprus

One of the main problems in the contemporary world is the physical, mental and spiritual separation that has occurred between humanity and nature, as well as among humans. This separation could be the root that explains the many issues that plague our modern world, from the deterioration of the environment to the injustice and inequality of the contemporary capitalistic systems that emerge in our communities. In modern day society where most spaces in the city are exclusive, green is being eliminated and the system is constantly opposed to any citizen intervention, it is time to look into what's connecting us and create a community rather than remaining in separation through this social and environmental crisis. In the place of "No-Time" citizens find relief and reconsider life's values in a state of mindfulness, that's so close physically but so far mentally from the stressful everyday rhythm of life in the city.
The project proposes a series of activities in shared spaces that promote a collaborative mode of urbanity and the inclusion of various groups of people. The programme includes activities like communal cooking \& eating, meditation spaces, exchange skills workshops and collaborative cultivation, making the community self-sustainable in a constant state of solidarity rather than using pieces of paper(money). The vertical gardens expand into a larger scale light structure, creating vibrant microclimates. Greenery that resists deterioration by the weather in the city invites more plant and animal life of plants and animals, while social spaces also form inbetween. Opportunities of connection and synergy are constantly being sought through the in-between spaces and functions, while reconnection to nature, grounding and healing occurs, attaining social and environmental sustainability. 


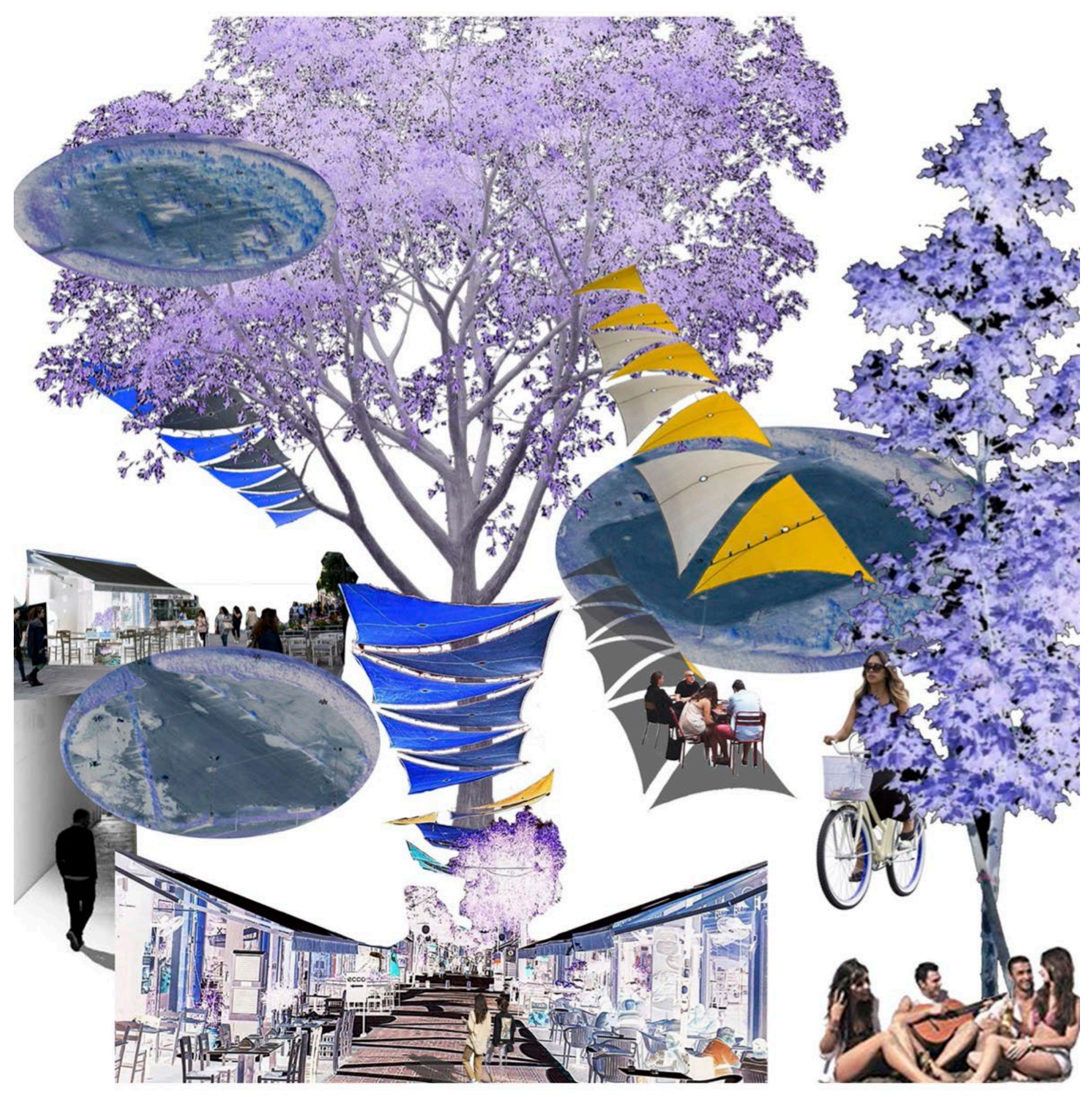




\section{Geneta field \\ in Södertälje, \\ Sweden}

\section{Racho, Ario ${ }^{1}$}

${ }^{1}$ University of Nicosia, Cyprus

Geneta Field is located in the middle of the area with a good connection to nature and it has good accessibility through a web of roads for cars and pedestrians. The incomplete development of the field created a unique space to be occupied mostly by youths of the area. The development looked at establishing a lively area that corresponds to the activities of different generations but with a focus on the youths, who were lacking recreational activity space. The undecided characteristics created a rivalry between two communities with different interests. Gangs find this place an attractive environment for their illegal activities. To free the site from criminal activities the idea is to have several interventions; social, economic, and recreational to make the site more active. The informal monitoring of the space merely by the existence of people there creates an unattractive environment for the illegal activity that flourishes in the dismal hidden spaces. The use of light structures that create node shelters was inspired by Ledra Street in Nicosia. The idea is to integrate that into Geneta field taking into consideration the weather differences and social structure. 

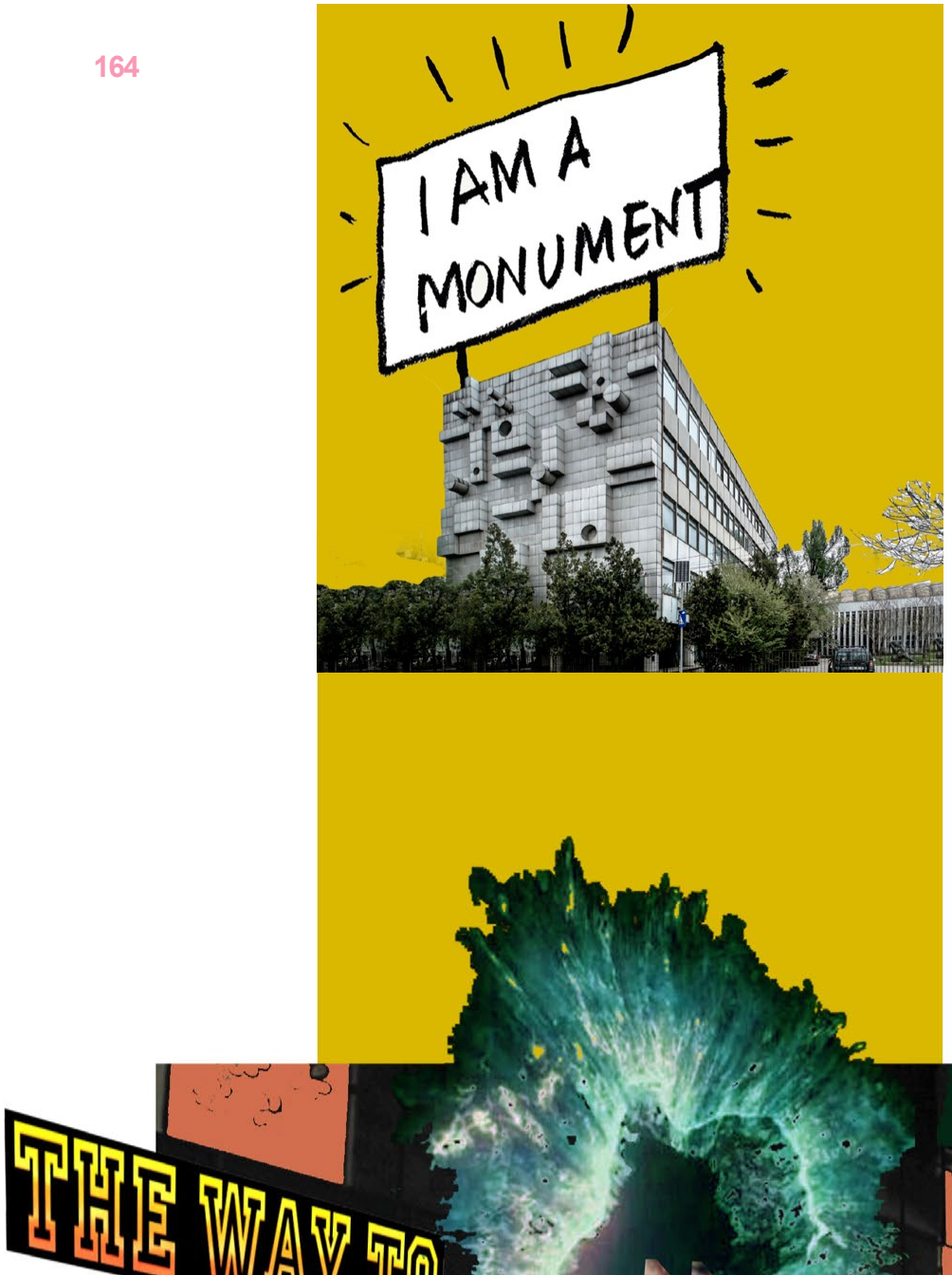

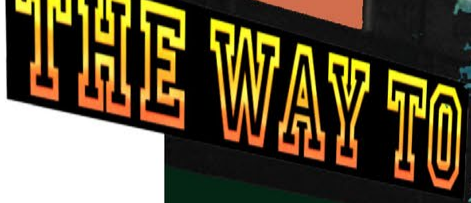

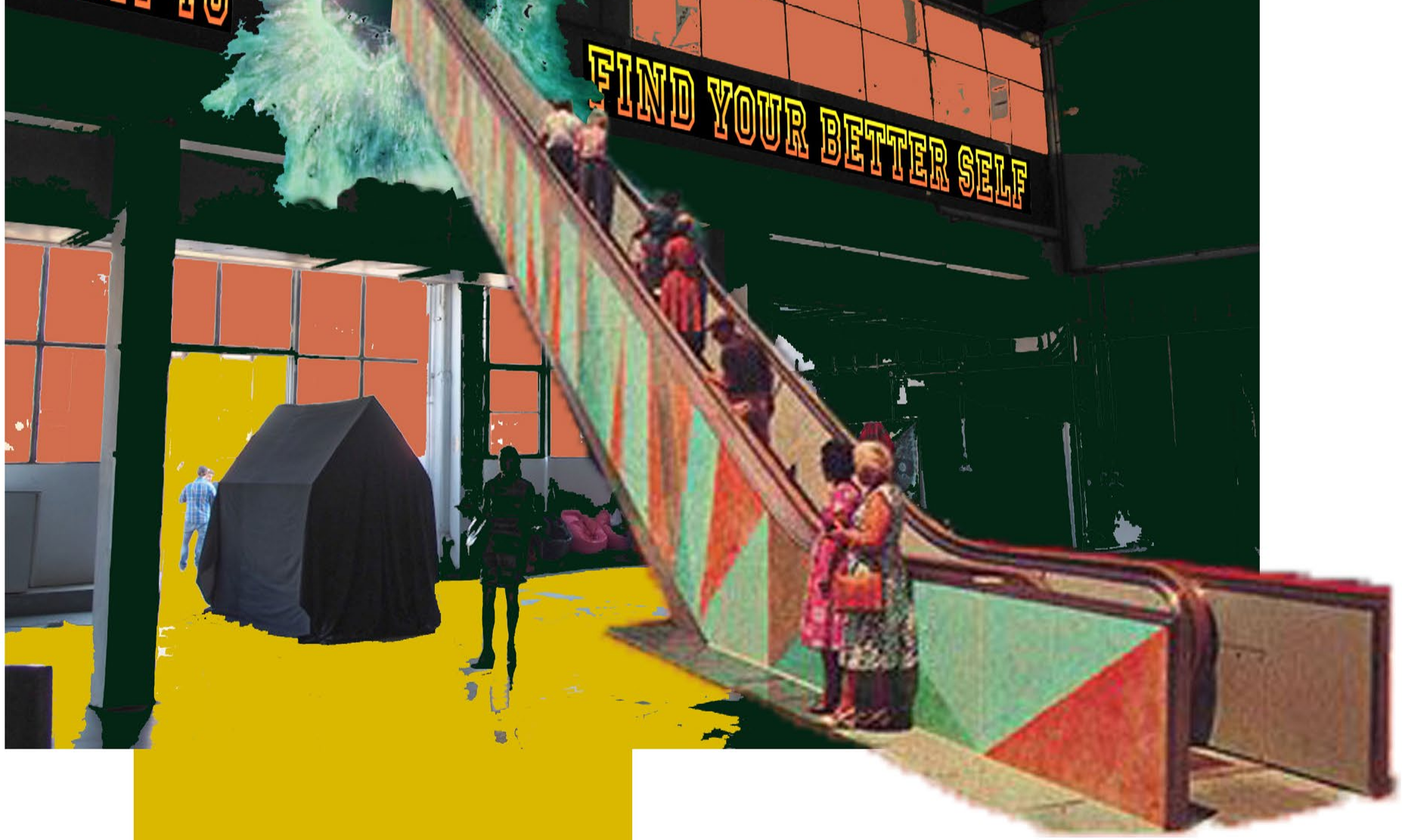




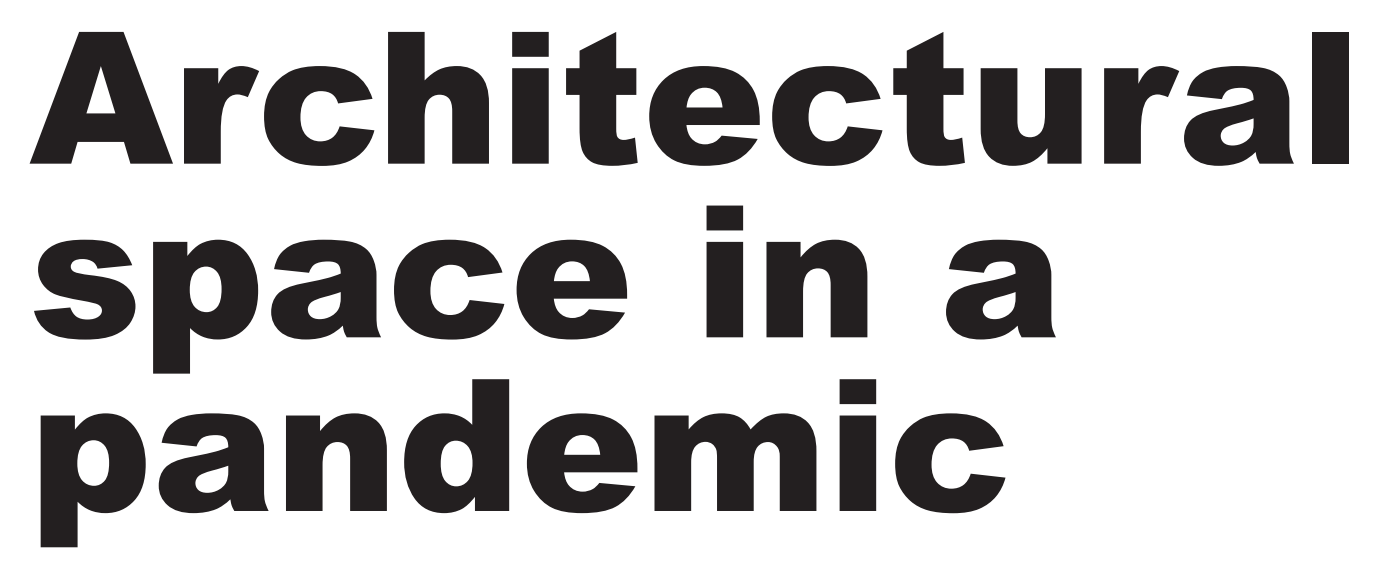

\title{
Roman, Andreea Diana1; Gabor, Larisa Daniela²
}

\author{
1"Ion Mincu" University of Architecture and Urbanism, Romania \\ 2"Ion Mincu" University of Architecture and Urbanism, Romania
}

Communities are formed by a gathering of people that share similar life values, wishes or are brought together by unpredictable circumstances. A community can choose you or you can choose to be a part of one.

"Combinatul fondului plastic" shares the values of a building which creates infinite spaces and relations with the city. It brings to life what the user makes of it. In the past it used to be the place where artists would purchase their supplies, today it's the very home of their art. It may look like a postclammy waste facility, but it's actually a maze of sculptures and paintings. If you linger around you can find questionable pieces of street design and unconventional interpretations of dreams and nightmares alike. By being the home of various artists' works, it brings together multiple types of communities: artists, art lovers, or curious and impressionable people. Together they form a new community as a part of the consumerist society. Thus, the building is seen as a result of the shift from the classical way of thinking to a modern and industrial perspective. Buildings became machines for people to live in. Function was the core element a space had; people would come to a certain place to fulfill specific activities.
Now the problem is shifting again. In a pandemic, where people are blocked in a singular space, not being able to press a pause button to their lives, the space becomes much more important and it should be a lot more versatile. Architecture and architects no longer give function to a space, the user now takes that role and is transforming the space so that it can become a place fit to fulfill certain needs. Architecture and architects have received a challenge and a new role, to create spaces that can easily adapt to the users' needs. Thus, a place is no longer set to serving one purpose. It creates infinite scenarios that are tailored on each individual.

If until now the community was defined as a larger group, even foreigners, we have reached the point where we define it as the group of close people around us. People are forced to define their own spaces and create their own realities. Function is no longer given by the place but by humans, forming a new dynamic in architecture. The buildings will become easily re-modelled spaces in order to be able to submit to the needs of each individual simultaneously with other individuals. 


\section{Limited Infinity}

\section{Stupariu, Laura Adina'; Contantin, Alina loana²}

1"Ion Mincu" University of Architecture and Urbanism, Romania

2"Ion Mincu" University of Architecture and Urbanism, Romania

If we had to describe 2020 with one word, it would be "Toxic". During the pandemic together with all the sad events that have happened during this year, we came to realise how important we all are. Thinking of how we can transform something real through the experience of the pandemic, we realised how a space so small as our own home for example can depict a whole new universe now, surrounded by uncertain barriers Therefore, in this scenario, everything around us is temporary; things our lives used to revolve around, like streets, workplace, society, films, are unreachable now and we need to learn how to live without them. All that was left for us is to search for other ways of communication, in order to keep our relationships alive. How lucky do we consider ourselves that we have come to accept and love equality? Getting deep into thoughts, we tried to create something new through the picture of a man made out of different races. We can place our infinite place anywhere in the world, as it isn't something standardized, as we, as human beings, have different needs and different approaches to the same problem. We portray this problem as a path, going through different places. The beginning of this path has a place where we breathe peace, not just air. This also reflects the idea that we're all born free. Thinking about it from a different point of view, instead of laying nonchalantly on a hill, you can imagine the number of tunnels constructed during wars that are now forgotten, taking part in this whole scenario, opening themselves to the public. Staying inside for so long, most of us get bored of the same image, so we try to bring something new, to open as much as we can to the outside we're limited to reach. Continuing our path, we framed a venue that seems to lose its placement in time due to its details, both technical and decorative; it is our time capsule - the place that converts our lives. It is an axis mundi, with exaggerated directions, the idea through which we tend towards the absolute from an utopian point of view, bringing it closer to the idea of infinite. This segment could also be considered a place of rebirth, showing the consequences of the pandemic on human kind, turning upside down the premise "as free as birds" into a state of being stuck to the ground. The final destination emphasises an amalgam of possibilities. This ending is also a new beginning full of opportunities. One can reach this state only to discover what life can offer, even when it is limited. Such an infinite place can provide greater satisfaction due to its versatility. 


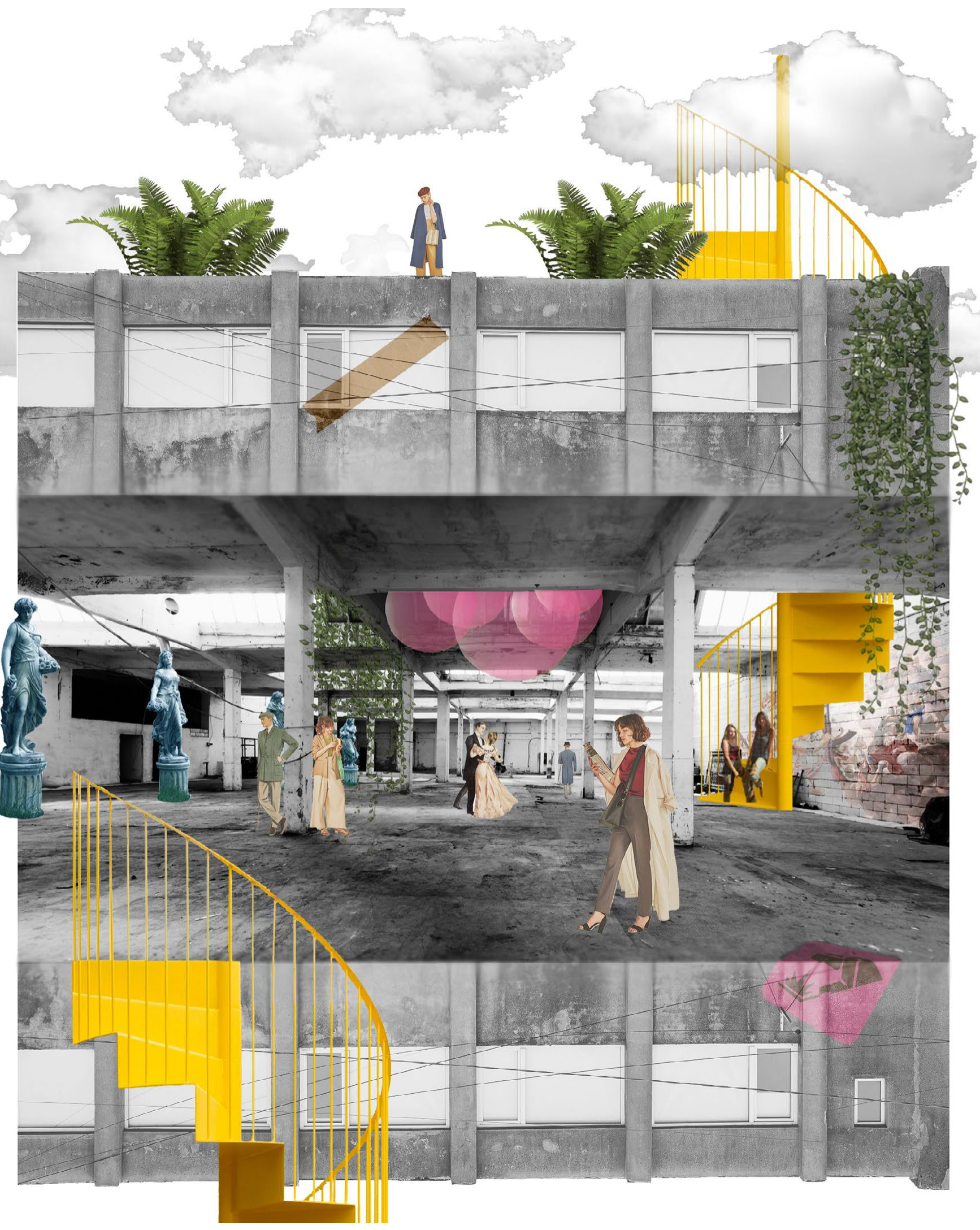


Nod Makerspace

\section{Negoescu, Raluca ${ }^{1}$; Ciungana, lulia ${ }^{2}$}

${ }^{1}$ Alicante University, Spain

${ }^{2}$ Alicante University, Spain

Our infinite space is located in the south of Bucharest, Romania, and it is known by the name of 'Nod Makerspace'.

The place used to be a cotton factory during the communist period (from 1947 to 1989) but afterwards it was abandoned and forgotten. A few years ago someone noticed the huge potential of the place and decided to bring the old factory back to life with the help of some volunteers. Nowadays it represents one of the most active places of Bucharest, it hosts coworking offices, fully equipped spaces for wood and metal workshops, 24 studios, 4 event halls and a materials library.

Our proposal it is meant to transform the place into one of the main spots in the city for creative industry, to bring people together, not only for working but also for meeting and socialising. In order to fulfill the potential of the space we imagined an open studio, a place that knows no boundaries where people are encouraged to work together. The design transformation of our infinite space completes Nod Makerspace initiative and enriches it. 


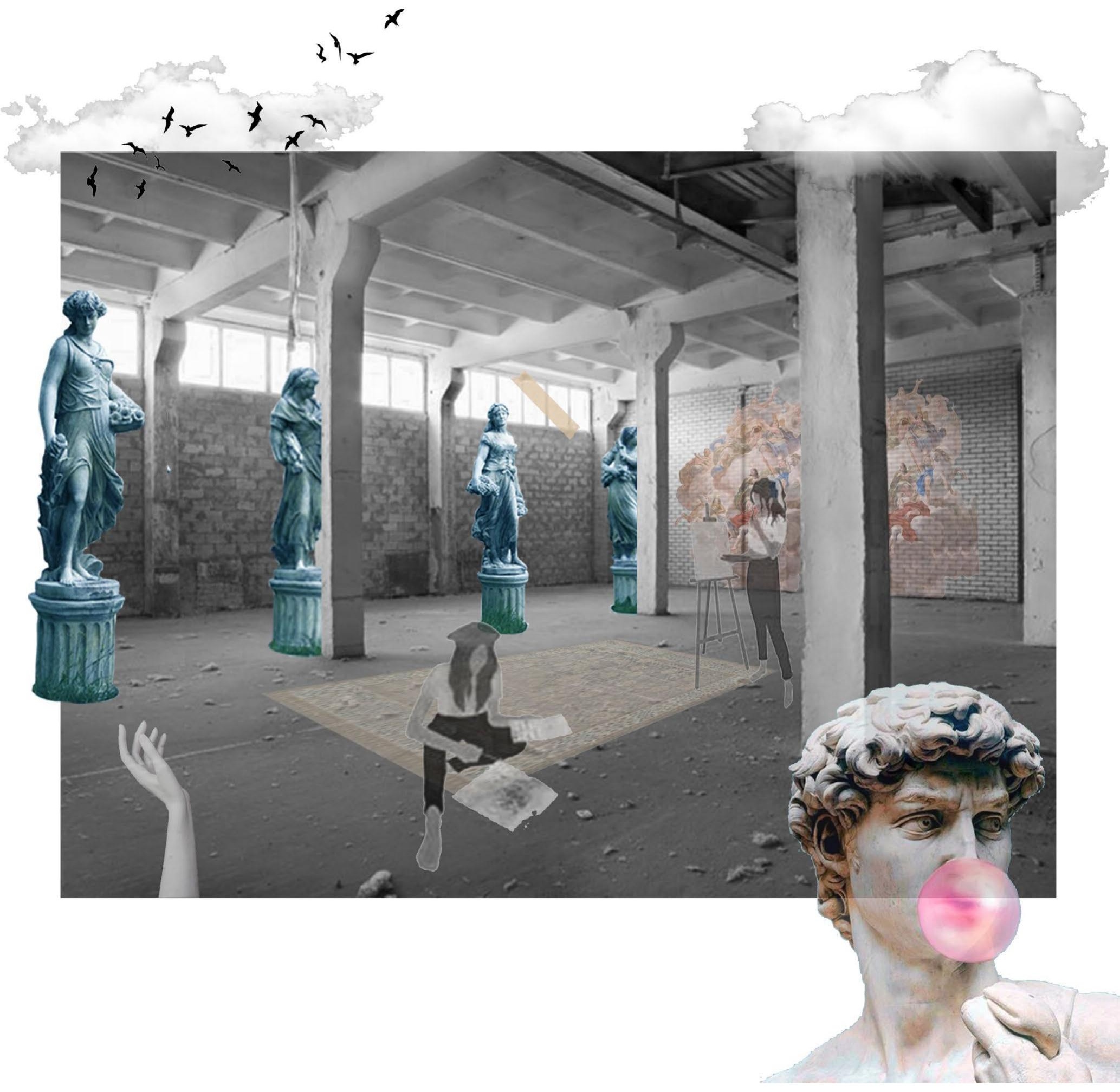




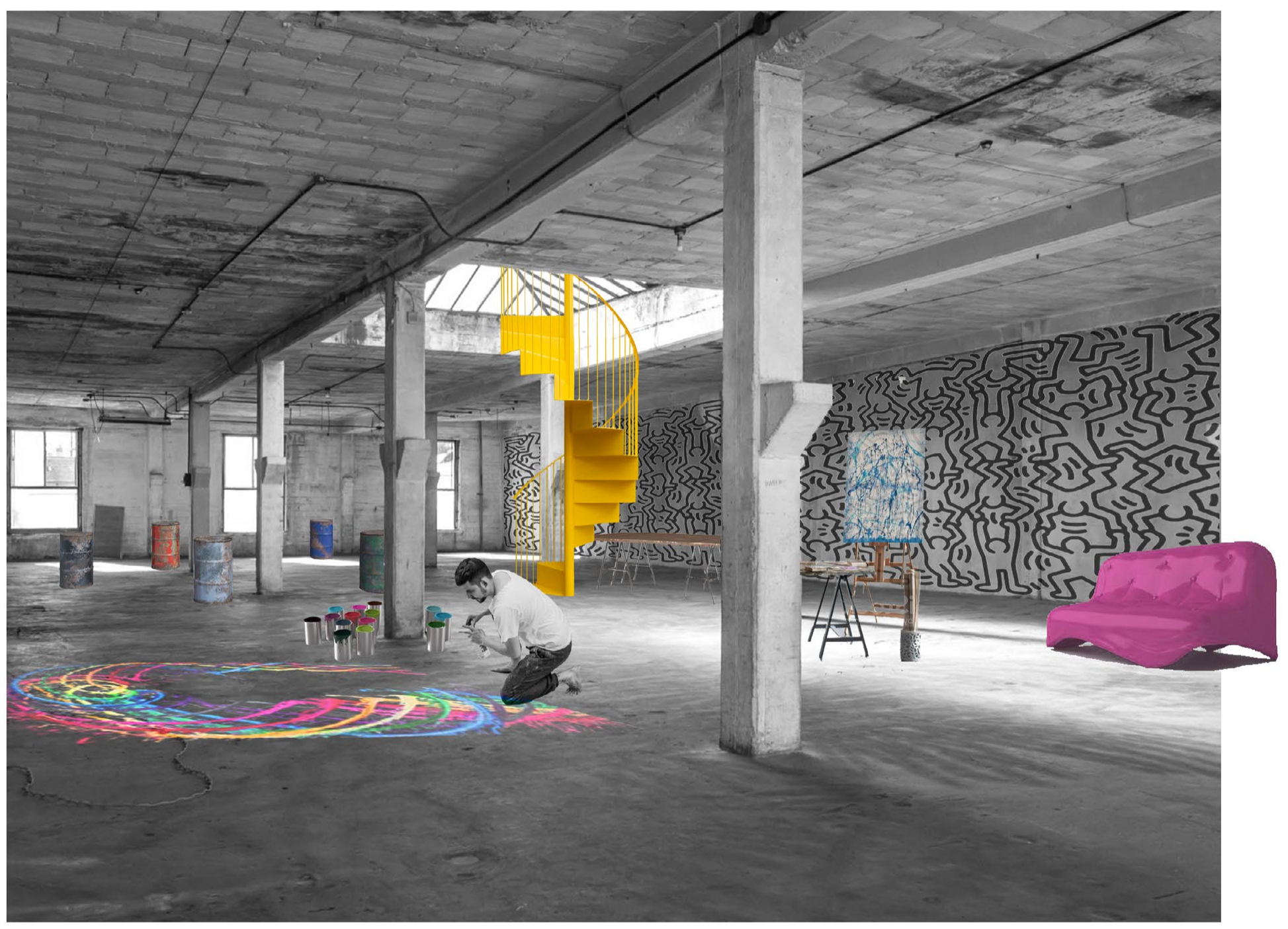




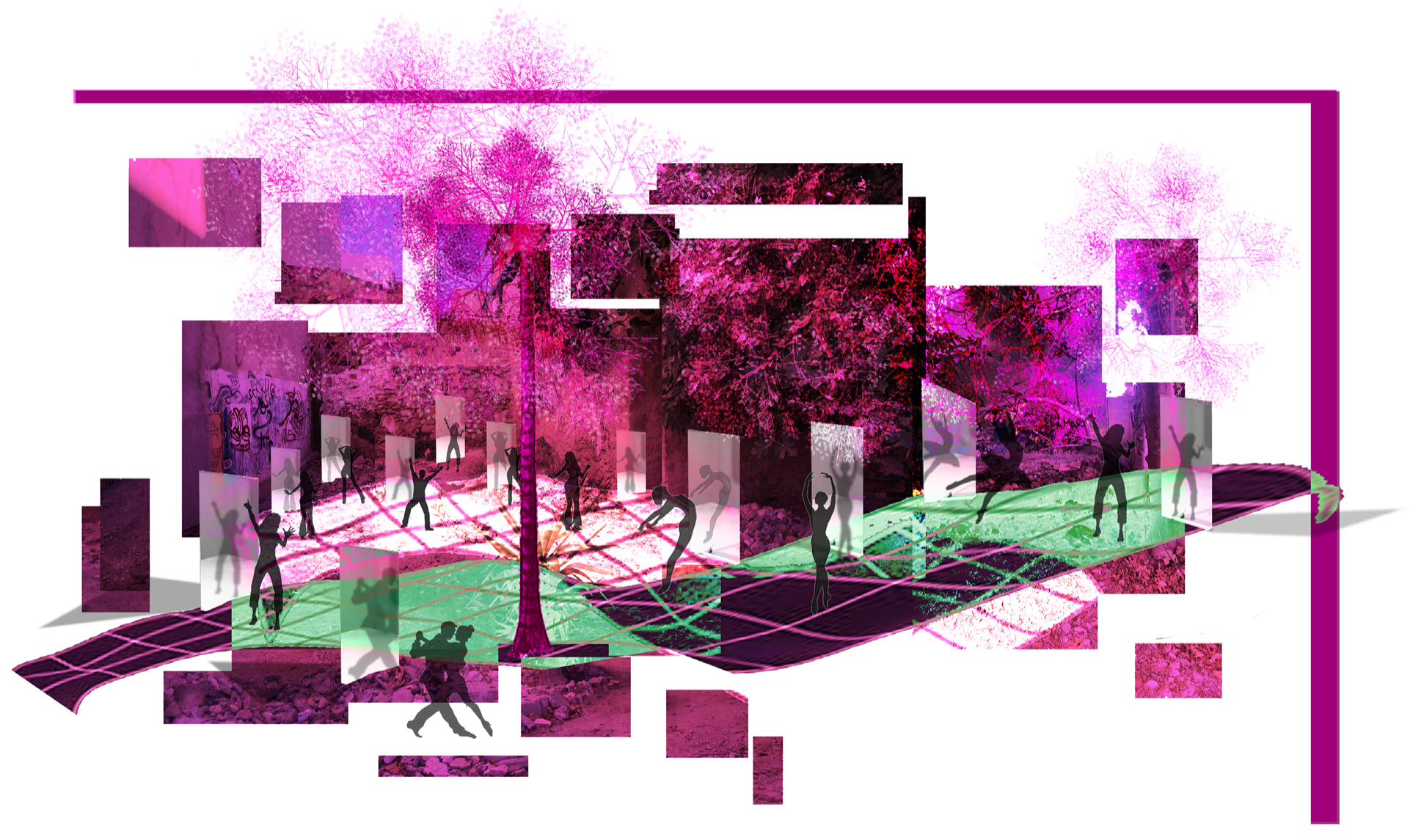




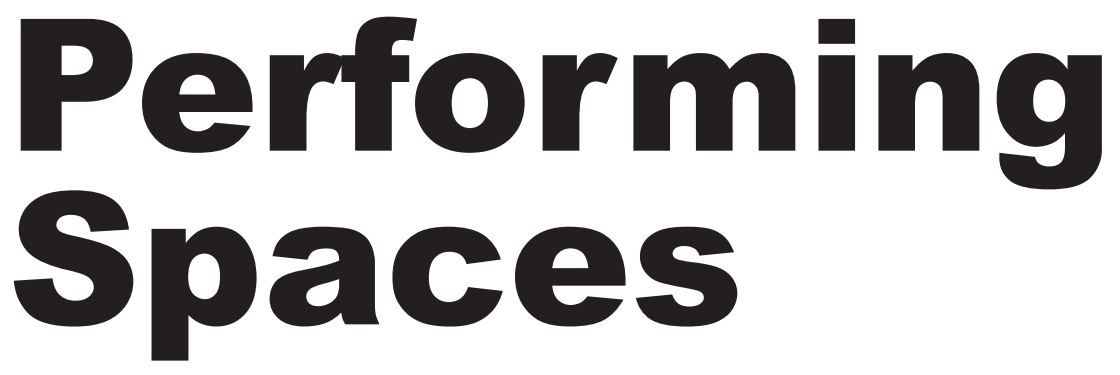

\section{Sellés Armendia, Marta ${ }^{1}$}

${ }^{1}$ Alicante University, Spain

We often underestimate abandoned spaces. When we walk through the streets of our city, we often fall into the monotonous vision of space, reducing ourselves to seeing only what is in front of us, instead of stopping to think about the infinite possibilities of the place. I was just walking my dog along our usual route, where we always pass by an abandoned and somewhat neglected plot of land.

A place that, perhaps for some might go unnoticed, but if you stopped for just a few seconds, you could see how this apparently unsuspecting and insignificant space came to life when a neighbour decided to plant a palm tree in its centre.

That is why my proposal to create an infinite place is based on fostering a free outdoor space on a non-uniform terrain with mirrors scattered throughout the plot, encouraging a new public dance hall design around this palm tree located at its centre.

This new community activity in the neighborhood seeks to encourage dance and dance as a form of expression in a free and accessible space, where the space will not be brought to life by a painstaking and studied design, but by the experiences of the people who will perform in it. place where you can dance alone or accompanied, where you can live an occasional and sporadic apprenticeship with people who, like you, will bring the space to life. Because the true potential of a space is measured in the experiences that will be lived there and because, at the end of the day, the places that mark you are those in which you live experiences that make you feel alive. 


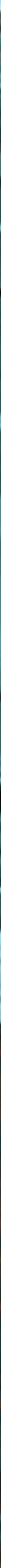




\section{Architecture is the Art of Building Communities}

\section{Alonso Banegas, Enric ${ }^{2}$; Ponce Garrido, María²}

${ }^{1}$ Alicante University, Spain

${ }^{2}$ Alicante University, Spain

\section{La Británica refinery is an open space} surrounded by the Mediterranean Sea and the Serra Grossa (which is an urban forest park). It is and abandoned place that nature has conquered because, although it is a very closed to the centre of the city, being surrounded by mountains makes it be unnoticed by humans. Turning the refinery into an infinite place... When we think of culture, big places like theatres and stages come to mind, but what about all those people who want to express themselves on the street? Those who seek nothing but to meet people with whom to share and express emotions through art.

Spaces dedicated to poetic, musical or dance jams are missing. It is here that Refinery comes into play, with that historical structure reminiscent of Alicante's past, with the acoustics that surrounds it giving you inspiration.

It therefore becomes a place to go to simply enjoy being present, to create new connections with people so far unknown but that art unites. Unions that allow you to grow, open new door in an artistic world that sometimes seems difficult to enter.

That is how, with casual gatherings in infinite places, communities come alive.

We propose...
+ The creation of an ephemeral roof that surrounds the exterior allowing the creation of an open and closed space at the same time, place where small artistic or rest activities are located.

+ Keep the feeling of being in nature by having the central area exposed.

+ To take advantage of the circular shape so that people's eyes meet even if they are not doing the same activity.

+ Create a balcony in the heights that is accessed by the outside stairs that until now did not lead anywhere.

+ Resting places created with recycled materials.

As for the activities...

Inside the space we find musicians anywhere om the place who discover how to take advantage of the unique acoustics, dancers who move to rhythm of such melodies in the central area, people whose speeches are transmitted from the new balcony located at the heights of the space, people who take advantage of recycled seats to talk or simply observe what is happening around them. It is a place to attend to inspire you and escape the routine of the city, because every day people make it different and unrepeatable. We are, as a community, the ones who transform and give life to a space. 


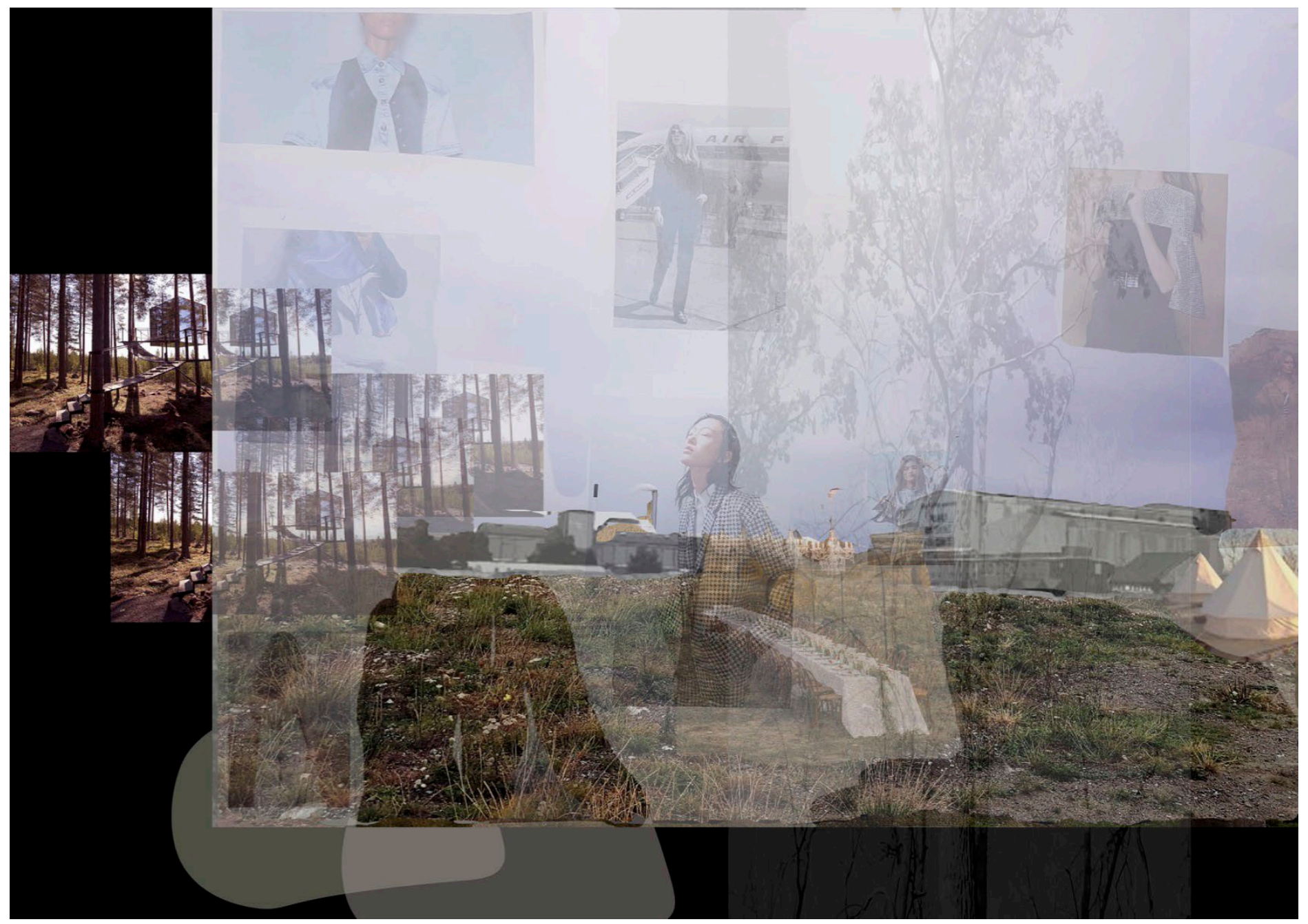




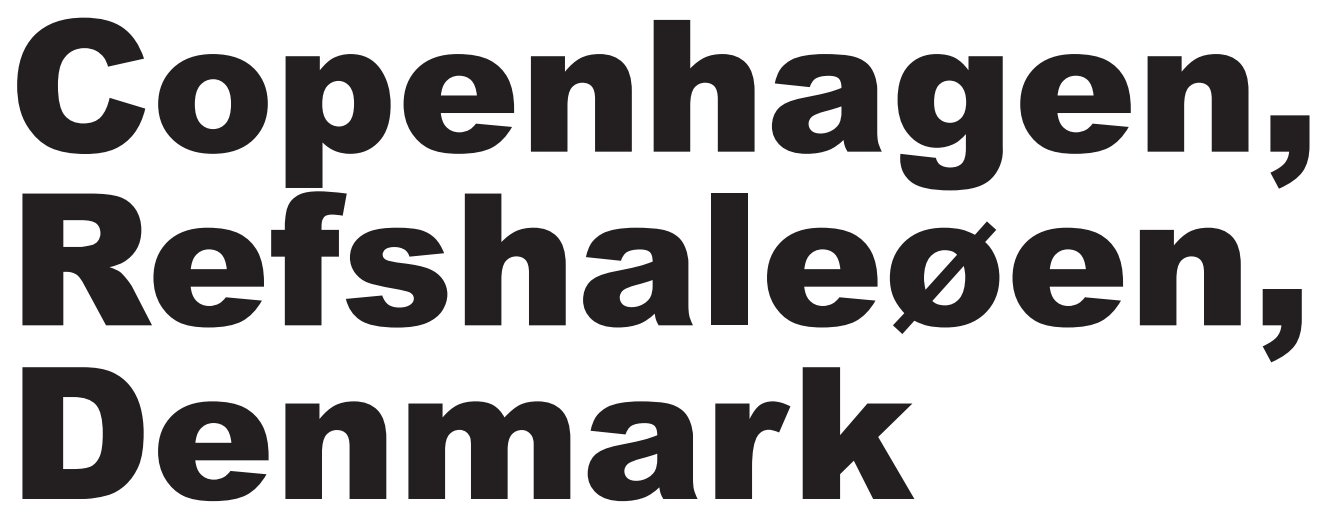

\section{Serreli, Vendela ${ }^{1}$}

${ }^{1}$ Malmö University, Sweden

"Reffen" is an artificial island with good communication possibilities to Copenhagen city centre. The area is characterized by previous industrial activities. and the The former shipyard with large warehouse buildings and flexible spaces is reborn as a place for creative works and social meetings. The common space which is surrounded by water encourages interaction, on the one hand between people and on the other hand between people and the urban environment. Reffen offers activities as music events, art, performances, recreation, a food court, dwelling places and spaces for rent. The development of the area is described as a dynamic process, parallel with the constant change of the city, as a result of collaboration over a diverse network. A dialogue with both regional and national politicians as well as different cultural projects form the foundations to deliver a multidimensional atmosphere. Since "Reffen" already includes multiple different criteria as a common space it was a bit hard to imagine exactly what would complement the existing place and eventually bring a new and broader crowd, with different perspectives and thoughts but still with some kind of a common goal, to the area. Integration, interaction and safety became leading words for a new vision.

The imaginary space that I want to share is a free, open-minded place with opportunities to stay overnight. Some kind of glamping or tree hotel. A safe room, regardless of individuals background and with a focus on common areas. Boundaries between private and shared would be flexible, depending on individual preferences and the specific occasion. The goal is to give a warm and welcoming feeling to the large open field. The proposal aim to take advantage of the site's potential and proximity to nature based on the needs that exist at the site today and at the same time offer something new for today's visitors at Reffen. 


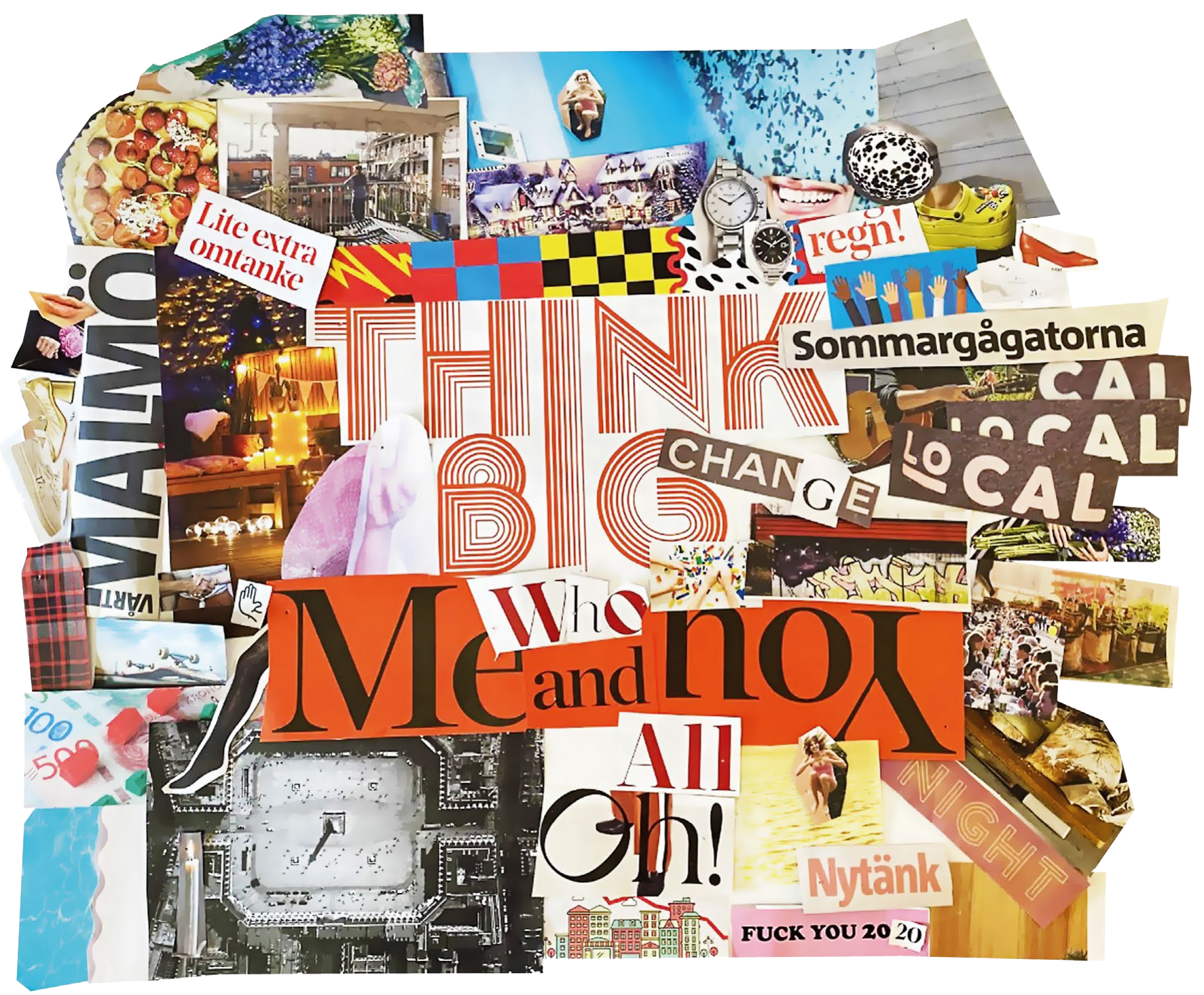




\section{Think big. Who? Me and you.

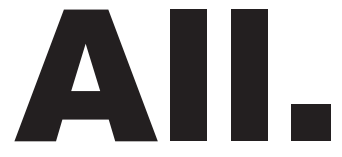 Oh!}

\section{Van Amersfoort, Anna ${ }^{1}$}

${ }^{1}$ Malmö University, Sweden

What makes a place is worth giving thoughtful consideration to. A liveable place is to be balanced. An inclusive, usable, common space is to be balanced; balanced between common knowledge with future scenarios; between peoples needs and other peoples pleasure. Architects and planners are meant to create these places out of empty, or existing, spaces, for all to share, for local and universal use. The value of space has to be considered. Architecture and planning affects us all. Planners' interrogation with the users must be consistent and taken into account. The social capital will grow with social relations built on mutual understanding and shared values.

Think big and don't be selfish. Think twice. Use common knowledge and make sure it's a place for several users. Include universal values rather than bringing something new and foreign to a set location. Let all people talk and think about how a place works in different situations. What brings people together and makes a safe and shared place? During the time of the COVID pandemic the common use of space has faced challenges, as well as the definition of an architects or planners purpose. In our daily lives during the last year, we have been taught to deal with adaptation in various ways, especially adaptation to space, both physical and non physical. Many of us are now more familiar with spending time together in a virtual space. A space with various opportunities, but for us to adapt to. Flexibility and adaptation are the survivors of this pandemic and will be the survivors during other crises such as climate change. Implementing this with an architect's profession creates a changeable space for whoever finds it attractive to visit; adapting to its surroundings with the weather and with societal structures. Cities are rapidly changing and so has the architect be able to be open to the unplanned and think through the contingencies before creating new places. Think big by starting with using local knowledge to share. Make cooperative actions possible. Think about you, think about others. Think bigger than yourself. Places can not be individualised. Architects have a great responsibility, making common use of urban public open spaces possible. The agency of 'Society' has the assets that needs to create a more socially sustainable quality. 


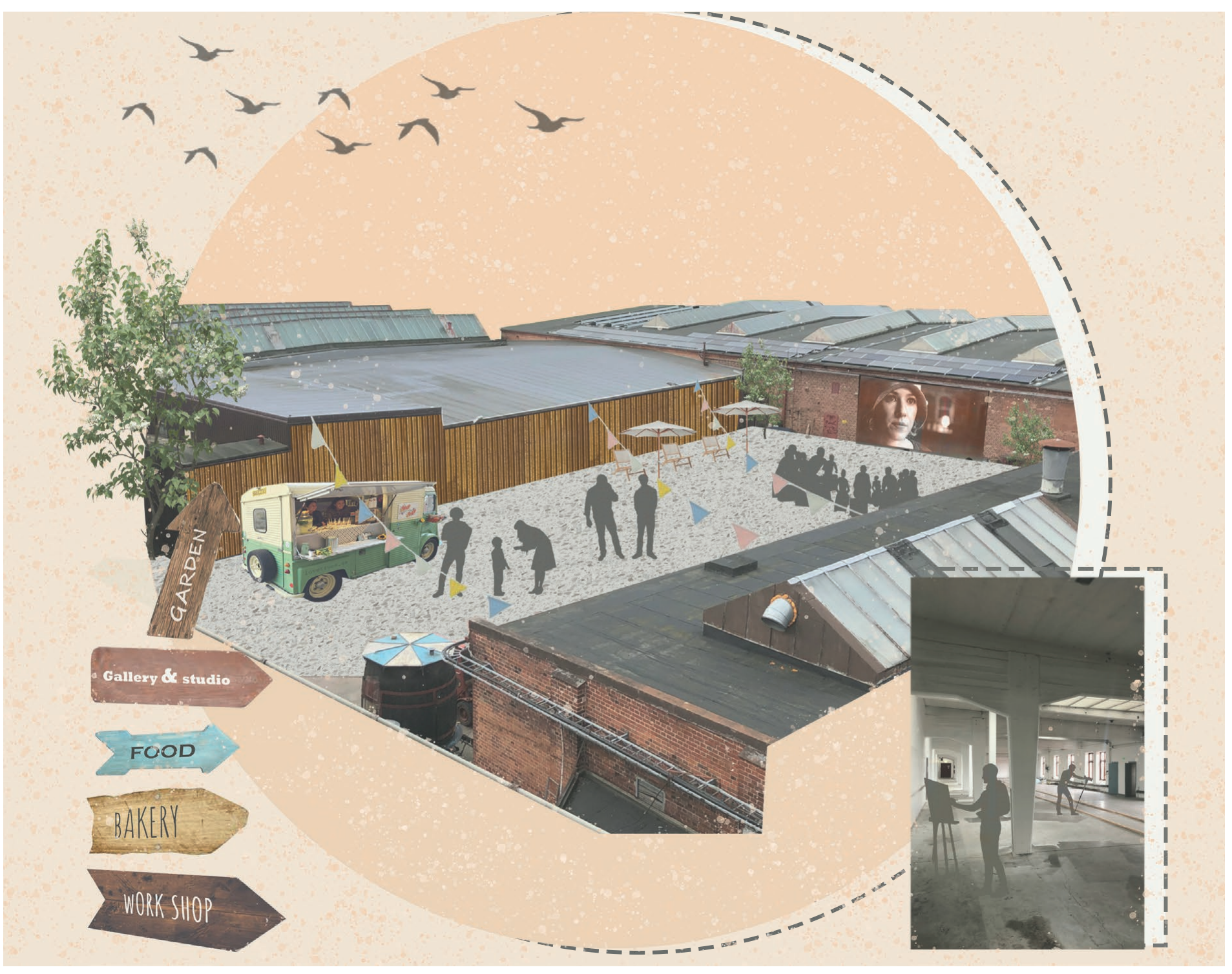




\section{The resurrection of Yllefabriken}

\section{Gustafsson, Cecilia Elisabeth Eleanora ${ }^{1}$}

${ }^{1}$ Malmö University, Sweden

In Marieholm 40 kilometres north of Malmö resides "Yllefabriken". The 17000 square metre brick facility was built in 1898 and served as an important employer in the region, processing wool for the textile industry. One can say that the factory, up until its closure in 2002, shaped the village of Marieholm, attracting employees to move where work was to be found, and by providing housing for workers.

Since 2017 Yllefabriken, with its new owner, has served as a host for various recycling and up-cycling businesses, artists and even a bakery. The community has arranged different cultural events over the years and has a vision for the place to become $A$ Swedish version of Christiania - without the drugs. Unfortunately, the great vision came to a halt in 2019 when the municipal fire department closed the operation down owing to safety hazards.

At first glance the enormous space currently brings the word "ghost town" to mind. Looking further, it is hard to miss the endless possibilities that the old factory possesses, based on the space itself and the creativity and engagement of the community surrounding it.
Because of how the separate buildings are situated, in a square, it provides a protected courtyard that invites different types of activities. One idea is that this space could be used fluently by whoever wants to throw an event, just hang out or try out a new idea.

The flat, sun soaked, surface of the big roofs brings communal gardens to mind.

The ceiling windows of the tall factory buildings illuminate the rooms and makes them ideal for artists, workshops as well as for temporary workspace for startup companies. Why not let them serve as an alternative home office in this new time when "workplace" has turned into a floating concept.

More re-cycling and up-cycling businesses could join the already existing thrift store - there is plenty of room available.

If kept alive, Yllefabriken has a great potential to enrichen the community. It previously only provided with employment and production. Now in the shape of a common space it can provide culture and creativity. 



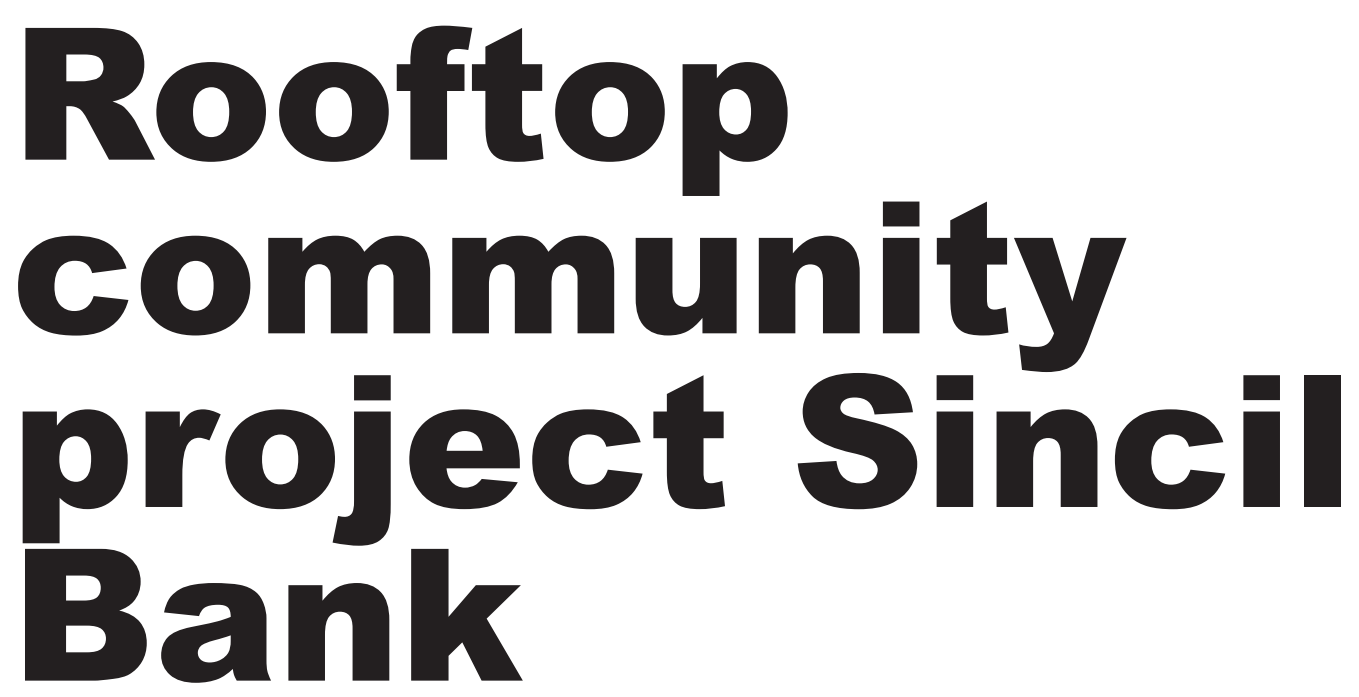

\section{Bromley, Thomas ${ }^{1}$}

${ }^{1}$ University of Lincoln, UK

The rooftop community project (RCP) has the goal of activating unused opportunity spaces for community-built projects in the private terraced housing of Sincil Bank, located in Lincoln, UK. The project aims to strengthen the local community, induce community cohesion and recapture a lost sense of ownership and belonging through "common" spaces, responding to societal changes accelerated by the implications of the ongoing pandemic. It has been found that the requirement to remain indoors has shifted the "normal" from prepandemic conditions, with people leaving their homes for only essential purposes, transitioning to online working and learning. The pandemic will pass, but the changes identified may have a lasting impact on post-pandemic lifestyles with many continuing to work and learn from home. This has left the notion of "common" space in question. With less incentive to leave the home there will be less use of common space and therefore less natural face-to-face socialisation. The proposal provides a reconfiguration of common space from public, external space to more localised, semi-private space. These spaces are conceived, designed, built and used by the members of the Sincil Bank community. They will be governed by residents to nurture possession of the space, inducing a sense of belonging. By including the local residents in the proposal, it ensures the project directly responds to their specific needs. The requirements of each resident differ depending on social status, occupation, age, family etc, and is something that can be addressed locally. With a dense urban fabric like Sincil Bank, there are little to no opportunistic areas for the development of these common, semi-private spaces. The structure is to be suspended over the existing housing using a series of spaced timber columns. Using timber allows residents to easily attach their own creations to the main structure as well as causing minimal disruption during construction. The existing rooftops are to be stripped down to allow for this new structure, with new storage space being readily available close-by to site. Removing this existing roofing, gives the opportunity of directly connect the residents houses to the proposal through the existing attic door, providing a unique access point for the able, however, any person of disability can still gain full accessibility through the proposed core. The project has the potential to recapture this lost community presence in the area through ownership and belonging. The scope of this can be widely expanded, providing more vertical, semi-private "common" spaces for the residents. 


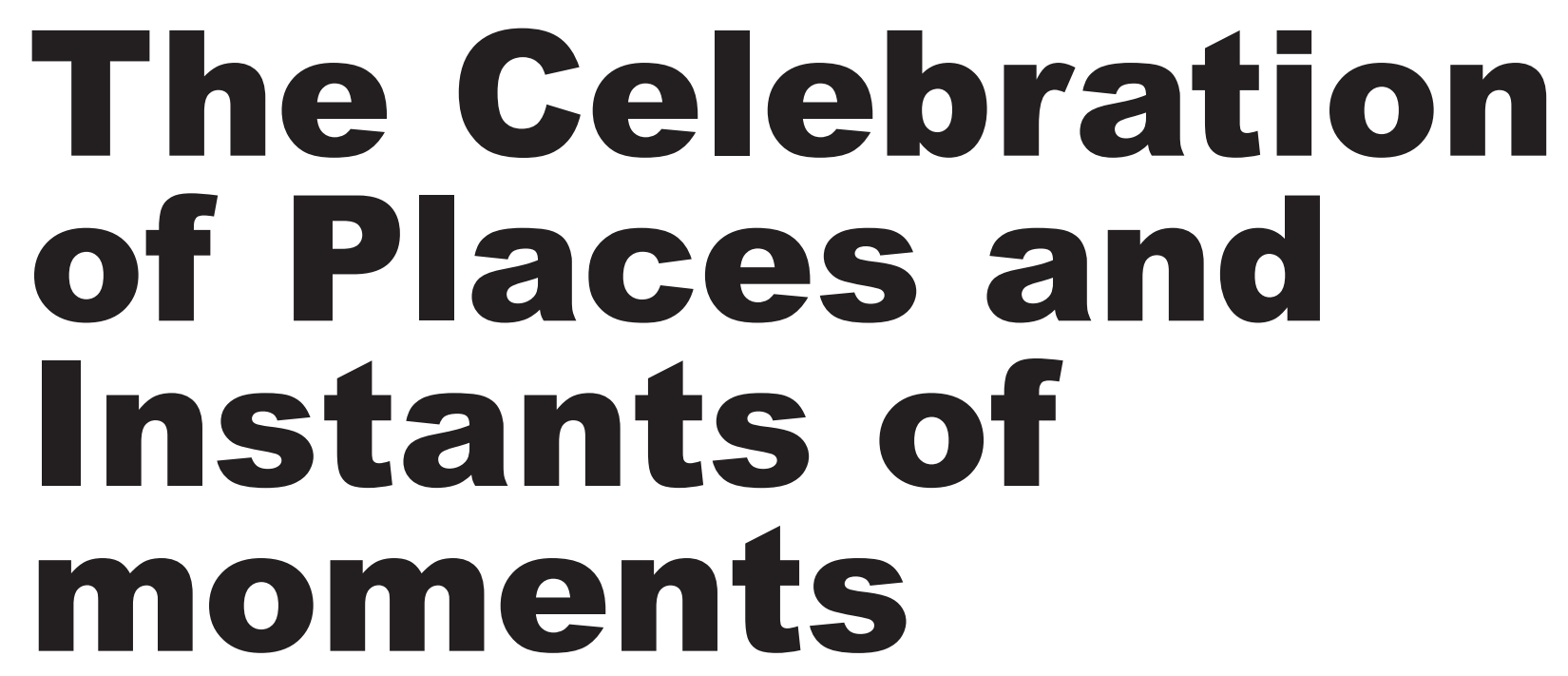

\section{Ponce Garrido, María ${ }^{1}$}

${ }^{1}$ Alicante University

John Hejduk, in his work "Victims", proposed to rethink architecture from the point of view of the memory of the inhabitants living in Berlin, a place that at the time was empty, but at the same time full of stories to tell, of memories that could not be forgotten. He turned a devastating situation into an opportunity to create a utopia based on lived experiences, far from just focusing on an architecture of needs. I propose to compare Hejduk's work with the UOU course (1), which appeared because of the exceptional pandemic situation we live with. To do this I start with a word list of what was essential and should not be forgotten, thus avoiding a utopia based on the disappearance of the existing and focusing on drawing on my memory, moments and encounters I had during the course. Through instantaneous reflections, I try to transform memories into actions. Using Hejduk as a reference, each workshop becomes an object, and my way of approaching it becomes an avatar. That way, I created a series of stories as a critical reflection of the UOU course.
John Hejduk, en su obra "Víctimas", se propuso repensar la arquitectura desde el punto de vista de la memoria de los habitantes que vivían en Berlín, un lugar que en ese momento estaba vacío, pero al mismo tiempo lleno de historias que contar, de recuerdos que no se podían olvidar. Convirtió una situación devastadora en una oportunidad para crear una utopía basada en las experiencias vividas, lejos de centrarse únicamente en una arquitectura de necesidades. Me propongo comparar el trabajo de Hejduk con el curso de UOU (1), que apareció debido a la excepcional situación de pandemia que vivimos. Para ello parto de una lista de palabras de lo que era esencial y no debía olvidarse, evitando así una utopía basada en la desaparición de lo existente y centrándome en mi memoria, momentos y encuentros que tuve durante el curso. A través de reflexiones instantáneas, trato de transformar los recuerdos en acciones. Utilizándolo como referencia, cada taller se convierte en un objeto, y mi forma de abordarlo en un avatar. De este modo, Hejduk he creado una serie de relatos como reflejo crítico del curso de UOU. 


\section{The Mycelium Pavilion - The Cook}

A chef went to the countryside every day to collect the food he would later use for his restaurant's meals. His star food was mushrooms.

Due to the pandemic he had to close the restaurant temporarily, but he continued with the routine of collecting mushrooms on his daily walk through the countryside.

As he could not consume them all, he left them in his garden where they accumulated. After a while he realised the potential of the mushrooms as they created shapes.

Thanks to this he now has a new restaurant made with mycelium (2) where every day it has a new shape as it grows organically. It does not need to have a specific place in the city as it is an ephemeral space that is constantly evolving.

\section{The Infinite Place - The Musician}

A globetrotting musician came to the city in times of pandemic looking for a place to stay. He was always used to staying in hostels in shared rooms, but this was not possible now because of the pandemic, so he scoured the whole city looking for abandoned places to live in. He found an oil refinery (3) that had just failed and saw that it had a lot of potential for living but also for developing his music. He found its circular shape curious because of the echo it created which he could take advantage of in his solo concerts.

Now that the situation has improved, musicians, artists and people who are interested in art come here every day without any aspirations other than to share their experiences, their art, their dance and to enjoy a community and a place, even if they have no artistic background.

\section{THE GELEBRATION OF PLAGES AND INSTANTS OF MOMENTS}

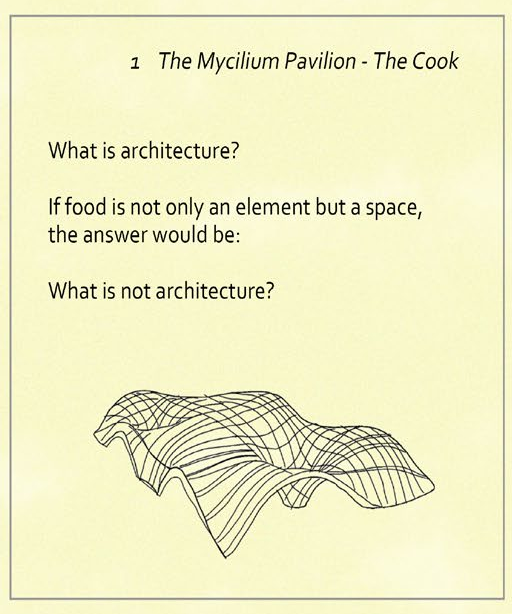

4 The Ramp Ceiling Pavilion - The Ecologist

A ramp.

A ceiling.

In which context do you know them?

They are in a constant transformation to help citizens with new realities.

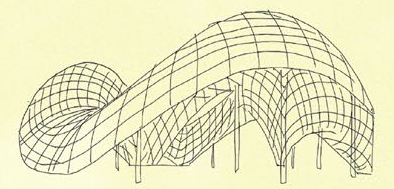

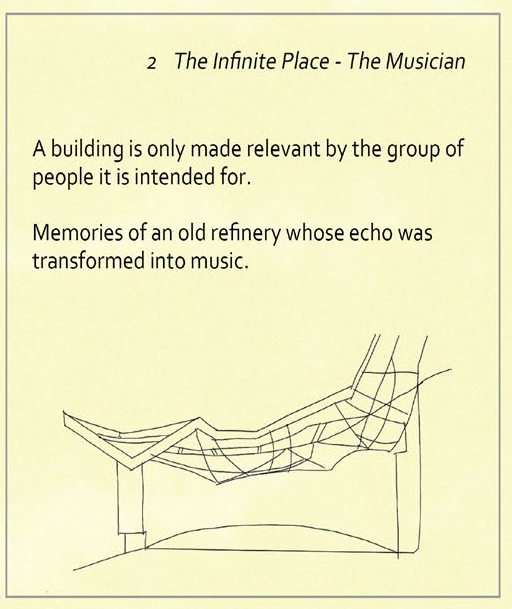

5 The Prison Visiting Room - The Thinke

A room which is not defined by functions, but rather by moments, emotions, encounters.

A room which represents the attempt to achieve the total realisation of a possibility.

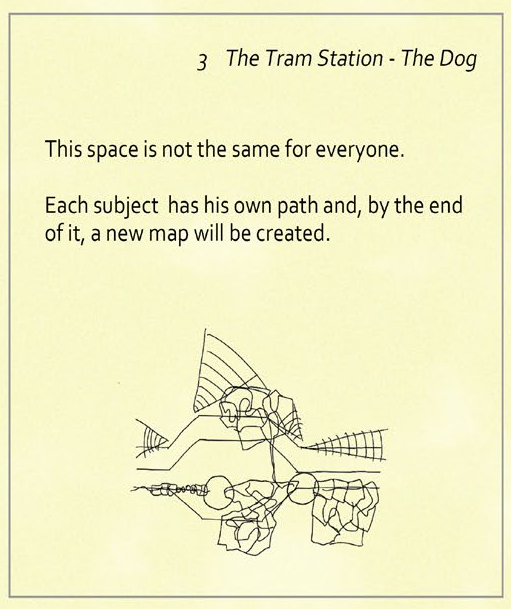

6 The Triangle building - The Tree

The way you enter this building does not depend just on it, but also on where in the community you come from.

If you get lost, look for the tree who towers over the building, it will be your witch. 


\section{The Tram Station - The Dog}

One family decided to let their dog roam the city freely while they were housebound. They put a camera on the dog to record his walk. They

noticed how the city changed from their dog's perspective. They found beautiful aspects that they would never have stopped to look at but also elements that were not designed for a dog to enjoy. They saw that instead of going to the places they always took him, like the parks, he went to the train station, a place where dogs were not allowed to enter. He had to make a unique journey as you could say that the train station was like an island for him where he had to skirt around certain places and avoid others. On returning home the family made a map of the dog's route and realised how different this was to the route they would have taken. (4) Now in this new city a train station has been created based on the map that the dog created. Each avatar who goes to that station creates a new route and therefore a new map which is then transformed into other important elements of that same city, thus creating a chain of maps where each avatar is in the end transformed into an architect.

\section{The Ramp Ceiling Pavilion - The Ecologist}

In times of pandemic an ecologist needed to plant different vegetables that could not be exposed to the sun, but he could not go and buy the structure he needed to protect them as he was confined. Strolling through his garden he was looking for ways to build a natural structure and realised that there were trees of different sizes that, by linking together from the ground to the tallest trees, he could create a ramp. With the help of other branches and plants he had in the garden, he managed to create this shelter. In addition to serving as a ceiling to cover the plants, it also functioned as a ramp that could be cultivated. (5) Now, in the new city, he has realised the possibilities of reinventing himself, of transforming columns into trees, of rethinking existing elements and adapting them to new needs. This is how he created his network of pavilions and bridges that span the entire city and whose structure is based on trees of different sizes, as well as branches and large leaves that cover them.

\section{5 .The Prison Visiting Room - The Thinker}

There was one thinker who was very much affected by the pandemic because he was living alone in a very small flat. He realised that it was affecting him so much because what he needed was contact with other people. In his writings he compared his flat to a prison room, and the lift in his building to a prison visiting room, as it was the only time he had contact with other people. He could see how such a small space, which until now even made him claustrophobic, became a different place every day depending on the moment he lived with each person or the mood of both himself and the person with whom he shared those seconds. Thus, the lift became the perfect place to socialise as it was the only possibility he had at that time. Now the elements of the city are interconnected with each other, trying to create small spaces where glances or small conversations are exchanged and can transform people's vision of the next place they are going to. These spaces are not decorated at all because the important thing is that conversations, encounters and glances transform them into something new every day.

\section{The Triangle Building - The Tree}

The Indian Rubber tree was the central icon in the city hall. It always had the same shape as it was carefully pruned every week. Due to the pandemic, this had to stop and the tree had time to grow organically. Thus, the tree took over the space and even destroyed part of the roof, rising above it. From the houses it was rumoured that it had been changed, it looked totally different depending on the window from which you looked at it.

In this new city, each tree is arranged in a way that gives them more importance. First they are allowed to grow freely and then the space is created to collect them, always leaving gaps for them to continue to expand and become citizens of a city, where until now only the importance of people was contemplated. These short tales based on the UOU, in the end, create a single drawing of an infinite equilibrium. 


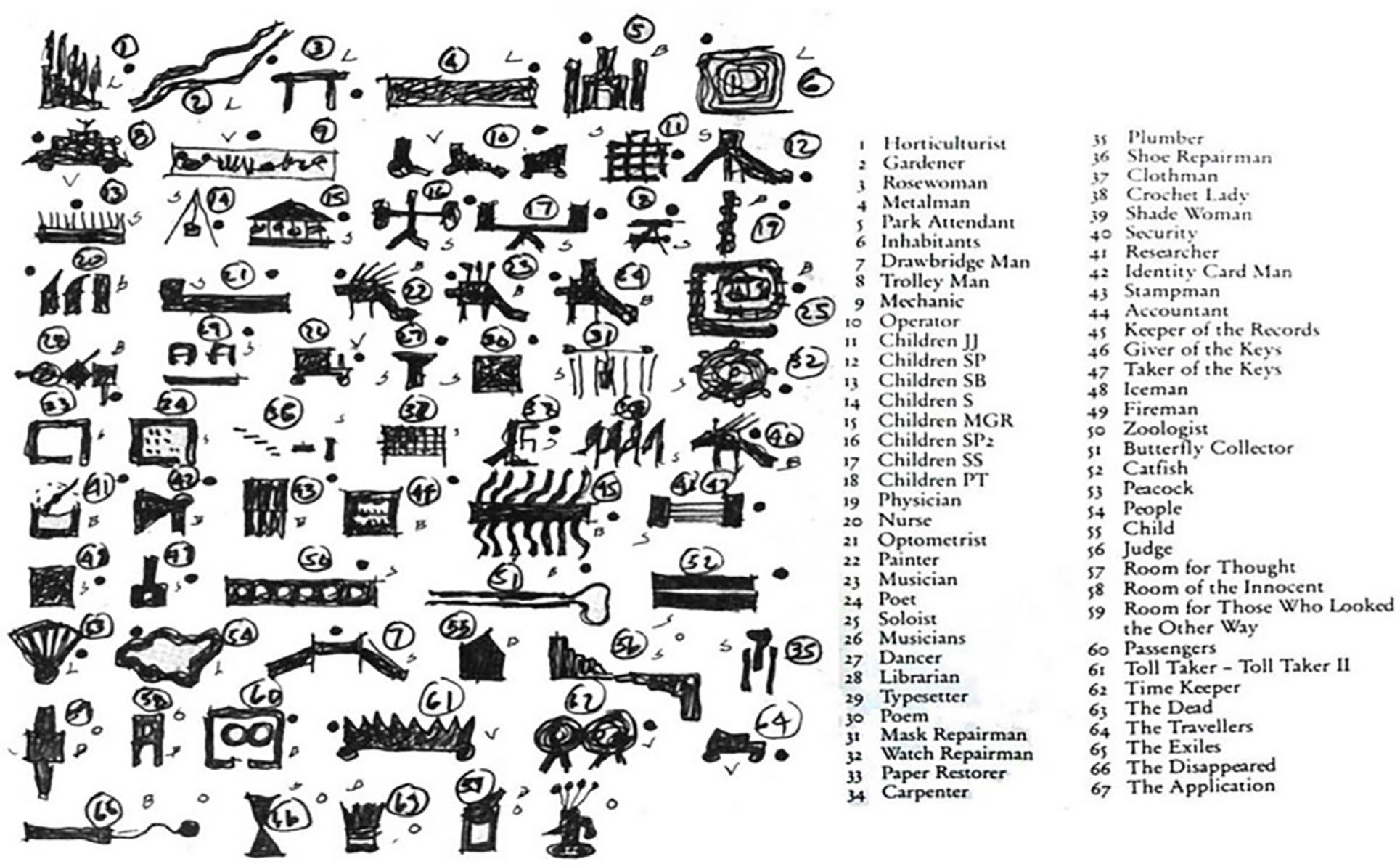

\section{Notes}

1.University of Universities UOU consists of a course built on a network of different academics from different schools of architecture around the world. Each tutor has the trust of the team and freedom to propose and direct a 2-week online workshop for all the students from the different schools participating in the experience.

2.Mycelium is the vegetative part of a fungus or fungus-like bacterial colony, which, after a process of a few weeks that we analysed in this workshop, can be used in construction.

3. This story is based on 'La Británica' oil refinery, which is in Alicante. It is now intended to be transformed it into a cultural space.

4. This story is based on my experience. I took my dog for a walk with a camera on him and after visiting a tram station - Mercado tram station, Alicante - I created a map based on what that place meant for him.

5. This story is based on the book 'Lo-TEK Design by Radical Indigenism', of Julia Watson. In concrete, on the Living Root Bridges of the Khasis, India.

\section{Bibliography}

Hejduk J., 'Victims' project, an AA publication from 1986. 


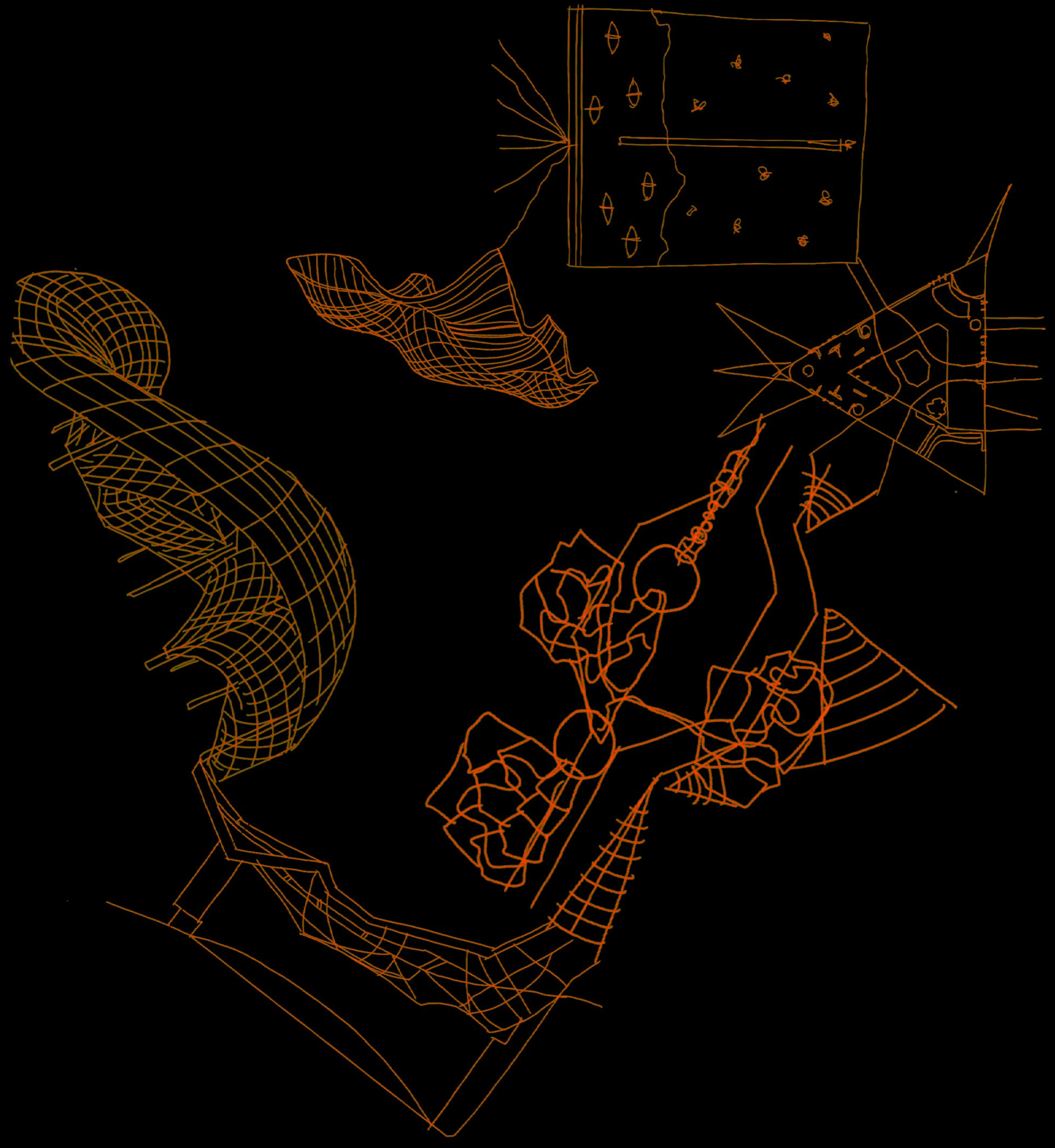



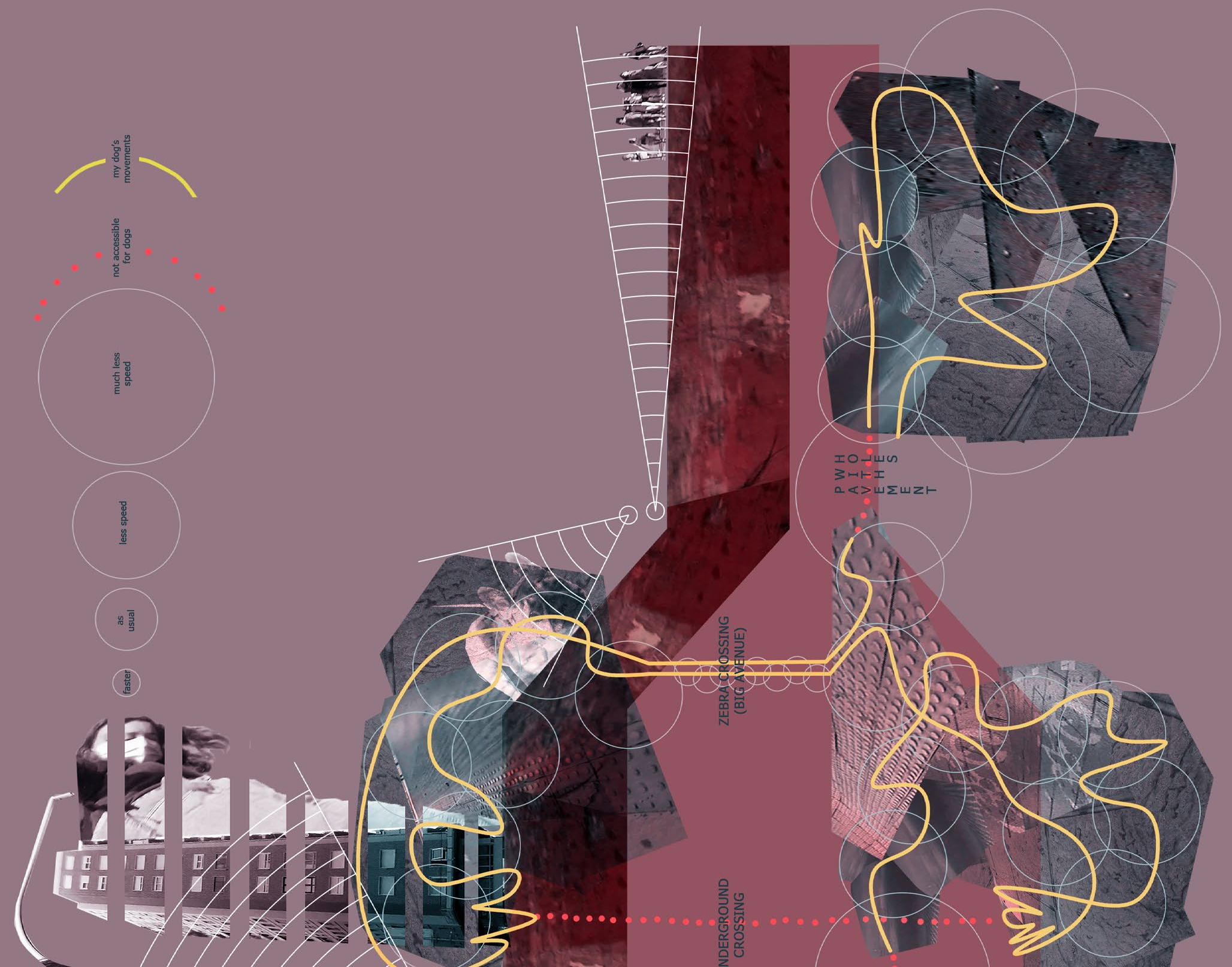


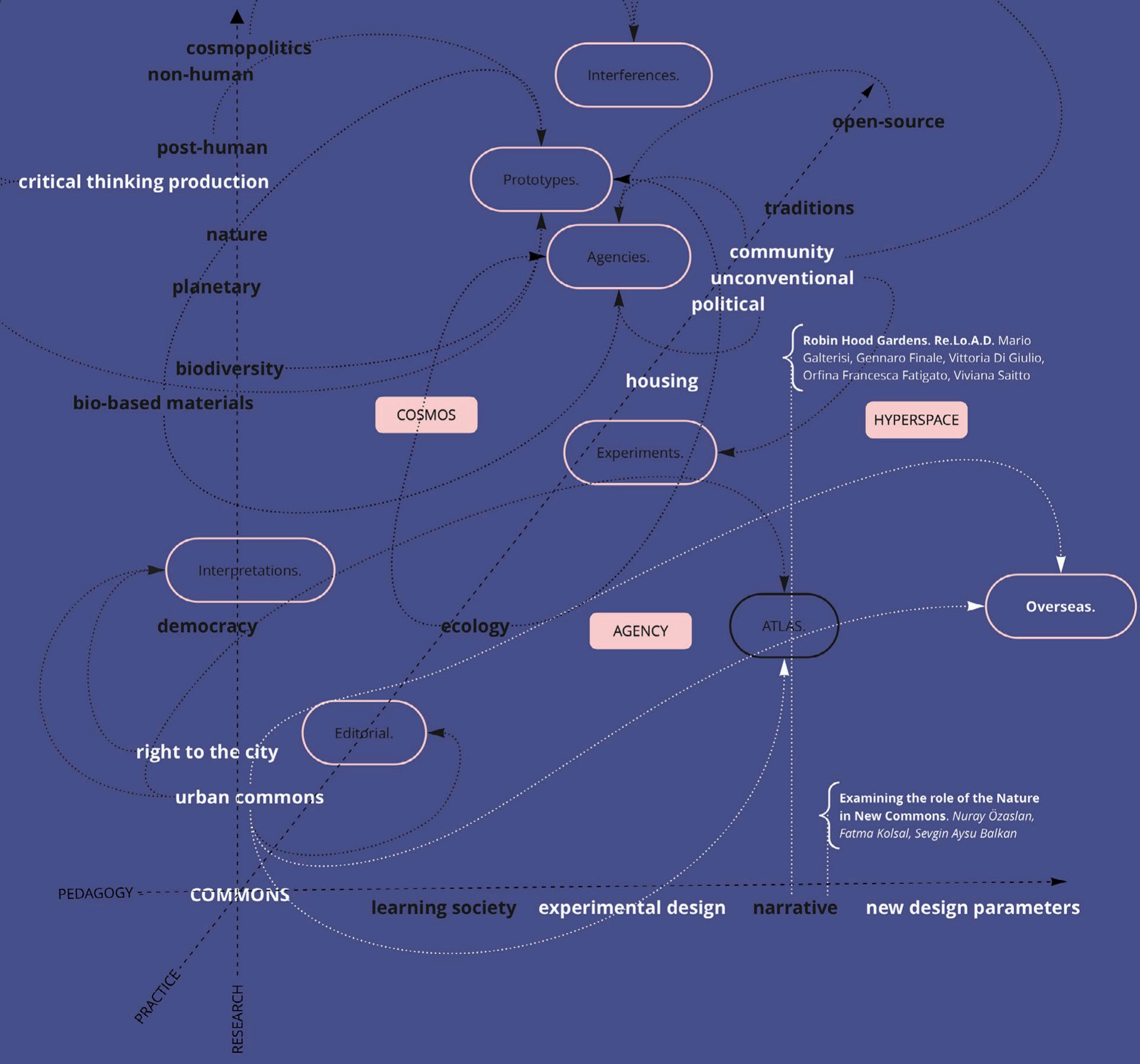




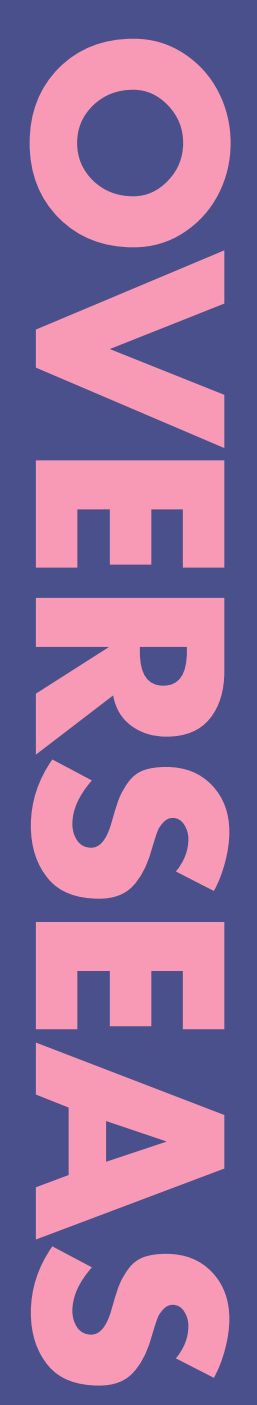




\section{Examining the in the New

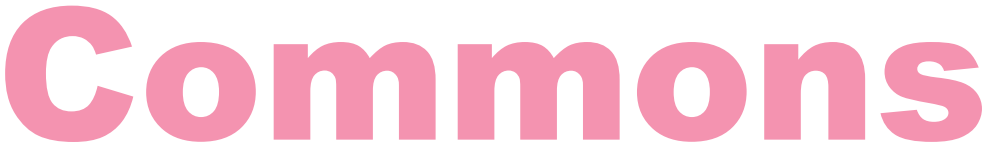

\section{Two Experimental Architectural Design Studios}

\section{Özaslan, Nuray ${ }^{1}$; Kolsal, Fatma²; Balkan, Sevgin Aysu ${ }^{3}$}

${ }^{1}$ Architecture / Eskişehir Technical University, Eskişehir, Turkey

müştereklik deneysel tasarım stüdyolar yeni mekan yaklaşımları yeni tasarım parametreleri

commonality

experimental design studios https://orcid.org/0000-0002-4458-8059 nozaslan@eskisehir.edu.tr

${ }^{2}$ Architecture / Eskişehir Technical University, Eskişehir, Turkey https://orcid.org/0000-0002-5569-2046

fatmakolsal@eskisehir.edu.tr

${ }^{3}$ Architecture / Eskişehir Technical University, Eskişehir, Turkey https://orcid.org/0000-0001-8695-3897

sevginaysuoryasin@eskisehir.edu.tr

Citation: N.Özaslan; F. Kolsal; S. A. Balkan. (2021). Examining the Role of Nature in the New Commons. Two 


\section{Yeni Müştereklerde Doğanın Rolünü Anlamak}

\author{
İki Deneysel Mimari Tasarım Stüdyosu
}

COVID-19 salgının sağlık, ekonomi, kültür ve sanat üzerindeki olumsuz etkileri sürerken, sosyal mesafe ve temassız olma durumu sosyalleşme biçimlerini değiştirmekte ve kamusal alanların kullanımını köklü biçimde dönüştürmektedir. Dijital çağ ve iklim değişikliğinin ortaya çıkardığı yeni durumların salgının etkisiyle hızla geleceğin inşasında etkin olacağı görülmektedir. Post-covid birçok boyutuyla uygarlığın yeniden şekillendiği bir dönem olarak karşımıza çıkacaktır. Gündelik pratiklerin değişmesiyle birlikte gelişen yeni müşterekler salgın öncesi müşterekliklerin yerini alacaktır. Yapılaşmış çevrede yeni müştereklerin tanımlanmasında mimarlık insiyatif alabilir. Ancak mevcut kavramlar yeni müştereklerin tanımlanması için yeterli olmayacak, bunun için önemli paradigma değişimleri gerekecektir. Yeryüzünde yaşamın tehdit altında olduğu bu tarihsel süreçte yeni müştereklerin oluşturulmasında doğa başat paradigma olarak öne çıkmalıdır. Bu anlayışın mimarlık eğitiminde nasıl değerlendirilebileceğini ele alan bu makalenin amacı mimari tasarım stüdyosunda tanımlanan tasarım sorunsalının temel paradigması olan doğa'nın yeni müşterekler oluşturma konusundaki rolünu irdelemektir. Bu bakış açısıyla, Eskişehir Teknik Üniversitesi, Mimarlık Bölümü'nde farklı ölçek ve bağlamlarda iki mimari tasarım stüdyosu gerçekleştirildi. Bu stüdyolarda yeni mekânsal açılımları içeren yeni müştereklerin keşfine dair tasarım problemleri tartışıldı. Tasarım süreçleri sonucunda, doğa ve insanın uzlaşmasına dayanan yeni müştereklerin keşfinde, doğanın belirleyici ve birleşirici rolünün bir mekansal tasarım parametresi olarak değerlendirilmesi gerektiği gözlemlendi.
While the adverse effects of the COVID-19 pandemic on health, economy, culture, and art continue, social distancing and non-contact are changing forms of socialization and radically transforming the use of public spaces. It can be seen that the new situation in which we live, arising from the digital age and climate change, will have an effect on the rapid construction of the future caused by the effect of the pandemic. Post-Covid will appear as a period in which civilization is reshaped in its many dimensions. The new commons that develops with the change of daily practices will replace pre-pandemic commonalities. Architecture can take the initiative in defining the new commons in the built environment. However, existing concepts will not be sufficient to define new commons, which will be requiring significant paradigm shifts. In this historical process, where life on earth is under threat, nature should come to the fore as the dominant paradigm in creating the new commons. The purpose of this article, which discusses how this understanding may be evaluated in architectural education, is to examine the role of nature in creating the new commons, which is the basic paradigm of the design problem defined in our architectural design studios. From this perspective, two architectural design studios, of different scales and contexts, were realized in the Department of Architecture at Eskişehir Technical University. In these studios, design problems related to discovering the new commons, including new spatial arenas, are discussed. As a result of the design processes, it was observed that the determining and unifying role of nature should be considered as a spatial design parameter in the discovery of new commons, based on the reconciliation of nature and human beings. 


\section{INTRODUCTION}

The interaction of nature and human beings, which has differed throughout history, has evolved into a form that affects the environment in which we live today. Changes in the atmospheric abundance of greenhouse gases and the depletion of the ozone layer, combined with the effects of solar radiation on the earth, transform the balance of the climate system. Increasing global temperature has resulted in extraordinary meteorological events. Human beings steadily alter the Earth's surface and its natural cycle, and has become named the Anthropocene Epoch as the recent, new geological time. Human intervention into natural life has caused environmental problems, one of which is the COVID-19 pandemic, which affects the whole world. The globalizing world is connected with cities and public transport networks, where the vast majority of the world's population of up to eight billion live, which causes pandemics to spread rapidly and affect many people. The world will never be the same world after this pandemic.

It is widely accepted that there will be a 'new normal', defined as the adapted way of life to a sudden change in the normal flow. The time, space, and system of modern life, based on industrial production and cities, differs from the Earth's system and time. While the first of these results from a fictional system established by human beings, the second has been in action according to its own rules and order for millions of years.
It can be said that phenomena started to harm each other as they became increasingly incompatible systems due to different time, space, and life cycle parameters. Since the Renaissance, humanism has been the central attitude that determines the course of civilization as a way of perceiving nature. At this point, to redefine the relationship of humans with/to nature is extremely critical. However, both share the same features that set the ground for commonality.

The city presents everyday life in a constructional spatial manner with a mechanical time layout in an artificial fiction. Nature is a creation that sets the life cycle consisting of time, space, matter, and the will for existence. Nature is common to existence. The recent conflict between nature and the manmade environment raises the question of a new commonality. A city and nature are both common spaces of forms of being. The city undoubtedly needs nature to exist, but nature does not need a manmade environment. Nature also has the potential to transform space and to form a new common. So, how can we treat nature as a new parameter of commons? Current concepts of ecology and sustainability are integrated into new design approaches as the main parameter and become the fundamental notion to organize the common space.

\section{Nature as a design} parameter, and its role in the new commonality, has gained importance through the pandemic. Nevertheless, the 'new normal' does not need to have a dystopian definition, but can be regarded as an agreement between nature and man. This concept can offer a fresh understanding that may be considered with its positive aspects. The perception of nature has been changed through history, which has also affected the condition of the space. Nature has been the reason for the existence of human beings, providing them a life, space, and cultural code. Nature conditioned the space and time parameters for Man until the modern era. Mathematicians invented the modern conception of space by appropriating space and time scientifically, as Lefebvre (1991:2) points out. Abstract space produced by the rational rules of the modern state was formed according to the function of an economy rooted in industrial production.

The dramatic change in space, from real and natural to abstract and fictional, influenced the social life performed in these spaces. This change resulted in a discussion of the publicness of public space. Arendt (1998) and Habermas (1974) point out the significance of political representation in public space, which consists of private space. Publicness is possible by expressing personal opinions on common issues. Each individual presents themself and communicates with others in the public space that, in turn, creates commonness. However, as Sennett (2002) indicates, the boundaries between public and private space are uncertain in the modern city. 
Space is accepted as a determinant of in and out, where 'in' describes being isolated from an uncontrollable out. 'Out' defines public and nature, while 'in' defines private and human. Therefore, there seems to be a clear boundary between in and out, private and public, human and nature. This strict condition underlines the idea of space as a producible good. When something is produced, it excludes life. The main argument in this statement is the exclusion of everyday life within the sterile constructed patterns of the cities that have developed in modernity. (Lefebvre, 1991). Everyday life is related to the needs of human nature. It is a natural process. This natural process is interrupted by the imposition of the space considered as an object of production. These determinations have brought the concept of thresholds to the agenda, which is frequently discussed today. (Lefebvre, 1998). Boundary means the end in a physical sense. An end can be thought of as the beginning of another point. If 'place' also involves interaction, it means more than physical space (Boettger, 2014 p 10).

Therefore, it can be said that the concept of boundary is also a dynamic phenomenon. This versatile and mobile structure provides opposing associations, such as interiorexterior, open-closed, or publicprivate. The boundary itself that creates these interactions exists as an 'in-between'. In this context, the threshold plays an essential role in determining spatial qualities. Transition areas, where actions that have acquired their natural identity within the existing inflexible forms, can transform the space and appear as spatial thresholds. Thresholds are common areas that reveal the spatial potential other than the defined ones. (Stavrides, $2018,12)$. There is ambiguity in the concept of threshold, and it draws its strength from this ambiguity.

Sennet does not characterize public and private as contradictory concepts. He mentions that they can be alternatives to each other. The impulses that govern the public sphere are will and artifact; those that rule the private sphere are restrictions and the erasure of artifacts. The public sphere is a human creation, and the private sphere is a human condition. What strikes a balance between public and private is proportionality (Sennet,1996, 133-135).

Nevertheless, will these definitions remain the same when personal freedoms come into play? When public policies and individual characters differ, will the public and private sphere relationships remain the same?

Spaces are conventionally classified as private, semiprivate, semi-public, and public spaces. Thresholds connect these intervals. When defining these spatial intervals, boundaries occur. Boundaries are essential for identifying definitions. A human experiences space and thinks and dreams through it (Stavrides, 2016, 53). Public space, semi-private, and private spaces are the means of defining the individual's urban identity through spatiality. Today, public space and its commonality have gained importance in establishing a sense of belonging and the acquisition of civil initiative and identity. At this point, threshold spaces become essential and act as a mediator that removes hard borders. Creating threshold spaces can mean creating spaces of encounter between identities instead of spaces corresponding to specific identities. Collective inventiveness can take place within the production of threshold spaces. As people use these spaces for constant negotiation, comparisons between emerging identities become possible. Therefore, communities living in these places are constantly emerging communities (Stavrides, 2016, 13).

The concept of the commons has become a phenomenon that has been widely-used in both academic and political fields in recent years. It was initially used for non-proprietary natural assets, such as seas, streams, forests, and air. It is a concept that is now used in a wide range, from the built environment to daily living spaces. According to David Harvey, it is not correct to define the common as a specific object. It is the relationship of a defined social group with its social and physical environment in life and subsistence (Harvey, 2012, 73). Stavrides (2016, 263) contributes to the discussion by suggesting that common space is a form of collective survival strategy against capitalist dominance. 
On the other hand, communing is a kind of practice and relationship that leads to different social values, preferences, and influx of newcomers (Stavrides 2016, 262). Common space is not merely a place, and needs reinterpretation by reevaluating spatial relationships (Stavrides 2016, 262). This paper suggests that nature and the city are places where communing takes place as a form of relationship creating common space. Capitalism dominates today's metropolises and privatizes public spaces, redefining streets, neighborhoods, and parks by disregarding that nature is the only home of life. Public space is reduced to shared space, as space is seen as material production valued economically. The pandemic experience has shown that social relationships are the active agent of public places. Space occurs during the process of social interaction. The relationship between individuals and nature needs to be reinterpreted to define a new communing against the dominance of power and to form a new type of collaboration for the sake of nature, human beings, and the life cycle.

From this point of view, two experiential architectural design studios (ADS) were conducted at Eskişehir Technical University, Department of Architecture, to discuss the role of nature, not only in creating common spaces, but also in redefining the commons. Therefore, the central axis of the discussions was to promote a new spatial design that reconsidered the interaction of nature and humans and which proposes a new and different vision of our view of nature in the process of defining the 'New Normal' being shaped by climate change and digital technology.

\section{DESIGN BRIEF, ARGUMENTS, AND DISCOVERIES}

The two experimental architectural design studios are a medium to discuss the potential of the new normal, deciphering the role of nature in both the natural and urban environment. While the first of these allows a rethinking of the interaction of nature and man, the second aims to evaluate this interaction in the built and social environment. Both studios are designed to discuss possible new forms of social relationships in the new normal, and their spatial reflections in the natural and built environment. These are parallel studios run separately, consisting of third year and fifth semester students. Both of these question nature's new role in discovering new spatial potential. The design brief of both studios is based on the view that nature should be one of the most potent parameters in spatial construction and expression of general commonality in the 'new normal'.

On the one hand, nature constitutes the commonality of existence, while on the other hand, the objective space of the public space, created by man as a social entity, becomes spatial with the realization of social relations. Different forms of social relations transform the public space into a performance space and, as Stavrides

(URL-1) states, evolve into the common space of ordinary lifestyles, where a series of spatial relationships produced by collective practices are experienced. While this state of commonality creates the social representation of urban identity, collective memory enables the commons to emerge. Therefore, the common space attracts attention as the most constructive element that determines the cultural structure. As one of the most important representations of cultural reflection, architecture should evaluate the commons as a design criterion.

Studio I concentrated on the new form of relationship between humans and nature in living areas. The studio's theme was 'Gaia', the ancient Greek goddess who personified the earth. This historical symbol was specially chosen to help students conceptualize the phenomenon of nature. This conceptualization process is thought to be necessary for design, which is above all an intellectual and cognitive activity, to achieve a creative result. Nature's status of being the primary design parameter in the imagination of a new type of life was explored in the same geographical conditions, but with different programs. The life scenarios proposed for this area, that is the programs, created content in which the global conditions of the new normal were considered, but the problem of the local context was also a practical consideration. 
Studio II, which had a theme of 'Speculations on Post-Covid Neighborhood Design', concentrated on a new interpretation of Neighborhood Design under the circumstances drawn by post-pandemic perspectives. Studio II aimed to generate spatial speculation on housing, transportation, recreation, daily needs, commonality, work, and study within the scale of a neighborhood. The design was conceptualized through leading ideas, such as sustainability, urban agriculture, pedestrian life, or self-sufficiency, all of which are concepts related to nature. Concerning this embracing idea, the spaces needed to be varied for a new understanding of living, consuming, working, and socializing. In addition, original scenarios were required for transformed habits and the needs of the post-pandemic period.

\section{ADS-I: GAIA}

In the fall term of 2020-2021, the architectural design project III (5th semester) course was carried out in fifteen weeks with eight students. The studio aimed to discuss a living space design that reconsidered the interaction of nature and humans and proposed a new and different vision of our view of nature in the process of defining the 'New Normal'. The process was to be carried out face-to-face due to the Covid 19 pandemic and was continued remotely through various digital platforms; Zoom, Google Classroom, platforms provided by the University, and so on. A request was made to construct a 'place' using architectural tools that would create for children and young people a perspective, contrary to the current understanding that exploits, consumes, and destroys nature. In this, it would enable them to experience this alternative approach with the areas of life, observation and study it would offer. Instead of the existing arrogant civilization that takes and exploits the knowledge of nature, the aim was to design a 'place' that constituted the cycle of nature and tried to explain to children and young people an understanding that human beings are only a tiny part of this cycle. Understanding the common space is a public space involving a collective knowledge of acting, relating, and memorizing in a physical and social environment in which nature and the cityscape generate and determine the form of relationships. In this context, Eskişehir Borabey Pond and its surroundings, which belong to Eskişehir Technical University, have been determined as a design area.

During the first week of the project, students were asked to research current issues relating to the agenda; the ecosystem, biodiversity, global warming, environmental degradation, Society 5.0, climate change, sustainable agriculture, and pollution. They were expected to find and compile news about these issues in the local and foreign press, published in recent years (2019-2020). The students' presentations were made by interpreting their research and the news they compiled, in the context of human impact on the environment in the Anthropocene Age. Within this context, the human-nature relationship was discussed; a topic which has gained momentum in recent years. The students pointed out that news headlines, such as environmental degradation, pollution, global warming, and climate change proliferate. It was noted that there were many reports on sustainable approaches that aim to reverse the human relationship with the environment which is based on consumption. However, these approaches cannot become widespread, due mainly to economic and political reasons. In the second week, certain key words were created by considering the subjects that the students mentioned in their first-week presentations, such as sustainability, renewable energy, and organic agriculture. $A$ request was made to review the current academic publications (articles, theses, projects) and news on these topics in order to prepare a presentation, including their comments. In addition to this study of the concepts, work has also started on a first analysis of the given project area. In this way, it can be seen that this research is also influential on the projects produced, while at the same time students were provided with an idea of the current topics discussed in the context of the relationship between nature, man, and architecture. In the following process, the students were expected to prepare a report evaluating different situations regarding the concept of nature in the historical process through readings, such as 'The Idea of 


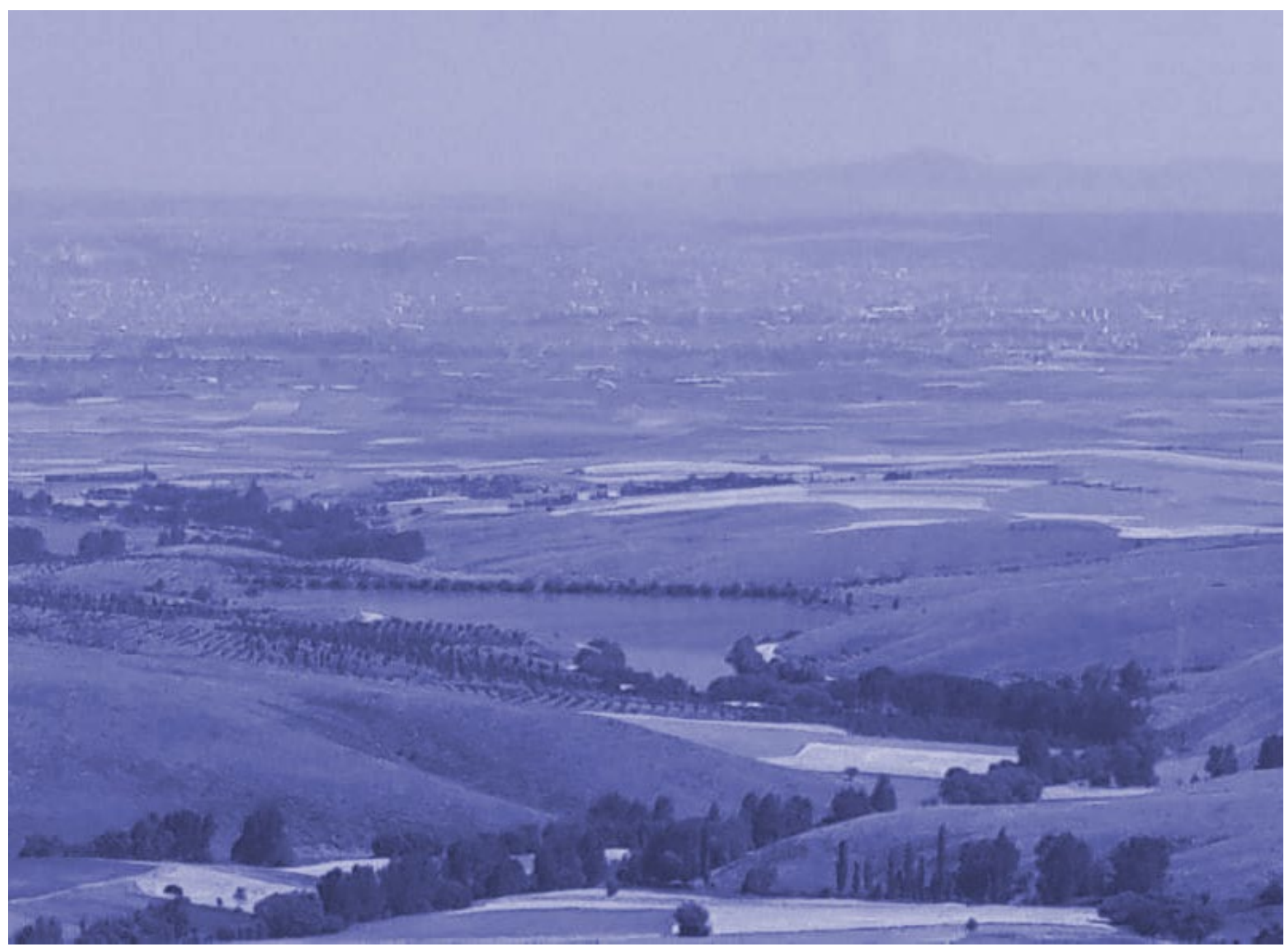

Fig. 1 - The project area, Borabey Pond, Eskişehir

Nature' (Collingwood, 20020; Andrea, 2015). In the light of all this research, original comments are expected to develop regarding the design question (Fig. 1).

After the first spatial ideas were formulated, the project process continued with updates in line with criticism. In this process and weekly meetings, two midterm juries and one final jury were held. To increase the students' interest in the subject, a seminar on 'New normal: human and environmentally sensitive architecture' was held in the eleventh week of the project process; a specialist architect from the Institute of Building Biology attended and conveyed his experiences. All this research and activities have fed the project process conceptually and enabled students to internalize the subject by making inquiries in the context of the human, nature, and architecture relationship.

\section{Design Concepts Developed by Students in ADS-I}

Following industrialization, contemporary cities became the mega-urban area of the new society, in which public and private spaces are organized according to economic relationships disregarding the natural environment as the basis of life. The activities and relationships of human beings became limited to urban life, which resulted in a crisis of the environment with severe effects on the health of human beings. Developing a new relationship between human beings and nature would remind people of the possibility of actual place, which can be formed by paying attention to the new relationships between people, leading to an alternative common space. This project, therefore, focuses on the health issues that occur due to the problems people encounter in their daily lives, their daily routines, and the active use of technology in the capitalist society. It is known that these problems primarily cause psychological and 
neurological problems. These problems are fairly common in the young generation who need support to cope with the stress. The aim is to create a center that will solve some of the psychological health problems by strengthening the relationship between man and nature. The main idea of the design is based on the healing power of nature. An approach has been set up to create a new vision by changing young people's perspective on nature. Another aim is to bring a new interpretation, to create the new commons within the scope of nature's state of transforming space and its potential.

The other project focuses on an experimentation of the cycle of nature by the route of thematic stations. The main idea of this project is to remind and rehabilitate the relationship between nature and people by developing new practices. New commoning practices will generate alternative common spaces, depending on economic relations and a social relationship. The potential of the project area is to create a new situation between the city and the countryside and to become a visual attraction point. A meeting place on one of the highest points of the area was designed, with the aim to make it a center of attraction. There is an attempt to create a new interpretation of commonality in the context of urban/rural tension. The information center is designed as a starting point for the experience of the natural cycle, which targets children aged 5-7. In the project area, the aim is to provide the opportunity to observe living forms. For this purpose, observation points and routes for the experience have been designed (Fig. 2).

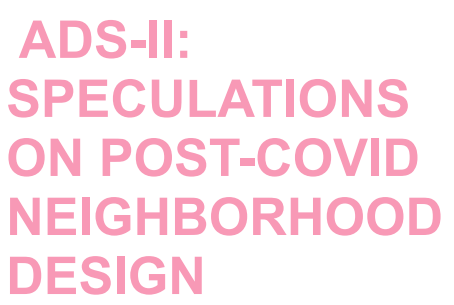

In the fall term of 20202021, the Architectural Design Studio III was designed as an experimental studio to develop a discursive and argumentative platform to raise spatial speculation following the pandemic. A group of seventeen candidatearchitects, who were all in the third year of their education, had the challenge to discuss, interrogate, criticize and regulate the new socio-spatial conditions concerning the postcovid circumstances.

The studio aimed to conduct this interrogation by and through design. The studio was conducted through digital and online platforms of distanced education, primarily through the Zoom platform. The design process was developed weekly, and students uploaded their work to the Google classroom each week. One midterm and one final jury were organized through the participation of related guests with digital compatibilities.

After a period of restrictions due to the pandemic, experienced as remaining at home and a compulsory shut down, urban and daily routines were all under question, together with spatial preferences. Not only was the perception of space changed, but also the flow of time was revised. The determinants of work, day, and consumptionbased habits were all criticized during this period and how they corresponded spatially. Within the framework of the studio, social and spatial reflections were discussed from a critical and architectural point of view. New urban life elements were reworked and rethought using the design of a neighborhood as a tool. The candidate architects were asked to design an eight-lots-size area having social, commercial, and recreative relations, and at least three housing units, with an alternative transportation/ pedestrian scenario.

The designers were free to choose contextual parameters, such as place, climate, topography, solar orientation, precipitation, and so on. They were asked to propose a main design concept, such as sustainable design, energyefficient design, green design, minimal design, and urban agriculture. They produced a number of possibilities for a new way of life using sections and diagrams and concentrated on ground floor relationships, which organize the interaction of the inner space with the outer.

The proposed new layers of interaction point to other than the ground plane. Another critical contribution of the studio is to adopt intrinsically sustainable ideas into spatial parameters, which have been underestimated by consideration of additional external equipment. The holistic design philosophy is essential for the studio process. 


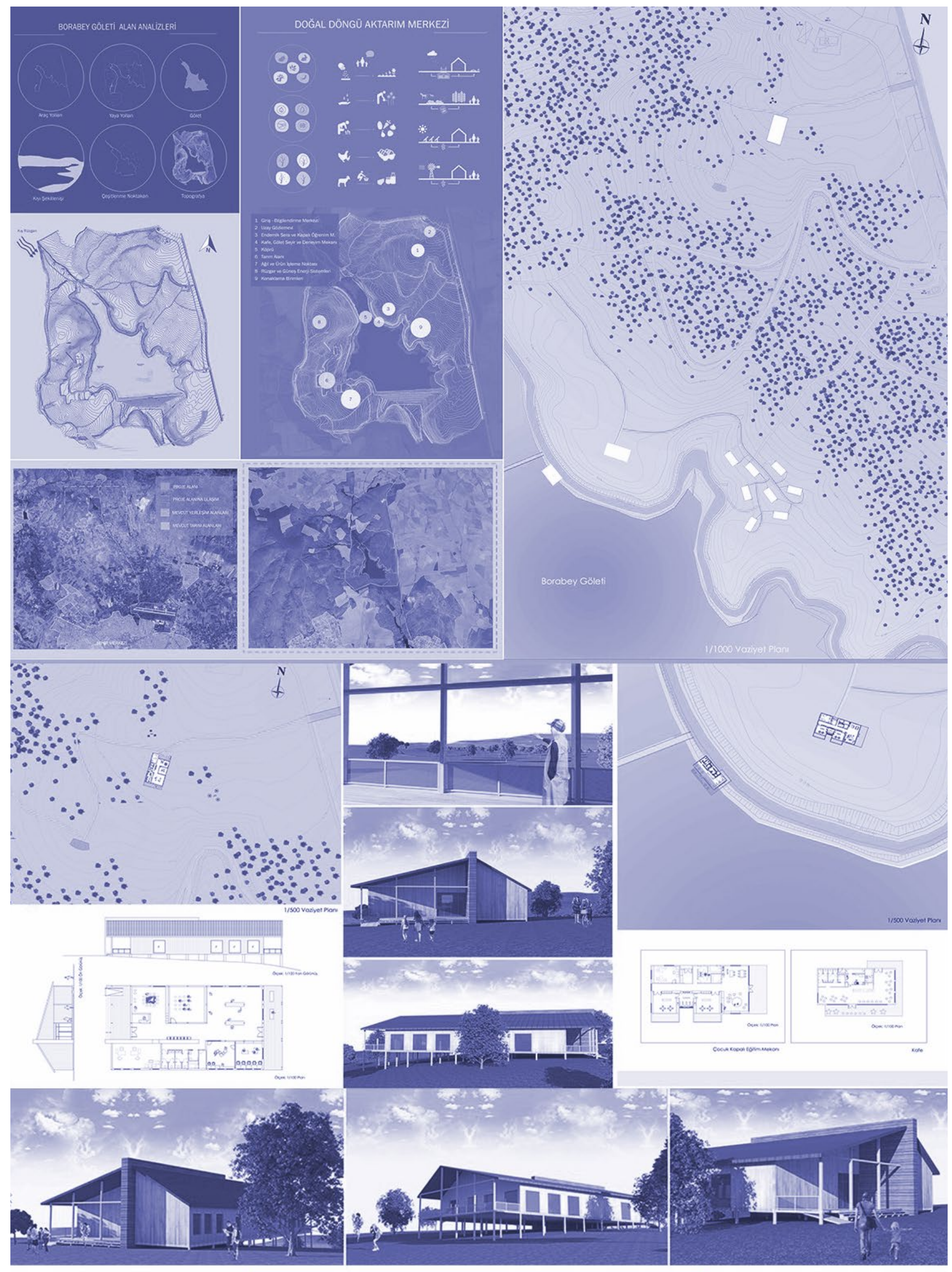

\footnotetext{
ADS I - GAIA - SÜNDÜS KILINÇ NATURAL CYCLE EXPERIENCE CENTER
} 
Design Concepts Developed by Students in ADS-II

Pandemics are events that have changed and transformed urban spaces throughout history. Covid-19 is also reducing the density of people in spaces leading to a search for new ways of communing. It causes changes in urban space. Social isolation is crucial behavior in preventing the spread of the pandemic. In this context, while starting to construct the design idea, distance was kept, while trying to ensure healthy ventilation creating isolated areas. People have lost contact with life outside, so the maintenance of human relationships is of great importance in the design approach. Another significant point of the design is the consideration of nature as an integrated design parameter. Nature is adopted as agricultural facilities, yet it is also recreation, socialization, production, and self-sufficiency. The walkways, which form the main scenario of the design, derive from a single linear street axis of circulation. This axis is suitable for different experiences at different heights and integrates with the commercial area. While providing access to the area, it breaks the linearity of the street by establishing a level relationship with the ground. The walkways on the facades are positioned so that they remain interacting with the inner garden. The presence of green roofing in the design, consisting of different levels, ensures the ventilation needs and, at the same time, strengthens its bond with greenery. Sustainability is also of great importance during the pandemic process. Private aquaponic farming areas within the residential area, where users can produce their own food, form the main structure. Therefore, it is an ecological and sustainable design with a self-sufficient design approach (Fig.3).

The Covid19 outbreak can be regarded as a turning point in terms of accelerating awareness and change. During the pandemic period there have been noticeable changes, such as the need for work and school life at home, an increase in people producing their own food, the proliferation of online shopping (especially in the food sector), changes in neighborhood relationships, and the widespread use of bicycles. The answer to how these factors, which it is thought will continue to affect space and the city after the pandemic, are examined, and solutions are produced based on a continental climate and street structure. The design developed around the idea of a variant upper 'street' that is an idea produced as a model adapted to the city. The circulation area for pedestrians, bicycles, and motorized service vehicles are between commercial areas at the upper from the ground level. Accommodation units are the main elements that add to the design. In this way, terraces and living spaces can establish direct contact with commercial units, neighboring accommodation units, and study/work areas. By isolating itself from the busy flow of traffic and daily life, the design produces semi-public open spaces.

Sustainable solutions for human biology and building ecology have been utilized with sunlight, the serpent effect, with seating units produced from compacted soil. Neighborhood relationships have been developed in the backyards, and social distancing areas have been produced with green walls to promote the rehabilitating effect of nature. In between the semi-borders of the gardens, agriculture is encouraged. It is intended to revive nature's positive and underestimated characteristics through this backyard design of the housing units. In addition, lighting and social distancing in the workplace and public spaces are encompassed by a green border (Fig. 4).

\section{CONCLUSION}

The global epidemic has necessarily changed certain seemingly immutable perceptions, habits, and practices. However, this necessary state has increased our capacity to think outside of our comfort zones and without our familiar surroundings. Challenging conditions prepare creative grounds for new understanding. This reflects the way we live, think, and design.

Architectural design studios are mediums to discuss certain socio-economic and actual events from a spatial point of view. Moreover, they are, in a way, the forerunner of new tendencies reflected in society. The pandemic is a compelling case that makes us think about the standards of living we all take for granted. Therefore, the 

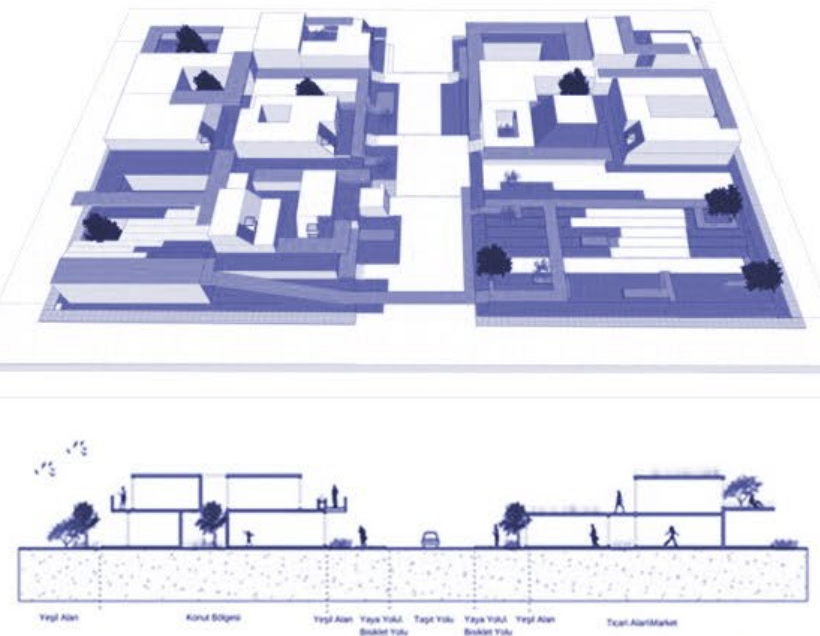

mass fragmentation
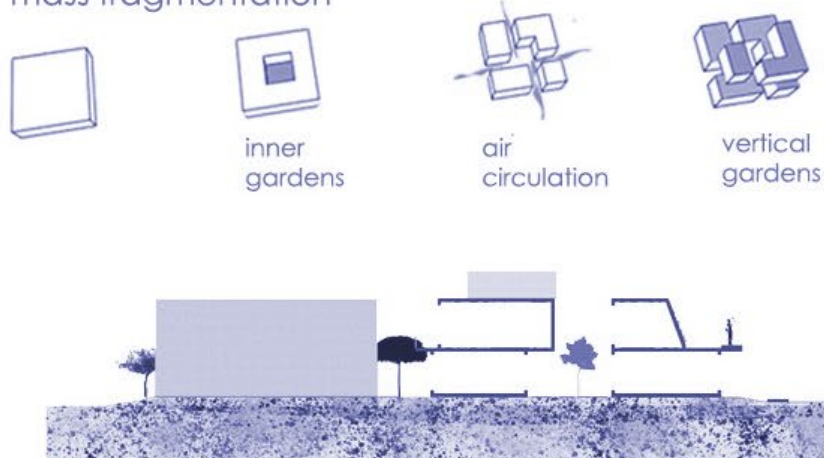

residential areas
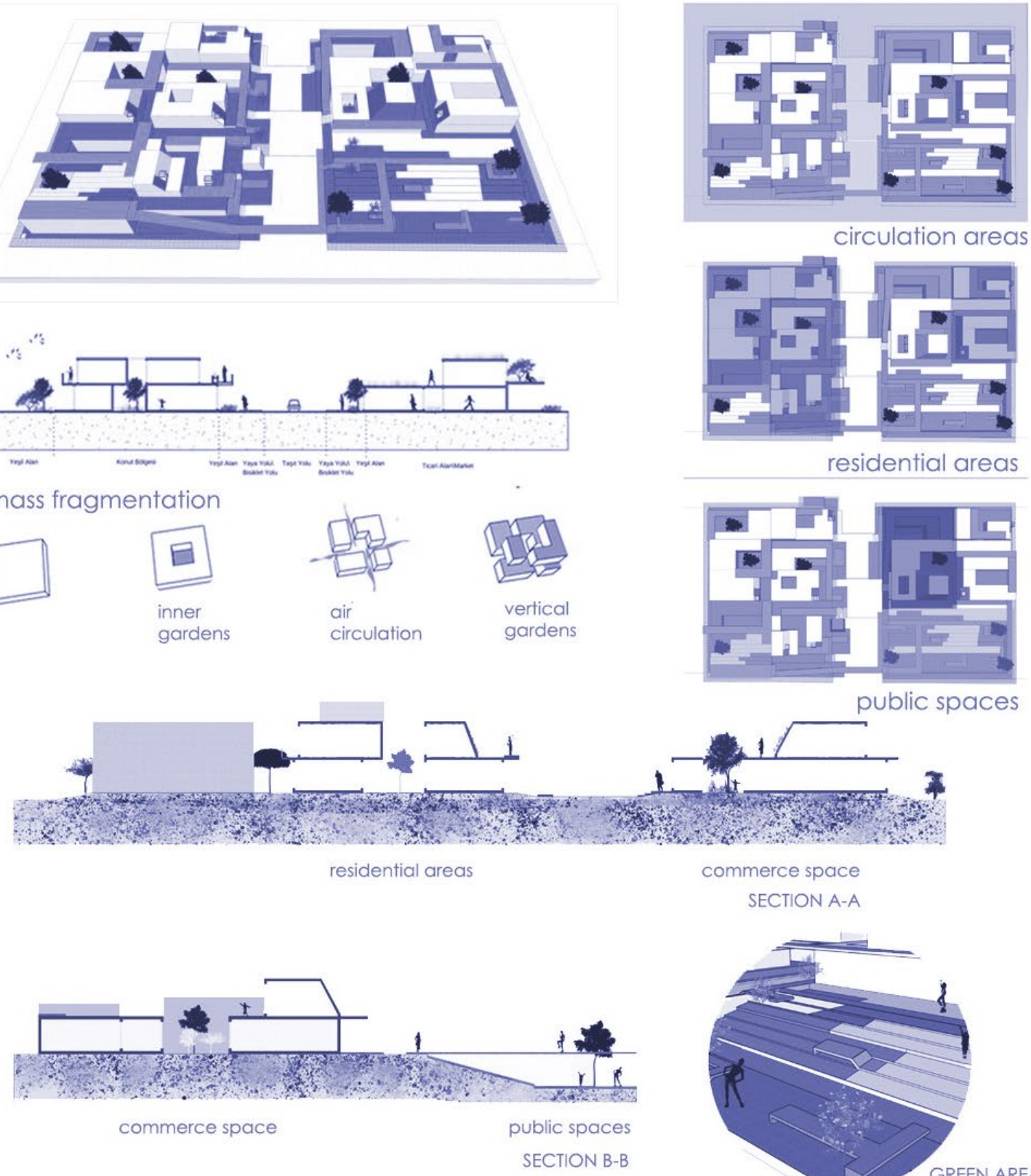

circulation areas

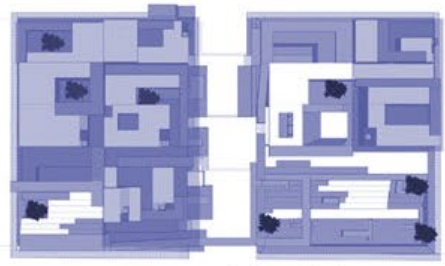

residential areas

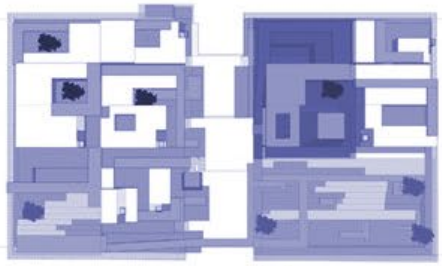

public spaces
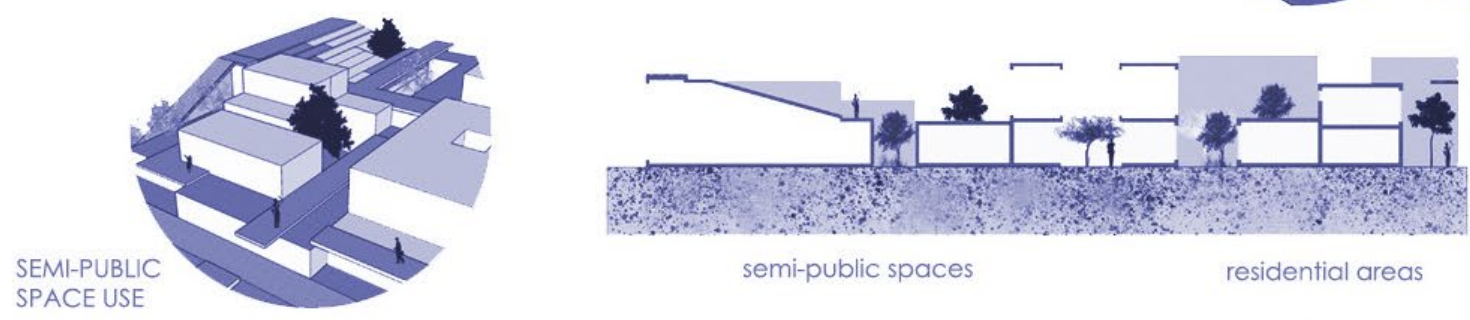

semi-public spaces

residential areas

SECTION C-C

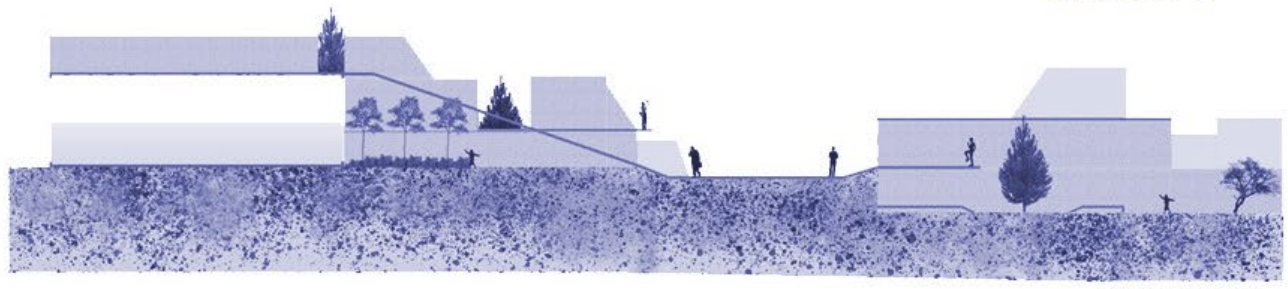

SECTION D-D

\section{ADS II - Speculations on Post-Covid Neighborhood Design CEYDA DÖNMEZ- NEIGHBORHOOD IN THE "NEW NORMAL"}

Fig. 3 - ADS-II, Neighborhood Design of Ceyda Dönmez, Emphasizing the New Pedestrian Use, the Public, and Private Aquaponics Agricultural Spaces Integrally Designed for the Whole Neighborhood with Embracing Walkable Terraces 
discussion is more profound than customarily posited as a design problem in architectural education. It implies a turning point about the re-positioning of humans, nature, and space, and rethinking them together without keeping them apart. Cities are the product of such a separation, as much as the recreation and commercial spaces designed as supporting elements of the city. Therefore, holistic handling is necessary to discover new potential options for a world where socialization, production, consumption, and commons are under question (Fig. 5).

For this questioning, certain concepts are utilized for the general themes of the design studios and the design ideas of the student proposals. These are:

- The healing power of nature. Nature heals. Discussions are conducted to underline the gap between the natural and the man-made. Therefore, how can we design space to integrate nature as a healing element and to propose alternatives for new possible common spaces?

- The cycle of nature. Nature has its own cycle other than city life. Therefore, can we find a common point to meet with the cyclic facts of nature and discover a possible better relationship between humans and nature?

- Recreation and sports. Can nature be a natural element of recreation? Do we have to encapsulate nature in recreative spaces as an additional element?

- Activities in nature. Is there a list of activities that can be carried out in nature, or is it not possible to be guided by space in a designed portion of nature?

- Sustainability. What should be sustainable in the new normal?

- New commonality by nature. How can we meet and socialize with other people through a new understanding of common space? The definition of 'the new' and the 'new common' is critical. After all, we can ask if there is a new commonality in or with nature.

- Experiencing by doing.

Experiences are more substantial when we actively participate in the event.

Therefore, could the power of experience through space be a design concern?

- Urban/domestic agriculture. Production is a crucial concept for the new normal. Most of the proposals include selfsufficient lifestyles with a spatial component providing this selfsufficiency. Urban and domestic agricultural spaces and the usage scenarios are discussed, which is questioned as follows: Could these agricultural aspects be a natural element of the design?

\section{- New alternatives of} transportation. Nature is integrated into the urban neighborhood design.

However, in an urban context, transportation is still the main requirement for people's mobility. Could there be new alternatives for a nature friendly design?

Both ADS-I and ADS-II examined the role of nature through the students' design process for a semester regarding the key concepts and questions above. It is difficult to get a clear conclusion and a project-based result at the end. Nevertheless, the negotiation of nature and humans through a holistic spatial design understanding, embracing all the faculties of life such as culture, social life, economy, education, health, and space concerning the new definitions, becomes a very fertile field of research, not only for architectural design studios, but also for all disciplines. It is seen from the two experiential architectural design exercises that a new look for the parameters of design could bring new ideas for different scales of spatial design.

Two studios, where the role of nature in the new commons is examined, attempt to show a spatial threshold where nature and humans could negotiate. There is a new positive approach where nature could become an inseparable design parameter. Moreover, design by and through nature is more than concern for contextual conditions, and it is something that creates the commons of the space that was once defined by the relationships of a cityscape. The commons form the public space that builds identity and memory, which are the basis of cultural existence. As much as nature is involved in forming this common area, it will be possible to build a shared and democratic future that considers the ecological balance. It is time to set a common concern and goal in the education of architects to make this change happen. 


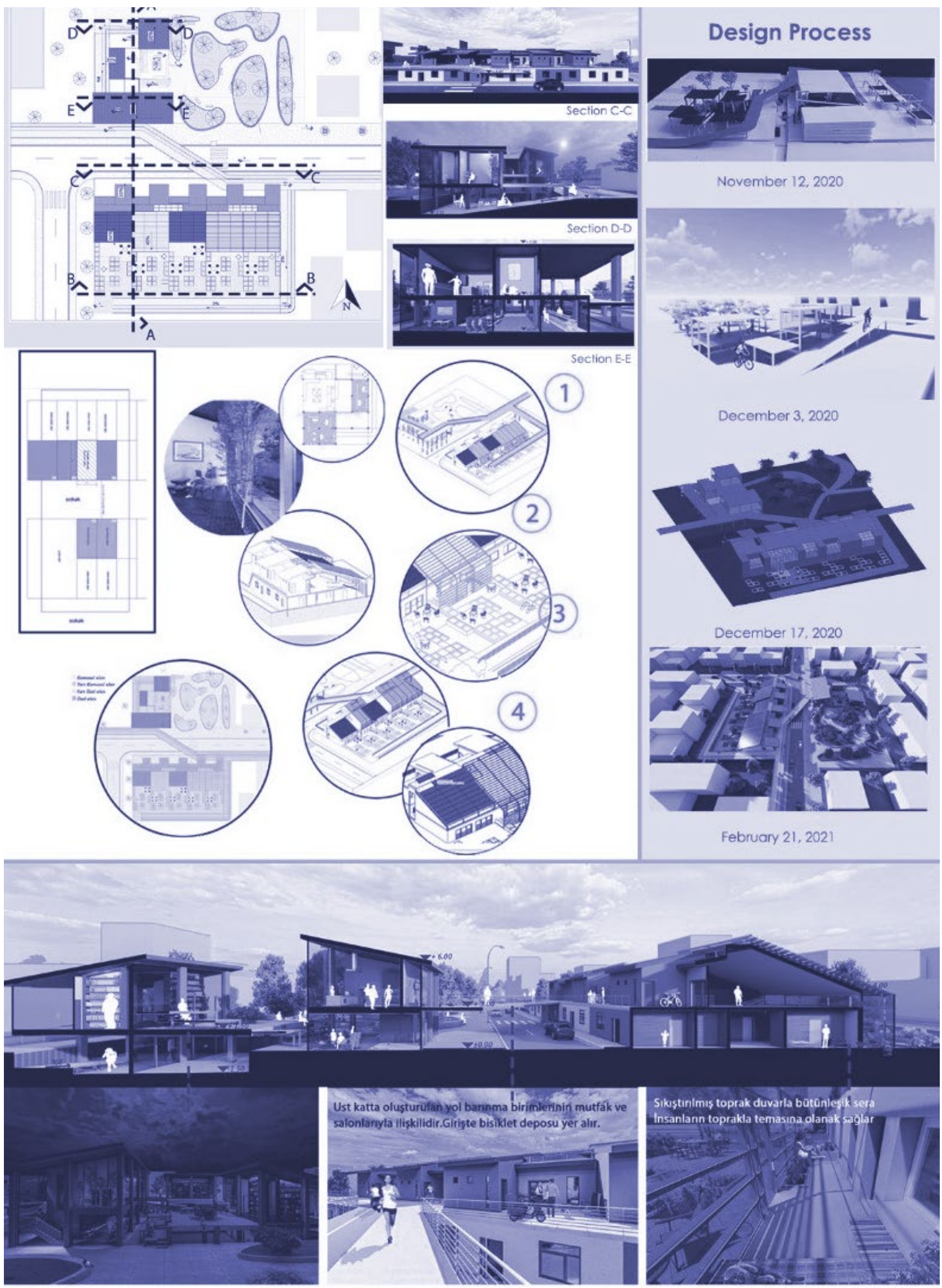

ADS II - Speculations on Post-Covid Neighborhood Design IREM KAHRAMAN - POST COVID CITY MODEL: STREET DESIGN 


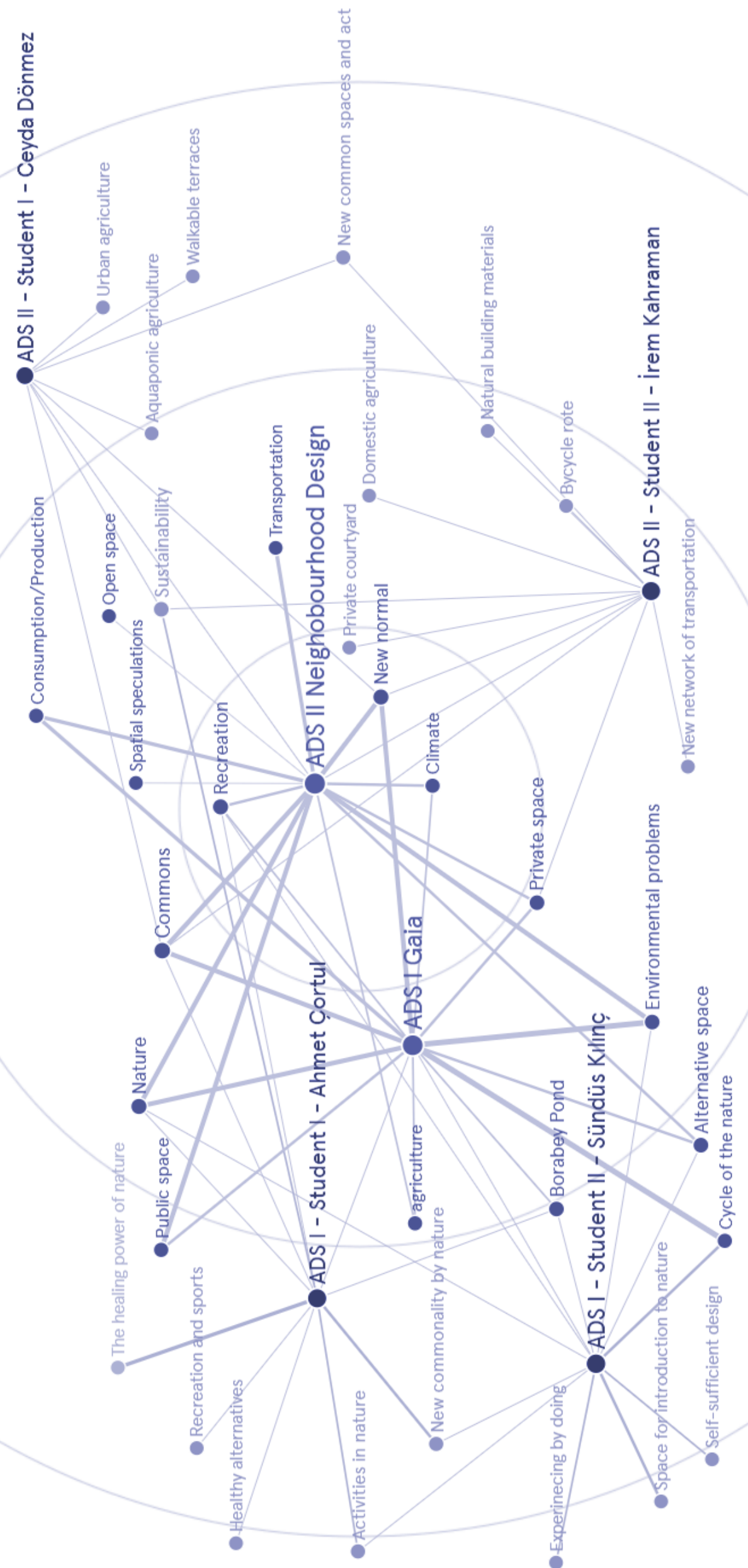

Fig.5 - The Conceptual Mapping of the ADS-I and ADS-II by Correlating Design Ideas of the Students.

\section{BIBLIOGRAPHY}

Arendt, H. (1998) The Human Condition, University of Chicago Press: Chicago\& Londonhttps:// monoskop.org/images/e/e2/ Arendt_Hannah_The_Human_ Condition_2nd_-1998.pdf accessed: 07.04.2021

Boettger, T. (2014). Threshold Spaces: Transitions in Architecture. Analysis and Design Tools. Birkhäuser.

Collingwood, R.G. (2020) Doğa Tasarımı (the Idea of Nature) Translated by Kurtuluş Dinçer, Ayrıntı yayınları, İstanbul

Habermas, J. (1974) The Public Square: An Encyclopedia Article (1964), New German Critique, No.3 (Autumn, 1974), pp.49-55.

https://www.unige.ch/sciencessociete/socio/files/2914/0533/6073/ Habermas_1974.pdf accessed: 07.04.2021

Harvey D. (2012) Rebel Cities: From the Right to the City to the Urban Revolution, İstanbul: Metis

Lefebvre, H. (1991). The production of space, trans. Donald NicholsonSmith, Blackwell Publishers, UK.

Lefebvre, H. (1998). Modern Dünyada Gündelik Hayat,(Çev. I. Gürbüz). İstanbul: Metis Yayınları.

Sennett, R. (2002) The Fall of Public Man, Penguin Books, London.

Stavrides, S. (2016). Common Space: The City as Commons, Zed Books. London.

Stavrides, S. (2018). Kentsel Heterotopya, Özgürleşme Mekânı Olarak Eşikler Kentine Doğru. İstanbul: Sel.

Wulf, Andrea (2015) Doğanın Keşfi (The Invention of Nature) Translated by Emrullah Ataseven, Ayrıntı yayınları, İstanbul 


\section{Re-thinking
Poplar District}

\section{A new perspective for Robin Hood Gardens}

\section{Fatigato, Orfina F.'; Saitto, Viviana $^{2}$; Di Giulio, Vittoria ${ }^{3}$; Finale, Gennaro ${ }^{4}$; Galterisi, Mario ${ }^{5}$}

1Department of Architecture "DiARC" / University of Naples "Federico II", Naples, Italy https://orcid.org/0000-0002-3280-8771

orfina.fatigato@unina.it

2Department of Architecture "DiARC" / University of Naples "Federico II", Naples, Italy https://orcid.org/0000-0003-1553-4171

viviana.saitto@unina.it

3Department of Architecture "DiARC" / University of Naples "Federico II", Naples, Italy https://orcid.org/0000-0002-7155-927X

vit.digiulio@gmail.com

4Department of Architecture "DiARC" / University of Naples "Federico II", Naples, Italy https://orcid.org/0000-0002-7100-2340

gen.finale@gmail.com

${ }^{5}$ Department of Architecture "DiARC" / University of Naples "Federico II", Naples, Italy https://orcid.org/0000-0003-1553-4171

galterisimario@gmail.com

Citation: O. Fatigato; V. Saitto; V. Di Giulio; G. Finale; M. Galterisi. (2021). Re-thinking

Poplar District. A new perspective for Robin Hood Gardens. UOU scientific journal \#01, 206-221.

ISSN: 2697-1518. https://doi.org/10.14198/UOU.2021.1.15

This document is under a Creative Commons Attribution 4.0 International license (CC BY 4.0) comunità

housing

Robin Hood Gardens

spazi intermedi

Alison \& Peter Smithson

communities

housing

Robin Hood Gardens intermediate spaces

Alison \& Peter

Smithson 


\section{Ripensare il quartiere di Poplar}

Una nuova prospettiva per i

Robin Hood Gardens

La pandemia da Covid-19 ha evidenziato numerosi problemi e l'inadeguatezza di alcuni modelli di città occidentali, come New York - o Londra, se ci spostiamo nel continente europeo - il cui sviluppo è profondamente legato alle leggi di mercato. Essi iniziano a vacillare ancor prima del diffondersi della malattia da Coronavirus. Basti pensare alla grande quantità di immobili, destinati ai ricchi investitori stranieri, rimasti invenduti nella metropoli americana. II distretto londinese di Canary Wharf, modello europeo vicino a quello della east coast americana, rappresenta un paradigma emblematico per comprendere come quel modello, costituito da uffici di grandi corporazioni, da servizi privati e da costose abitazioni, non sia affatto sostenibile a lungo termine e anzi pericoloso se inserito in un contesto urbano, economico e sociale - come quello del quartiere popolare dell'East End - completamente estraneo ad esso.

Il lavoro che introduciamo, ha consentito la sperimentazione di un modello progettuale capace di rispondere alle difficoltà emerse durante la pandemia, attraverso il parziale recupero del complesso dei Robin Hood Gardens di Alison e Peter Smithson, completati nell'East End di Londra nel 1972 e oggi in fase di demolizione.

L'ipotesi parte dall'idea di recuperare il blocco superstite del complesso e di reinterpretare gli elementi fondamentali dello stesso in un nuovo modello residenziale in grado di rispondere in maniera critica alle problematiche che caratterizzano il suddetto modello di città.

La nostra ricerca progettuale ha indagato la natura profonda e il significato che i progettisti intendevano attribuire agli elementi fondamentali e li ha rielaborati, nel tentativo di instillare continuità tra spazi privati e pubblici, punto di partenza per istituire legami tra residenza, strada, edificio e città.

Lavorare su architetture iconiche del Ventesimo secolo significa anche tentare di interpretare e manipolare le idee del movimento moderno in un contesto urbano completamente mutato, e nei riferimenti e nei valori, non per nostalgia ma per ambizione.

There are several issues related to living generated by the Covid-19 pandemic. These topics underlined the inadequacy of some western cities as models for the twenty-first century. City models such as New York - or London, if we look towards Europe - whose development is deeply linked to the laws of the market, began to falter even before Coronavirus spread. We need only think of the amount of housing stock, destined for wealthy foreign investors, left unsold in the American metropolis. The London district of Canary Wharf, the European model closest to the American east coast, represents an emblematic paradigm to understand how this example, consisting of big corporate offices, private services, expensive dwellings accessible to the wealthiest class only, is not sustainable. And in the long term at all, and even dangerous if placed in an urban, economic and social context - such as Tower Hamlets and the East End working-class district - completely unrelated to it.

The project we are introducing has allowed us to experiment with a design approach capable of responding to the difficulties that emerged during the pandemic, through a partial recovery of the Alison and Peter Smithson's Robin Hood Gardens complex, completed in 1972 in London' East End and currently under demolition.

The hypothesis that we propose starts from the idea of recovering the surviving block of the complex and reinterpreting its fundamental elements in new residential model that can respond critically to the problems that characterize the aforementioned city model ${ }^{1}$. Our design research has investigated the meaning that the designers attributed to these elements and has reworked them to instil continuity between private and public spaces, the starting point to establish a link between dwelling and street, street and building, building and city. 


\section{INTRODUCTION}

Contemporary research on multi-family residences today is a highly topical issue. The constant technological and social changes that characterize modernity have a radical impact on people's lifestyles and require a continuous rethinking of ways of living. Thus, designers are asked to prepare updated residential models. These models give us the opportunity to instil a sense of security and favouring, in Le Corbusier's words, an 'organic development of existence'3 for the inhabitants. The Modern Movement attempted to rescue the contemporary individual from the alienation of the moment. Therefore, it produced works designed on the concepts of "freedom" and "identity" for a long time. "Freedom" meant primarily liberation from the absolutist systems of the Baroque age and their successors, that is, a new right to choose and participate. "Identity" meant to bring man back to what is original and essential ${ }^{4}$.

Contemporary collective residential buildings inherit the premises of the Modern Movement, overcoming the standardization of the complexes built in the Sixties and Seventies, to give space to a design responsive to the relationship between the collective and individual dimensions, and capable of responding to an increasingly differentiated and multicultural catchment area. The housing unit, meant as a basic unit for the construction of buildings, is today a flexible space,

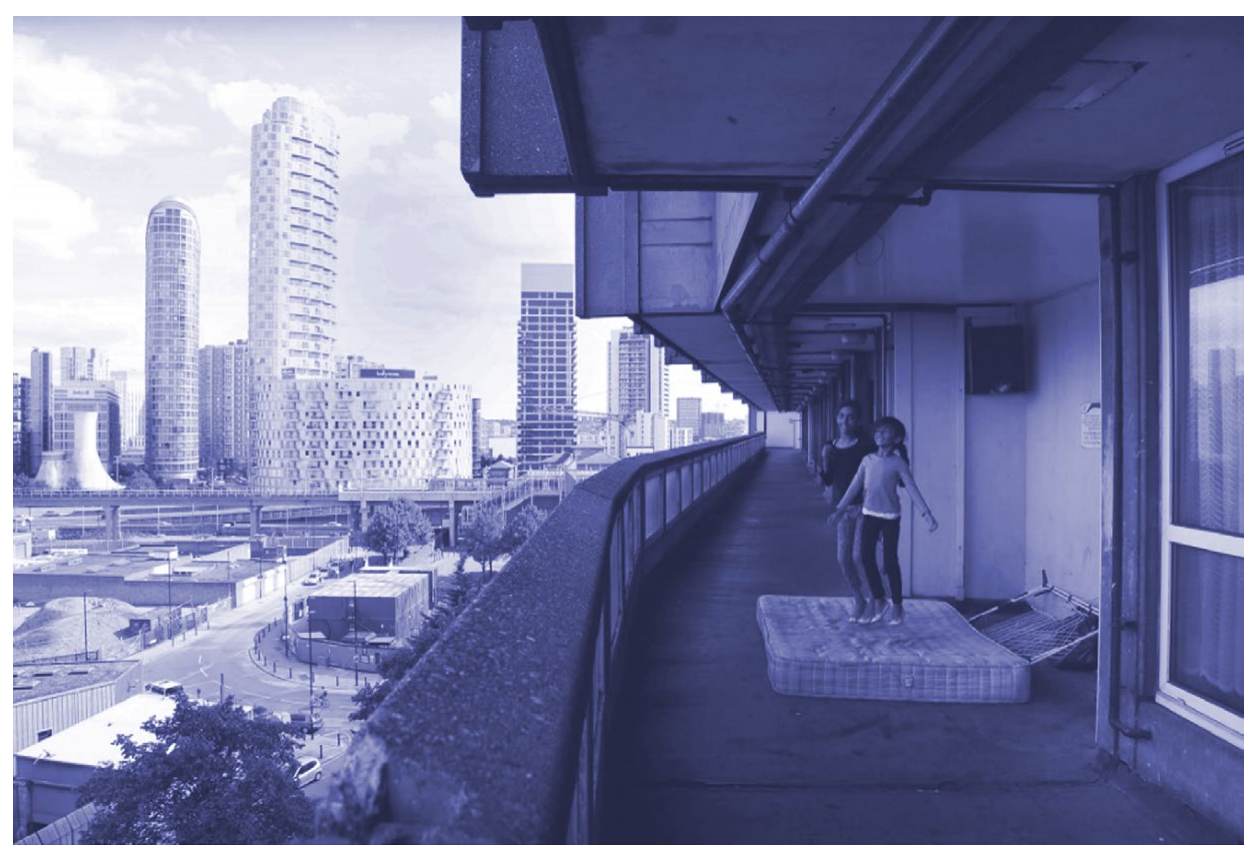

Fig. 1 - View from Robin Hood Gardens of the new residential estates built in Tower Hamlets (Getty images).

never static, able to meet the needs of the inhabitants and respond to temporal changes; a reflection on the meanings of "public", of "sociality" and on the complicated relationship between the collective and the private sphere ${ }^{5}$.

Recent studies, in particular devoted to northern Europe, have shown a renewed way of making these places, often highlighting ecological values as the basis of the recovery of iconic buildings of the twentieth century. It is in the wake of these researches that it was decided to experiment with the theme of collective housing unit, by imagining a different future for a controversial twentieth-century building: Alison and Peter Smithson's Robin Hood Gardens (Fig.1), built in London's East End in 1972. Recently one of the two buildings of the housing complex has been demolished, and the last still standing is also going to be demolished, to make way for the new Blackwall Reach's district. It is not easy to establish what would have been the right way to save it. It is difficult to imagine if the residential intervention that will replace it will satisfy the needs of a neighbourhood, that continues to preserve its popularity.

The experimentation described in this contribution, therefore, examines two particularly topical themes: on the one hand, it investigates the fate of respected residential architecture of the twentieth century, on the other, it experiments with collective living, in all its forms, through new buildings and new public spaces.

The idea of "protecting" and "taking care" of the surviving block of an icon of English Brutalism is not a romantic and nostalgic attitude, it is rather an ambition: an attempt to project the idea of community into the future that the Smithsons, perhaps too early, had imagined. 


\section{LIVING, TOGETHER}

'Have you ever thought that we shape, day by day and all together, this space?'. 'How we will live together?'. Two fundamental questions related to collective housing, expressed almost seventy years apart by Gian Carlo De Carlo at the Urban Planning Exhibition of the 10th Milan Triennale in 1954, and by Hashim Sarkis, current curator of the 17th International Architecture Exhibition in Venice. Two questions that still highlight today 'in the context of widening political divides and growing economic inequalities, we [need to] imagine spaces in which we can generously live together'6.

Architects, urban planners and designers are called to face the environmental crisis and social inequality. This double crisis along with the global pandemic have highlighted the inadequacy of urban space ${ }^{7}$ and, on the other hand, raised fundamental issues about the importance of residential buildings. 'Defending the pleasure of living seems eminently political to us today. It is a need that must be treated on the same level as an environmental priority's. Dwellings can no longer be considered as profitable financial products: they must be spatially generous, economic, the heart of a more comprehensive program capable of promoting a possible social and collective living ${ }^{9}$.

The house must be considered as a "gift" for the community; it plays an active role in fostering the sense of "hospitality" and inclusiveness that the whole city needs.

In a speech given in 2018 at the Parents Circle Families Forum in Tel Aviv, David Grossmann said that 'the home is the place whose walls - whose boundaries are clear and agreed upon. Whose existence is stable, unassailable and serene. [...] A place that projects a sense of the future'10. The intimate codes that govern the internal order of the house and its relations with the collective spaces of the building must return to be an explicit reference to civil coexistence, continuously updated and made operational ${ }^{11}$. The starting point becomes the organization of public and private human activities, to generate spaces capable of responding to changing needs.

The activities and uses of the inhabitants, only partially predictable, lead to a reflection on the definition of spaces with specific functions, relatively fixed in time, and places with flexible functions, continuously transformable. Dwellings and collective spaces described in the following paragraphs, offer freedom of use, generate the possibility of evolution, 'providing as much extra space as programmed space, free for use, to promote relationships' ${ }^{\prime 2}$. Our proposal is an 'escape route', withdrawing from reality with the aim of 'fabricating [a] possibility, [a] project within the project'13. The system of domestic and collective spaces, into which the project is divided, is conceived as the fundamental 'elements' of a project that has the ambitious goal of being welcoming, inclusive, capable of promoting relationships through the design of programmed spaces of an evolutionary nature, variously appropriable and transformable over time.

\section{EAST END OF LONDON AND THE SMITHSONS' LESSON}

Are there spaces in which the sense of community is more concretized? Following the Second War, there was a focus on "in-between spaces", taking an interest in those places that help integrate the concept of traditional living. The definition of "in-between spaces" is not univocal, but can be framed in a certain constellation of spaces that form communities starting from a hierarchy of associative elements, which express various level of association: house, street, district, city.

In 1947, Aldo van Eyck introduced into the architectural debate the importance of the areas we call today "proximity spaces", by designing a dense network of playgrounds for Amsterdam. This theme was subsequently taken up in the urban and domestic theories proposed by the members of Team 10 at the 9th International Congress of Modern Architecture (CIAM) in Aix en Provence in 1953. The idea behind the construction of these spaces, is linked to the ability that human beings have to recognize themselves in the environment in which he or she lives, and in the community that it inhabits. Through the actions that constitute living in between - of which threshold spaces, balconies, galleries, gardens, courtyards, buffer zones are 
spatial expression - Team 10 configured new spaces for relationships, capable of transcending divisions, fears and inconsistencies caused by the post-war reconstruction ${ }^{14}$.

In this regard, London's East End represents an exemplary case study. For a long time, a changing and multi-ethnic territory, it housed the Robin Hood Gardens lot, in a border position between two factions of the neighbourhood that, in the sixties, represented an interesting study area from an urban and social point of view. Starting from Judith Stephen and Nigel Henderson's photographs and studies of the area, the Smithsons, studying the game activities of children, drew up the Urban Re-Identification Grid, a visual map based provocatively on the ASCORAL group grid, proposed during CIAM 7 of Bergamo in 1949. The polemical attitude of the couple, shared by the other Team 10 members, this set the stage for some reflections on the very nature of the Modern Movement's method, whose positivist reduction was considered constrictive and excluded various aspects of social relations and neighbourhood collective life, based on stereotypical categorized actions. The project of Robin Hood Gardens emerged after a long series of experiments on collective living that the Smithsons first expressed in the Golden Lane project. This unrealized project clearly conveyed the nature of their theories about a continuous search for a space not limited to basic functions - dwelling, working, recreation, transportation - as of the Modern Movement, but could be hybrid, interpenetrated, and that could generate spontaneous interactions and unpredictable uses.

This area is greatly changed. The gradual gentrification, which has plagued the area after the conversion of the old docks from 1989 onwards, seems today unavoidable and high-density housing complexes have gradually arisen around Robin Hood Gardens, with costs per square meter far above the means of local residents, who become forced to leave the area. The new City of London is spreading like wildfire towards Poplar, and the fate of the neighbourhood seems increasingly to lean towards an exclusive use of the middle and upper class. If we look at recent events in the area and the events following the Covid19 pandemic, it is instructive to make a comparison with the urban theories of Team 10.

The depopulated arteries and the glass cathedrals of the big corporations, emptied of their content by the forced remote working condition, bring to our mind the criticism made by van Eyck on the sectorialization of the city, which certainly cannot be ascribed to the urban theories of the Modern Movement, but shares its negative effects. The urban fabric of Canary Wharf, its unfair relationship with the adjacent Poplar - from the point of view of income, scale of the buildings, data on deprivation, etc. - contributes to the fragmentation of the district, ongoing for several decades, and af the presence of infrastructure makes change inpracticable. The presence of fast-flowing roads around the site makes the neighbourhood difficult to cross for pedestrians and cyclists; the Aspen Way to the south and the Blackwall Tunnel, which connects the neighbourhood on the northsouth axis, make the district a disjointed sequence difficult to read. The Smithsons had already dealt with such infrastructures in the Sixties when designing the two buildings so they defined a large internal area, named a "stress free zone". The two buildings develop longitudinally to protect this area, and the circulation spaces are located on the external fronts. The connotation that they intended to attribute to the central open space was mainly aimed at play and leisure. The artificial hills were intended to stimulate the sense of discovery and spontaneous use, and at the same time to mitigate the sense of estrangement that would have been perceived from the upper floors of the two buildings. The configuration of the space, therefore, on the one hand defines a protected internal environment, on the other is one of the main reasons for the isolation of the complex from the surrounding space. The arrangement of the two blocks, together with the perimeter walls designed to muffle the noises of vehicular traffic, constitute the elements causing the segregation of the area from the neighbourhood.

The west building of the complex, placed along Cotton 


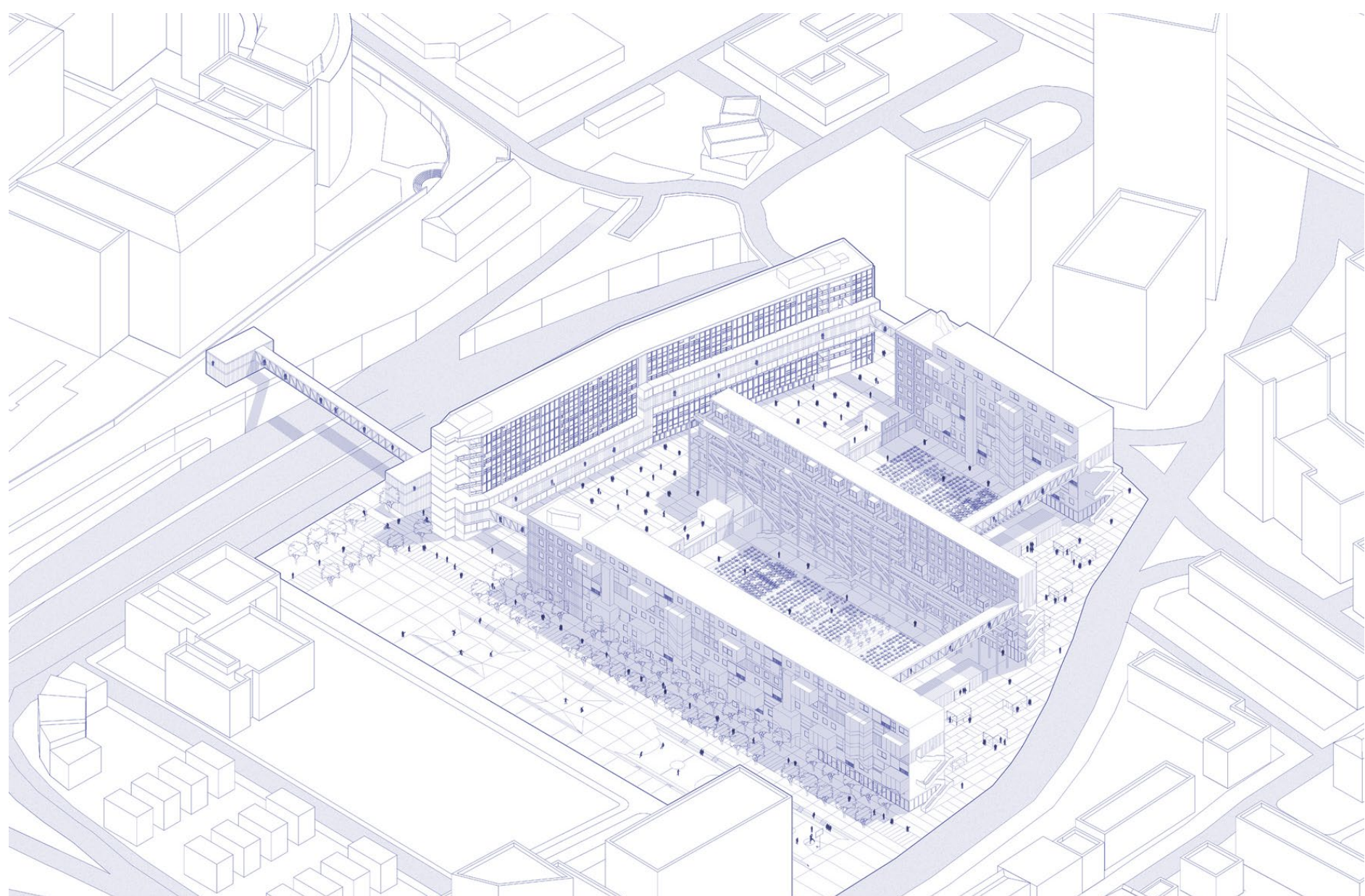

Fig. 2 - The new hybrid district.

Street, was demolished in 2017, compromising the urban layout of the district irremediably. Despite the mobilization of many illustrious insiders - Richard Rogers and Zaha Hadid among many the only successful attempt to preserve the complex, is the one promoted by the Victoria \& Albert Museum, which bought and musealized a section of three floors, including accommodation, complete with street in the sky, testifying not only the importance of the complex, but also to the relationship between residence and street ${ }^{15}$.

From these premisses, comes the need to understand how this absence can be an incentive to redesign a renewed urban layout, which can encourage a dialogue with the pre-existing city, establishing relations with it that take into account the evolution of the neighbourhood, established over the last forty years without any involvement of the brutalist complex. Observing the development of the city around Robin Hood Gardens, it is interesting to understand how the decisions of the designers have had an effect on the life of this part of the city. The large noise barriers placed on the east and west fronts of the complex produce two blind fronts, along Cotton Street and towards the Blackwall Tunnel. This strong separation from neighbourhood, which only allows residents to cross the stress-free zone, dictated that public pedestrian paths move only along these roads. Around this area, statistics show a significantly higher incidence of crime than the neighbourhood average, which is in turn much higher than the rest of the city $^{16}$. There is no certain direct correlation between the shape of the Robin Hood Gardens and this data, but they offer us food for thought about its relationship with the city ${ }^{17}$.

Starting from these premisses, it was necessary to carry out design research that looks at the whole system as a way to stimulate the relationship between the individual and the community, generating a sequence of in-between spaces through the relationships in which it is involved, placing itself as an element capable of accentuating, underlining and defining them (Fig.2). We therefore tried to think, above all, about the relationship between the parts rather 
than the shape of the new residential complex, thinking about human associations and how the project can encourage them, thus trying to imagine a system flexible enough to be at the same time a space for circulation, to stay, to play and to live, and able to be adapted to future unpredictable uses.

\section{RE=THINKING SMITHSONS' \\ FUNDAMENTALS}

'In order to keep ease of movement, we propose a multi-level city with residential 'streets-in-the-air'. These are linked together in a multilevel continuous complex, connecter where necessary to work places and to those ground elements that are necessary at each level of association. Our hierarchy of associations is woven into a modulated continuum, representing the true complexity of human associations' 18 .

In a speech given during CIAM 9, Alison and Peter Smithson highlighted the value of "building community" through the design of a hierarchy of associative elements: the house, the street, the district, the city. This concept derives from Van Eyck's intuition to dwell on an interstitial view. Focusing on the space among the buildings, in those places in the balance between inside and outside theorized by van Eyck, is fundamental to encourage interaction and cohesion among people and to develop a sense of belonging to places capable of promoting a new organization of space. According to the Smithsons, in the associative complexity of a community, social cohesion can only be achieved through a multilevel city, organized by cluster, based on a network of spaces, situations and new communication structures. A new layer covers the city, respects the existing buildings and gives more freedom to the inhabitants.

\section{In the Robin Hood Gardens} project, the new layer is represented by a street in the sky: rue - in Le Corbusier's view - placed on the facade, imagined as a space for casual interaction. They are horizontal surfaces to take a walk, overcoming the traditional idea of balconies and reproduce, at high level, the relational quality of the classic English alley. By the designers' admission, the streets of Robin Hood Gardens did not get the residents consent as they hoped. Although streets are animated by the thresholds of the different dwellings, they are used exclusively as places of transit, to walk in the shortest possible time and never seen as a space for socializing between neighbours. 'The darkening of the windows facing the corridors for privacy reasons, sometimes associated with a lack of internal or district services, invalidates the comparison with the city arteries, crowded with people and pervaded by a vital atmosphere'19. Peter Smithson will admit that this is, in fact, the greatest failure of Robin Hood Gardens: the threshold of the housing unit, imagined as a customizable environment, as he says, becomes an indeterminate area.

The "streets" of the Robin
Hood Gardens extend the concept of the "in-between space" to all public or private areas and to the threshold with the alcove in front of the access to houses. It is a space that interacts among different and contrasting spatial areas and that 'designates at the same time proximity and distance, similarity and difference, interiority and exteriority. [...] It confuses them, letting the outside in and the inside out, separating and uniting them' 20 . This dualism between inside and outside is no longer dichotomous but outlines a way of living between things. This way belongs to both and becomes a joining space. The streets in the sky are, therefore, the place for relationships and, at the same time, they are an amplification of the intimacy of the domestic space. To reinterpret the fundamental elements of one of the manifestos of English Brutalism allowed us to reflect on an "indeterminate architecture", capable of suggesting flexible methods of use, starting from a careful analysis of potential users. Therefore, the spaces of the relationship among the buildings are fundamental. They embrace the community proposed by the Smithsons in their theories, evolving in a new network of relationships that connect the pre-existing and the new hybrid district to the urban layout from which the building was originally isolated. The new streets in the sky network is present in every building of the new complex and connects all the collective spaces that serve the district and those reserved for residents (Fig. 3). 


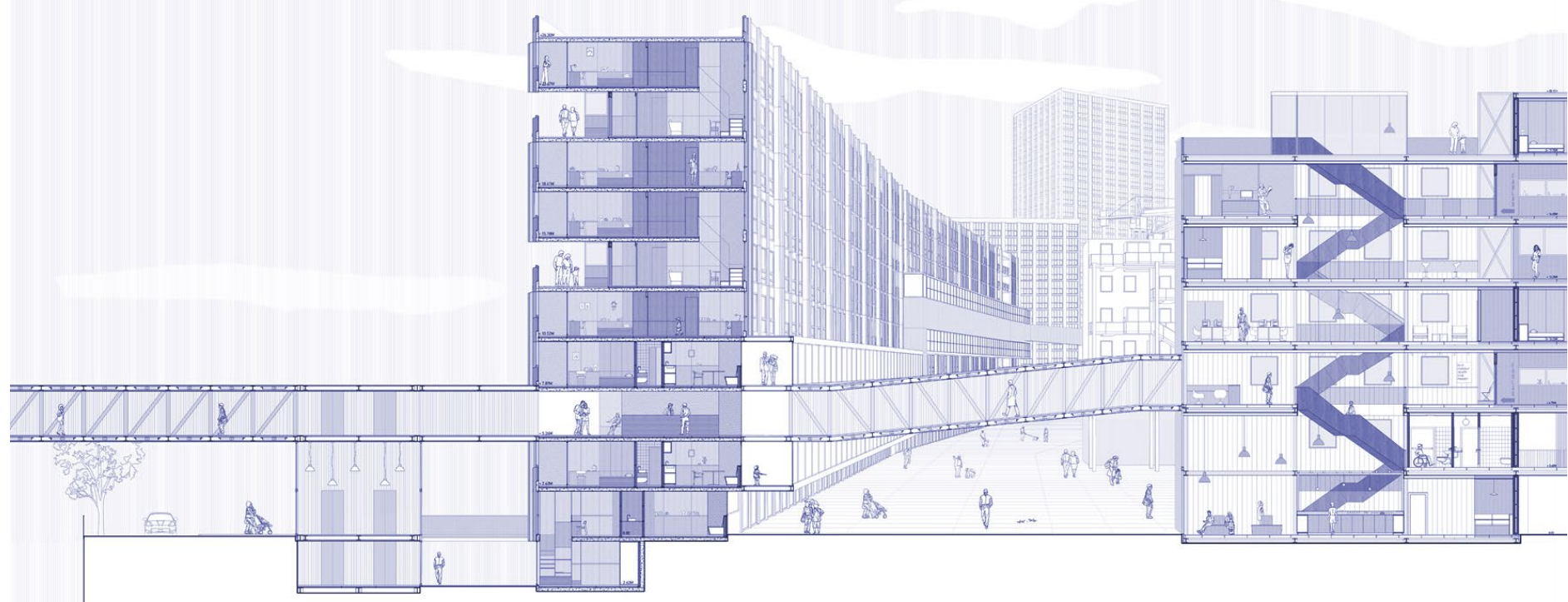

Fig. 3 - New Urban link: a reinterpretation of cluster.

The layout of the new district is based on an articulated system of open spaces planned as multi-scale devices. Spaces between things are hinge spaces and are used for the development of new relationships among pre-existing buildings and new projected volumes. The proposal stems from critical reflection on the original open space of Robin Hood Gardens and not creating new spaces of a univocal and completed way. It is configured as a critical reinterpretation of the fundamentals ${ }^{21}$ of the Smithsons' project.

\section{Robin Hood Gardens Square}

The space between the Robin Hood Building and the three new buildings - the Woolmore Building, the Cotton Building and the Poplar High Building - placed across it, is interpreted as the main circulation space of the neighbourhood. This function is underlined by the relation between the three new buildings and the pre-existing, whose ground floors function as laboratories and home-studios, defining a space dedicated to artists and creatives able to dialogue with the three transverse buildings.

The new intervention is a sequence of open and closed spaces, a place that is both internal and external, porous, stretched, crossing the base of the Robin Hood Building until it reaches the front of the Blackwall Tunnel. At this point the car parking space, becomes elevated and sees the addition of a shop front on Robin Hood Lane, and a cycle and a pedestrian path (Fig.4).

\section{The playgrounds}

The relationship between the north building, named Woolmore Building, and the school complex of the Woolmore Primary School, invites us to reflect on the playful dimension of the urban space and its spontaneous uses. Starting from the Smithson's reflections on the public space and the study conducted by van Eyck on the architecture of Dutch playgrounds, it was decided to design a free space, open to the interpretation of the users, characterized by ground movements that generate small depressions, in which different and unexpected activities are supposed to be carried out (Fig. 4). These spaces lend themselves to partial flooding during rainy periods, acting as a rainwater collection system, 


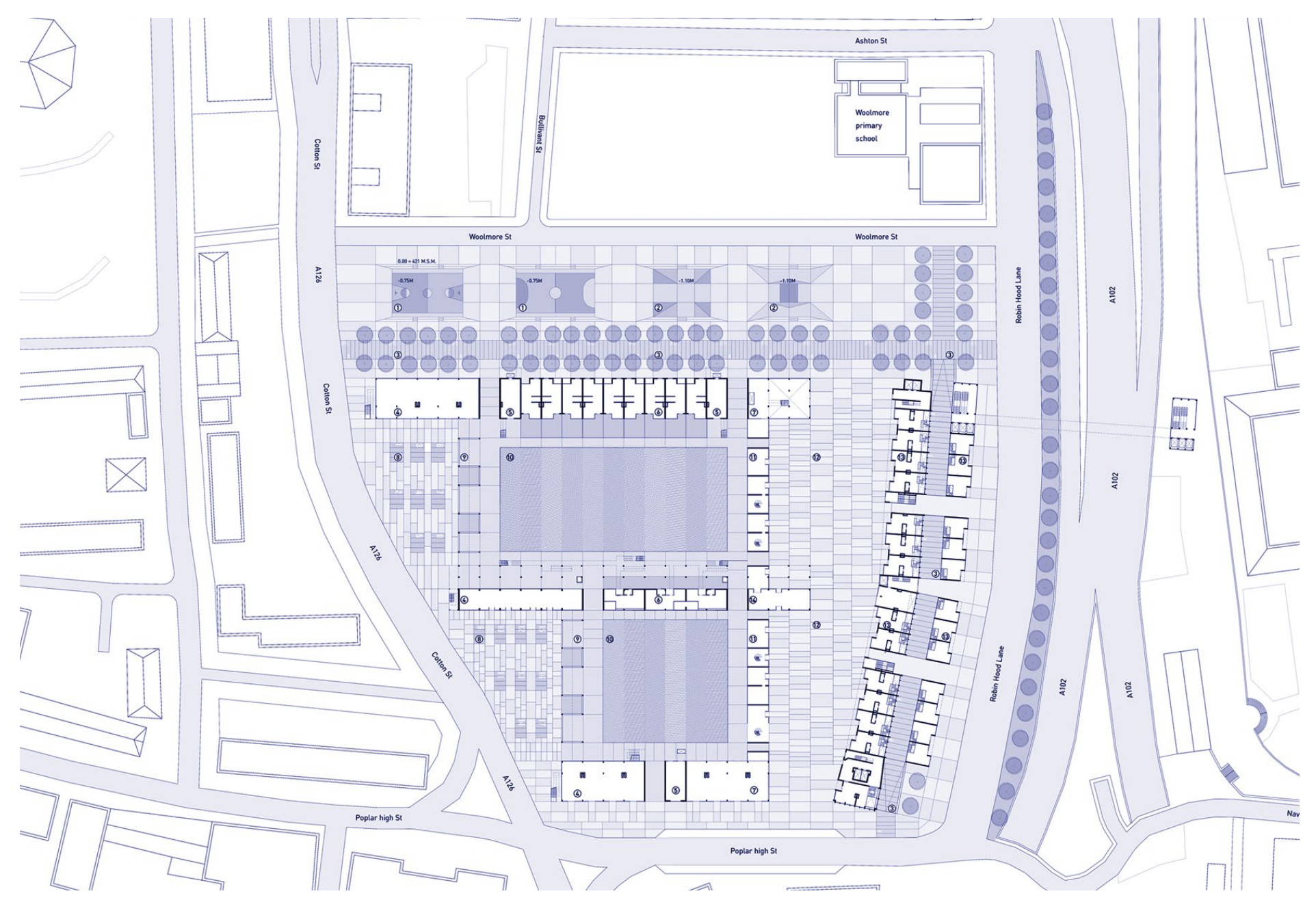

Fig. 4 - Ground floor plan of the district.
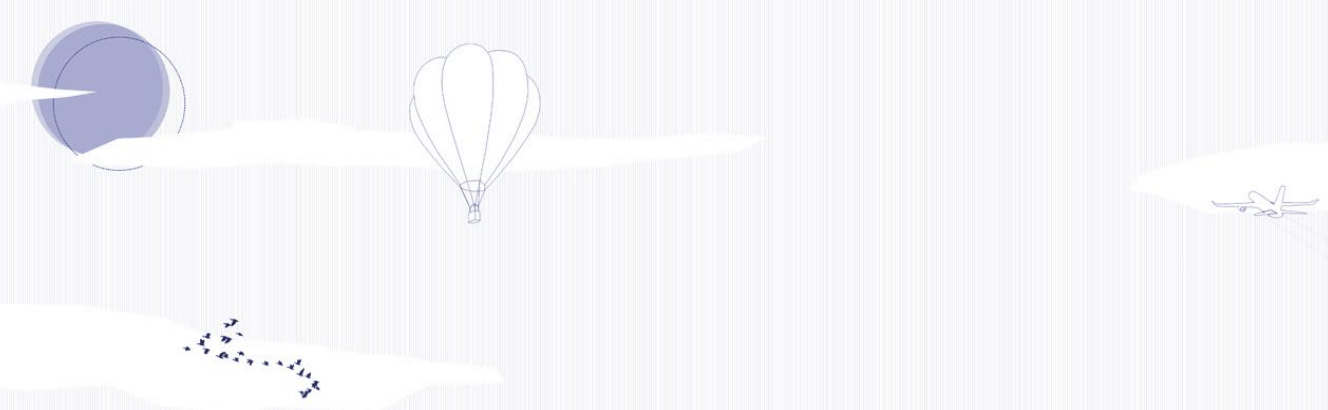

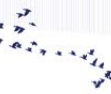

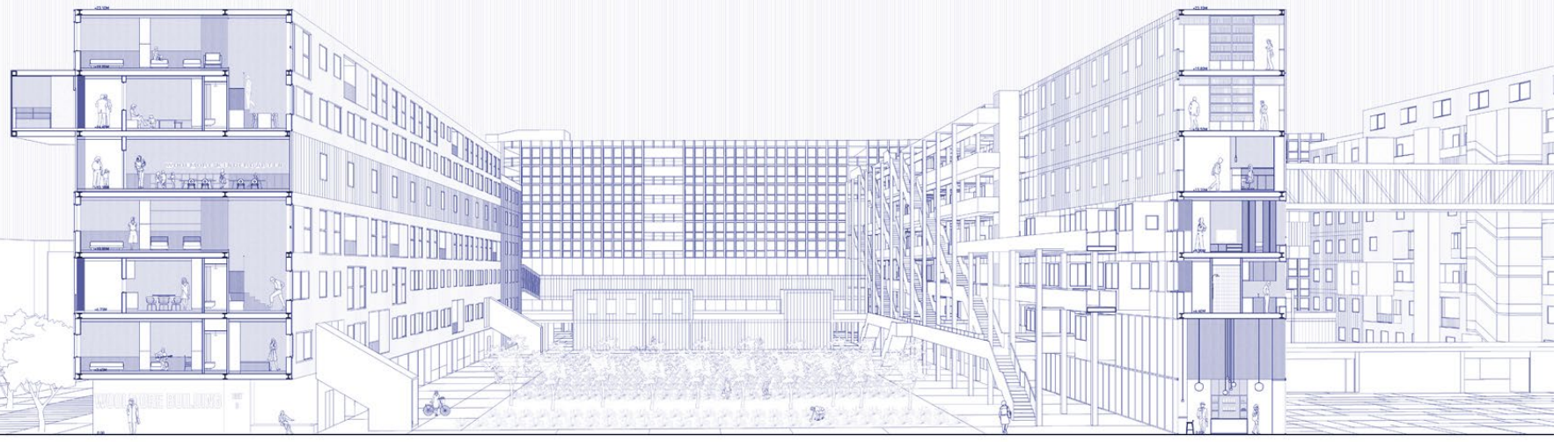

Fig. 5 - Inner courtyard section. 
and at as an ideal reminder of the scenario of the merchant docks, that represent a part of the collective memory of the neighbourhood until the Eighties.

\section{THE PRODUCTIVE COURTYARDS}

The space between the three buildings transversal to the Robin Hood Building, is configured as a sequence of two communicating courtyards. This space takes up the intimate nature of the stress-free zone, altering its morphological connotations, resizing and dividing it into two smaller spaces. The original configuration of the complex provided housing for the elderly in the ground floors of the two buildings, with direct access to the green area. A part of this, difficult to manage in its extension, has been turned in our project into urban gardens, a function suggested by the users of the Robin Hood Gardens, who in recent years have created small gardens between the public space and the homes of the elderly to ensure the privacy of ground floors. In the new configuration, this accommodation is moved to the private courtyards area, providing a large filter between the two parts, consisting of a patio - sometimes private, sometimes common to several dwellings - which is proposed as an access and as an autonomous user appropriation area. This solution recalls the classic terraced blocks of the English city, a mediation space between inside and outside, a buffer zone, a further contact space between the public and private spheres (Fig. 5). The sequence of urban gardens, placed in the private courtyards, mitigates the relationship between inside and outside by offering a place for co-operation and meeting.

\section{From the street in the sky to new inhabited threshold}

The retrofit of the Robin Hood Building begins from a spatial and functional reinterpretation of the street in the sky. Starting with the temporality studies proposed by Lacaton and Vassal and by LAN studio ${ }^{22}$, the possibility of changing partitions and interior finishes, was imagined responding to varying conditions of use over time. A plan was emptied from the original functions and destined for public functions. The streets in the sky, which previously became spaces to walk quickly, are enriched with domestic elements and bow windows that interact with the same street, taking on a new meaning and defining a place poised between inside and outside where people can identify and recognize themselves.

In the new buildings, the deck is also a reinterpretation of the street in the sky. It is a space characterized by customizable access thresholds to the housing unit and allows a strong relationship with the domestic space, thanks to the large glass surfaces of the bow windows.

The Smithsons' hypotheses are reinterpreted to generate a tension between the spaces of relationship, replacing the void of the streets in the sky with functional boxes that are designed as extrusions on the facade (Fig. 6). In between habitats capable of combining the desire for intimacy with the pleasure of socializing, which, by restoring the value of a real urban artery to this street in the sky, represents at the same time a public extension of the domestic space. The domesticity of these places is emphasized by the finishes, which can be associated with a private space. The areas imagined are characterized by different functions: reading rooms and play areas that differ according to the needs of users. The new deck can also be customized, not only thanks to the furnishings of the residents, but also through the large windows that become a representation of infinite rituals and ways of living.

In other cases, the deck is further reinterpreted because it is detached from the facade of the building (Fig. 7). The access threshold to the house is extended: it is a suggestive aerial path that isolates the domestic space from the busy activity of the path. In the space that is generated between the gallery and the building, suspended rooms are inserted, a further interpretation of the bow window. These spaces, together with the loggias on the opposite side, allow a certain margin of appropriation by the residents. Faced with a system of fixed furnishings, these places suggest ways of use and allow the inhabitant to occupy the spaces with their objects according to their needs.

\section{EVOLUTIVE HOUSING}

Investigating the most intimate details of living is indispensable. The domestic 


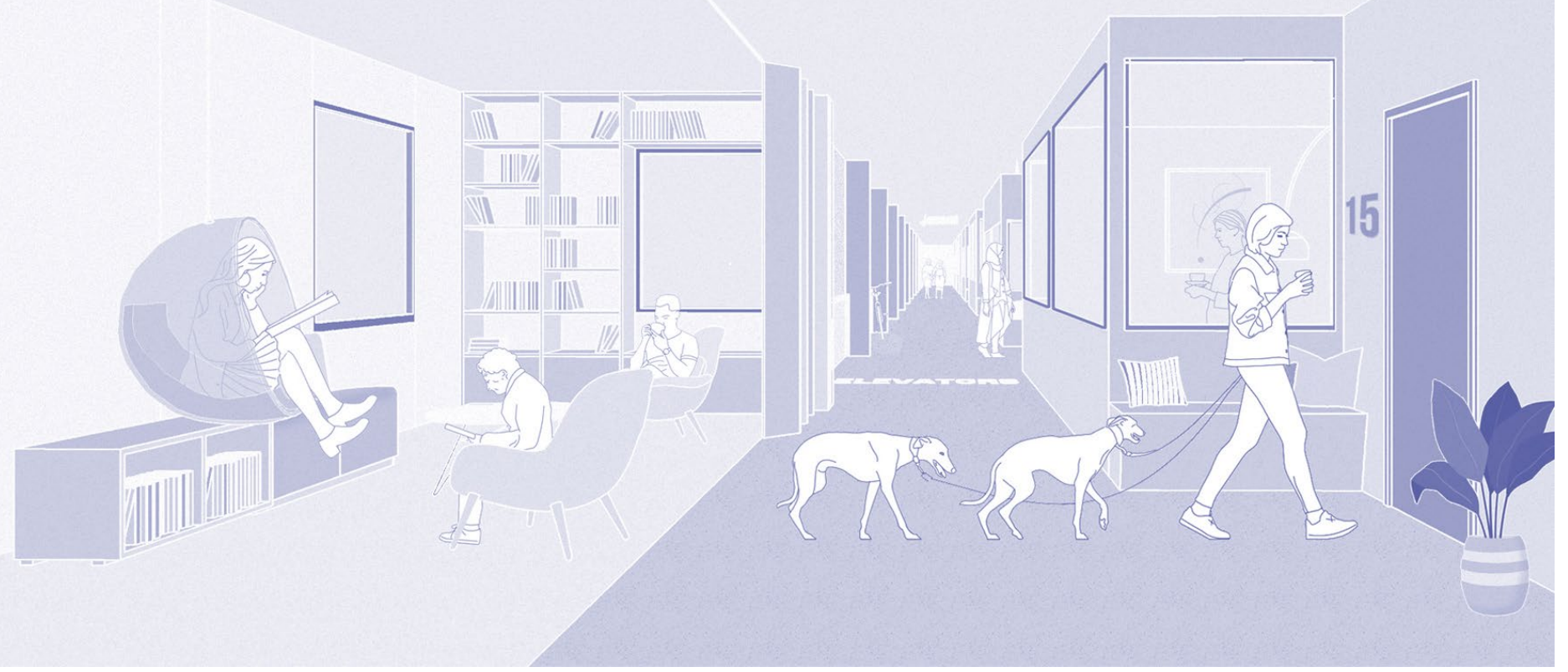

Fig. 6 - Woolmore building. Interior view of a deck.

interior, a place where needs and desires are condensed and amplified, is here interpreted as a constantly evolving space, as are human needs, after all. That is the reason why it's important to imagine dynamic, "democratic» ${ }^{23}$ and flexible spaces. But before exploring spaces issues, it is necessary to briefly note the methodology and the kind of representation used in this work.

Starting again from the experiences of some French studies $^{24}$, and of northern Europe in general, it has been chosen to describe these places with a "humanized" representation, in order to give the sense of domesticity sought in all fields of this workshop. We devised an atlas of unconventional households, reflecting a community of residents, referring to the study of the interviews conducted by Gennaro Postiglione, professor at the Politecnico di Milano, to the most recent research published by Viviana Saitto and Cristina Colombo ${ }^{25}$, and to the workshop of photographer Kois Miah and sociologist Nick Thoburn - Lived Brutalism: portraits from Robin Hood Gardens housing estate. This atlas allowed us to "customize" the drawings, to tell the life of these places over time, thanks to the introduction of a "time variable". This kind of representation enabled us to imagine an endless and unpredictable network of situations, to make visible the numerical and human variety of the catchment area. The new residential complex is, in this way, told through the lives of its inhabitants as imagined by the Smithsons - and by the other members of Team 10 in general - that have always considered the reality related to human needs in their drawings, collages and axonometrics.

\section{The Robin Hood Gardens and the new housing units}

'At number 146a Muslim woman lives with her one-yearold baby. A lively, smiling, but wary Ghanaian woman lives at number 134. At number 206 lives a Central African couple. At number 164 there is a woman with a few years old child, which we only know by reflection; the smell of food suggests they are Indian. At 202 lives a tall, mighty man, 


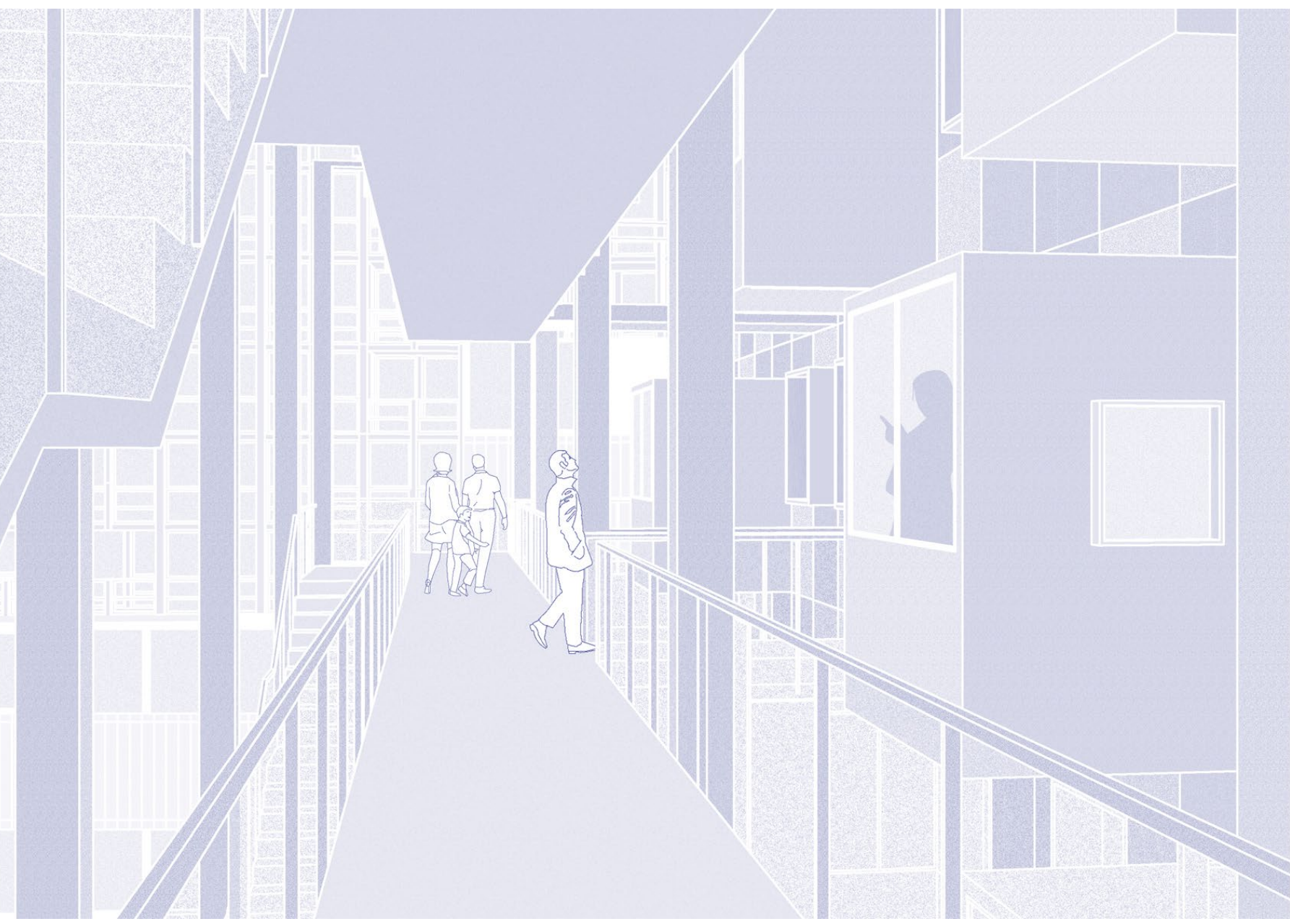

Fig. 7 - Cotton building. Interior view of a deck.

that we only saw from the back. At 172 lives Carolina, she is Polish and she has a Great Dane; she hates this place. Then there is the maintenance man; he was sure he had known us and had seen us there before. He allowed us to visit an apartment. [...] The rooms are very small and have few free available walls. As a matter of facts, desks and wardrobes are often improperly approached to the windows. The kitchen is the only equipment supplied, so it is the only room still furnished'26.

There are different types of accommodation, single and duplex, designed by the Smithsons in the Robin Hood Gardens, but all of them follow the same criteria: the "noisy" living rooms are facing the road, while bedrooms and kitchens look into the inner courtyard, maybe to give the possibility of checking on kids playing in the stress free zone. The study of the characteristics of the Smithsons project whose intentions were to connote the domestic interior using different thresholds - led to a critical interpretation of the accommodation and to its declination in different types.

The new housing unit projected for the Robin Hood Building respects the reinforced concrete structure. A new layer of extremely light and dryinstalled equipment overlaps the hardware of load-bearing walls and existing cables. The neutral, homogeneous and unifying container is a device that allows people to customize the space according to their needs (Fig. 8).

The threshold space is reinterpreted: the bow window marks the gradual transition to a more intimate dimension of the dwelling. A sliding panel inside this first internal area, gives the possibility to make the bow window completely introverted, linked to the intimacy of the dwelling; but, if necessary, the full opening of the panel makes this room almost an extension of the "road". This space, poised between semi-public and private, is then transformed into a hinged space: the threshold acquires its "tridimensionality" and becomes habitable. This customizable place is the representation of the personal way of living of each inhabitant. 

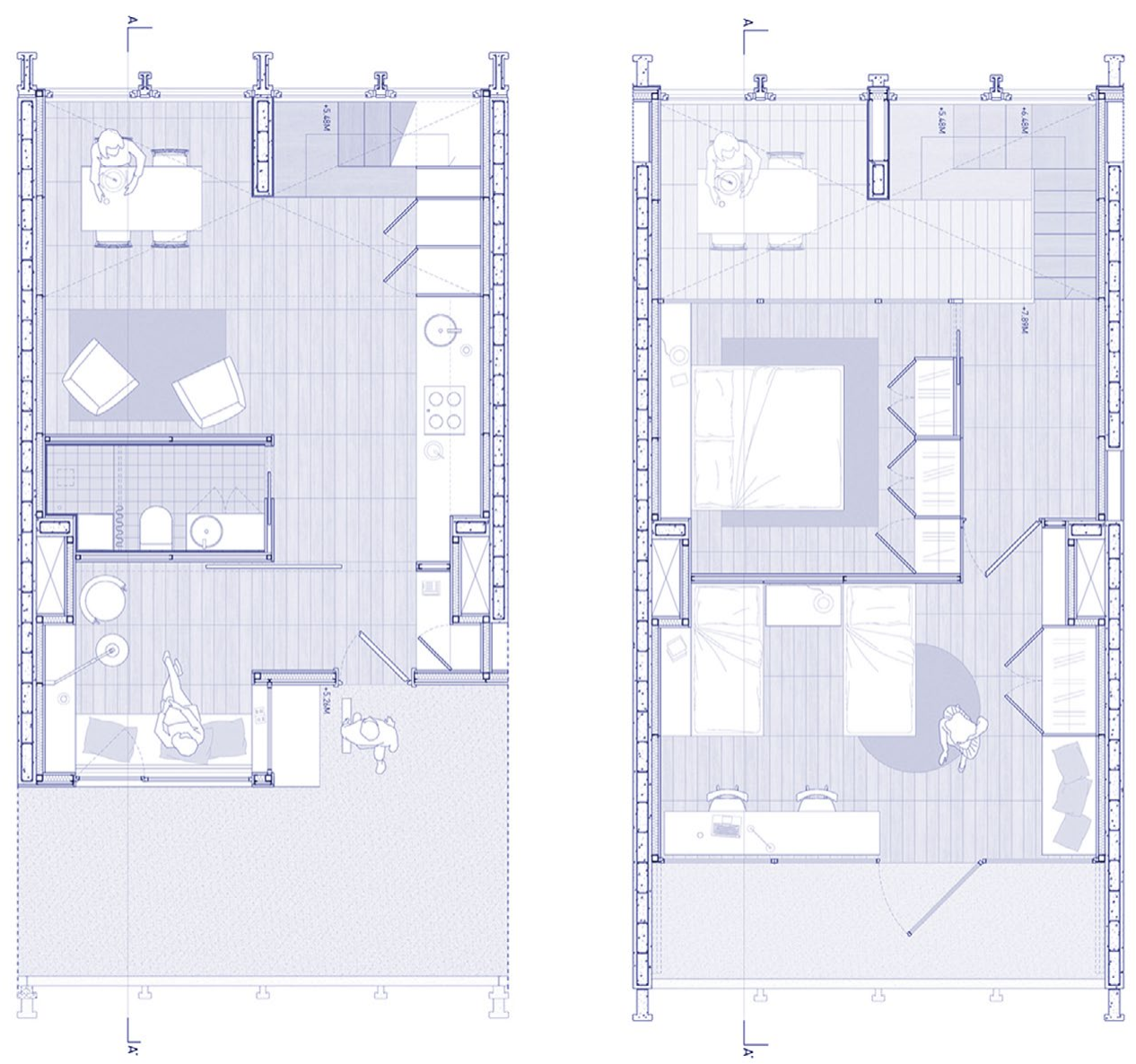

Fig. 8 - Robin Hood building. Lower and upper-level plans of new dwelling.

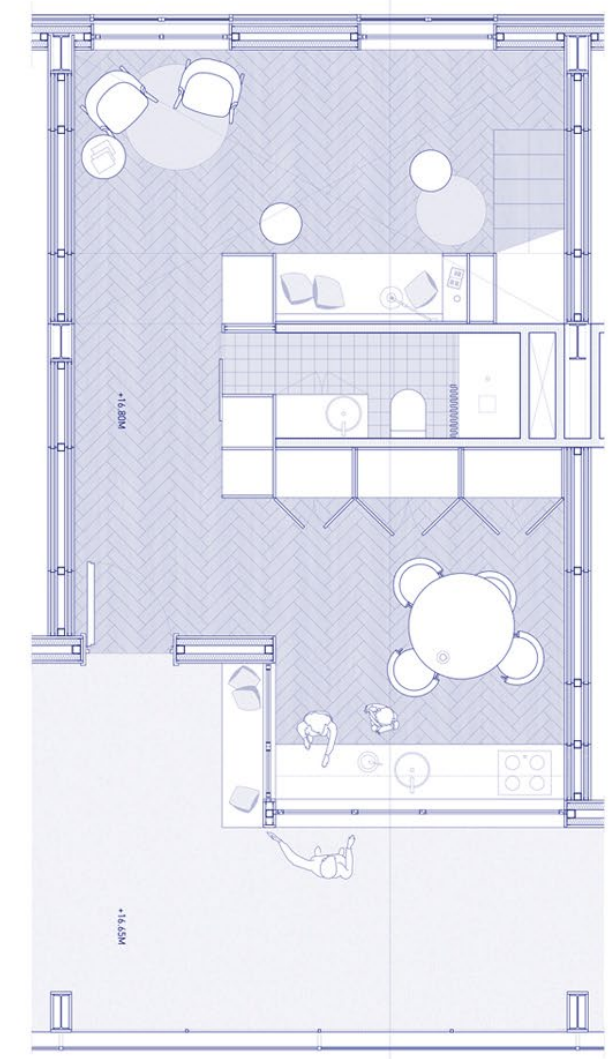

2035

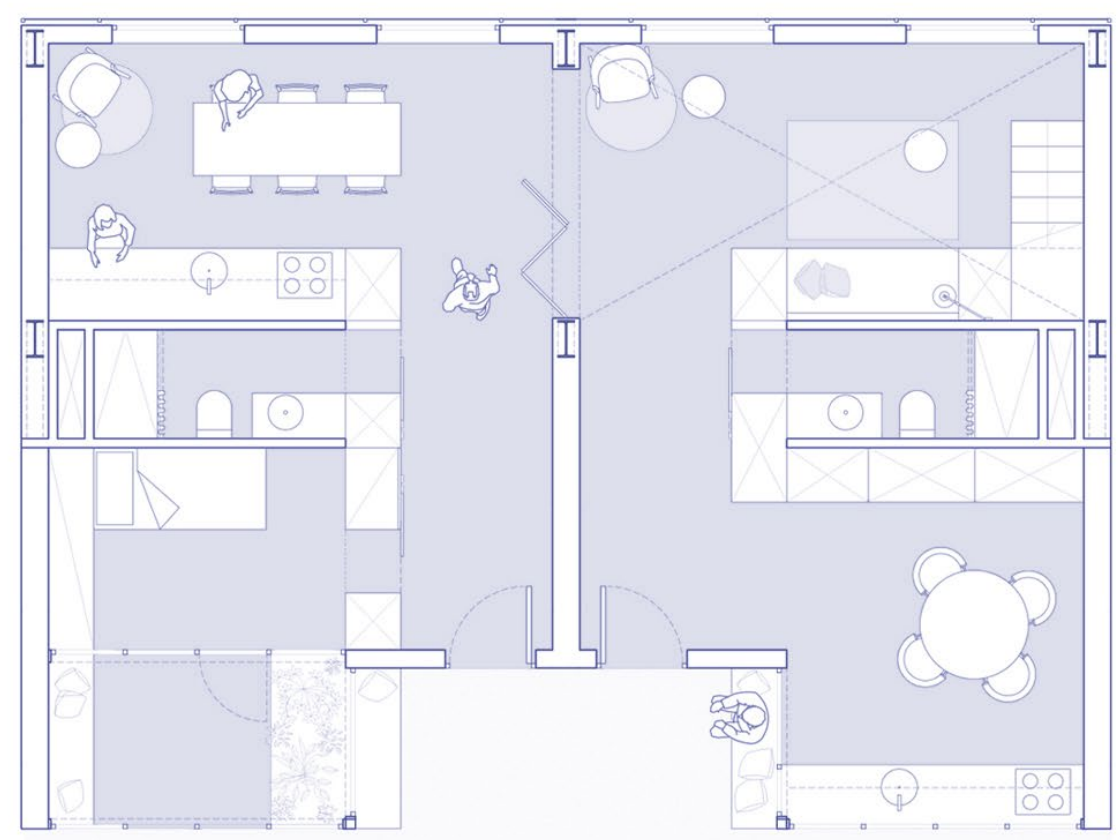

I

I

2050

Fig. 9 - Woolmore building. Lower-level plans. From left to right: configuration of dwelling in 2035 and 2050. 

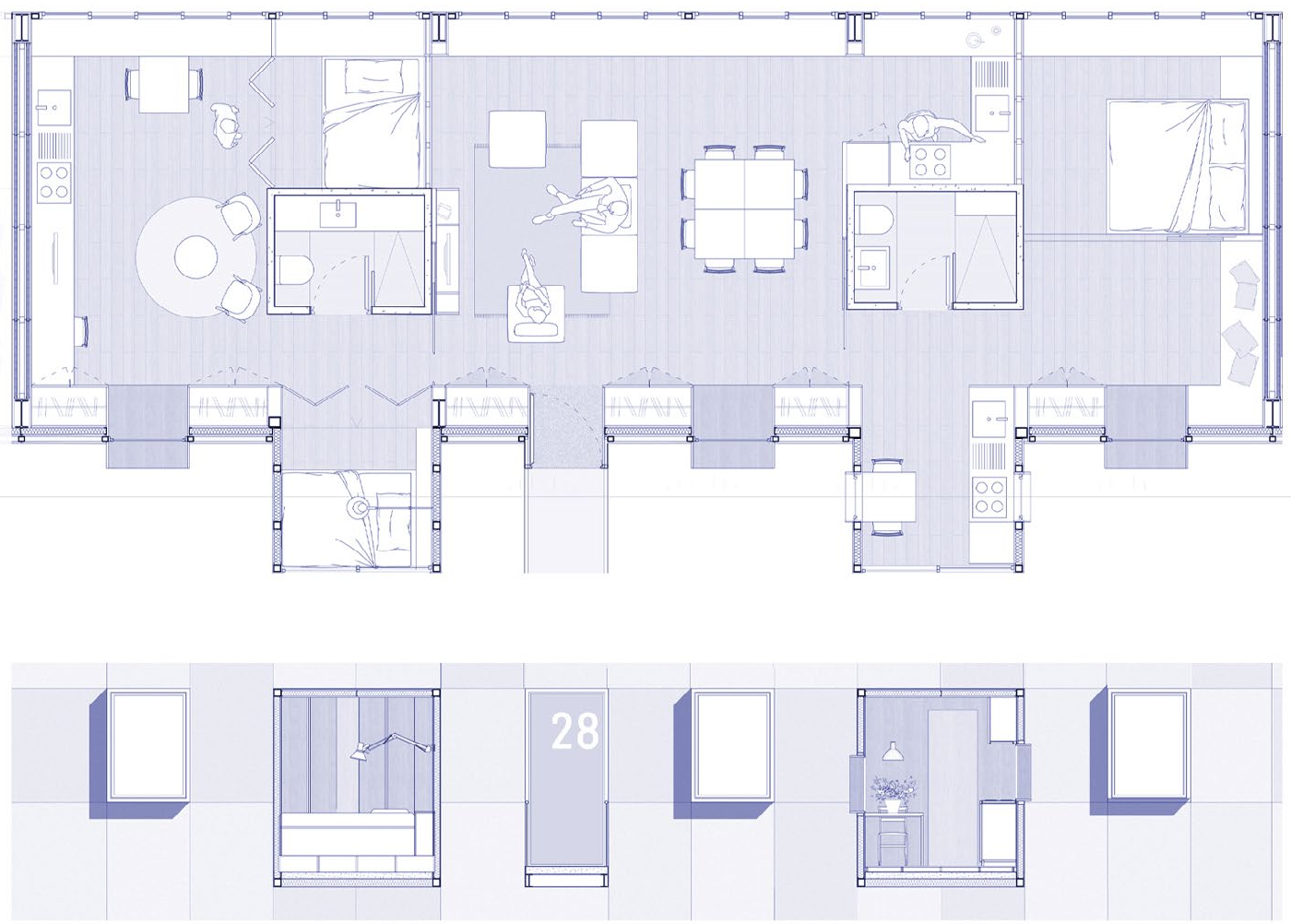

Fig. 10 - Cotton building. Plan of a cohousing typology.

This is the difference with the original Smithsons' project: customizing the deck does not just mean placing the furniture outside, but also tells the habits, the history of the inhabitants.

The internal staircase, originally located at the entrance of the house, turns into a piece of furniture rather than a pure connecting element, is able to shield the facade and to establish a relationship with the outside. The facade changes: it is a surface characterized by a new system of loggias that allows a private relationship with the outer space.

The evoling housing unit of the Woolmore Building is similarly designed. The threshold space is here customizable too, not only through the alcove that hosts the entrance to the lodgings, but also thanks to the bow window system, which in this case accommodates different functions - kitchens, winter gardens, smart working areas. Varying accommodations are made by a system of light and easily changeable partitions. So, it is possible to imagine a potential expansion of the space too, which could respond to the variation of households over time (Fig. 9).

In the Cotton Building different types of houses coexist, they not only reflect on the number of inhabitants, but also on their habits. Studios for singles and dwelling for unconventional families are characterised by sufficiently flexible spaces to allow infinite internal variations (Fig. 10).

\section{CONCLUSIONS}

This proposal tries to meet the housing needs of the Poplar district, putting the housing issues before any potential financial benefit for the residential estate that will replace Robin Hood Gardens. It relates to a plurality of need, in constant evolution, of today's society and to the need to create community. Architectural practice, often victim of building speculation, has not always been able to imagine spaces collective and/or private - able to respond to the needs of individuals over time.

The project idea described above, is part of a current of thought that, for several years now, defends the existing building stock. 'Never demolish, always add' is an increasingly widespread modus operandi 
that interprets the assumptions of the Modern Movement: '[...] not for nostalgia but for ambition'. The architecture promoted by the members of Team 10 during the years following the CIAM 9, laid the foundations for the creation of flexible, generous spaces, free from constraints. Contemporary practice has the duty to take up these concepts and to imagine new ways of producing, predicting and transforming the spaces of everyday living, because the pleasure of living must be treated as a design priority - as well as current environmental and social issues - and, of course, looking at the problems highlighted by the pandemic crisis.

'Defending the pleasure of living seems eminently political to us today. It is a need [...] Space is a common good, just like the sun, air or light. It is a vital material' .

Author contributions: the authors jointly conceived and developed the approach and decided on the overall objective and structure of the paper. In particular, conceptualisation and methodology, O.F., V.S.; methodology, investigation and validation, writing original draft, writing review and editing, O.F., V.S.; methodology, investigation, project elaboration, writing original draft, writing, editing V.D.G., G.F., M.G. In particular: Introduction and Living, together O.F. and V. S.; East End of London and the Smithsons' lesson G.F.; Re-thinking Smithsons' fundamentals M.G.; Evolutive Living V.D.G.
NOTES

${ }^{1}$ The research starts from the investigation held in the Master Degree Thesis Robin Hood Gardens Re.Lo.A.D by V. Di Giulio, G. Finale, M. Galterisi at DiARC, UNINA, supervised by O. Fatigato e V. Saitto e co-supervised by M. Cerreta.

${ }^{2}$ La ricerca parte dallo studio effettuato durante la Tesi Magistrale dal titolo: Robin Hood Gardens Re.Lo.A.D di V. Di Giulio, G. Finale, M. Galterisi presso il DiARC, UNINA, con la relazione di $\mathrm{O}$. Fatigato e $\mathrm{V}$. Saitto e correlazione di M. Cerreta.

${ }^{3}$ LE CORBUSIER. Vers une architecture. Paris : Éditions Crès, 1923, p. 6.

${ }^{4}$ NORBERG-SCHULTZ, Christian. Genius Loci: Towards a Phenomenology of Architecture. New York: Rizzoli, 1980, p. 192.

${ }^{5} \mathrm{Cfr}$. FATIGATO, Orfina. I grands ensembles una "singolare plurale" eredità. In: BDC. 2015, vol.15, issue 2.

${ }^{6}$ Introduction to the exhibition How we will live together?, XVII International Architecture Exhibition in Venice, Venice, May 22 to November 21, 2021. https://www.labiennale.org/ it/architettura/2021

${ }^{7}$ Cfr. CHIPPERFIELD, David. We need a vision for housing. In: Domus. February 2020, issue 1043, p. 5.

${ }^{8}$ LACATON, Anne, VASSAL, Jean Philippe, Pleasure of living. In: Domus. November 2020, issue 1051 , pp. 29-33.

\section{9ibidem}

${ }^{10}$ To read the dialogue see GROSSMANN, David. Israele sia una casa, non una fortezza. Ricordando Uri. In Corriere della Sera. April 18, 2018, p. 15.

${ }^{11}$ Cfr. CONSONNI, Giancarlo. Carta dell'habitat. Milan: La Vita Felice, 2019, p. 43.

${ }^{12}$ LACATON, Anne, VASSAL, Jean Philippe, op.cit., pp. 32.

${ }^{13}$ Ivi, pp. 30.

${ }^{14}$ Housing theories by Alison and Peter Smithson are documented in: SMITHSON, Alison. Team 10 Primer. London: Studio Vista Limited, 1968.
${ }^{15}$ The assumptions underlying the original project are documented in: SMITHSON, Alison. Team 10 Primer. London: Studio Vista Limited, 1968.

${ }^{16} \mathrm{Cfr}$. London police data store: https://data.london.gov.uk/dataset/ recorded_crime_summary.

${ }^{17}$ The report conducted by the municipality of Tower Hamlets in 2011 provides information for understanding the needs of citizens, who very often focus on the possibility of making the study more permeable to pedestrian and cycling flows.

${ }^{18}$ Alison and Peter Smithson, CIAM 9, Aix-en-Provence, July 24th, 1953.

${ }^{19} \mathrm{COLOMBO}$, Cristina F., SAITTO Viviana. Utopia srl. Icone sconfitte dell'housing sociale. Siracusa: LetteraVentidue, 2018, pp. 38-40, p. 40.

${ }^{20}$ GENETTE, Gerard. Soglie. Turin: Einaudi Paperbacks,1966.

${ }^{21} \mathrm{Cfr}$. KOOLHAAS R., OMA, Fundamentals Catalogue, Marsilio, Venezia, 2014

${ }^{22} \mathrm{Cfr} .530$ housing trasformation project for the Grand Parc du Bordeaux by Lacaton \& Vassal, Frédéric Druot and Christophe Hutin.

${ }^{23}$ ERSKINE, Ralph. Democratic architecture. The universal and useful art: projects and reflections. In Thomas Cubitt Lecture. March 31, 1982, pp. 642-659.

${ }^{24} \mathrm{Cfr}$. the methodological approach to the design of the Pritzker Prima Lacaton \& Vassal.

${ }^{25}$ COLOMBO, Cristina F., SAITTO, Viviana, op.cit., pp. 35-41, 54-75.

${ }^{26}$ COLOMBO, Cristina F., SAITTO Viviana, op.cit., p. 65.

${ }^{27}$ ZABALBEASCOA, Anatxu. Architectural priorities are challenged in the revolutionary renovations carried out by the studio Lacaton \& Vassal. In: Domus. April 2019, issue 1034, pp. 428-429.

${ }^{28}$ LACATON, Anne, VASSAL, Jean Philippe,14th International Docomomo Conference. Docomomo international, september 6-9, 2016.

${ }^{29}$ LACATON, Anne, VASSAL, Jean Philippe, Pleasure of living, op.cit., p. 29. 


\section{BIBLIOGRAPHY}

BIANCHI Roberto, Spartaco PARIS. Ri-abitare il moderno, II progetto per il rinnovo dell'housing. Macerata: Quodlibet, 2018.

DRUOT, Frederic, Anne LACATON, Jean-Philippe VASSAL. Plus. Barcelona: Editorial Gustavo Gili, 2007.

GUIDARINI, Stefano. New Urban Housing. L'abitare condiviso in Europa. Losanna: Skira, 2017.

LIGTELIJN, Vincent, Francis STRAUVEN. The child, the city and the artist: an essay on architecture: the in-between realm/Aldo van Eyck. Amsterdam: SUN, 2008.

MAAS, Winy. Farmax: Excursion on density. Rotterdam; 0:10 Publishers, 1998.

\section{POSTIGLIONE Gennaro. A+P}

Smithson: Una piccola antologia della critica. Siracusa: LetteraVentidue, 2015.

SMITHSON, Alison, Peter SMITHSON. Ordinariness and light: Urban theories 1952-1960 and their application in a building project 19631970. London: Faber and Faber, 1970.

\section{WORKS CITED}

CHIPPERFIELD, David. We need a vision for housing. In: Domus. February 2020, issue 1043, p. 5.

COLOMBO, Cristina F., Viviana SAITTO. Utopia srl. Icone sconfitte dell'housing sociale. Siracusa: LetteraVentidue, 2018, pp. 38-41, 54-75.

CONSONNI, Giancarlo. Carta dell'habitat. Milan: La Vita Felice, 2019, p. 43.

ERSKINE, Ralph. Democratic architecture. The universal and useful art: projects and reflections. In Thomas Cubitt Lecture. March 31, 1982, pp. 642-659.

FATIGATO. Orfina, I grands ensembles una "singolare plurale" eredità. In: BDC. 2015, vol.15, issue 2.

GENETTE, Gerard. Soglie. Turin: Einaudi Paperbacks,1966. sia una casa, non una fortezza.

Ricordando Uri. In Corriere della Sera.

April 18, 2018, p. 15.

KOOLHAS. Rem. Fundamentals catalogue. Venice: Marsilio, 2014.

LACATON, Anne, Jean Philippe VASSAL, Pleasure of living. In: Domus. November 2020, issue 1051, pp. 29-33.

LE CORBUSIER. Vers une architecture. Paris: Éditions Crès, 1923, p. 6.

NORBERG-SCHULTZ, Christian. Genius Loci: Towards a Phenomenology of Architecture. New York: Rizzoli, 1980, p. 192.

SMITHSON, Alison. Team 10 Primer. London: Studio Vista Limited, 1968.

ZABALBEASCOA, Anatxu. Architectural priorities are challenged in the revolutionary renovations carried out by the studio Lacaton \& Vassal. In Domus. April 2019, issue 1034, pp. 428-429. 


\section{UOU scientific journal Issue \#02 / FOLLIES}

editor in chief: sofia aleixo

June 21st: OPEN CALL

July $15^{\text {th }}$ : Abstract Submission DEADLINE

August $15^{\text {th }}$ : Submission DEADLINE

September $1^{\text {st: }}$ Notification of PEER-REVIEW

Evaluation

September $30^{\text {th }}$ : Final Submission DEADLINE

This call for articles aims at exploring the notion of FOLLIES in the field of research in architecture and urbanism in an international framework.

https://revistes.ua.es/uou

UOU is the scientific journal of UNIVERSITY of Universities. It is born out of the collaboration of international schools of architecture, sharing their intercultural interests.

Every issue underlines a specific topic addressed by one of the universities involved in the Research Project, with a focus on Pedagogy in Architecture. 


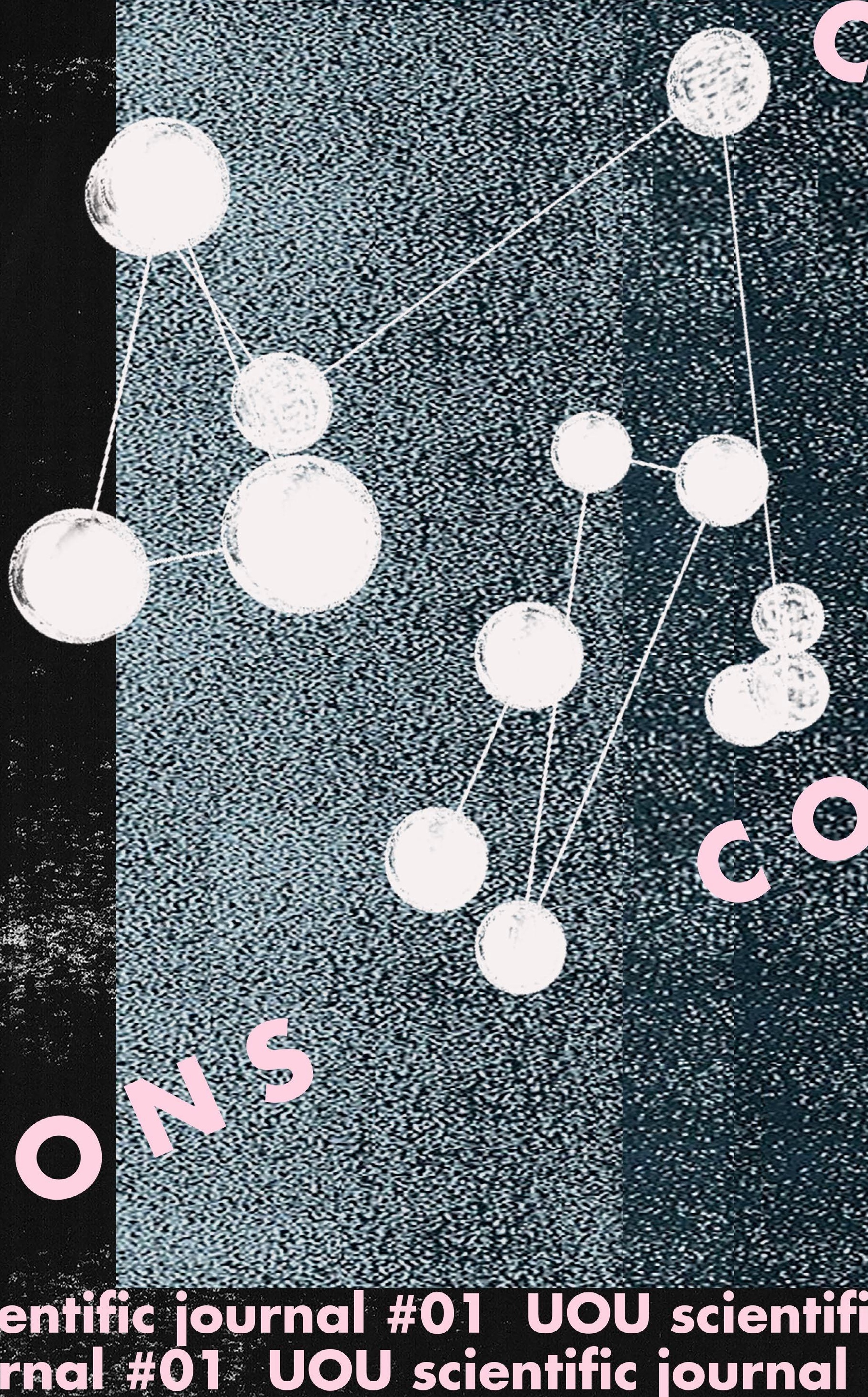

